\title{
Florida International University
}

FIU Digital Commons

\section{The Adaptive Evolution of Herbivory in Freshwater Systems}

Jessica Lynn Sanchez Montelongo

Florida International University, jsanc318@fiu.edu

DOI: $10.25148 /$ etd.FIDC006820

Follow this and additional works at: https://digitalcommons.fiu.edu/etd

Part of the Biology Commons, Evolution Commons, and the Other Ecology and Evolutionary Biology Commons

\section{Recommended Citation}

Sanchez Montelongo, Jessica Lynn, "The Adaptive Evolution of Herbivory in Freshwater Systems" (2018). FIU Electronic Theses and Dissertations. 3813.

https://digitalcommons.fiu.edu/etd/3813 


\section{FLORIDA INTERNATIONAL UNIVERSITY \\ Miami, Florida}

THE ADAPTIVE EVOLUTION OF HERBIVORY IN FRESHWATER SYSTEMS

A dissertation submitted in partial fulfillment of

the requirements for the degree of

DOCTOR OF PHILOSOPHY

in

BIOLOGY

by

Jessica L. Sanchez Montelongo

2018 
To: Dean Michael R. Heithaus

College of Arts, Sciences and Education

This dissertation, written by Jessica L. Sanchez Montelongo, and entitled The Adaptive Evolution of Herbivory in Freshwater Systems, having been approved in respect to style and intellectual content, is referred to you for judgment.

We have read this dissertation and recommend that it be approved.

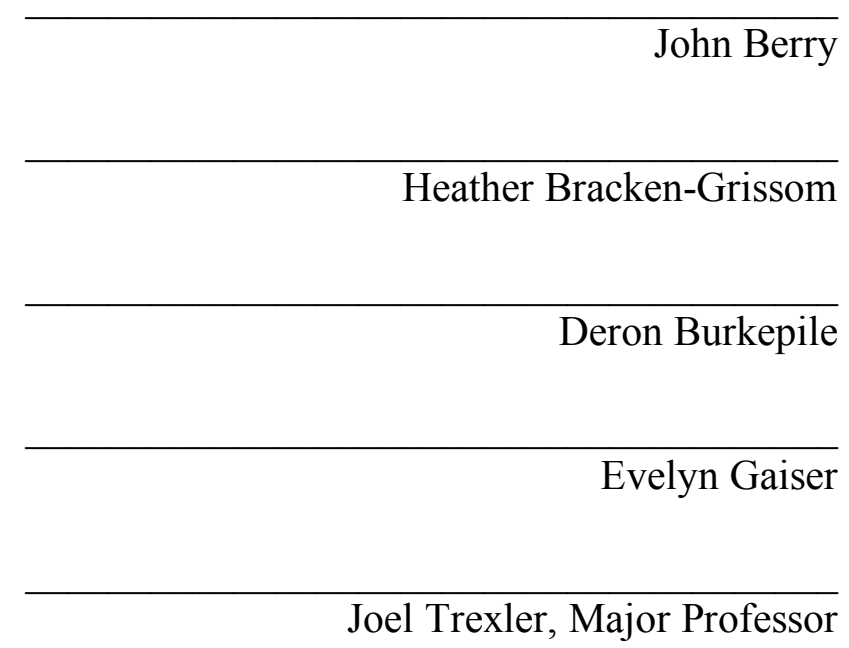

Date of Defense: May 29, 2018

The dissertation of Jessica L. Sanchez Montelongo is approved.

Dean Michael R. Heithaus College of Arts, Sciences and Education

Andrés G. Gil

Vice President for Research and Economic Development and Dean of the University Graduate School

Florida International University, 2018 


\section{ACKNOWLEDGMENTS}

I wish to thank the members of my committee for their commitment to this work. Their guidance, resources and patience were undoubtedly the main contributors to my success. I'd like to especially thank my major advisor, Dr. Joel Trexler, for his endless optimism and support. He has always had confidence in my abilities, even when I did not. In addition, I'd like to thank the many individuals that assisted in some form throughout the course of my work. Specifically, I want to acknowledge Dr. Henry Briceño and his lab manager, Sandro Stumpf (FIU), Dr. Miro Gantar (FIU), Dr. Donovan German (UCIrvine), Dr. Asha Jaja (former FIU graduate student), Dr. John Kominoski (FIU), Christina Lydon (FIU), Dr. Barry Rosen (USGS), Nicholas Schulte (former FIU graduate student), and Franco Tobias (FIU) for their willingness to teach me the lab protocols necessary to complete this work. I'd like to extend my thanks to Dr. Gary Rand and his former lab members, Abe Smith and Javier Casariego (FIU) for allowing me to use their outdoor lab space. I am grateful to Dr. Xavier Chiappa-Carrara (UNAM), Dr. David Reznick (UC-Riverside), and Dr. Juan Schmitter-Soto (ECOSUR) for hosting my international collection trips, and to Drs. Adeljean Ho (CAS) and Margaret Ptacek (Clemson) for providing access to their data. The list of thanks I have for William (Bill) Chamberlain is much too long, but in short, everything listed above would not have happened without him. Finally, I want to thank the Tinker Foundation (FIU) for giving me the funds to travel internationally and collect specimens that were vital for my work, and I wish to thank the Florida Coastal Everglades LTER program for funding my lab work. These funding opportunities were integral to advancing my career. 


\section{ABSTRACT OF THE DISSERTATION}

\section{THE ADAPTIVE EVOLUTION OF HERBIVORY IN FRESHWATER SYSTEMS}

by

Jessica L. Sanchez Montelongo

Florida International University, 2018

Miami, Florida

Professor Joel Trexler, Major Professor

Herbivory is thought to be nutritionally inefficient relative to carnivory and omnivory. But, herbivory evolved from carnivory in many lineages, suggesting that there are advantages to eating plants. To understand the adaptive significance of the transition from carnivory to herbivory, I proposed five hypotheses for the adaptive evolution of herbivory and reviewed the current freshwater literature to identify conditions where eating plants might be adaptive over eating animals. I tested three of these ideas (Suboptimal Habitat, Heterotroph Facilitation, and Lipid Allocation) using the herbivorous Sailfin Molly (Poecilia latipinna) and identified each as a potential mechanism for the evolution of herbivory.

To understand the origins of herbivory in Sailfin Mollies, I reconstructed ancestral habitats and diets across a phylogeny of the genus Poecilia and then used phylogenetically independent contrasts to identify patterns of diet evolution. I found that the degree of herbivory increases with increasing salinity affiliation, suggesting that in this genus, herbivory evolved as an adaptation for invading less productive saline habitats from freshwaters. This result is consistent with the Suboptimal Habitat hypothesis, which states that herbivory allows organisms to invade and persist in 'suboptimal' habitats. To 
understand how herbivory is maintained in extant populations, I raised juvenile Sailfin Mollies in mesocosms and enclosure cages placed in the Everglades to document that dietary autotrophic lipids play a role in early life history by supporting rapid growth (Lipid Allocation). However, dietary bacterial fatty acids promoted fish survival, consistent with the Heterotroph Facilitation hypothesis, which states that indirect detritivory supplements the herbivorous diet. Finally, I quantified periphyton quality/availability and consumer density across the Everglades landscape to examine the correlates of trophic dynamics in nature. Results revealed that herbivores can persist in diverse habitats and survive on varying resources when habitats are unfavorable, supporting the Suboptimal Habitat hypothesis. 
TABLE OF CONTENTS

CHAPTER PAGE

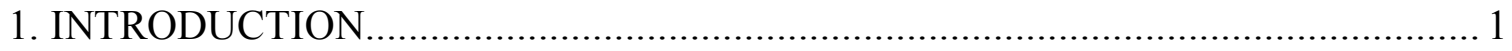

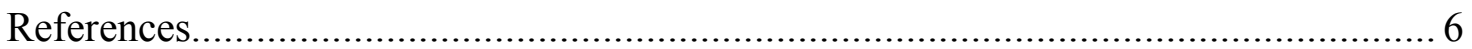

2. THE ADAPTIVE EVOLUTION OF HERBIVORY IN

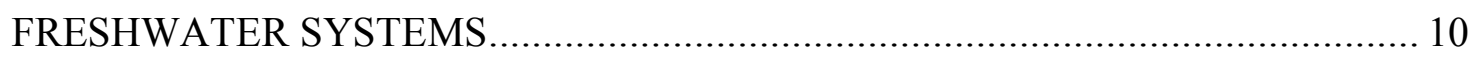

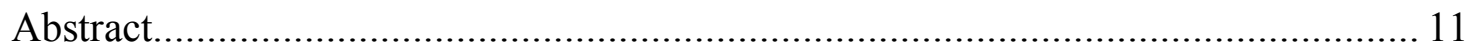

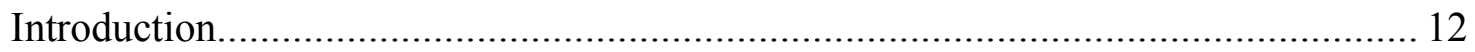

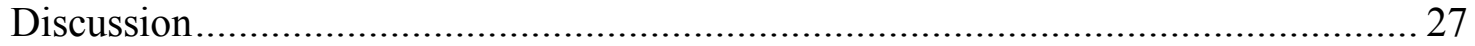

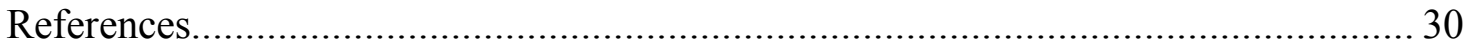

3. FRESHWATER-TO-MARINE TRANSITIONS MAY EXPLAIN

THE EVOLUTION OF HERBIVORY IN THE SUBGENUS

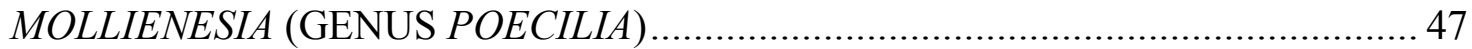

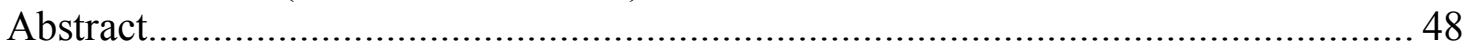

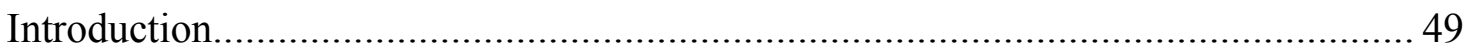

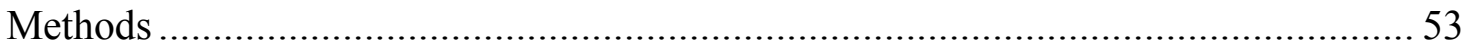

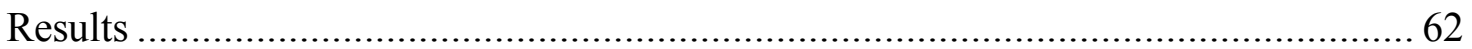

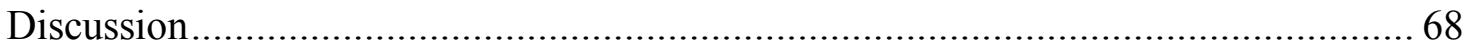

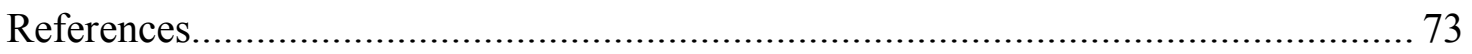

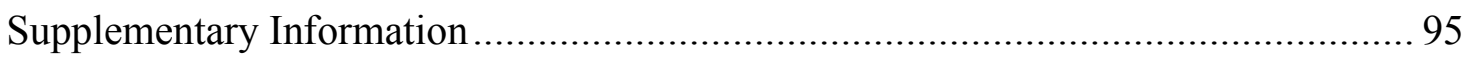

4. WHEN IS AN HERBIVORE NOT AN HERBIVORE?

DETRITIVORY FACILITATES HERBIVORY IN A

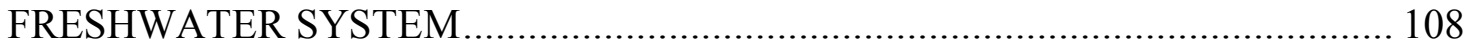

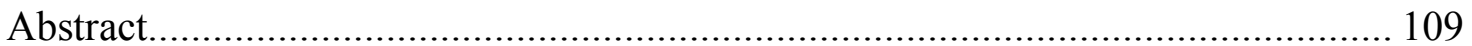

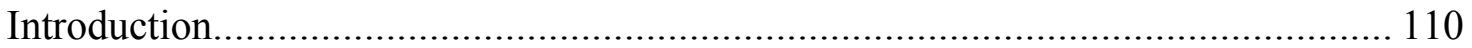

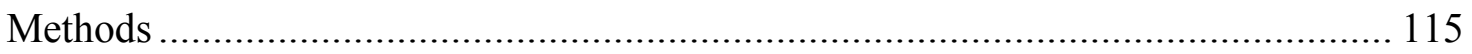

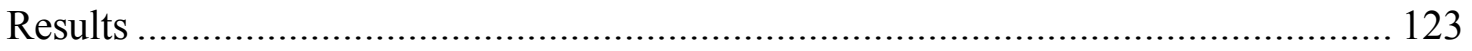

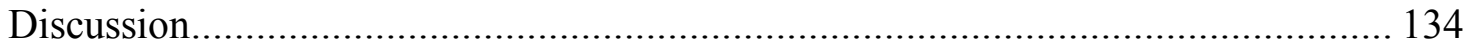

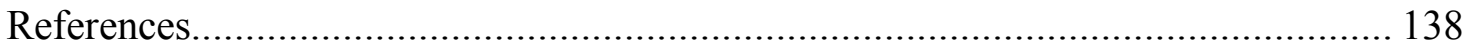

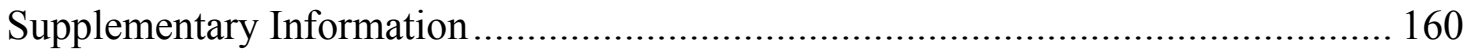

5. CARNIVORY IS BEST, BUT HERBIVORY IS GOOD ENOUGH:

A TEST OF THE HETEROTROPH FACILITATION AND LIPID

ALLOCATION HYPOTHESES FOR DIET EVOLUTION …................................ 167

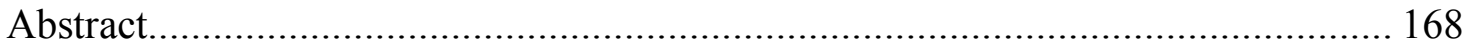

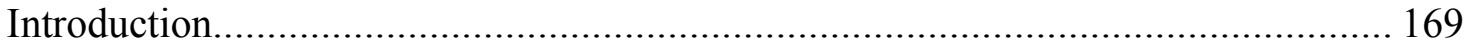

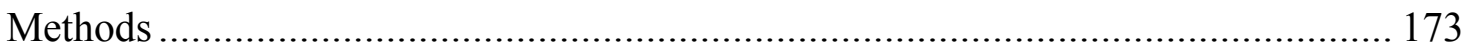

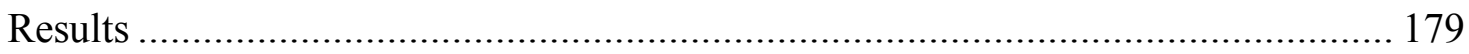




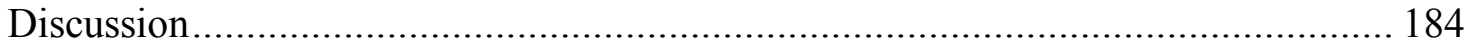

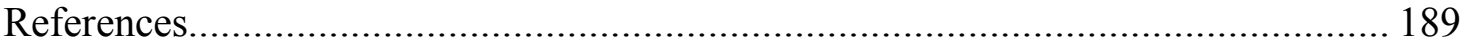

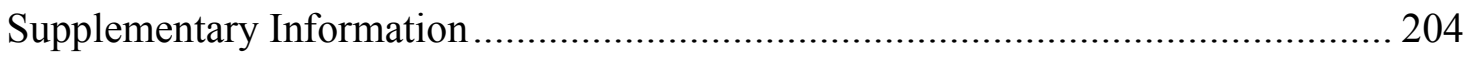

6. NUTRITIONAL LANDSCAPE OF THE EVERGLADES: MECHANISMS SHAPING CONSUMER NICHE DIVERSITY ALONG THE BROWN-GREEN

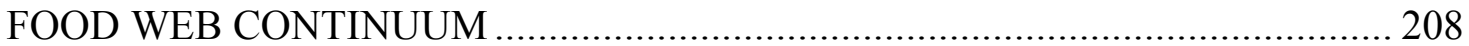

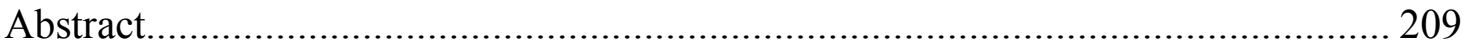

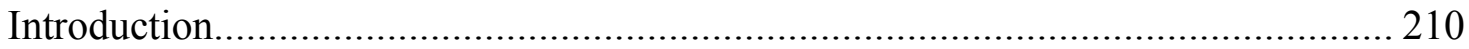

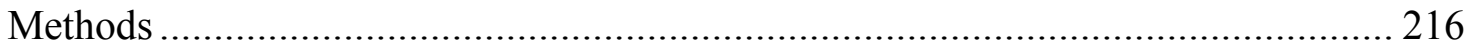

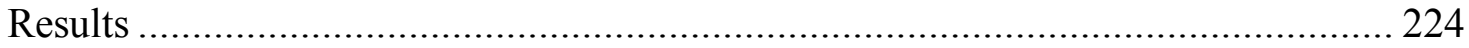

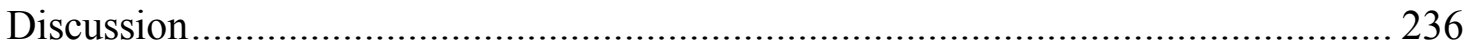

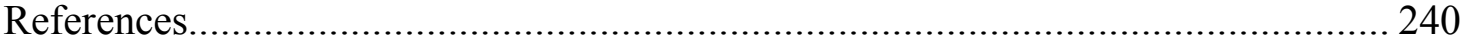

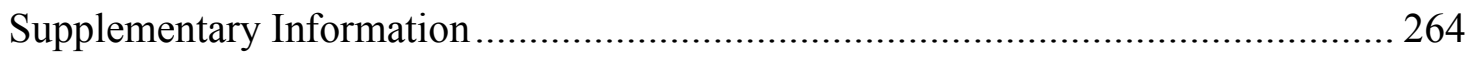

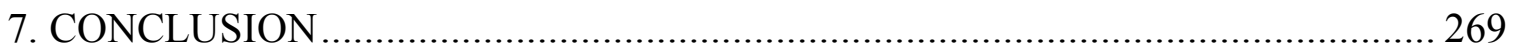

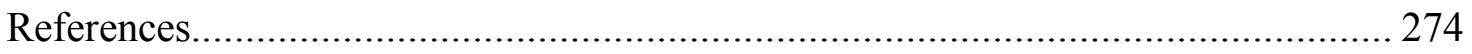

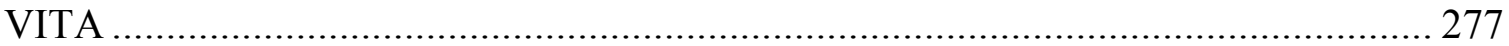




\section{LIST OF TABLES}

TABLE

PAGE

Chapter 2

Table 2.1. Description of the proposed hypotheses for the adaptive evolution of herbivory in freshwaters

Table 2.2. Assumptions of proposed hypotheses. Testing these hypotheses may be best accomplished by evaluation the assumptions necessary for them to be viable explanations for adaptive evolution of herbivory.....

Table 2.3. Examples of experimental designs that could be used as tests of the posed hypotheses

\section{Chapter 3}

Table 3.1. Complete list of sampled Poecilia specimens for gut and jaw morphology analyses. Asterisks indicate museum samples obtained from the Fishnet2 data base (http://www.fishnet2.net/)

Table 3.2. Proportion of habitat types occupied by each species based on collections logged in the Fishnet2 data base (http://www.fishnet2.net/)

Table 3.3. Measured jaw angles of each sampled Poecilia species. IMB = Intramandibular bending (angle subtracted from $180^{\circ}$ ), $\mathrm{GA}=$ Gape angle, $\mathrm{NCR}=$ Neurocranial rotation

Supplementary Information

Table S.3.1. GenBank accession numbers for genes used to construct Poecilia phylogeny

Table S.3.2. Relative abundance of diet items in the get of each sampled Poecilia species

\section{Chapter 4}

Table 4.1. Sources of fatty acid tracers used in this study (modified from Belicka et al. 2012)

Table 4.2. Summary of results showing differences between experimental treatments for epiphyton, periphyton and fish tissues at 3 weeks. FA ratio $=$ SAFA+MUFA:PUFA ratio. Upward facing triangles indicate relatively high values, whereas downward facing triangles indicate relatively low values. Values that are not statistically significant are indicated by 
"ns". Blanks indicate metrics that could not be measured

Table 4.3. Summary of results showing differences between experimental treatments For epiphyton, periphyton and fish tissues at 6 weeks. FA ratio $=$ SAFA+MUFA: PUFA ratio. Upward facing triangles indicate relatively high values, whereas downward facing triangles indicate relatively low values. Values that are not statistically significant are indicated by "ns". Blanks indicate metrics that could not be measured.

Table 4.4. Comparison of structural equation models used to predict diet type (epiphyton vs. periphyton). $\mathrm{AIC}_{\mathrm{w}}=$ Akaike weights, $w_{\min } / w_{j}=$ Evidence ratios. $\triangle \mathrm{AICc}$ values $\leq 2$ are highlighted in bold

Table 4.5. Comparison of structural equation models used to test 'Heterotrophic facilitation' and 'Lipid allocation' hypotheses. A:H $=\mathrm{A}: \mathrm{H}$ biovolume, Bac.FA $=$ percentage of bacterial fatty acids, $\mathrm{FA}$ ratio $=$ $\mathrm{SAFA}+\mathrm{MUFA}:$ PUFA ratio. $\mathrm{AIC}_{\mathrm{w}}=$ Akaike weights, $w_{\min } / w_{j}=$ Evidence ratios. $\triangle \mathrm{AICc}$ values $\leq 2$ are highlighted in bold

Supplementary Information

Table S.4.1. Average values \pm 1 SD for all measured epiphyton variables by treatment.

Table S.4.2. Average values $\pm 1 \mathrm{SD}$ for all measured periphyton variables by treatment.

Table S.4.3. Average values $\pm 1 \mathrm{SD}$ for all measured fish variables by treatment.

Table S.4.4. Average values \pm 1 SD for Ivlev's Electivity Index by treatment. $\mathrm{NA}=$ variables that could not be measured for that treatment

\section{Chapter 5}

Table 5.1. Sources of fatty acid tracers used in this study (modified from Sanchez and Trexler 2018).

Table 5.2. Summary of results showing differences between experimental treatments for diet types (epiphyton and bloodworms) and periphyton. FA ratio $=$ (SAFA+MUFA):PUFA ratio. For epiphyton diets, upward facing triangles indicate relatively high values, whereas downward facing triangles indicate relatively low values. Because bloodworms and periphyton were significantly different in quality than epiphyton, triangles for these variables represent relative comparisons rather than statistical comparisons. Values that are not 
statistically significant are indicated by "ns". Blanks indicate metrics that could not be measured

Table 5.3. Summary of results showing differences between tissues from fish reared on different diets. $\mathrm{FA}$ ratio $=($ SAFA + MUFA $):$ PUFA ratio. Upward facing triangles indicate relatively high values, whereas downward facing triangles indicate relatively low values. Values that are not statistically significant are indicated by "ns". There were no surviving fish from 'Light + P' treatments at the end of the experiment, therefore, I was unable to analyze tissues from these fish

Table 5.4. Comparison of structural equation models used to test 'Heterotrophic facilitation' and 'Lipid allocation' hypotheses. A:H = A:H biovolume, Het. $\mathrm{FA}=$ percentage of heterotrophic fatty acids, $\mathrm{FA}$ ratio $=(\mathrm{SAFA}+\mathrm{MUFA})$ : PUFA ratio. $\mathrm{AIC}_{\mathrm{w}}=$ Akaike weights, $w_{\min } / w_{j}=$ Evidence ratios. $\triangle \mathrm{AICc}$ values $\leq 2$ are highlighted in bold 200

Supplementary Information

Table S.5.1. Average values $\pm 1 \mathrm{SD}$ for all measured diet variables by treatment. $\mathrm{NA}=$ values could not be measured

Table S.5.2. Average relative abundances \pm 1 SD of autotrophs and heterotrophs comprising ambient periphyton and experimental epiphyton diets. 206

Table S.5.3. Average values $\pm 1 \mathrm{SD}$ for all measured fish variables by treatment. There were no surviving individuals from 'Light $+\mathrm{P}$ ' treatments, so fatty acid profiles were not available for these fish (represented by NA in the table)

\section{Chapter 6}

Table 6.1. Environmental data from the 22 sampled sites across the Everglades landscape in the wet season (July 2016) and the dry season (February 2017)

Table 6.2. Percentage of each periphyton type at each site in the wet season (July 2016) and the dry season (February 2017). Sites A55 and A60 were not able to be sampled in the dry season. Sorted in order from shortest to longest hydroperiod

Table 6.3. Principal components loadings for environmental, food availability, and food quality variables for the wet season (July 2016) and the dry season (February 2017). Loadings $\geq 0.30$ (abs. value) are highlighted in grey. $\mathrm{DSD}=$ Days since last dry-down, $\mathrm{TP}=$ Total phosphorus 
Table 6.4. Comparison of structural equation models used to predict omnivore density in the wet and dry seasons. Total model includes paths between Periphyton Quality PC 1 \& 2 (Q1 \& Q2), Periphyton Availability PC 1 \& 2 (A1 \& A2), herbivores and omnivores. Paths between consumers were not varied. $\mathrm{AIC}_{\mathrm{w}}=$ Akaike weights, $w_{\min } / w_{j}=$ Evidence ratios. $\Delta \mathrm{AICc}$ values $\leq 2$ are highlighted in bold

Table 6.5. Comparison of structural equation models used to predict herbivore density in the wet and dry seasons. Total model includes paths between Periphyton Quality PC 1 \& 2 (Q1 \& Q2), Periphyton Availability PC 1 \& 2 (A1 \& A2), herbivores and omnivores. Paths between consumers were not varied. $\mathrm{AIC}_{\mathrm{w}}=$ Akaike weights, $w_{\min } / w_{j}=$ Evidence ratios. $\Delta$ AICc values $\leq 2$ are highlighted in bold

Table 6.6. Summary of the changes (by hydroperiod) in food quality and availability from the wet season to the dry season. Upward facing triangles indicate relatively high values, whereas downward facing triangles indicate relatively low values. $\mathrm{FA}=$ fatty acid, $\mathrm{NC}=$ no change.

Table 6.7. Summary of the changes in consumer diet and tissue composition (herbivores and omnivores) from the wet season to the dry season. Values are averages across all hydroperiods. Upward facing triangles indicate relatively high values, whereas downward facing triangles indicate relatively low values. $\mathrm{FA}=$ fatty acid, $\mathrm{NC}=$ no change

Supplementary Information

Table S.6.1. Additional environmental characteristics of the 22 sampled sites across the Everglades landscape in the wet season (July 2016) and the dry season (February 2017). WCA 1 periphyton was not processed for nutrients in the wet season due to sample contamination, and sites A55 and A62 were inaccessible by boat in the dry season and thus not able to be sampled. Sorted in order from shortest to longest hydroperiod.

Table S.6.2. Detailed periphyton quality metrics of the 22 sampled sites across the Everglades landscape in the wet season (July 2016) and the dry season (February 2017). 


\section{LIST OF FIGURES}

FIGURE

PAGE

Chapter 3

Figure 3.1. Bayesian phylogenetic tree (50\% majority-rule) derived from concatenated mitochondrial Cytochrome Oxidase subunit I, ATPase 8/6, NADH dehydrogenase subunit 2, and Ribosomal Protein $S 7$ genes for 36 Poecilia and 2 Limia species. Bullets at each node represent the Posterior Probability (PP). Nodes with posterior probabilities $>99 \%$ are considered highly supported, those with posterior probabilities $>95 \%$ are well-supported, nodes with posterior probabilities $>75 \%$ are moderately supported, and those with posterior probabilities $>75 \%$ have no support. Genbank ID for each species is listed in parentheses. Species are colored by subgenus.

Figure 3.2. Pruned Bayesian phylogenetic tree (50\% majority-rule) derived from concatenated mitochondrial Cytochrome Oxidase subunit I, ATPase 8/6, $N A D H$ dehydrogenase subunit 2, and Ribosomal Protein $S 7$ genes for the 15 subsampled Poecilia species. Bullets at each node represent the Posterior Probability (PP). Nodes with posterior probabilities $>99 \%$ are considered highly supported, those with posterior probabilities $>95 \%$ are well-supported, nodes with posterior probabilities $>75 \%$ are moderately supported, and those with posterior probabilities $>75 \%$ have no support. Genbank ID for each species is listed in parentheses. Species are colored by subgenus.

Figure 3.3. Classification of Poecilia diets using Sorensen (Bray-Curtis) distance measures with flexible beta linkage. Hierarchical Cluster analysis identified 6 diet categories.

Figure 3.4. (A) Relationship between degree of intramandibular bending (IMB) and percent animal material in the diet for 15 Poecilia species plotted as phylogenetically independent contrasts. (B) Relationship between gape angle (GA) and percent animal material in the diet for 15 Poecilia species

plotted as phylogenetically independent contrasts

Figure 3.5. Maximum Parsimony (left cladogram) and Maximum Likelihood (right cladogram) ancestral character reconstruction for the evolution of habitat (salinity affiliation) in the genus Poecilia. Circles at terminal nodes represent the observed character states for extant species, and pie charts for ancestral nodes show estimated probabilities for reconstructed character states. Species are colored by subgenus and nodes with large circles indicate the most recent common ancestor for that subgenus. Genbank ID for each species is listed in parentheses. 
Figure 3.6. Maximum Parsimony (left cladogram) and Maximum Likelihood (right cladogram) ancestral character reconstruction for the evolution of diet in the genus Poecilia. Circles at terminal nodes represent the observed character states for extant species, and pie charts for ancestral nodes show estimated probabilities for reconstructed character states. Species are colored by subgenus and nodes with large circles indicate the most recent common ancestor for that subgenus. Genbank ID for each species is listed in parentheses.

Figure 3.7. Maximum Parsimony ancestral character reconstruction for the evolution of intramandibular bending (left cladogram) and gape angle (right cladogram) in the genus Poecilia. Circles at terminal nodes represent the observed character states for extant species, and pie charts for ancestral nodes show estimated probabilities for reconstructed character states. Maximum likelihood could not be performed because jaw metrics are continuous data. Species are colored by subgenus and nodes with large circles indicate the most recent common ancestor for that subgenus. Genbank ID for each species is listed in parentheses.

Figure 3.8. (A) The relationship between salinity affiliation and intramandibular bending (plotted as phylogenetically independent contrasts) suggests that IMB did not evolve as an adaptation to saline habitats. (B) The relationship between salinity affiliation and gape angle (plotted as phylogenetically independent contrasts) suggests that GA did not evolve as an adaptation to saline habitats. (C) The relationship between salinity affiliation and percent animal material in the gut (plotted as phylogenetically independent contrasts) suggests that herbivory evolved in response to increased salinity

Supplementary Information

Figure S.3.1. Bayesian phylogenetic tree (50\% majority-rule) derived from mitochondrial Cytochrome Oxidase subunit I, ATPase 8/6, and NADH dehydrogenase subunit 2 from 36 Poecilia and 2 Limia species. Genbank ID for each species is listed in parentheses. Species are colored by subgenus.

Figure S.3.2. Bayesian phylogenetic tree (50\% majority-rule) derived from ribosomal gene, S7, from 36 Poecilia and 2 Limia species. Genbank ID for each species is listed in parentheses. Species are colored by subgenus. . 104

Figure S.3.3. Pruned Bayesian phylogenetic tree (50\% majority-rule) derived from mitochondrial Cytochrome Oxidase subunit I, ATPase 8/6, and NADH dehydrogenase subunit 2 from 15 Poecilia species. Genbank ID for each species is listed in parentheses. Species are colored by subgenus. . 105 
Figure S.3.4. Pruned Bayesian phylogenetic tree (50\% majority-rule) derived from ribosomal gene, $S 7$, from 15 Poecilia species. Genbank ID

for each species is listed in parentheses. Species are colored by subgenus. . 106

Figure S.3.5. Maximum Parsimony ancestral character reconstruction for the evolution of neurocranial rotation (left cladogram) and standardized gut length (right cladogram) in the genus Poecilia. Circles at terminal nodes represent the observed character states for extant species, and pie charts for ancestral nodes show estimated probabilities for reconstructed character states. Maximum likelihood could not be performed because jaw and gut metrics are continuous data. Genbank ID for each species is listed in parentheses.

\section{Chapter 4}

Figure 4.1. (A) Male Sailfin Molly (Poecilia latipinna). (B) Female Sailfin Molly (Poecilia latipinna). Images retrieved from the Florida Museum Ichthyology Collection, University of Florida, Gainesville, FL, (C) George Burgess.

Figure 4.2. (A) Standard length ( $\mathrm{mm}$ ) of juvenile Sailfin Mollies raised on biofilms grown in various treatments. (B) Probability of survival (p') of juvenile Sailfin Mollies showing high survival of those grown in 'shade only' treatments

Figure 4.3. (A) Relative abundance of algal species comprising fish guts reared in various treatments at 3 weeks. Guts are composed of similar proportions of diet items across treatments, and are dominated by diatoms and cyanobacteria. (B) Relative abundance of algal species comprising fish guts reared in various treatments at 6 weeks. Fish guts from light treatments are composed of similar proportions of diet items, and are dominated by cyanobacteria. Those from shaded treatments also contain a high proportion of cyanobacteria, but also have higher proportions of green filamentous algal species than fish guts from the light treatments ... 154

Figure 4.4. (A) Ivlev's Electivity Index $\left(\mathrm{L}_{\mathrm{i}}\right)$ calculated for fish reared in various treatments at 3 weeks. All fish expect those in 'Shade $+\mathrm{P}$ ' cages are actively avoiding filamentous cyanobacteria. (B) Ivlev's Electivity Index $\left(\mathrm{L}_{\mathrm{i}}\right)$ calculated for fish reared in various treatments at 6 weeks. Fish reared in 'Light $+\mathrm{P}$ ' cages are avoiding all diet types, whereas, all other fish are only avoiding coccoid cyanobacterial species

Figure 4.5. The structural equation model with the best fit showing epiphyton at 3 weeks as the best predictor of fish life history at 3 weeks. Numbers indicate regression coefficients for each path analyzed. 
Figure 4.6. The structural equation model with the best fit showing A:H biovolume, the percentage of bacterial fatty acids and the ratio of

SAFA+MUFA:PUFA (FAratio) at 3 weeks as the best predictor of fish life history at 3 weeks. Numbers indicate regression coefficients for each path analyzed

Figure 4.7. The structural equation model with the best fit showing 6-week bacterial fatty acid percentage as the best predictor of fish life history at 6 weeks. Numbers indicate regression coefficients for each path analyzed.

Figure 4.8. The structural equation model with the best fit showing 3-week bacterial fatty acid percentage as the best predictor of fish life history at 6 weeks. Numbers indicate regression coefficients for each path analyzed.

Supplementary Information

Figure S.4.1. Field experimental set-up. Boxes represent $1 \mathrm{~m}^{2}$ mesh cages (shaded and open) randomly distributed across a $980 \mathrm{~m}^{2}$ plot located in an

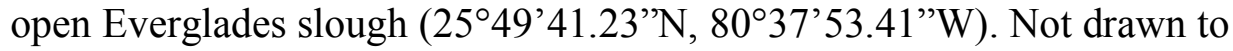
scale.

Figure S.4.2. (a) Photo showing mesh cages in the field. (b) Photo showing cages wrapped with $3 \mathrm{~mm}$ clear plastic following nutrient dosing. Phosphorus $\left(\mathrm{Na}_{2} \mathrm{HPO}_{4}\right)$ was added once per week and the cages remained wrapped for 24 hours to avoid seepage to cages without nutrient addition

\section{Chapter 5}

Figure 5.1. (A) Standard length ( $\mathrm{mm}$ ) of juvenile Sailfin Mollies raised on experimental diets showing increased growth of fish consuming epiphyton grown in 'Light only' and 'Light $+\mathrm{P}$ ' conditions at 3 weeks. (B) Probability of survival (p') of juvenile Sailfin Mollies showing low survival of fish consuming epiphyton grown in 'Light + P' treatments ..... 202

Figure 5.2. (A) The structural equation model with the best fit $(\triangle \mathrm{AICc}=0.00)$ showing autotroph: heterotroph $(\mathrm{A}: \mathrm{H})$ biovolume and heterotrophic fatty acid percentage as the best predictors of fish life history at 3 weeks. Numbers indicate regression coefficients for each path analyzed, suggesting that decreased A:H biovolume and decreased heterotrophic fatty acid percentage results in increased fish life history. (B) The structural equation model with the best fit $(\triangle \mathrm{AICc}=0.00)$ showing $\mathrm{A}: \mathrm{H}$ biovolume and heterotrophic fatty acid percentage as the best predictors of fish life history at 6 weeks. Numbers indicate regression coefficients for each path analyzed, suggesting that increased A:H biovolume and increased heterotrophic fatty acid percentage results in increased fish life history. This is opposite of the 3-week model results ... 203 
Chapter 6

Figure 6.1. Map showing location of 22 sampled locations across the Everglades landscape

Figure 6.2. Classification of diets by gut contents using Sorensen (Bray-Curtis) distance measured with flexible beta linkage. Although some species showed seasonal diet shifts, Hierarchical Cluster analysis identified the same 2 diet categories in the wet season (A) and in the dry season (B). Pie charts represent the amount of each food type present in the gut (estimated from Loftus 2000). White $=$ periphyton, grey= detritus, black= animal material

Figure 6.3. Seasonal variation of periphyton quality by hydroperiod. (A) Periphyton Quality PC 1 represent macronutrients (protein, carb, lipid), edibility and $\%$ of heterotrophic fatty acids. These food quality variables decrease with increasing hydroperiod in the wet season. (B) Periphyton Quality PC2 represents PUFA ratio (-), EPA and total phosphorus (-). Periphyton Quality PC2 increased with increasing hydroperiod, suggesting that long hydroperiod sites have decreased PUFA ratios, increased EPA and decreased TP in the wet season. (C) Periphyton Quality PC1 represents macronutrients (protein, carb, lipid), edibility, EPA and \% of heterotrophic fatty acids in the dry season. These variables increase with increasing hydroperiod, contrary to the pattern in the wet season. (D) Periphyton Quality PC2 represent PUFA ratio (-) and total phosphorus (-) in the dry season. Similar to the wet season, Periphyton Quality PC2 increased with increasing hydroperiod, suggesting that long hydroperiod sites have decreased PUFA ratios and TP

Figure 6.4. Number of consumers (omnivores and herbivores) per $\mathrm{m}^{2}$ found in sites with different hydroperiods in the wet season (A) and dry season (B) 260

Figure 6.5. The structural equation models with the best fit $(\triangle \mathrm{AICc}=0.00)$ showing (A) herbivore density as the best predictor of omnivore density in the wet season, (B) and PUFA ratio and TP as the best predictors of omnivore density in the dry season. Solid lines indicate statistically significant relationships and dashed lines indicate non-significant relationships. Numbers indicate regression (path) coefficients for each path analyzed..... 261

Figure 6.6. The structural equation models with the best fit $(\triangle \mathrm{AICc}=0.00)$ showing (A) PUFA ratio, TP, EPA \%, and omnivore density as the best predictors of herbivore density in the wet season, (B) and no statistically significant relationships between periphyton variables and herbivore density in the dry season. Solid lines indicate statistically significant relationships and dashed lines indicate non-significant relationships. Numbers indicate 
regression (path) coefficients for each path analyzed.

Figure 6.7. Verified predictions of the Suboptimal Habitat Hypothesis. (A) In the wet season, herbivore density decreases with periphyton quality $(\mathrm{PC} 1$ : macronutrients, edibility and \% of heterotrophic fatty acids). Herbivore residuals were taken from a regression with environmental variables and herbivore density to obtain the unique pattern attributable to periphyton quality. (B) In the dry season, Periphyton Availability PC1 represents periphyton cover \% (-) and floating mat abundance (-), and Periphyton Quality PC1 represents macronutrients (protein, carb, lipid), edibility, EPA and \% of heterotrophic fatty acids. The relationship between these PC scores suggest that periphyton quality decreases with increasing periphyton cover estimations and floating mat abundance.

Supplementary Information

Figure S.6.1. Examples of various periphyton types sampled in this study.

(A) Floating mat aggregation (WCA 8, dry season). (B) Alternative floating mat form; epiphytic growth on emergent vascular plant stems (WCA 3, dry season). (C) Filamentous green algae mass occupying the water column (see red arrow; PHD-A59, wet season). (D) Epiphyton collected from submerged stems of aquatic macrophytes (see red arrow; TSL-MDA, wet season) 
CHAPTER 1

INTRODUCTION 
Herbivores are key consumers in ecosystems because they harvest energy from plants, which is thereby transferred up the food web when other animals eat herbivores. Without this important diet strategy, energy would not reach higher order consumers (e.g., large game fish, humans, etc.) and their populations could not be sustained. However, from a nutritional perspective, carnivory (eating animals) and omnivory (eating both plants and animals) are "better" diets than herbivory (Sanchez and Trexler 2016). Omnivores and carnivores consume animal prey that are high in nutritional value (Mattson, 1980; Sterner \& Hessen, 1994; Choat \& Clements, 1998; Karban \& Agrawal, 2002), and omnivores have the additional advantage of supplementing their diets with abundant and easy to obtain plant items (Coll \& Guershon 2002; Diehl, 2003). Obtaining comparable energy from an exclusively herbivorous diet is difficult because plants are nutritionally variable and usually employ structural and/or biochemical mechanisms to deter herbivores (Mattson, 1980; Porter \& McDonough, 1984; Horn 1989, Chivers \& Langer, 1994; Sterner \& Hessen, 1994; Choat \& Clements, 1998; and others). Herbivores may also be limited by time and/or space by predators and competitors, by the ability to produce digestive or detoxifying enzymes (see Karban \& Agrawal, 2002), or the amount of time it takes for food to pass through the gut (Horn, 1989; Bruggeman et al. 1994; Bellwood, 1995; Choat \& Clements 1998). The unfavorable characteristics of herbivore diets affect consumer life histories (i.e., reproduction, growth, survival) and raise the question of why herbivory is common in nature. However, many herbivores have evolved from carnivorous ancestors (see Sanchez and Trexler 2016)., suggesting that there are adaptive advantages to this seemingly inferior diet strategy. 
Current research has thoroughly delineated the ecological context of the herbivorous diet (i.e., food selection, assimilation, nutrient regulation, etc.), but has yet to determine the conditions that favor herbivory over eating animals. The paucity of knowledge concerning the adaptive evolution of herbivory is a missing piece to an overall theory of the origins of diet. To understand the adaptive significance of the herbivorous diet, I posed five hypotheses on the evolution of herbivory from carnivory: 1) Intake-Efficiency - herbivores use part of their food source as habitat, thus minimizing the energy/time spent searching for food and avoiding predators; 2) Suboptimal Habitat herbivory allows organisms to invade and establish populations in habitats that have high primary production but low abundance of animal prey; 3) Heterotroph Facilitation herbivory is adaptive because herbivores consume microbes associated with producers; 4) Lipid Allocation - herbivory is adaptive because producers are rich in fatty acids, which fuel reproduction and storage; and 5) Disease Avoidance - herbivory minimizes animalfacilitated disease transmission. In Chapter 2, I reviewed the current literature and used evidence from these works as support for these five adaptive hypotheses in order to establish a framework to test them.

The genus Poecilia is an excellent model system for studying the evolution of herbivory because Poecilia species exhibit a variety of diet preferences, with herbivory concentrated in the subgenus Mollienesia. Furthermore, this group has evolved the ability to disperse across marine water barriers, and extant species inhabit both fresh and euryhaline habitat types (Meffe and Snelson 1989). 
Although marine systems cover $99 \%$ of the Earth's surface, these habitats are less productive per unit area than freshwater aquatic habitats (e.g., Colinvaux 1980; May and Godfrey 1994; Vermeij and Grosberg 2010) and could therefore be considered 'suboptimal' under the Suboptimal Habitat Hypothesis. As such, transitions from freshwater to less productive marine waters may have prompted the evolution of the herbivorous strategy in the genus Poecilia, particularly in the subgenus Mollienesia. In Chapter 3, I evaluated the Suboptimal Habitat Hypothesis by reconstructing ancestral states of habitat and diet across a phylogeny of the genus Poecilia to identify patterns of diet evolution and habitat transition. I then used phylogenetically independent contrasts to identify patterns of diet evolution in response to habitat transition.

In Chapters 4 and 5, I tested the Heterotroph Facilitation and Lipid Allocation Hypotheses using the Sailfin Molly (Poecilia latipinna), an exclusively herbivorous member of the subgenus Mollienesia. The herbivorous Sailfin Molly is native to the Florida Everglades, although there is evidence that herbivory is not an efficient diet in this area. Several studies have suggested that periphyton (the primary basal resource in the Everglades) is a poor-quality food source for herbivores (e.g., Geddes and Trexler 2003).

As a result, the system supports a low diversity and abundance of higher order consumers relative to primary producers (Turner et al. 1999; Geddes and Trexler 2003). To test my adaptive hypotheses, I used enclosure cages stocked with juvenile Sailfin Mollies placed in the field (Chapter 4) and lab (Chapter 5). I used shading and phosphorus addition to manipulate the heterotrophic and autotrophic composition of colonizing epiphyton (food for Sailfin Mollies), and then examined the effects of this 
varying food quality on Sailfin Molly life history to determine the explanatory power of these alternative adaptive hypotheses in nature.

Although my posed hypotheses were developed to describe the evolution of herbivory, they may also be incorporated into current ecological theory to describe how communities are assembled based on the role of consumers in a food web. Ecological niche-based models predict that species' abilities to establish in a locality are determined by their traits (Chase and Leibold 2003), whereas dispersal-based models predict that community assembly is driven by stochastic colonization, independent from species traits (Hubbell 2001; Chase and Leibold 2003; Chase 2007). Some studies have shown that dispersal-based models yield similar results to relatively complicated niche-based models (e.g., Condit et al. 2000; Bell 2001; Hubbell 2001, Volkov et al. 2003), suggesting that we can predict community assembly without considering the species traits. But, in nature, resources vary across the landscape, resulting in natural variation in consumer life history that drives species relative abundances and distributions (Kareiva 1990; Tilman 1994; Polis et al. 1997; Power and Dietrich 2002; McIntosh et al. 2004; Torres-Ruiz et al. 2007; Doi 2009; Guo et al. 2016). Therefore, relying on models that ignore the role of species traits in shaping communities limits our ability to understand the evolutionary consequences of ecological processes. In Chapter 6, I determined if niche- or dispersalbased predictions best described consumer dynamics in the Florida Everglades based on the nutritional landscape and interpreted these results in the contexts of the Heterotroph Facilitation and Suboptimal Habitat Hypotheses. By identifying an evolutionary mechanism that promotes herbivory, I was able to more fully describe the complex role of these consumers in functional food webs. 
Herbivory has been the focus of many ecological studies spanning many subdisciplines, but there is a significant gap in knowledge pertaining to the adaptive evolution of herbivory in nature. I began this research to explore the conditions that would favor the evolution of an herbivorous diet from a carnivorous or omnivorous one. These studies represent a starting point that may lead to more comprehensive studies of diet evolution.

\section{References}

Bell, G. 2001. Neural Macroecology. Science 293:2413-2418. Bellwood, D. R. (1995). Direct estimate of bioerosion by parrotfish species, Chlorurus gibbus and $C$. sordidus, on the Great Barrier Reef, Australia. Marine Biology 121:419-29.

Bellwood, D. R. (2003). Origins and escalation of herbivory in fishes: a functional perspective. Paleobiology 29(1):71-83.

Bellwood, D.R., Goatley, C.H.R., Brandl, S.J, and O. Bellwood. (2014). Fifty million years of herbivory on coral reefs: fossils, fish and functional innovations. Proceedings of the Royal Society B 281: 2013-3046.

Bruggemann, J. H.,J. Begeman, E. M. Bosma, P. Verburg, and A. M. Breeman. (1994). Foraging by the stoplight parrotfish Sparisoma viride. II.Intake and assimilation of food, protein and energy. Marine Ecology Progress Series 106:57-71.

Chase, J. M. (2007). Drought mediates the importance of stochastic community assembly. PNAS 104(4): 17430-17434.

Chase, J. M.., and M. A. Leibold. (2003). Ecological Niches: Linking Classical and Contemporary Approaches. The University of Chicago Press, Chicago and London.

Chivers, D. J., and P. Langer. (1994). The Digestive System in Mammals: Food, Form and Function. Cambridge Univ. Press, Cambridge.

Choat, J. H., and K. D. Clements. (1998). Vertebrate herbivores in marine and terrestrial environments: A nutritional ecology perspective. Annual Review of Ecology and Systematics 29:375-403. 
Colinvaux, P. (1980). Why big fierce animals are rare. Princeton University Press.

Coll, M. and Guershon, M. (2002). Omnivory in terrestrial arthropods: Mixing plant and prey diets. Annual Review of Entomology 47: 267-297.

deMaintenon, M. J. (1999). Phylogenetic analysis of the Columbellidae (Mollusca: Neogastropoda) and the evolution of herbivory from carnivory. Invertebrate Biology 118(3): 258-288.

Diehl, S. (2003). The evolution and maintenance of omnivory: Dynamic constraints and the role of food quality. Ecology 84(10): 2557-2567.

Doi, H. (2009). Spatial patterns of autochthonous and allochthonous resources in aquatic food webs. Population Ecology 52: 57-64.

Espinoza, R.E., J. J. Wiens, and C. R. Tracy. (2004). Recurrent evolution of herbivory in small, cold-climate lizards: Breaking the ecophysiological rules of reptilian herbivory. Proceedings of the National Academy of Science 101(48): 1681916824.

Eubanks, M.D., Styrsky, J.D., and Denno, R.F. (2003). The evolution of omnivory in heteropteran insects. Ecology 84(10): 2549-2556.

Geddes, P. and J.C. Trexler. (2003) Uncoupling of omnivore-mediated positive and negative effects on periphyton mats. Oecologia 136:585-595.

Guo, F., M. Kainz, F. Sheldon, and S. E. Bunn. (2016). The importance of high-quality algal food sources in stream food webs- current status and future perspectives. Freshwater Biology $<$ doi: 10.1111/fwb.12755>.

Horn, M. H. (1989). Biology of marine herbivorous fishes. Oceanography and Marine Biology Annual Review 27:167-272.

Hubbell, S. P. (2001). The unified neutral theory of biodiversity and biogeography. Princeton University Press, Princeton.

Karban, R., and A. A. Agrawal. (2002). Herbivore offense. Annual Review of Ecology, Evolution and Systematic 33:641-664.

Kareiva, P. (1990). Population dynamics in spatially complex environments: theory and data. Philosophical Transactions of the Royal Society, London, Series B 330: 175190.

Mattson, W. J. Jr., (1980). Herbivory in relation to plant nitrogen content. Annual Review of Ecology and Systematics 11:119-161. 
May, R. M., and J. Godfrey. (1994). Biological Diversity: Differences between land and sea. Philosophical Transactions: Biological Sciences 343(1303): 105-111.

McIntosh, A. R., B. L. Peckarsky, and B. W. Taylor. (2004). Predator-induced resource heterogeneity in a stream food web. Ecology 85(8): 2279-2290.

Meffe, G. K., and E. E. Snelson. (1989). An ecological overview of Poeciliid fishes. In: Ecology and Evolution of Livebearing Fishes. Prentice Hall, NJ, pp. 13-32.

Pauls, S. U., W. Graf, P. Haase, H. T. Lumbsch, and J. Waringer. (2008). Grazers, shredder and filtering carnivores- The evolution of feeding ecology in Drusinae (Trichoptera: Limnephilidae): Insights from a molecular phylogeny. Molecular Phylogenetics and Evolution 46:776-791.

Polis, G. A. W. B. Anderson, and R. D. Holt. (1997). Toward and integration of landscape and food web ecology: The dynamics of spatially subsidized food webs. Annual Review of Ecology and Systematics 28(1997): 289-316.

Porter, K. G., and R. McDonough. (1984). The energetic cost of response to blue-green algal filaments by cladocerans. Limnology and Oceanography 29:365-369.

Power, M. E., and W. E. Dietrich. (2002). Food webs in river networks. Ecological Research 17: 451-471.

Reisz, R. R., and J. Frobisch. (2014). The Oldest Caseid Synapsid from the Late Pennsylvanian of Kansas, and the Evolution of Herbivory in Terrestrial Vertebrates. PLoS ONE 9(4): e94518. doi:10.1371/journal.pone.0094518

Sanchez, J. L., and J. C. Trexler. (2016). The adaptive evolution of herbivory in freshwater systems. Ecosphere 7(7) doi e01414. 10.1002/ecs2.1414.

Sterner, R. W., and D. O. Hessen. (1994). Algal nutrient limitation and the nutrition of aquatic herbivores. Annual Review of Ecology and Systematics 25:1-29.

Tilman, D. (1994). Competition and biodiversity in spatially structured habitats. Ecology 75: 2-16.

Torres-Ruiz, M., J. D. Wehr, and A. A. Perrone. (2007). Trophic relations in a stream food webs: Importance of fatty acids for macroinvertebrate consumers. Journal of the North American Benthological Society 26: 509-522.

Turner, A. M. J. C. Trexler, C. F. Jordan, S. J. Slack, P. Geddes, J. H. Chick and W. F. Loftus. (1999) Targeting ecosystem features for conservation: Standing crops in the Florida Everglades. Conservation Biology 13:898-911. 
Van Damme, R. (1999). Evolution of herbivory in Lacertid lizards: Effects of insularity and body size. Journal of Herpetology 33(4):663-674.

Vermeij, G. (1992). Time of origin and biogeographical history of specialized relationships between Northern marine plants and herbivorous mollusks. Evolution 46(3): 657-664.

Vermeij, G. J., and R. K. Grosberg. (2010). The great divergence: When did diversity on land exceed that in the sea? Integrative and Comparative Biology 50(4):675-682.

Vermeij, G., and D. R. Lindberg. (2000). Delayed herbivory and the assembly of marine benthic ecosystems. Paleobiology 26(3): 419-430.

Volkov, I., J. R. Banavar, S. P. Hubbell, and A. Maritan. (2003). Neutral theory and relative species abundance in ecology. Nature 424: 1035-1037. 


\section{CHAPTER 2}

THE ADPATIVE EVOLUTION OF HERBIVORY IN FRESHWATER SYSTEMS

\section{Published in Ecosphere}

May 2016

Volume 7(7), Article e01414, Pages 1-15

Available for reproduction with appropriate citation 


\begin{abstract}
Herbivory is thought to be nutritionally inefficient relative to carnivory and omnivory. But, herbivory evolved from carnivory in many terrestrial and aquatic lineages, suggesting that there are advantages of eating plants. Herbivory has been well-studied in both terrestrial and aquatic systems and there is abundant information on feedbacks between herbivores and plants, coevolution of plant and herbivore defenses, mechanisms for mediating nutrient limitation, effects of nutrient limitation on herbivore life history and more recently, the origins of the herbivorous diet. Researchers have sufficiently defined the ecological context and evolutionary origins of the herbivorous diet, and these main areas of research have laid the groundwork for studying herbivory as an adaptation. However, I have yet to synthesize this information in a way that allows us to establish a framework of testable adaptive hypotheses.
\end{abstract}

To understand the adaptive significance of this diet transition, I review the current literature and use evidence from these works as support for five hypotheses on the evolution of herbivory from carnivory: 1) Intake-efficiency - herbivores use part of their food source as habitat, thus minimizing the energy/time spent searching for food and avoiding predators; 2) Suboptimal habitat - herbivory allows organisms to invade and establish populations in habitats that have high primary production but low abundance of animal prey; 3) Heterotroph facilitation - herbivory is adaptive because herbivores consume microbes associated with producers; 4) Lipid allocation - herbivory is adaptive because producers are rich in fatty acids, which fuel reproduction and storage; and 5) Disease avoidance - herbivory minimizes animal-facilitated disease transmission. 
Due to the extensive literature, I have limited this review to discussing herbivory in freshwater systems. To my knowledge, no prior work has compiled a comprehensive list of conditions that favor an herbivorous diet in nature. With backgrounds in both theoretical and experimental ecology, the incorporation of these hypotheses to the current literature will provide information about diet evolution, where it is currently lacking.

Key-words: Adaptive evolution, diet evolution, freshwater herbivory, herbivory

\section{Introduction}

Herbivory is thought to be an inefficient feeding strategy relative to omnivory and carnivory (Sterner and Elser 2002, Laspoumaderes et al. 2010). From an energetic perspective, herbivores are important consumers because they process primary production for use at higher trophic levels. However, at the individual level, the adaptive significance of herbivory is unclear. Omnivory is adaptive because food abundance is usually highest at lower trophic levels, whereas food quality (relative measure of energy content; defined below) increases with trophic position (e.g. Hastings and Conrad 1979, Hairston and Hairston 1993, Elser et al. 2000; Coll and Guershon 2002, Eubanks et al. 2003, Diehl 2003). Omnivores benefit by supplementing energetically costly prey with easy to obtain, but nutritionally variable, food items (Diehl 2003). Similarly, a carnivorous diet may be adaptive because prey items are of high quality and readily digested and assimilated (Stevens and Hume 2004, Choat and Clements 1998; Raubenheimer et al. 2005). Despite the vast herbivory literature on both terrestrial and aquatic systems, comparable hypotheses of herbivory are lacking. 
There are few similarities of herbivory patterns between terrestrial and aquatic systems, and as a result, these literatures have developed independently. However, the majority of herbivory work in both systems focuses on these five ideas:

\section{Feedback between herbivores and primary producers}

Herbivores can control nutrient storage and recycling through their consumption rate of primary production (Cebrian and Lartigue 2004). In turn, herbivore consumption rates can be affected by nutrient composition of the producers (Sterner et al. 1997; Cebrian et al. 1998; Griffin et al 1998; Cebrian and Lartigue 2004). These top-down and bottom-up processes drive both producer and consumer population dynamics in terrestrial and aquatic systems, although the relative strength of these forces is different between systems (see Burkepile 2013). There is a large literature (e.g. Hairston et al. 1960, Murdoch 1966, Ehrlich and Birch 1967, Slobodkin et al. 1967, Wiegert and Owen 1971, Fretwell 1977, Oksanen 1988 and others) and numerous reviews (see Power 1992, Strong 1992) on feedback mechanisms as they are one of the fundamental ideas in herbivory research.

\section{Coevolution of plant and herbivore defenses}

Increased plant mortality by grazers may lead to changes in the life history and population dynamics of producers. For example, many plants can produce harmful secondary metabolites in response to herbivory (e.g. Pare and Tumlinson 1999, Howe and Jander 2008, etc.), but this is energetically costly (Crawley 1983) and limits energy available for other life processes (e.g. Herms and Mattson 1992). 
In turn, herbivores expend energy in response to these defenses in order to obtain nutritional value from producers (e.g. detoxification pathways, Wiegand and Pflugmacher 2005, Jiang et al. 2012, Zhang et al. 2012) or to defend themselves against predators (e.g. sequestering plant metabolites, Duffy and Hay 1994, Stachowicz and Hay 1999, Nishida 2002), also diverting energy from other processes. Co-evolution of these and other plant and animal defenses (e.g. altered plant morphology/phenology/nutrient composition versus altered animal morphology/behavior/ digestive physiology) has been shown to influence population dynamics of both producers and herbivores. How herbivores mediate the effects of nutrient limitation

When consumers are confined to relatively poor quality diets, they may compensate by increasing the amount of food they consume (e.g. Sinclair et al. 1982, Targett and Targett 1990, Simpson and Simpson 1990, Pennings et al. 1993, Stachowicz and Hay 1996, Cruz-Rivera and Hay 2000b, Van der Wal et al. 2000, Fink and von Elert 2006), allowing them to obtain sufficient nutrients and potentially offset the negative fitness consequences of a low quality diet (Vanni and Lampert 1992, Cruz-Rivera and Hay 2000b, Fink and von Elert 2006). Diet selectivity has also been proposed as a mechanism to permit subsistence on the relatively poor quality herbivorous diet (outlined in Karasov and Martinez del Rio 2007; e. g., Grasshoppers, Behmer and Joern 1993; amphipods, Cruz-Rivera and Hay 2000b). Alternatively, organisms may differentially assimilate or excrete nutrients, allowing them to attain suitable quantities of limiting nutrients (Behmer 2009). 
Herbivores may also supplement their diets with food items of higher quality (e.g. other basal resources and/or animal prey), in order to sustain their imbalanced diet of primary food items (the "diet mixing hypothesis"; Simmonds et al. 1992, Bernays et al. 1994, Simpson and Rauenheimer 1996, Singer et al. 2002). Similarly, herbivores consuming chemically defended diets may consume other items of various qualities in order to "dilute" the toxin to benign concentrations ("toxin dilution hypothesis"; Freeland and Janzen 1974, Freeland and Saladin 1989). Herbivores may also consume less digestible items such as cellulose in order to increase the rate of food passage, thereby minimizing exposure of toxins in the diet (Berg et al. 2012). These hypotheses of nutrient acquisition by herbivores and resulting life history trade-offs (e.g. Duffy and Paul 1992, Raubenheimer and Simpson 1997, Cruz-Rivera and Hay 2000a-b, 2003, Ojala et al. 2005, Clements et al. 2009) have been a productive area of herbivory research.

\section{Effects of nutrient limitation on herbivore life history}

Basal resources are variable in their nutrient content as compared to animal prey (Sterner and Elser 2002), which limits energy allocation to individual growth and reproduction of primary consumers (Mattson 1980, Lika and Kooijman 2003). A multitude of studies on herbivores from terrestrial, marine and freshwater systems show that diet quality is linked to tradeoffs among life history traits (e.g. Rushton and Hassall 1983, Sterner 1993, Caceres et al.1994, Hietala et al. 1995, Lampert and Trubetskova 1996, Kilham et al. 1997, Schmidt and Jonasdottir 1997, Cruz-Rivera and Hay 2000b, Shin et al. 2003, Ojala et al. 2005, Trubetskova and Haney 2006, Guo and Xie 2011, Mitchell et al. 2012, Ortiz-Rodriguez et al. 2012). 
Growth of an organism affects overall fitness via changes in survival and reproduction (Hairston et al. 2001), and reproductive output can have implications for population regulation (Stearns 1992).

\section{Comparative analyses of related species with varying diet strategies}

There are some diet characters that distinguish herbivores and carnivores. For example, post-foraging food processing (i.e. digestion, assimilation, etc.) by omnivorous or carnivorous animals may be more efficient than that of herbivores (Mattson 1980, Sterner and Hessen 1994, Choat and Clements 1998, Sterner and Elser 2002), and herbivores have evolved gut morphologies that may increase food assimilation (Kramer and Bryant 1995) as a result of this processing deficit (e.g. German et al. 2010). Furthermore, "dull" teeth (e.g. German et al. 2010) or specialized feeding apparatuses (e.g. intramandibular bending; Gibb et al. 2008) may be typical of benthic herbivores. Many terrestrial studies have included digestive physiology as a characteristic of diet and recent aquatic studies have begun to do so as well (see Choat and Clements 1998). Recent comparative studies have used these and other characters to document the evolution of herbivory from carnivorous ancestors (e.g. lizards: Van Damme 1999, Espinoza et al. 2004, mollusks: deMaintenon 1999, heteropteran insects: Eubanks et al. 2003, caddisflies: Pauls et al. 2008, fishes: Bellwood 2003, Bellwood et al. 2014), bringing us closer to understanding the adaptive significance of herbivory. These evolutionary studies are the bases for future work examining diets from an adaptive perspective. 
Researchers have done a good job in delineating the ecological context and evolutionary origins of the herbivorous diet, and these main areas of research have laid the groundwork for studying herbivory as an adaptation. However, we have yet to synthesize this information in a way that allows us to establish a framework of testable adaptive hypotheses, which is a missing piece in the overall theory of diet evolution. For herbivorous lineages, at some point in time the cumulative benefits of switching from carnivory to herbivory were greater than both the costs of doing so, and the benefits of maintaining carnivory. However, carnivory remains a strategy in nature, suggesting that there are costs associated with herbivory. Similarly, the evolution of omnivory from herbivory seems beneficial, but both strategies are maintained in nature, further suggesting that there are adaptive advantages to herbivory. To understand the adaptive significance of this diet transition, I review the current literature and use evidence from these works as support for my ideas on the evolution of herbivory from carnivory (Table 1). Due to the abundant literature on this topic, I have limited this review to discussing herbivory in freshwater systems.

I propose five hypotheses that evaluate the adaptive evolution of herbivorous diets in freshwater systems (Table 2.1). I assume that in order for herbivory to evolve from a carnivorous ancestor: 1) there must be adequate genetic variation for herbivorous strategies to evolve; and 2) the ecological relationships revealed by contemporary research are similar to those that were present in the past. Here "herbivory" is defined as the consumption of algae and/or phytoplankton, and less commonly, the consumption of aquatic vascular macrophytes (reviewed by Newman 1991). 
Furthermore, "herbivore" refers to an organism that mainly eats primary producers but may indirectly consume detritus. A "carnivore" is defined as an organism that eats animals and an "omnivore" refers to an organism that eats both plants and animals. Arguments regarding sub-classifications of these diet strategies (e.g. obligate v. facultative herbivore) or other specialized feeding strategies (e.g. wood-eating, frugivory, etc.) are not discussed here. In freshwater systems, grazers include organisms that graze algae (Feminella and Hawkins 1995, Newman and Rotjan 2013); therefore, in this paper, "grazer" and "herbivore" are used interchangeably. The term "food quality" is used to describe the nutritional worth of a diet item to a consumer. Worth of a food item may be defined by macronutrient (e.g. nutritional ecology) or elemental (e.g. stoichiometry) composition, where food items are rich in protein or phosphorus, respectively. Alternatively, food quality may be defined as the ratio of food energy content to that assimilated by consumers. For both definitions, "food quality" is a relative term and can only be interpreted relative to other diets (e.g. a diet item can be both high and low quality depending on the comparison diet). The hypotheses presented here were developed to reflect the life cycles of freshwater organisms and may or may not be applicable to organisms that do not spend their entire lives in freshwater (e.g. diadromous fishes or terrestrial insects with aquatic larvae). Although the concepts behind these hypotheses are not novel, to my knowledge, no compilation of hypotheses exist. In the following sections, I discuss the five proposed adaptive hypotheses: 1) intake-efficiency; 2) suboptimal habitat; 3) heterotroph facilitation; 4) lipid allocation; 5) and disease avoidance. 


\section{Intake-efficiency hypothesis}

The intake-efficiency hypothesis is based on the predictions of simple optimal foraging models, which have proven robust for herbivores (Sih and Christensen 2001). This hypothesis states that selection favors herbivory over animal-containing diets because herbivorous organisms maximize energy intake by minimizing the energy and time spent searching for and subduing prey. Further, aquatic herbivores may use their food source as habitat (Brönmark and Vermaat 1998), or seek refuge in aquatic vegetation associated with their preferred food source (e.g. submerged vegetation and epiphytic algae, respectively; Alvarez and Peckarsky 2013), thereby decreasing energy expenditures related to locomotion (Cummins 1973) and/or predator avoidance. Therefore, the net energy gained from an herbivorous diet may be greater than a diet comprised of metazoan prey.

Herbivores are constantly grazing in order to meet energetic needs (e.g. Simpson and Simpson 1990, Cruz-Rivera and Hay 2000b), whereas energetic, physiological and encounter rate constraints prevent animal-consuming taxa from continuously foraging (Arrington et al. 2002; Karasov and Martinez del Rio 2007). As a result of these different foraging behaviors, herbivores continuously have plant material in their gut and omnivores/carnivores process their food in "batches" (discussed in Karasov and Martinez del Rio 2007). Batch processing may be followed by periods of hunger; therefore, herbivores are probably more continuously satiated relative to omnivores/carnivores. According to optimal foraging theory, satiated animals expend less energy foraging and more energy doing other activities such as mating (Krebs et al. 1983). 
Therefore, herbivores may gain an adaptive advantage by shifting their energetic focus from foraging to reproducing.

\section{Suboptimal habitat hypothesis}

The suboptimal habitat hypothesis states that herbivory may be adaptive by allowing organisms to invade suboptimal habitats. Here, the term "suboptimal habitat" is relative to habitats that support high abundance and diversity of secondary consumers. Food web interactions often occur over spatially heterogeneous landscapes (Oksanen et al. 1995), or "patches" of varying resource quality and quantity. Therefore, an optimal habitat might be a suboptimal habitat at another point in space or time. In freshwater systems, it is generally thought that habitat patches are strongly influenced by abiotic factors such as nutrient availability and/or disturbance frequency (Pringle et al. 1988). Higher trophic levels dominate communities when habitat productivity is increased (e.g. Marks et al. 2000, Deegan et al. 2002, Beveridge et al. 2010) or when disturbance occurs at low to intermediate frequencies (Marks et al. 2000). However, consuming a plant-dominated diet is favored in habitats where animal prey are scarce and plant abundance is high (Chubaty et al. 2014), such as those with frequent disturbance. Furthermore, the palatability of plants is thought to play a key role in structuring herbivore populations (Elger et al. 2004). The most palatable benthic and phytoplankton species are associated with early stages of succession, because fast-growing plants invest less energy in structural and toxic elements (e.g. Porter 1977, Elger et al. 2004). 
Elger et al. (2002) investigated the effects of disturbance and nutrient availability on freshwater plant palatability for herbivorous snails (Lymnaea stagnalis) and found that increased disturbance frequency, but not nutrient availability, positively influenced food availability for herbivores (Elger et al. 2002), providing evidence for an herbivore advantage in disturbed habitats (e.g. suboptimal habitats).

Classic optimal foraging theory (i.e. optimal diet) predicts that if a resource is abundant, specializing on that resource is preferred (see Chubaty et al. 2014). These predictions are supported by early food preference studies, which suggest that herbivores evolved in response to food availability rather than food value (e.g. Paine and Vadas 1969). Using an evolutionary simulation model, Chubaty et al. (2014) examined how quality and availability of plant and animal prey shapes the evolution of diet. Results indicate that relative availability of resources can predict an individual's trophic level (Chubaty et al. 2014). More specifically, an increased abundance of plants increases herbivore abundance relative to carnivorous animals (Chubaty et al. 2014) demonstrating that herbivory may be adaptive when plants are abundant and prey are not (e.g. suboptimal habitats).

Seasonality can also influence habitat quality and resource availability. Organisms are limited to resources that are immediately available. Constant and seasonally varying food supplies are known to influence life histories of many aquatic consumers by altering individual growth and reproduction (output, patterns, mode, etc.). The effects of seasonal food limitation have been well studied in Daphnia (e.g. Chapman and Burns 1994) and other cladocerans (e.g. DeMott and Kerfoot 1982, Boersma and Vijverberg 1996). 
More specifically, constant food supplies are known to increase growth and brood size of cladocerans. However, food supplies vary in nature and herbivores may gain an advantage by consuming different species or by switching between green, detrital and/or animal diets seasonally, thereby reducing the effects of specializing on a single food type (e.g. Kitting 1980, Sanders et al. 1996, DeMott 1998, Cruz-Rivera and Hay 2000a). Herbivory may allow organisms to minimize interspecific competition (via decreased niche overlap) by invading and establishing populations in suboptimal habitats. For example, the globally invasive golden apple snail (Pomacea canaliculata) specializes on freshwater macrophytes and has established successful populations in areas that are uncolonized by other phylogenetically similar species. Further, invading a suboptimal habitat may allow herbivores to escape predation. Trade-offs between foraging and predator avoidance in aquatic consumers are well documented (reviewed by Milinski 1985). Camacho and Thacker (2013) showed that freshwater amphipods exposed to fish predators sought refuge in toxic cyanobacterial mats. Further, amphipods exposed to predators showed higher survivorship on toxic mats as compared to non-toxic mats. These results suggest that herbivores at risk from predators benefit by seeking refuge in suboptimal habitats. If herbivores benefit from invading suboptimal habitats by avoiding predation, equally performing herbivores could be aggregated in both high and lowquality patches as predicted by an "ideal free distribution" (Fretwell and Lucas 1970). Therefore, the ability to colonize and persist equally in both inferior and relatively superior habitats can promote survival of herbivores by exploiting niche opportunities that are unavailable to carnivorous species. 


\section{Heterotroph facilitation hypothesis}

The heterotroph-facilitation hypothesis states that herbivory is adaptive because herbivores indirectly consume heterotrophic microbes (bacteria, fungi and/or protozoa) that are associated with primary producer communities. It has been shown that aquatic herbivores supplement their diets with essential nutrients originating from heterotrophic bacteria (Bowen 1984, Smoot and Findlay 2010, Belicka et al. 2012) and a strong positive correlation between primary production and bacteria has been documented in several aquatic systems (Cole 1982). In limnetic waters, heterotrophic microbes largely contribute to planktonic biomass and are under strong grazing pressure by zooplankton (Arndt 1993). Benthic algae in close association with heterotrophic microbes come in several forms (collectively called "periphyton") and are the primary food source for herbivores in benthic systems (Wetzel 2001).

Relative to algae, heterotrophic bacteria are superior competitors for phosphorus (P), incorporating the nutrient into their cell walls (Martin-Creuzburg et al. 2011); therefore, these microbes are a rich source of the limiting nutrient for herbivores (Martin-Creuzburg et al. 2011). Although $P$ is important for metazoan growth (Sterner and Elser 2002), diets composed only of heterotrophs are of poor quality for Daphnia magna suggesting that herbivores may rely on other dietary items for essential biochemicals like sterols (e.g. invertebrates) or fatty acids (Martin-Creuzburg et al. 2011). For example, growth rates of Daphnia magna increased when fed heterotrophic bacteria supplemented with sterols (important for molting) relative to growth of those fed only bacteria (Martin-Creuzburg et al. 2011). 
Related studies found that Daphnia require a diet composed of at least $50 \%$ green algae to compensate for a sterol deficiency (Martin-Creuzburg et al. 2005). In a vertebrate example, the sailfin molly (Poecilia latipinna) was shown to assimilate both algal material and fatty acids derived from heterotrophic bacteria (Belicka et al. 2012). Consumption of heterotrophs along with consumption of autotrophs may allow herbivores to obtain adequate amounts of both $\mathrm{P}$ and fatty acids for growth and other life processes, respectively.

\section{Lipid allocation hypothesis}

The lipid allocation hypothesis states that herbivory is adaptive because higher consumption of algae with high lipid concentrations may increase fitness. Algae are primary producers of essential lipids that cannot be synthesized by metazoans, but are necessary for their survival (Ahlgren et al. 1990, Sargent et al. 1995, Sharathchandra and Rajashekhar 2009, Guo et al. 2016). Although animal-prey are rich in lipids relative to algae, wild-caught herbivorous fishes have higher lipase activities in the gut than carnivores, suggesting that lipids are of major importance to herbivores (Nayak et al. 2003, German et al. 2004, Drewe et al. 2004).

Fatty acids can be incorporated into lipid bilayers of metazoan cells (phospholipids; Karasov and Martinez del rio 2007), can serve as precursors for important animal hormones (Brett and Muller-Navarra 1997), and can be stored as energy (Wiegand 1996) in aquatic consumers. Excess carbon that does not originate from fatty acids can also be stored as lipid reserves in primary consumers (e.g. Daphnia: Sterner and Hessen 1994, Gulati and DeMott 1997), emphasizing the importance of lipid storage. 
In aquatic organisms, a primary role of lipids is energy storage for reproductive purposes, as they are the main components of ova (Brooks et al. 1997). During reproductive periods, lipid compounds are mobilized to the gonads in fish (Wiegand 1996, Guler et al. 2007, Wang et al. 2013) and increased dietary lipids (from 12\%-18\%) result in increased fecundity (e.g. Durray et al. 1994). Lipid ingestion from algal sources has also been shown to positively correlate with reproductive success in several aquatic organisms (Daphnia, copepods, fishes), and with clutch size in particular (e.g. Goulden et al. 1982, Tessier et al. 1983, Schmidt and Jonasdottier 1997, Weers and Gulati 1997, MartinCruezburg et al. 2008, Guo and Xie 2011). In addition, organisms consuming diets rich in phospholipids allocate dietary P to ova (e.g. copepods, Laspoumaderes et al. 2010), thereby contributing to offspring growth and survival. Dietary phospholipids are the main constituents of embryonic yolk (Wiegand 1996) and thus serve as both an energy source and component of structural growth in developing embryos (Bell 1989, Wiegand 1996). Furthermore, phospholipids are abundant in the membranes of neural tissues and are thus integral for growth of larvae, which have a high percentage of neural tissue relative to their body mass (Bell et al. 1997). Since lipids (and phospholipids) are important for storage, structure and reproduction of aquatic organisms, herbivory may be favored over ominivory and carnivory if essential lipids are obtained from available algal sources.

\section{Disease avoidance hypothesis}

The disease avoidance hypothesis maintains that herbivory is advantageous because it reduces disease transmission via animals. 
Many secondary consumers such as piscivores are definitive hosts for parasites, with primary consumers (i.e. invertebrates or small vertebrates) serving as intermediate hosts (Covich et al. 1999, Marcogliese 2002). Furthermore, phylogenetic relatedness and similarity in biological traits between hosts has been shown to be a useful predictor of parasite prevalence in many taxa (see discussion in Huang et al. 2014). Specifically, carnivores that are phylogenetically and ecologically similar were shown to harbor similar parasite assemblages (Huang et al. 2014), suggesting that diet affects the probability of parasitic infection. Furthermore, a meta-analysis by Choudary and Dick (2000) showed that freshwater piscivorous fishes have rich parasite communities as compared to herbivores and zooplanktivores (Choudhury and Dick 2000; see Dogiel 1961 for examples). Although herbivores can contract a variety of parasites that do not originate from the diet (see Hoffman 1999 for a full review) and can experience negative effects as an intermediate host (e.g. Plaistow et al. 2001), herbivory may mediate the effects of animal-facilitated parasites and thus, energy allocation to maintenance mechanisms that respond to such parasites.

Alternatively, consuming animal prey may facilitate the transmission of prions, also referred to as transmissible spongiform encephalopathies. These infectious agents are composed of protein and are responsible for mad cow disease in mammals (Dalla Valle et al. 2008). Although prions are not as common in aquatic systems as they are in terrestrial systems, prions have been discovered in some fish species (e.g. Rivera-Milla et al. 2003, Dalla Valle et al. 2008). 
Animal tissues are built from proteins that are potentially harmed by these agents, thereby posing a significant threat to aquatic food webs. Because basal items are not protein-rich resources (Mattson 1980, Sterner and Elser 2002), herbivores may benefit from reduced exposure to infectious prions that could alter the functioning proteins comprising their somatic tissues.

\section{Discussion}

The presence of both ancestral (carnivory) and derived (herbivory and omnivory) diets in nature indicates that there are conditions that favor eating plants over animals. In support of the adaptive hypotheses presented here, the literature suggests that herbivory is favored when higher quality food is limiting. But, freshwater herbivore diets are not always inadequate as they can provide a different suite of important dietary elements (e.g. plant-derived lipids and sterols) that are deficient in carnivorous diets. Furthermore, these dietary elements are incorporated into both somatic and reproductive tissues and therefore may be related to fitness. Diet supplementation with heterotrophs also promotes growth and reproduction of freshwater herbivores. Testing these hypotheses will allow researchers to understand the circumstances that promote herbivory over nutritionally "better" diets.

With a few assumptions (Table 2.2), these hypotheses could be evaluated in current herbivory research programs. For example, the intake-efficiency hypotheses might be tested using a similar experimental design to Alvarez and Peckarsky's (2013). They measured growth rates of two grazers (caddisfly and mayfly), algal accrual rates and per capita effects of grazers on algae in chambers that differed in the presence of moss (submerged vegetation) and predation risk. 
They found no differences in growth; however, when mayflies were exposed to predators, algae associated with moss accrued at a slower rate, suggesting that mayflies were using moss as both habitat and a source of food in the presence of predators. Comparable experiments could be designed to include additional life history trait estimates (e.g. herbivore survival) and estimates of energy expenditure versus energy gain (as in optimal foraging theory) of animals eating herbivorous versus carnivorous diets. See Table 2.3 for more examples.

I present a series of hypotheses with independent explanations for each; however, these mechanisms are unlikely to function independently in nature and our knowledge of diet evolution may be limited by approaching them as such. Factorial designs evaluating multiple hypotheses and their interactions simultaneously may be more biologically relevant. For example, the heterotroph facilitation hypothesis may be tested using a design that examines the effects of diets composed of various heterotrophic: autotrophic ratios on consumer life histories (e.g. Fuller et al. 2004). Heterotrophs and autotrophs have unique lipid profiles that can be traced to consumer somatic and reproductive tissues (Iverson et al. 2004, Belicka et al. 2012). Therefore, the results from this experiment may also be explained in reference to the lipid allocation hypothesis, where consumer reproduction is affected by differential concentrations (and sources) of essential lipids in the diet. In another example, the suboptimal habitat hypothesis could be invoked in a system with high food availability and low food quality. This could be the case for Terapontid fishes, where availability of resources is hypothesized to be the driving force for their transition from marine to freshwater (e.g. a "suboptimal habitat") and subsequent diet shift from carnivory to herbivory (Davis et al. 2012). 
This hypothesis may explain Terapontid invasion and shift to herbivory, but any of the remaining four hypotheses (or others not proposed here) could further explain why herbivory was maintained and continues to exist in this group. Testing these as alternative hypotheses rather than single, independent ideas may improve our interpretation.

I explained these ideas using the freshwater herbivory literature, but testing these hypotheses in other systems would complement the existing works that draw comparisons between aquatic (freshwater and marine) and terrestrial herbivory. Recent terrestrial studies have begun to elucidate the evolutionary origins of herbivory and have found similar patterns of diet evolution to those in freshwaters. For example, Reisz and Frobisch (2014) found fossil evidence supporting the evolution of herbivorous Caseid reptiles from smaller carnivore lineages and suggested that herbivory began as a way to exploit untapped resources (e.g. suboptimal habitat hypothesis). Although relative patterns of herbivory are different between terrestrial and freshwater systems (e.g. Cyr and Pace 1993, Cebrian and Lartigue 2004; Burkepile 2013), invoking comparable mechanisms for the adaptive evolution of herbivory could imply similar patterns of diet evolution across ecosystems, thereby unifying these independent bodies of work.

Herbivory has been the focus of many ecological studies spanning many subdisciplines, but there is a significant gap in knowledge pertaining to the adaptive evolution of herbivory in nature. With backgrounds in both theoretical and experimental ecology, the incorporation of these hypotheses to the current literature will provide information about diet evolution, where it is currently lacking. The proposed hypotheses represent a starting point that may lead to more comprehensive studies of diet evolution in freshwater and other systems. 
Exploring these already established ideas from an adaptive perspective will establish a much-needed research framework, allowing us to more fully understand the evolution of diet in freshwater and other systems.

\section{Acknowledgements}

I was supported by cooperative agreement G10AC00409 between FIU and the US Geological Survey while working on this review. This material was developed with help from the FCE-LTER program under NSF Grant No. DBI-0620409 and is contribution number 800 from the Southeast Environmental Research Center at FIU. I am grateful to Drs. Jay Stachowicz, Charles Fox and Nora Underwood for providing useful comments on earlier versions of this manuscript.

\section{References}

Ahlgren, G., L. Lundstedt, M. Brett and C. Forsberg. 1990. Lipid composition and food quality of some freshwater phytoplankton for cladoceran zooplankters. Journal of Plankton Research 12(4):809-818.

Alvarez, M., and B. L. Peckarsky. 2013. The influence of moss on grazers in highaltitude streams: food, refuge or both? Freshwater Biology 58:1982-1994.

Arndt, H. 1993. Rotifers as predators on components of the microbial web (bacterial, heterotrophic flagellates, ciliates)- a review. Hydrobiologia 255/256:231-246.

Arrington, D. A., K. O. Winemiller, W. F. Loftus and S. Akin. 2002. How often do fishes "Run on Empty?". Ecology 83(8): 2145-2151.

Behmer, S. T., and A. Joern. 1993. Diet choice by a grass-feeding grasshopper based on the need for a limiting nutrient. Functional Ecology:7:522-527.

Behmer, S.T. 2009. Insect herbivore nutrient regulation. Annual Review of Entomology 54:165-187. 
Belicka, L.L., Sokol, E.R., Hoch, J.M., Jaffe, R. and Trexler, J.C. 2012. A molecular and stable isotopic approach to investigate algal and detrital energy pathways in a freshwater marsh. Wetlands 32:531-542.

Bell, M.V. 1989. Molecular species analysis of phosphoglycerides from the ripe roes of cod (Gadus morhua). Lipids 24:585-588.

Bell, J. G., B. M. Farndale, M. P. Bruce, J. M. Navas and M. Carillo. 1997. Effects of broodstock dietary lipid on fatty acid composition of eggs from sea bass (Dicentrarchus labrax). Aquaculture 149:107-119.

Bellwood, D.R. 2003. Origins and escalation of herbivory in fishes: A functional perspective. Paleobiology 29(1): 71-83.

Bellwood, D.R., Goatley, C.H.R., Brandl, S.J, and Bellwood, O. 2014. Fifty million years of herbivory on coral reefs: fossils, fish and functional innovations. Proceedings of the Royal Society B 281: 2013-3046.

Berg, J.M., Tymoczko, J.L., Stryer, L., and Gatto Jr., G.J. 2012. Biochemistry. Seventh Edition. W. H. Freeman, New York, New York, USA.

Bernays, E.A.,Bright, K.L.,Gonzalez, N. and Angel, J. 1994. Dietary mixing in a generalist herbivore: tests of two hypotheses. Ecology. 75:1997-2006.

Beveridge, O.S., Humphries, S. and Petchey, O.L. 2010. The interacting effects of temperature and food chain length on trophic abundance and ecosystem function. Journal of Animal Ecology 79(3): 693-700.

Boersma, M., and Vijverberg, J. 1996. Food effects on life history traits and seasonal dynamics of Ceriodaphnia pulchella. Freshwater Biology 35:25-34.

Bowen, S. 1984. Evidence of a detritus food-chain based on consumption of organic precipitates. Bulletin of Marine Science 35:440-448.

Brett, M.T., and Muller-Navarra, D.C. 1997. The role of highly unsaturated fatty acids in aquatic foodweb processes. Freshwater Biology 38:483-499.

Brooks, A., Tyler, C.R., and Sumpter, J.P. (1997) Egg quality in fish: what makes a good egg? Reviews in Fish Biology and Fisheries, 7, 387-416.

Brönmark, C., and Vermaat, J.E. 1998.Complex fish-snail- epiphyton interactions and their effects on submerged freshwater macrophytes. Pages 47-68 in E. Jeppesen, M. Sondergaard, M. Sondergaard, and K. Christofferson, editors. Structuring role of submerged macrophytes in lakes. Springer, New York, New York, USA. 
Burkepile, D. E. 2013. Comparing aquatic and terrestrial grazing ecosystems: is the grass really greener? Oikos 122:306-312.

Caceres, C.W., Fuentes, L.S. and Ojeda, F.P. 1994. Optimal feeding strategy of the temperate herbivorous fish Aplodactylus punctatus: the effects of food availability on digestive and reproductive patterns. Oecologia 99:118-123.

Camacho, F.A., and Thacker, R.W. 2013. Predator cues alter habitat use by the amphipod Hyalella Azteca (Saussure). Freshwater Science 32(4): 1148-1154.

Cebrian, J., and C. M. Duarte. 1998. Patterns in leaf herbivory on seagrasses. Aquatic Botany:60:67-82.

Cebrian, J., and J. Lartigue. 2004. Patterns of herbivory and decomposition in aquatic and terrestrial ecosystems. Ecological Monographs 74(2): 237-259.

Chapman, M.A., and Burns, C.W. 1994. Polymorphism and food limitation in 3 Daphnia carinata populations. Internationale Revue der gesamten Hydrobiologie 79:477509.

Choat, J.H., and Clements, K.D. 1998. Vertebrate herbivores in marine and terrestrial environments: A nutritional ecology perspective. Annual Review of Ecology and Systematics 29:375-403.

Choudhury, A., and Dick, T.A. 2000. Richness and diversity of helminth communities in tropical freshwater fishes: Empirical evidence. Journal of Biogeography 27(4): 935-956.

Chubaty, A.M., Ma, B.O., Stein, R.W., Gillespie, D.R., Henry, L.M., Phelan, C., Palsson, E., Simon, F.W., and Roitberg, B.D. 2014. On the evolution of omnivory in a community context. Ecology and Evolution 4(3): 251-265.

Clements, K.D., Raubenheimer, D., and and Choat, J.H. 2009. Nutritional ecology of marine herbivorous fishes: ten years on. Functional Ecology 23: 79-92.

Cole, J.J. (1982) Interactions between bacteria and algae in aquatic ecosystems. Annual Review of Ecology and Systematics 13:291-314.

Coll, M. and Guershon, M. 2002. Omnivory in terrestrial arthropods: Mixing plant and prey diets. Annual Review of Entomology 47:267-297.

Covich, A.P., Palmer, M.A., and Crowl, T.A. 1999. The role of benthic invertebrate species in freshwater ecosystems: Zoobenthic species influence energy flows and nutrient cycling. BioScience 49(2):119-127. 
Crawley, M. J. 1983. Herbivory. University of California Press, California.

Cruz-Rivera, E. and Hay, M.E. 2000a. The effects of diet mixing on consumer fitness: macroalgae, epiphytes, and animal matter as food for marine amphipods. Oecologia 123: 252-264.

Cruz-Rivera, E. and Hay, M.E. 2000b. Can quantity replace quality? Food choice, compensatory feeding, and fitness of marine mesograzers. Ecology 81(1):201219.

Cruz-Rivera, E. and Hay, M.E. 2003. Prey nutritional quality interacts with chemical defenses to affect consumer feeding and fitness. Ecological Monographs 73(3): 483-506.

Cummins, K.W. 1973. Trophic relations of aquatic insects. Annual Review of Entomology 18: 183-206.

Cyr, H. and Pace, M.L. 1993. Magnitude and patterns of herbivory in aquatic and terrestrial ecosystems. Nature, 361, 148-150.

Dalla Valle A.Z., Iriti, M., Faoro, F., Berti, C., and Ciappellano, S. 2008. In vivo prion protein intestinal uptake in fish. APMIS 116: 173-80.

Davis, A.M., Unmack, P. J., Pusey, B.J., Johnson, J.B., and Pearson, R.G. 2012. Marinefreshwater transitions are associated with the evolution of dietary diversification in terapontid grunters (Teleostei: Terapontidae). Journal of Evolutionary Biology 25(6): 1163-1179.

Deegan, L.A., Wright, A., Ayvazian, A.G., Finn, J.T., Golden, H., Merson, R.R., and Harrison, J. 2002. Nitrogen loading alters seagrass ecosystem structure and support of higher trophic levels. Aquatic Conservation: Marine and Freshwater Ecosystems 12:193-212.

deMaintenon, M.J. 1999. Phylogenetics analysis of the Columbellidae (Mollusca:Neogastropoda) and the evolution of herbivory from carnivory. Invertebrate Biology 118(3):258-288.

DeMott, W.R. and Kerfoot, W.C. 1982. Competition among cladocerans: nature of the interaction between Bosmina and Daphnia. Ecology 63:1949-1966.

DeMott, W.R. 1998. Utilization of a cyanobacterium and a phosphorus-deficient green alga as complementary resources by daphnids. Ecology 79:2463-2481.

Diehl, S. 2003. The evolution and maintenance of omnivory: Dynamic constraints and the role of food quality. Ecology 84(10):2557-2567. 
Dogiel, V.A., Petrushevskii, G.K., and Polyanski, Y. 1961. Parasitology of fishes. Oliver and Boyd, Edinburgh, Scotland.

Drewe, K., M. H. Horn, K. A. Dickson and A. Gawlicka. 2004. Insectivore to fruivore: ontogenetic changes in gut morphology and digestive enzyme activity in the characid fish Brycon guatemalensis from Costa Rican rainforest streams. Journal of Fish Biology 64:890-902.

Duffy, J.E. and Paul, V.J. 1992. Prey nutritional quality and the effectiveness of chemical defenses against tropical reef fishes. Oecologia 90:333-339.

Duffy, J. E., and M. E. Hay. 1994. Herbivore resistance to seaweed chemical defense: the roles of mobility and predation risk. Ecology 75:1304-1319.

Durray, M., Kohno, H., and Pscual, F. 1994. The effect of lipid-enriched broodstock diets on spawning and on egg and larval quality of hatchery-bred rabbitfish (Siganus guttatus). The Philippine Scientist 31:42-57.

Ehrlich, P.R., and L.C. Birch. 1967. The "balance of nature" and "population control." American Naturalist 101:97-107.

Elger, A., Barrat-Segretain, M.H., and Amoros, C. 2002. Plant palatability and disturbance level in aquatic habitats: an experimental approach using the snail Lymnaea stagnalis (L.). Freshwater Biology 47:931-940.

Elger, A., Bornette, G., Barrat-Segretain, M.H., and Amoros, C. 2004. Disturbances as a structuring factor of plant palatability in aquatic communities. Ecology 85(2):304311.

Elser, J.J., Fagan, W.F., Denno, R.F., Dobberfuhl, D.R., Folarin, A., Huberty, A., Interlandi, S., Kilham, S.S., McCauley, E., Schulz, K.L., Siemann, E.H., and Sterner, R.E. 2000. Nutritional constrains in terrestrial and freshwater food webs. Nature 408:578-580.

Espinoza, R.E., J. J. Wiens, and C. R. Tracy. 2004. Recurrent evolution of herbivory in small, cold-climate lizards: Breaking the ecophysiological rules of reptilian herbivory. Proceedings of the National Academy of Science 101(48):1681916824.

Eubanks, M.D., Styrsky, J.D., and Denno, R.F. 2003. The evolution of omnivory in heteropteran insects. Ecology 84(10):2549-2556.

Feminella, J.W. and Hawkins, C.P. 1995. Interactions between stream herbivores and periphyton: A quantitative analysis of past experiments. Journal of the North American Benthological Society 4(14):465-509. 
Fink, P. and von Elert, E. 2006. Physiological responses to stoichiometric constraints: nutrient limitation and compensatory feeding in a freshwater snail. Oikos 115:484-494.

Freeland, W.J. and Janzen, D.H. 1974. Strategies in herbivory by mammals: The role of plant secondary compounds. The American Naturalist 108(961):269-289.

Freeland, W.J. and Saladin, L.R. 1989. Choice of mixed diets by herbivores: the idiosyncratic effects of plant secondary compounds. Biochemical Systematics and Ecology 17:493-497.

Fretwell, S. 1977. The regulation of plant communities by the food chains exploiting them. Perspectives in Biology and Medicine 20:169-185.

Fretwell, S.D. and Lucas Jr., H.L. 1970. On territorial behavior and other factors influencing habitat distribution in birds. Theoretical Development. Acta Biotheoretica 19:16-36.

Fuller, R. L., B. P. Kennedy and C. Nielsen. 2004. Macroinvertebrate responses to algal and bacterial manipulations in streams. Hydrobiologia 523:113-126.

Gergs, R., Steinberger, N., Basen, T. and Martin-Creuzburg, D. 2014. Dietary supply with essential lipids affects growth and survival of the amphipod Gammarus roeselii. Limnologica 46:109-115.

German, D. P., M. H. Horn and A. Gawlicka. 2004. Digestive enzyme activities in herbivorous and carnivorous prickleback fishes (Teleostei: Stichaeidae): ontogenetic, dietary, and phylogenetic effects. Physiological and Biochemical Zoology 77:789-804.

German, D.P., Nagle, B.C., Villeda, J.M., Ruiz, A.M., Thomson, A.W., Balderas, S.C., and Evans, D.H. 2010. Evolution of herbivory in a carnivorous clade of minnows (Teleostei: Cyprinidae): Effects on gut size and digestive physiology. Physiological and Biochemical Zoology 83(1):1-18.

Gibb, A., Ferry-Graham, L.A., Hernandez, L.P., Romansco, R. and Blanton, J. 2008. Functional significance of intramandibular bending in Poeciliid fishes. Environmental Biology of Fishes 83:507-519.

Goulden, C.E., Henry, L.L and Tessier, A.J. 1982. Body size, energy reserves, and competitive ability in three species of cladocera. Ecology 63(6):1780-1789.

Griffin, M. P. A., M. L. Cole, K. D. Kroeger, and J. Cebrian. 1998. Dependence of herbivory on autotrophic content and net primary production across ecosystems. Biological Bulletin 195:233-234. 
Gulati R. and DeMott, W.R. 1997. The role of food quality for zooplankton: remarks on the state of the art, perspectives and priorities. Freshwater Biology 38:753-768.

Guler, G. O., Aktumsel, A., Citil, O.B., Arslan, A. and Torlak, E. 2007. Seasonal variations on total fatty acid composition of fillets of zander (Sander lucioperca) in Beysehir Lake (Turkey). Food Chemistry 103(4):1241-1246.

Guo, N. and Xie, P. 2011. A study of the effects of food quantity and quality on glutathione S-transferase (GST) activity and growth rate parameters of Daphnia carinata varying in age. Aquatic Ecology 45:63-73.

Guo, F., M. J. Kainz, F. Sheldon and S. E. Bunn. 2016. Effects of light and nutrients on periphyton and fatty acid composition and somatic growth of invertebrate grazers in subtropical streams. Oecologia 181 (2): 449-462.

Hairston, N. G. Jr. and Hairston, N.G. 1993. Cause-effect relationships in energy flow, trophic structure, and interspecific interactions. American Naturalist 142:379-411.

Hairston, N.G., F.E. Smith, and L.B. Slobodkin. 1960. Community structure, population control, and competition. American Naturalist 44:421-425.

Hairston, N. G., Holtmeier, C.L., Lampert, W., Weider, L.J., Post, D.M., Fischer, J.M., Caceres, C.E., Fox, J.A. and Gaedke, U. 2001. Natural selection for grazer resistance to toxic cyanobacteria: Evolution of phenotypic plasticity? Evolution 55(11):2203-2214.

Hastings, H.M. and Conrad, M. 1979. Length and evolutionary stability of food chains. Nature 282:838-839.

Herms, D. A. and W. J. Mattson. 1992. The dilemma of plants: To grow or defend. The Quarterly Review of Biology 67(3): 283-335.

Hietala, J., Reinikainen, M., and Walla, M. 1995. Variation in life history responses of Daphnia to toxic Microcystis aeruginosa. Journal of Plankton Research 17:23072318.

Hoffman, G. L. 1999. Parasites of Freshwater Fishes. Cornell University Press, Ithaca, New York, USA.

Howe, G. A., and G. Jander. 2008. Plant immunity to insect herbivores. Annual Review of Plant Biology 59:41-66.

Huang, A., Bininda-Emonds, O.R.P., Stephens, P.R., Gittleman, J.L., and Altizer, S. 2014. Phylogenetically related and ecologically similar carnivores harbor similar parasite assemblages. Journal of Animal Ecology 83:671-680. 
Iverson, S. J., C. Field, W. D. Bowen, W. Blanchard. 2004. Quantitative fatty acid signature analysis: a new method of estimating predator diets. Ecological Monographs 74:211-235.

Jäger, C.G., Vrede, T., Persson, L., and Jansson, M. 2014. Interactions between metazoans, autotrophs, mixotrophs and bacterioplankton in nutrient-depleted high DOC environments: a long-term experiment. Freshwater Biology 59:1596-1607.

Jiang, L., and P. J. Morin. 2004. Productivity gradients cause positive diversityinvasibility relationships in microbial communities. Ecology Letters 7(11): 10471057.

Jiang, J., Shi, Y., Shan, Z., Yang, L., Wang, X., and Shi, L. 2012. Bioaccumulation, oxidative stress and HSP70 expression in Cyprinus carpio L. Exposed to microcystin-LR under laboratory conditions. Comparative Biochemistry and Physiology Part C 155:483-490.

Karasov W.H. and Martinez del Rio, C. 2007. Physiological Ecology: How Animals Process Energy, Nutrients, and Toxins. Princeton University Press, Princeton, New Jersey, USA.

Kilham, S.S., Kreeger, D.A., Goulden, C.E. and Lynn, S.G. 1997. Effects of algal food quality on fecundity and population growth rates of Daphnia. Freshwater Biology 38: 639:647.

Kitting, C.L. 1980. Herbivore-plant interactions of individual limpets maintaining a mixed diet of intertidal marine algae. Ecological Monographs 50:527-550.

Kramer, D.L. and Bryant, M. J. 1995. Intestine length in the fishes of a tropical stream: 2. Relationships to diet-the long and short of a convoluted issue. Environmental Biology of Fishes 42:129-141.

Krebs, J.R., Stephens, D.W. and Sutherland, W.J. 1983. Perspectives in optimal foraging. Pages 165-216 in A.H. Bush and G. A. Clark, editors. Perspectives in Ornithology: Essays presented for the centennial of the American Ornithologists' Union. Cambridge University Press, Cambridge, New York, USA.

Lampert, W. and Trubetskova, I. 1996. Juvenile growth rate as a measure of fitness in Daphnia. Functional Ecology 10:631-635.

Laspoumaderes, C., Modenutti, B., and Balseiro, E. 2010. Herbivory versus omnivory: Linking homeostasis and elemental imbalance in copepod development. Journal of Plankton Research 32(11):1573-1582. 
Lika, K. and Kooijman, S.A.L.M. 2003. Life history implications of allocation to growth versus reproduction in dynamic energy budgets. Bulletin of Mathematical Biology 65:809-834.

Marcogliese, D.J. 2002. Food webs and the transmission of parasites to marine fish. Parasitology 124:S83-S99.

Marks, J.C., Power, M.E., and Parker, M.S. 2000. Flood disturbance, algal productivity, and interannual variation in food chain length. Oikos 90:20-27.

Martin-Creuzburg, D., Beck, B., and Freese, H.M. 2011. Food quality of heterotrophic bacteria for Daphnia magna: evidence for a limitation by sterols. FEMS Microbiology Ecology 76:592-601.

Martin-Creuzburg, D., von Elert, E. and Hoffman, K.H. 2008. Nutritional constraints at the cyanobacteria-Daphnia magna interface: The role of sterols. Limnology and Oceanography 53(2):456-468.

Martin-Creuzburg, D., Wacker, A., and von Elert, E. 2005. Life history consequences of sterol availability in the aquatic keystone species Daphnia. Oecologia 144:362372.

Mattson, W.J. Jr. 1980. Herbivory in relation to plant nitrogen content. Annual Review of Ecology and Systematics 11:119-161.

Milinski, M. 1985. The patch choice model: no alternative to balancing. The American Naturalist 125:317-320.

Mitchell, S.F., Trainor, F.R., Rich, P.H., and Goulden, C.E. 1992. Growth of Daphnia magna in the laboratory in relation to the nutritional status of its food species, Chlamydomonas reinhardtii. Journal of Plankton Research 14:379-391.

Murdoch, W.W. 1966. Community structure, population control, and competition: A critique. American Naturalist 100:219-226.

Nayak, J., P. G. Viswanathan Nair, K. Ammu and S. Matthew. 2003. Lipase activity in different tissues of four species of fish: rohu (Labeo rohita Hamilton), oil sardine (Sardinella longiceps Linnaeus), mullet (Liza subviridis Valenciennes) and Indian mackerel (Rastreooiger kanagurta Curvier) Journal of the Science of Food and Agriculture 83:1139-1142.

Newman, R.M. 1991. Herbivory and detritivory on freshwater macrophytes by invertebrates: a review. Journal of the North American Benthological Society 10: 89-114. 
Newman, R.M. and Rotjan, R.D. 2013. Re-examining the fundamentals of grazing: freshwater, marine and terrestrial similarities and contrasts (commentary on Burkepile 2013). Oikos 122:317-320.

Nishida, R. 2002. Sequestration of defensive substances from plants by Lepidoptera. Annual Review of Entomology 47:57-92.

Ojala, K., R. Julkunen-Tiitto, L. Lindstrom and J. Mappes. 2005. Diet affects the immune response and life history traits of an Arctiid moth Parasemia plantaginis. Evolutionary Ecology Research 7:1153-1170.

Oksanen, L. 1988. Ecosystem organization: mutualism and cybernetics or plain Darwinian struggle for existence. American Naturalist 131:424-444.

Oksanen, T., Power, M.E., and Oksanen, L. 1995. Ideal free habitat selection and consumer-resource dynamics. The American Naturalist 146(4):565-585.

Ortiz-Rodriguez, R., Son Dao, T., and Wiegand, C. 2012. Transgenerational effects of microcystin-LR on Daphnia magna. The Journal of Experimental Biology 215:2795-2805.

Paine, R.T. and Vadas, R.L. 1969. Calorific values of benthic marine algae and their postulated relation to invertebrate food preference. Marine Biology 4:79-86.

Pare, P. W. and J. H. Tuminson. 1999. Plat volatiles as a defense against insect herbivores. Plant Physiology 121:325-331.

Pauls, S.U., Graf, W., Haase, P., Lumbsch, H.T., and Waringer, J. 2008. Grazers, shredders and filtering carnivores- The evolution of feeding ecology in Drusinae (Trichoptera: Limnephilidae): Insights from a molecular phylogeny. Molecular Phylogenetics and Evolution 46 (2):776-791.

Pennings, S.C., Nadeau, M.T., and Paul, V.J. 1993. Selectivity and growth of the generalist herbivore Dolabella auricularia feeding upon complementary resources. Ecology 74(3):879-890.

Plaistow, S., J. P. Troussard, and F. Cezilly. 2001. The effect of the acanthocephalan parasite Pomphorhynchus laevis on the lipid and glycogen content of its intermediate host Gammarus pulex. International Journal for Parasitology 31(4):346-351.

Porter, K.G. 1977. The plant-animal interface in freshwater ecosystems: Microscopic grazers feed differentially on planktonic algae and can influence their community structure and succession in ways that are analogous to the effects of herbivores on terrestrial plant communities. American Scientist 65(2):159-170. 
Power, M. E. 1992. Top-down and bootom-up forces in food webs: Do plants have primacy? Ecology 73(3):733-746.

Pringle, C.M., Naiman, R.J., Bretschko, G., Karr, J.R., Oswood, M.W., Webster, J.R., Welcomme, R.L., and Winterbourn, M.J. 1988. Patch dynamics in lotic systems: the stream as a mosaic. Journal of the North American Benthological Society 7(4):503-524.

Proulx, M. and Mazumder, A. 1998. Reversal of grazing impact on plant species richness in nutrient-poor vs. nutrient-rich ecosystems. Ecology 79(8):2581-2592.

Raubenheimer, D., K. P. Lee and S. J. Simpson. 2005. Does Bertrand's rule apply to macronutrients? Proceedings of the Royal Society B 272:2429-2434.

Raubenheimer, D., and S.J. Simpson. 1997. Integrative models of nutrient balancing: application to insects and vertebrates. Nutrition Research Reviews 10:151-179.

Reisz, R.R. and Fröbisch, J. 2014. The Oldest Caseid Synapsid from the Late Pennsylvanian of Kansas, and the Evolution of Herbivory in Terrestrial Vertebrates. PLoS ONE 9(4): http://dx.doi.org/10.1371/journal.pone.0094518.

Rivera-Milla, E., Stuermer, C.A.O, and Málaga-Trillo, E. 2003. An evolutionary basis for scrapie disease: identification of a fish prion mRNA. Trends in Genetics 19:72 75.

Rushton, S. P., and M. Hassall. 1983. The effects of food quality on the life history parameters of the terrestrial isopod (Armadillidum vulgare (Latreille)). Oecologia 57:257-261.

Sanders, R.W., Williamson, C.E., Stutzman, P.L., Moeller, R.E., Goulden, C.E., and Aoki-Goldsmith, R. 1996. Reproductive success of "herbivorous" zooplankton fed algal and non-algal food resources. Limnology and Oceanography 41:12951305

Sargent, J.R, Bell, J.G., Bell, M.V., Henderson, R.J., and Tocher, D.R. 1995. Requirement criteria for essential fatty acids. Journal of Applied Ichythyology 11:183-198.

Schmidt, K. and Jonasdottir, S.H. 1997. Nutritional quality of two cyanobacteria: How rich is 'poor' food? Marine Ecology Progress Series 151: 1-10.

Sharathchandra, K. and Rajashekhar, M. 2011. Total lipid and fatty acid composition in some freshwater cyanobacteria. Journal of Algal Biomass Utilization 2(2):83-97. 
Shin, K., M. Jang, P. Jang, S. Ju, T. Lee, and M. Chang. 2003. Influence of food quality on egg production and viability of the marine planktonic copepod Acartia omorii. Progress in Oceanography 57:265-277.

Sih, A. and Christensen, B. 2001. Optimal diet theory: When does it work, and when and why does it fail? Animal Behaviour 61(2):379-390.

Simmonds, M.S.J., Simpson, S.J., and Blaney, W.M. 1992. Dietary selection behavior in Spodoptera littoralis: the effects of conditioning diet and conditioning period on neural responsiveness and selection behaviour. Journal of Experimental Biology 162:73-90.

Simpson, S.J. and Raubenheimer, D. 1996. Feeding behaviour, sensory physiology and nutrient feedback: a unifying model. Entomologia Experimentalis et Applicata 80:55-64.

Simpson, S.J. and Simpson, C.L. 1990. The mechanisms of nutritional compensation by phytophagous insects. Pages 111-160 in E.A. Bernays. Insect-plant interactions, Volume 2. CRC Press, Boca Raton, Florida, USA.

Sinclair, A.R.E., C. J. Krebs, and J.N.M. Smith. 1982. Diet quality and food limitation in herbivores: The case of the snowshoe hare. Canadian Journal of Zoology 60(5): 889-897.

Singer, M.S., Bernays, E.A., and Carriere, Y. 2002. The interplay between nutrient balancing and toxin dilution in foraging by a generalist insect herbivore. Animal Behaviour 64:629-643.

Slobodkin, L.B., F.E. Smith, and N.G. Hairston. 1967. Regulation in terrestrial ecosystems, and the implied balance of nature. American Naturalist 101:109-124.

Smoot, J.C. and Findlay, R.H. 2010. Caloric needs of a detritivorous gizzard shad Dorosoma cepedianum are met with sediment bacterial and algal biomass. Aquatic Biology 8:105-114.

Stachowicz, J.J. and Hay, M.E. 1996. Facultative mutualism between and herbivorous crab and a coralline alga: advantages of eating noxious seaweeds. Oecologia 105:377-387.

Stachowicz, J. J., and M. E. Hay. 1999. Reducing predation through chemically mediated camouflage: indirect effects of plant defenses on herbivores. Ecology 80:495509. 
Stearns, S.C. 1992. The Evolution of Life Histories. Oxford University Press, Oxford, London.

Sterner, R.W. 1993. Daphnia growth on varying quality of Scenedesmus: Mineral limitation of zooplankton. Ecology 74:2351-2360.

Sterner, R. W., J. J. Elser, E. J. Fee, S. J. Guildford, and T. H. Chrzanowski. 1997. The light:nutrient ration in lakes: the balance of energy and materials affects ecosystem structure and process. American Naturalist 150:663-684.

Sterner, R.W. and Elser, J.J. 2002. Ecological stoichiometry. Princeton University Press, Princeton, New Jersey, USA.

Sterner, R.W. and Hessen, D.O. 1994. Algal nutrient limitation and the nutrition of aquatic herbivores. Annual Review of Ecology and Systematics 25:1-29.

Stevens, C.E. and Hume, I.D. 2004. Comparative physiology of the vertebrate digestive system: $2^{\text {nd }}$ Edition. Cambridge University Press, Cambridge.

Strong, D. R. 1992. Are trophic cascades all well? Differentiation and donor-control in speciose ecosystems. Ecology 73(3):747-754.

Targett, T. E. and Targett, N.M. 1990. Energetics of food selection by the herbivorous parrotfish Sparisoma radians: roles of assimilation efficiency, gut evacuation rate, and algal secondary metabolites. Marine Ecology Progress Series 66:13-21.

Tessier, A.J., Henry, L.L., Goulden, C.E., and Durand, M.W. 1983. Starvation in Daphnia: Energy re- serves and reproductive allocation. Limnology and Oceanograph 28:667-676.

Tessier, A.J. 1986. Comparative population regulation of two planktonic Cladocera (Holopedium gibberum and Daphnia Catawba). Ecology 67:285-302.

Trubetskova, I.L. and Haney, J.F. 2006. Effects of differing concentrations of microcystin-producing Microcystis aeruginosa on growth, reproduction, survivorship and offspring of Daphnia magna. Archiv fuer Hydrobiologie 167:533-546.

Van Damme, R. 1999. Evolution of herbivory in lacertid lizards: Effects of insularity and body size. Journal of Herpetology 33(4):663-674.

Van der Wal, R., N. Madan, S. van Lieshout, C. Dormann, R. Langvatn and S.D. Albon. 2000. Trading forage quality for quantity? Plant phenology and patch choice by Svalbard reindeer. Oecologia 123:108-115. 
Vanni, M.J. and Lampert, W. 1992. Food quality effects on life history traits and fitness in the generalist herbivore, Daphnia. Oecologia 92:48-57.

Wacker, A. and Martin-Creuzburg, D. 2007. Allocation of essential lipids in Daphnia magna during exposure to poor food quality. Functional Ecology 21:738-747.

Wang, L., D. Zuo, W. Lv, J. Li, Q. Wang and Y. Zhao. 2013. Effects of dietary soybean lechithin on gonadal development and vitellogenin mRNA expression in the female redclaw crayfish Cherax quadricarinatus (von Martens) at first maturation. Aquaculture Research 44:1167-1176.

Weers, P.M.M. and Gulati, R.D. 1997. Growth and reproduction of Daphnia galeata in resposnse to changes in fatty acids, phosphorus, and nitrogen in Chlamydomonas reinhardtii. Limnology and Oceanography 42(7):1584-1589.

Wetzel, R G. 2001. Limnology Third Edition. Academic Press, San Diego, California, USA.

Wiegand, M.D. 1996. Composition, accumulation and utilization of yolk lipids in teleost fish. Reviews in Fish Biology and Fisheries 6:259-286.

Wiegand, C. and Plugmacher, S. 2005. Ecotoxicological effects of selected cyanobacterial secondary metabolites a short review. Toxicology and Applied Pharmacology 203:201-218.

Wiegert, R.G., and D.F. Owen. 1971. Trophic structure, available resources and population density in terrestrial vs. aquatic ecosystems. Journal of Theoretical Biology 30:69-81.

Zhang, D., Yang, Q., Xie, P., Deng, X., Chen, J. and Dai, M. 2012. The role of cysteine conjugation in the detoxification of microcystin-LR in the liver of bighead carp (Aristichthys nobilis): a field and laboratory study. Ecotoxicology 21:244-252. 
Table 2.1. Description of the proposed hypotheses for the adaptive evolution of

herbivory in freshwaters.

\begin{tabular}{|c|c|c|}
\hline Name & Hypothesis & References \\
\hline I. Intake-efficiency & $\begin{array}{l}\text { Aquatic herbivores may use all or part of } \\
\text { their food source as habitat. Herbivory } \\
\text { may allow an organism to maximize intake } \\
\text { energy by minimizing the time spent } \\
\text { searching for food, energy consumed } \\
\text { during prey capture, and energy costs } \\
\text { avoiding predators. }\end{array}$ & $\begin{array}{l}\text { Brönmark and Vermaat } \\
1998\end{array}$ \\
\hline II. Suboptimal habitat & $\begin{array}{l}\text { Herbivory may allow organisms to invade } \\
\text { suboptimal or recently disturbed habitats. } \\
\text { Such habitats are often characterized by } \\
\text { having high primary production relative to } \\
\text { consumer biomass. }\end{array}$ & $\begin{array}{l}\text { e.g. Proulx and } \\
\text { Mazumder } 1998\end{array}$ \\
\hline III. Heterotroph facilitation & $\begin{array}{l}\text { Herbivory may be adaptive because } \\
\text { herbivores supplement their diets by } \\
\text { indirectly consuming heterotrophic } \\
\text { microbes that are associated with algae. } \\
\text { These heterotrophs can provide nutrients } \\
\text { that are not attainable by eating algae } \\
\text { alone. }\end{array}$ & $\begin{array}{l}\text { e.g. Martin-Creuzberg et } \\
\text { al. } 2011\end{array}$ \\
\hline IV. Lipid allocation & $\begin{array}{l}\text { Some freshwater algae are sources of } \\
\text { essential lipids and herbivorous organisms } \\
\text { consume large quantities of these lipids } \\
\text { relative to animal-consuming species. } \\
\text { Because aquatic organisms use lipids for } \\
\text { energy storage and reproduction } \\
\text { consuming a diet rich in fatty acids may } \\
\text { result in greater reproductive allocation. } \\
\text { Herbivory may be adaptive because higher } \\
\text { lipid consumption leads to higher } \\
\text { reproductive allocation and thus, increased } \\
\text { fitness. }\end{array}$ & $\begin{array}{l}\text { Brett and Muller- Navarra } \\
1997, \text { Karasov and } \\
\text { Martinez del rio 2007, } \\
\text { Sharathchandra and } \\
\text { Rajashekhar } 2009\end{array}$ \\
\hline V. Disease avoidance & $\begin{array}{l}\text { Animal prey may serve as intermediate } \\
\text { hosts and facilitate transmission of } \\
\text { parasites or prions through the diet. } \\
\text { Herbivory may be adaptive because it } \\
\text { reduces animal-facilitated disease } \\
\text { transmission. }\end{array}$ & $\begin{array}{l}\text { Covich et al.1999, } \\
\text { Marcogliese } 2002\end{array}$ \\
\hline
\end{tabular}


Table 2.2. Assumptions of proposed hypotheses. Testing these hypotheses may be best accomplished by evaluating the assumptions necessary for them to be viable explanations for adaptive evolution of herbivory.

\begin{tabular}{cl}
\hline \multicolumn{1}{c}{ Hypothesis } & \multicolumn{1}{c}{ Assumptions } \\
\hline I. Intake-efficiency & $\begin{array}{l}\text { Freshwater herbivores are relatively small and require } \\
\text { refuge from predators, usually in the form of submerged } \\
\text { aquatic vegetation. Submerged aquatic vegetation is } \\
\text { associated with more palatable plants like algae that are } \\
\text { consumed by herbivores. }\end{array}$ \\
II. Suboptimal habitat & $\begin{array}{l}\text { Herbivores are able to detect food availability and/or } \\
\text { quality in the current habitat and make dispersal decisions } \\
\text { accordingly. }\end{array}$ \\
III. Heterotroph & $\begin{array}{l}\text { Heterotrophic microbes (heterotrophic bacteria, protoza, } \\
\text { etc.) are in close association with freshwater primary } \\
\text { producers and herbivores consume them indirectly. }\end{array}$ \\
IV. Lipid allocation & $\begin{array}{l}\text { At least some essential lipids come from freshwater } \\
\text { primary producers. }\end{array}$ \\
V. Disease avoidance & $\begin{array}{l}\text { Parasites and prion diseases are only transmitted via } \\
\text { animal vectors. }\end{array}$
\end{tabular}


Table 2.3. Examples of experimental designs that could be used as tests of the posed

hypotheses.

\begin{tabular}{|c|c|}
\hline Hypothesis & Example \\
\hline I. Intake-efficiency & See text (Alvarez and Peckarsky 2013). \\
\hline II. Suboptimal habitat & $\begin{array}{l}\text { Jiang and Morin (2004) constructed microcosms with a } \\
\text { productivity gradient and subjected plankton communities to } \\
\text { invading species. Invaders and resident species increased their } \\
\text { abundances with resource enrichment. This hypothesis could be } \\
\text { tested by replacing herbivores as "residents" and carnivores as } \\
\text { "invaders" and measuring herbivore and carnivore abundances as a } \\
\text { function of increasing productivity and/or disturbance levels. }\end{array}$ \\
\hline
\end{tabular}

III. Heterotroph facilitation

Jäger et al. (2014) examined the interactions between Daphnia spp., phytoplankton and bacteria using three algal species compositions. Daphnia grew to high densities with a mixed diet and high light conditions. Similar field or lab feeding experiments could be designed by manipulating the autotrophic: heterotrophic ratio of the herbivorous diet and measuring life history effects relative to those resulting from a carnivorous diet. A norm-ofreaction may be used to assess the conditions where a mixed autotrophic and heterotrophic diet is equal to or better than a carnivorous diet (in terms of fitness).

IV. Lipid allocation Wacker and Martin-Cruezburg (2007) fed Daphnia spp. either algae with high lipid content or algae with low lipid content and measured lipid allocation to somatic and reproductive tissue. They found that essential lipids were preferentially allocated to offspring when provided foods with high lipid content. Gergs et al. (2014) measured growth and survival of amphipods fed diets with or without essential lipid supplementation and found that both were positively affected by the addition of lipids. Comparable feeding experiments should be conducted with these and other herbivores using natural dietary items. Life history effects of non-herbivorous diets that vary in lipids should also be assessed. Identifying the source of lipids allocated to somatic and reproductive tissues will provide further support for the lipid allocation hypothesis.

V. Disease avoidance

Huang et al. (2014) examined factors that influence parasite sharing between carnivore hosts using a large data set on reported parasites and previously published phylogenies. They found that viruses and helminths infect phylogenetically related carnivores more than expected by chance. Similar comparative analyses could be implemented to determine patterns of parasite and prion infection across diet types. 
CHAPTER 3

FRESHWATER-TO-MARINE TRANSITIONS MAY EXPLAIN THE EVOLUTION OF HERBIVORY IN THE SUBGENUS MOLLIENESIA (GENUS POECILIA)

Formatted for: Journal of Evolutionary Biology 


\begin{abstract}
The ability of organisms to cross ecosystem boundaries is an important catalyst of evolutionary diversification. The genus Poecilia is an excellent model system for studying ecosystem transitions because species display a wide range of salinity affiliations. Furthermore, Poecilia species exhibit a variety of diet preferences, with herbivory concentrated in the subgenus Mollienesia. It has been suggested that herbivory may be an adaptive strategy to allow organisms to invade habitats with decreased resource quality, also known as the Suboptimal Habitat Hypothesis. I evaluated this hypothesis by reconstructing ancestral states of habitat and diet across a phylogeny of the genus Poecilia to identify patterns of diet evolution and habitat transition, and then used phylogenetically independent contrasts to identify patterns of diet evolution in response to habitat transition.

I found that the subgenus Mollienesia had freshwater or euryhaline roots and crossed ecosystem boundaries at least once following the divergence of the three recognized species complexes (P. mexicana, $P$. sphenops and $P$. latipinna). Increased salinity affiliation explained $26 \%$ of the decrease in animal material in the gut, and jaw morphology was associated with percent animal material in the gut, but not with percent of species occupying saline habitats. These findings suggest that in the genus Poecilia, herbivory evolved in response to transitions from fresh to euryhaline habitats, and jaw morphology evolved in response to the appearance of herbivory. These results support herbivory as an adaptation for invading less productive saline habitats, which is consistent with the Suboptimal Habitat Hypothesis.
\end{abstract}


Keywords: Diet evolution, herbivory, Poecilia, habitat transition, freshwater habitat, marine habitat, adaptive evolution, phylogeny, ancestral state reconstruction, Mollienesia

\section{Introduction}

The ability of organisms to cross habitat and ecosystem boundaries and invade new space is an important driver of evolutionary diversification. Habitat shifts by organisms may provide new foraging opportunities with little competition and decreased predation threats for organisms (Betancur-R et al. 2012). In addition, invading a new habitat can have significant evolutionary consequences for the invading species by enhancing the possibility for novel phenotypes to spread. These novel phenotypes can promote new ecological interactions between species, ultimately resulting in species radiation (Lee 1999; Betancur-R et al. 2012; Davis et al. 2012). However, there are physiological costs associated incurred by organisms that transition between habitats, because the ability of an organism to transition requires a suite of specialized adaptations suited for the new environment (Vermeij and Dudley 2000; Betancur-R 2009). Many metazoans are derived from ancestors that have crossed ecosystem boundaries, suggesting that the relative costs of transitioning can be outweighed by the ecological opportunities afforded to those with the ability to do so.

In aquatic systems, the interface between marine and freshwater habitats represents a boundary that creates a physiological challenge for potential invaders (Lee 1999). As a result, approximately half of marine animal phyla have failed to colonize freshwater habitats (Betancur-R 2009). 
Annelids, crustaceans, mollusks and fish are among those that were able to make the marine-to-freshwater transition (e.g. Lee and Bell 1999; Lovejoy et al. 2001; Lovejoy et al. 2006; Augusto et al. 2009; Betancur-R 2009; Yamanou et al. 2011). Following their incursion from marine waters, these groups experienced rapid radiation resulting in high diversification in the freshwater clades relative to their marine counterparts (Bloom et al. 2013). For example, fish from the family Terapontidae originated in marine habitats, but after a single marine-to-freshwater transition, 40 out of 54 extant species are restricted to freshwaters (Davis et al. 2012). In addition, the freshwater Terapontids experienced three times faster diversification than the marine clade, accompanied by a shift from a carnivorous diet in marine habitats to an herbivorous diet in freshwaters (Davis et al. 2012).

While marine-to-freshwater transitions are relatively common in fishes (Betancur-R 2009), colonization of marine habitats by freshwater organisms, or reinvasion of freshwater by secondary marine clades, have occurred less frequently (McDowall 1997; Vermeij 2000; Betancur-R 2009). In addition, diversification of marine fishes tends to be slower than diversification of freshwater fishes, likely because of the heterogeneity offered by freshwater habitats (Bloom et al. 2013). Despite these slower rates of colonization and diversification, several clades have moved into marine habitats from fresh waters (e.g., catfish, Ferraris 2002, Sullivan et al. 2006). One of these families, Poeciliidae (Cyprinodontiformes), has evolved the ability to disperse across marine water barriers, and extant species inhabit both fresh and euryhaline habitat types (Meffe and Snelson 1989). 
As a result, this group has undergone a significant evolutionary radiation (Hrbek et al. 2007), resulting in a multitude of endemic taxa (Palacios et al. 2016). One genus, Poecilia, is an excellent model system for studying transitions across ecosystem boundaries, because it consists of species with limited ranges and species with wide, overlapping distributions (Palacios et al. 2016). In addition, Poecilia species occupy several continents, informing phylogeographic analyses that have provided insights into the historical processes that shaped distribution patterns of this group (Palacios et al. 2016).

Phylogeographic analyses of the genus Poecilia have suggested that it originated in South America and dispersed to the Greater Antilles via the Aves land bridge (Hrbek et al. 2007; Palacios et al. 2016; Reznick et al. 2017). Through migration and vicariance events, Poecilia species also dispersed into Middle America (Central and North America) approximately 2-7 mya, where they underwent significant evolutionary radiation (Hrbek et al. 2007; Ho et al. 2016). Extant species inhabit these continents, but they have experienced divergence that is linked to their biogeography (Ho et al. 2016). Uncovering these biogeographical patterns (e.g., Alda et al. 2013; Ho et al. 2016; Palacios et al. 2016) has allowed researchers to improve previously unresolved phylogenies of the genus Poecilia (e.g., Ptacek and Breden 1998; Breden 1999; Mateos 2005; Hrbek 2007; Meredith 2010), but no studies have used these phylogenetic relationships to trace characters related to habitat or diet of Poecilia species. 
Although all members of the genus have some capacity to survive in both fresh and euryhaline waters, some species thrive in freshwater habitats, whereas others fare better in brackish and/or marine habitats (Meffe and Snelson 1989). In addition, all Poecilia species exhibit some degree of herbivory, however, I hypothesize that obligate herbivory is concentrated in the subgenus Mollienesia (pers. obs.). Most of the species comprising this subgenus inhabit Middle America and occupy both fresh and euryhaline habitats (Ho et al. 2016). I hypothesize that dispersal of the subgenus Mollienesia into Middle America resulted in habitat transitions across the freshwater-marine barrier (e.g., David et al. 2012) that potentially drove the evolution of herbivory in this group.

Herbivory is generally thought to be an inefficient feeding strategy relative to omnivory and carnivory (see Sanchez and Trexler 2016 for a review). However, many herbivorous metazoans have evolved from carnivorous/omnivorous ancestors, so there is some adaptive value associated with eating plants (Sanchez and Trexler 2016). It has been suggested that herbivory is an adaptive strategy to allow organisms to invade habitats with decreased resource quality, to escape the negative effects of competition and/or predation (i.e., 'Suboptimal Habitat Hypothesis', Sanchez and Trexler 2016). Although marine systems cover $99 \%$ of the Earth's surface, these habitats are less productive per unit area than freshwater aquatic habitats (e.g., Colinvaux 1980; May and Godfrey 1994; Vermeij and Grosberg 2010) and could therefore be considered 'suboptimal' under the Suboptimal Habitat Hypothesis. As such, transitions from freshwater to less productive marine waters may have prompted the evolution of the herbivorous strategy in the Poecilia group, particularly in the Mollienesia clade. 
My objective for this study is to reconstruct ancestral states of habitat and diet across a phylogeny of the genus Poecilia to identify patterns of diet evolution and habitat transition from freshwater to euryhaline systems (or vice versa) in the subgenus Mollienesia. This information will allow us to evaluate the Suboptimal Habitat Hypothesis by determining if habitat affiliations explain patterns of diet evolution.

\section{Methods}

\section{Taxon Sampling}

There are 44 documented species in the genus Poecilia, spread across 7 subgenera (Poeser et al. 2005; Ho et al. 2016): Acanthophacelus, Poecilia (subgenus), Micropoecilia, Curtipenis, Psychropoecilia, Allopoecilia, and Mollienesia. Currently, the most complete phylogenies of the genus Poecilia are based on gene sequences from 1119 distinct species (Alda et al. 2013; Ho et al. 2016; Palacios et al. 2016), sampled from 1-5 of the described subgenera. Previous studies sampled between 1-14 Poecilia species, belonging to 1-3 subgenera, but resulted in unresolved phylogenetic relationships (Ptacek

and Breden 1998; Breden 1999; Mateos 2005; Hrbek 2007; Meredith 2010). In this study, I sampled 36 distinct Poecilia species with at least one representative from all 7 of the described subgenera, as well as 2 species from the sister genus Limia to construct an updated topology. I chose $P$. reticulata as an outgroup taxon. Although this species is in the genus Poecilia, it has been shown to be a reliable outgroup taxon in previous studies focusing on the subgenus Mollienesia (e.g. Ptacek and Breden 1998), as well as the genus Poecilia (Alda et al. 2013; Ho et al. 2016). This sampling represents the highest number of representative species collected across all Poecilia subgenera to date. 
I collected diet and habitat data (see methodology below) from a subsample of the collection, represented by 15 Poecilia species spread across 6 sampled subgenera (excluding Curtipenis). These were: P. butleri, P. orri, P. mexicana, P. sphenops, P. gilli, P. caucana, P. hispaniolana, $P$. dominicensis, $P$. vivipara, $P$. latipinna, $P$. kyesis, $P$. velifera, P. picta, P. parae, and P. reticulata (Table 3.1). Of these, 8 were representatives of the Mollienesia subgenus (P. butleri, P. orri, P. mexicana, P. sphenops, P. gilli, $P$. latipinna, $P$. kyesis, and $P$. velifera) and represent individuals from the three recognized Mollienesia complexes (P. mexicana, P. latipinna, and P. sphenops) listed in Ho et al. (2016).

\section{Phylogenetic Analyses}

Previous Poecilia phylogenies were constructed using several mitochondrial genes and one ribosomal gene (Alda et al. 2013; Ho et al. 2016; Palacios et al. 2016): 5' prime region of the cytochrome oxidase subunit I (COI; mtDNA), ATPase 8/6 (mtDNA), NADH dehydrogenase subunit 2 (ND2; mtDNA), and the nuclear S7-like ribosomal protein $(S 7)$. These previous topologies did not include all available Poecilia species sequences, as well as a few of the sub-sampled species $(P$. velifera, $P$. dominicensis, $P$. parae, and P. picta). To compare diet and habitat characteristics, it was necessary to create an updated tree that included all of the sampled species. I retrieved sequences (36 Poecilia species +2 Limia species) for the same suite of genes used in previous works, as they were reliable at resolving phylogenetic relationships at both the genus (e.g., Alda et al. 2013; Ho et al. 2016) and subgenus (e.g., Palacios et al. 2016) level. 
These sequences were obtained from data deposited in Dryad by the previous authors (Alda et al. 2013 and Ho. et al. 2016) and were supplemented with additional sequences not included in these previous works using GenBank (see Table S.3.1 for accession numbers and sample IDs). I assembled the sequences using MEGA 7 (Kumar et al. 2015). Pseudogenes were investigated by: 1) translating nucleotides to amino acids; 2) examining the sequences for stop codons; 3 ) and searching for insertions/deletions (mitochondrial and ribosomal genes). The sequences were aligned using the Muscle option in MEGA 7 and concatenated $(C O I+$ ATPase $8 / 6+N D 2+S 7)$ using Sequence Matrix (Vaidya et al. 2011). I removed the first base of the COI sequences to set them in reading frame 1 (651bp) and split the ATPase $8 / 6$ sequences into the partial ATPase 8 (158bp) segment and complete ATPase 6 (684bp) sequence. We used PartitionFinder v2.1.1 (Lanfear et al. 2012) to identify the best partitioning scheme and models of evolution that fit the data. I used Bayesian Information Criterion (BIC) to evaluate the best-fit scheme and model with the greedy search algorithm, linked branch lengths, and models restricted to those that can be used in MrBayes. I repeated these methods to obtain the best-fit scheme for a second dataset comprised of the subsampled sequences (15 Poecilia species). All replicate sequences were included in the pruned tree except $P$. mexicana, $P$. sphenops and $P$. reticulata. For these species, I only included individuals that were sampled in the same country as the specimens I used to collect dietary data. 
I used MrBayes v3.2 (Huelsenbeck and Ronquist, 2001; Ronquist and Huelsenbeck, 2003) to create a Bayesian Inference (BI) phylogeny using the partitions and models specified in PartitionFinder for the concatenated datasets (all sequences and sub-sampled sequences). I constructed an analysis with uninformed priors, that ran for $1 \times 10^{6}$ generations, on four Markov chains. Trees were sampled every 100 generations. I performed three separate runs, each running 2 replicate runs. Following methods of Ho et al. (2016), I evaluated convergence of parameters using Tracer v1.6 (Rambaut et al. 2014) for each replicate and combined run, and found that all values for effective sample size were $>200$. Pairwise convergence of resulting tree topologies was evaluated using the RWTY package (Warren et al. 2017) in R v3.4.1 (R core team 2017), using a 25\% burn-in. In addition, I visually verified that the $50 \%$ majority-rule consensus trees for the three separate runs had matching topologies with minor deviations in branch lengths. I randomly selected one of the independent runs and constructed a consensus tree, computed Bayesian posterior probabilities, and visualized the topologies using FigTree v1.4.2 (http://tree.bio.ed.ac.uk/software/figtree/).

\section{Habitat Characterization}

Because Poecilia species can survive in most both fresh and salt waters, they show marked intraspecific variation in habitats they occupy. However, the rate of occurrence of individual species in fresh, brackish and marine habitats varies among species, revealing subtle differences in species-specific habitat preferences (Meffe and Snelson 1989). I used the Fishnet2 data base to estimate interspecific habitat preferences. 
For each of the subsampled species, I performed a Fishnet 2 search using the species name and collected habitat information on the first 25 independent hits with logged lat/long coordinates. Using the field collection notes provided by Fishnet2, Google Earth searches, and accompanying geographical information, I determined if each sample was collected from a freshwater, brackish or marine site. I then calculated the proportion of samples collected from each habitat type for all species (Table 3.1). I verified the predicted habitat associations with data reported in the literature for well-studied species (e.g., P. reticulata, P. mexicana, P. latipinna; Trexler and Travis 1990, Nordlie et al. 1992, Bussing 1998, Miller 2005), but these classifications are approximate and do not take into account seasonal or climatic changes in salinity, migration/dispersal events to or from different habitat types, or effective population sizes at each site. I made the assumption that if a species was able to be collected at a site, it has established there.

\section{Diet Characterization}

Subsampled species were obtained from Florida Museum of Natural History (retrieved from the Fishnet2 data base, http://www.fishnet2.net/), University of Michigan Museum of Zoology (Fishnet2), El Colegio de la Frontera Sur (ECOSUR) Ichthyology Collection (donations made to the authors), and collections made by the authors (Table 3.2). I used the most recent naming convention for $P$. kykesis, so the Fishnet2 search was performed using the former species name, P. petenensis (Poeser 2002). Individuals of each species were sampled from 2 distinct populations (i.e., no gene flow likely) within their native range using methods that do not interfere with diet characterization (e.g., by seining or cast nets, but not minnow traps). 
They were fixed in formalin and preserved in 70\% Ethanol following capture. An analysis of several Poeciliid species found that jaw morphologies varied among genera with different diet habits, with more herbivorous species displaying a larger degree of intramandibular bending (IMB), larger gape angles (GA), and a large degree of neurocranial rotation (NCR; Gibb et al. 2008; Hernandez et al. 2008 \& 2009). I measured these jaw angles to the nearest $0.01 \mathrm{~mm}$ standard length and placed them under a dissecting scope with an attached digital camera. Using ImageJ software, I measured the vertex of a line along the ventral margin of the dentary bone that forms the lower jaw, and a second line along the ventral margin of the angular-articular bone complex. I then subtracted the measured angle from $180^{\circ}$ to obtain the degree of IMB. For GA, I measured the vertex of a line along the anterior-ventral margin of the upper jaw and a line along the anterior-dorsal margin of the lower jaw. Finally, I measured NCR by measuring the angle between a vertical line posterior to the eye, and a line along the top of the skull above the eye (modified methods of Gibb et al. 2008). I compared these measurements among and within species using Analysis of Variance (ANOVA) and Tukey's Post-hoc tests.

Following jaw measurements, I assessed gut contents and morphology for each of the sub-sampled species. I was unable to dissect any specimens of $P$. parae, or specimens of P. butleri from a second locality due to museum limitations; therefore, only jaw measurements were obtained for these individuals. I dissected all other fish to remove the gut tract. Once the tract was removed, I weighed it to the nearest $0.001 \mathrm{~g}$, stretched it out onto a petri dish lined with grid paper $(6.35 \mathrm{~mm} / \mathrm{grid})$ and recorded the length. 
To standardize the length for comparison among species, I divided the length of the gut in $\mathrm{mm}$ by standard body length $(\mathrm{mm})$. I compared standardized gut lengths among species using ANOVA followed by a Tukey test.

I removed a subsample from each gut (from the esophagus to the first bend of the gut tract) and weighed it to the nearest $0.0001 \mathrm{~g}$. I extracted the contents of the subsample onto a tared microscope slide using the blunt end of a razor blade. I then added a drop of DI water to each slide, mounted them with a coverslip, and sealed them using clear nail polish. I examined slides using a light microscope at 40x magnification and counted and identified all organisms (to genus) in 10 random fields of view (counted area $=2.37 \mathrm{~mm}$ ). I grouped the organisms found in the guts by trophic group (diatoms, green algae, cyanobacteria, metazoans) and calculated relative abundance of each group for each fish species at both sampled localities. I did not quantify detritus and assumed that it marginally contributed to the diet, although this is probably not the case for Poecilia species (e.g., Sanchez and Trexler 2018). I used a hierarchical clustering procedure using the Sorensen (Bray-Curtis) distance measure (CLUSTER package in R; Maechler et al. 2017) to classify gut contents into diet categories (e.g., carnivore, omnivore, herbivore). All individuals of the same species (collected from different localities) clustered together, suggesting that intraspecific variation in gut contents was less than interspecific variation in gut contents. As such, I performed the clustering procedure again using the average gut content values for each species. 
I used the morphological data (IMB, GA, NCR and standardized gut length) and gut content estimations to determine if these diet characters are potential adaptations for the herbivorous diet in Poecilia species. For simplicity, I converted gut content data into percent animal material in the gut. I then generated phylogenetically independent contrasts (PIC) between percent animal material in the gut and each morphological character with the ape package in R (Paradis et al. 2004) using branch lengths from the pruned topology (containing only subsampled species). Contrasts were used in linearregression analyses, where the regression was forced through the origin (Felsenstein 1985). Any characters that significantly correlated $(\mathrm{p}<0.05)$ with percent animal material in the gut were assumed to have evolved as an adaptation to herbivory. These were used as characters in ancestral state reconstruction.

\section{Tracing the Evolution of Habitat and Diet}

I used ancestral state reconstruction to trace the dietary habits and salinity affiliations of ancestral Poecilia species. First, I coded diet categories estimated from Hierarchical Cluster Analysis as categorical traits (0-5, and '?' for P. parae). Similarly, I coded the proportion of samples collected from each habitat type (estimated from Fishnet2) as categorical traits $(0-2)$, where $0=$ species with $100 \%$ of samples collected in freshwaters ("Low salinity affiliation"), $1=$ species with samples collected in both freshwater and brackish waters ("Medium salinity affiliation"), and 2= species with samples collected in fresh, brackish and marine habitats ("High salinity affiliation"). I created character matrices from these coded diet and salinity characters. 
In addition, I created character matrices from the morphological characters (IMB, GA, NCR, standardized gut length) that had significant relationships with percent animal material in the gut (contrasts).

I uploaded the pruned consensus tree (subsampled species only) and character matrices into MESQUITE v3.2 (Maddison and Maddison 2017) and ran the "trace character" analysis using maximum parsimony (MP) and maximum likelihood (ML) methods for salinity affiliation and diet category. I was only able to run MP analyses for the morphology characters because these are continuous data and ML can only analyze categorical data. Parsimony ancestral state reconstruction minimizes the amount of character change over the tree topology based on the character state distribution and has thus been criticized for underestimating rates of evolutionary change (Cunningham et al. 1998; Royer-Carenzi et al. 2013). Maximum likelihood makes use of branch lengths and possible rates of character evolution to find the ancestral state that maximizes the probability that the observed character state (i.e., diet or salinity affiliation) would evolve under a stochastic model of evolution (Schluter et al. 1997). In this study, I used the symmetrical Mk1 model, which assumes equal forward and backward character transition rates (Lewis 2001). Because there has been some debate between using maximum parsimony (MP) and maximum likelihood (ML) methods, and because I was limited to more conservative MP methods for a subset of the data, I present the resulting reconstructions from both methods. The reconstructed states were plotted with the "balls and sticks" model, with ancestral states marked at each node. 


\section{Identifying Patterns of Diet Evolution in Response to Habitat Transitions}

I used phylogenetic independent contrasts (derived from the pruned tree) to compare diet and habitat affiliations across the genus Poecilia. Because this method can only be performed on continuous data, I generated contrasts from the percent of samples collected from euryhaline habitats (brackish + marine; Fishnet2 data) as a metric for salinity affiliation. I then used contrasts for salinity affiliation and all characters related to diet ( $\%$ animal material in gut and the 4 measured morphological characters) in linearregression analyses to identify the relationships between salinity affiliation, herbivory and the morphological adaptations related to herbivory.

\section{Results}

\section{Phylogenetic Analyses}

Full-Phylogeny (37 Poecilia species). I partitioned the dataset by genes and by codons for the mtDNA (COI, ATPase 8/6, ND2) genes. PartitionFinder identified four subsets of partitions (out of 13) for the complete Poecilia dataset (36 Poecilia species +2 Limia species). Their estimated models of DNA substitution were as follows: 1) GTR $+\mathrm{I}+\mathrm{G}$ for $C O I$ codon position 1, positions 2 and 3 of ATPase 8, ATPase 6, and ND2,2) K80+ G for $C O I$ position 2 and complete $S 7,3$ ) F81 for $C O I$ codon position 3, and 4) $\mathrm{HKY}+\mathrm{G}$ for position 1 of ATPase $8 / 6$ and ND2. I specified these data partitions and best-fit models of DNA substitution in subsequent phylogenetic analyses. 
The Bayesian phylogenetic analysis derived from the concatenated mitochondrial COI, ATPase 8/6, ND2, and the ribosomal $S 7$ genes from 36 Poecilia species (and 2 Limia species) resulted in a well-supported consensus tree, with the exception of the node linking the subgenera Poecilia and Micropoecilia ( $85 \%$ Posterior probability, PP).

Furthermore, these subgenera grouped together as an unresolved polytomy, which is not a supported relationship in previous studies. The low nodal support and polytomy likely resulted from missing sequence data for individuals of the subgenus Micropoecilia, as only ND2 sequences were available for these species.

Although the analyses resulted in a tree with high resolution, I found that $P$. mexicana species are not monophyletic as suggested by Ho et al. (2016). Their topology placed $P$. salvatoris and several P. mexicana morphs (Clades I-VI, yellow, and red morphs) in a monophyletic group.

In this study, Bayesian analysis placed $P$. salvatoris, $P$. maylandi, $P$. limantouri, $P$. sulphuraria and $P$. thermalis with $P$. mexicana species, resulting in paraphyly. Although monophyly was not supported, the position of these species within the P. mexicana complex is supported in this tree. The exception is P. maylandi, which is hypothesized to belong to the $P$. sphenops complex (Ho et al. 2016). Because no phylogenetic work has included P. maylandi, I am unable to conclude if this species is in fact part of the $P$. mexicana complex instead of the $P$. sphenops complex, or if missing data and/or misidentification of the voucher specimen has resulted in the incorrect assignment of this species. 
Furthermore, $P$. wandae (sequences obtained from Ho et al. 2016) was included in the subgenus Mollienesia, although this species has been classified as belonging to the subgenus Allopoecilia. Correspondence with Ho et al. (2016) suggests that these vouchers were possibly misidentified and could be $P$. koperi, although this claim was never verified. All other deep nodes were highly supported ( $\mathrm{PP} \geq 90 \%)$ and congruent to those revealed in previous studies (Fig. 3.1).

Subsampled Phylogeny (15 Poecilia species). Similar to the full-phylogeny, I partitioned the dataset by genes and by codons for the mtDNA (COI, ATPase 8/6, ND2) genes. PartitionFinder identified four subsets of partitions (out of 13) for the subsampled Poecilia dataset (15 species). Their corresponding models of evolution were: 1) GTR + G for $C O I$ position 1 and position 3 of ATPase $8 / 6$ and $N D 2,2) \mathrm{K} 80+\mathrm{G}$ for position 2 of $C O I$ and ATPase 8 , and for complete $S 7,3) \mathrm{HKY}+\mathrm{I}$ for $C O I$ codon position 3 and for position 2 of ATPase 6 and ND2, and 4) HKY + G for codon position 1 of ATPase 8/6 and of ND2. The phylogenetic analysis of the subsampled Poecilia species resulted in a well-supported consensus tree, with few nodes of low support. Sepcifically, the node linking species of the subgenus Micropoecilia (72\% PP) and the node linking the subgenus Poecilia to the other subgenera (73\% PP) had low support, likely due to missing sequence data (see previous section). However, unlike the full-phylogeny, the pruned tree placed P. vivipara (subgenus Poecilia) in a different clade than P. parae and P. picta (subgenus Micropoecilia), a relationship that is congruent with previous studies (e.g., Palacios et al. 2016). Unlike the full-phylogeny, I found that $P$. mexicana species formed a monophyletic clade with two sub-specific groups (100\% PP). 
The entire P. mexicana complex was comprised of three sub-groups: 1) P. mexicana species (including species listed above); 2) P. orri and P.gilli; 3) and P. butleri. This relationship, and all others were highly supported ( $\mathrm{PP} \geq 90 \%$ ) and congruent to those revealed in previous studies (Fig. 3.2).

\section{Habitat Characterization}

Of the sub-sampled species, 7 were classified as having a low salinity affiliation based on the proportion of habitats they were collected from (data retrieved from Fishnet2). These are: $P$. hispaniolana, $P$. parae, $P$. dominicensis, $P$. sphenops, $P$. caucana, and $P$. reticulata. High salinity affiliation species are $P$. mexicana, $P$. vivipara, $P$. velifera, $P$. butleri, $P$. picta and $P$. orri. The species that emerged as having a medium salinity affiliation were $P$. gilli, P. latipinna and P. kykesis (Table 3.1).

\section{Diet Characterization}

I found differences in jaw and gut morphology among the sub-sampled species. Specifically, $P$. reticulata had the largest angles of neurocranial rotation, which was $75 \%$ more than the species with the smallest angles, $P$. velifera $\left(\mathrm{F}_{15,587}=23.314, \mathrm{p}<0.0001\right)$. Intramandibular bending was greatest in P. mexicana, where the degree of IMB was $13 \%$ greater than $P$. reticulata, the species with the smallest IMB angle $\left(\mathrm{F}_{15,587}=32.109, \mathrm{p}<\right.$ 0.0001). Gape angles showed a 53\% difference between the species with the largest gape (P. sphenops) and the smallest gape (P. picta $\left.; \mathrm{F}_{15,559}=3.658, \mathrm{p}<0.0001\right)$. There were intraspecific differences in all 3 jaw measurements for $P$. vivipara where the Rio de Janiero population had $38 \%$ greater neurocranial rotation and $24 \%$ greater gape angles

(NCR: $\mathrm{F}_{1,49}=30.824, \mathrm{p}<0.0001 ; \mathrm{GA}: \mathrm{F}_{1,49}=13.325, \mathrm{p}=0.001$ ). 
However, the Bahia population had $9 \%$ greater $\operatorname{IMB}\left(\mathrm{F}_{1,49}=6.105, \mathrm{p}=0.017\right)$. All other species did not differ in intraspecific jaw measurements. Poecilia sphenops had the longest standardized gut length, which was $43 \%$ longer than $P$. reticulata, the outgroup species, $\left(\mathrm{F}_{14,391}=13.787, \mathrm{p}<0.0001 ;\right.$ Table 3.3).

The hierarchical cluster analysis of gut content data produced six broad feeding categories (coded 0-5 in ancestral state reconstructions): Carnivore ( $\geq 50 \%$ animals), 2 omnivore categories ('cyanobacteria + animals', and 'cyanobacteria + diatoms + animals'), and 3 herbivore categories ('green algae', 'cyanobacteria', and 'cyanobacteria + diatoms'). Based on these groupings, $P$. reticulata (outgroup) were classified as carnivores, and $P$. picta and $P$. caucana were classified as omnivores ('cyanobacteria + animals' and 'cyanobacteria + diatoms + animals', respectively). All other Poecilia species were grouped as herbivores, although the plant items present in their gut varied (Fig. 3.3). Relative abundance of each gut item can be found in Table S.3.2 in the supplementary material.

Contrasts on jaw morphology characters (IMB, GA) and percent animal material in the gut were phylogenetically informative. Specifically, intramandibular bending and gape angles showed inverse relationships with percent animal material in the gut, irrespective of phylogenetic relationship among species (IMB: $y=-0.608 x, r^{2}=0.38, p<$ 0.0001; GA: $y=-0.312 x, r^{2}=0.21, p<0.0001$; Fig. 3.4a \& b). Neurocranial rotation angles and standardized gut lengths were not driven by percent animal material in the diet once the phylogenetic relationships were accounted for (NCR: $y=-0.105 x, r^{2}=-0.015, p$ $=0.670$; Gut length: $\mathrm{y}=-2.16 \mathrm{x}, \mathrm{r}^{2}=0.08, \mathrm{p}=0.003$ ). 


\section{Tracing the Evolution of Habitat and Diet}

Ancestral state reconstructions estimating habitat varied between the methods used. Specifically, MP analyses suggest that the most recent common ancestor (MRCA) of subgenera Acanthophacelus, Micropoecilia, Psychropoecilia, Allopoecilia and Mollienesia inhabited freshwater habitats, whereas the MRCA of the subgenus Poecilia had high salinity affiliation. The ML analyses revealed that the MRCA of subgenus Acanthophacelus, Psychropoecilia and Allopoecilia inhabited freshwater habitats, the MRCA of subgenus Poecilia inhabited high salinity habitats, and the MRCA of subgenera Micropoecilia and Mollienesia had medium-high salinity affiliations (Fig. 3.5). Both analyses suggest that the MRCA of the $P$. mexicana complex (within the subgenus Mollienesia) was associated with high salinity habitats, the MRCA of the P. sphenops complex inhabited freshwater habitats, and the MRCA of the P. latipinna complex had medium salinity affiliation.

Ancestral diet reconstructions suggest that ancestral Poecilia species displayed varying diet strategies. Both MP and ML analyses revealed that the MRCA of the subgenus Acanthophacelus was carnivorous (Fig. 3.6) and showed relatively small degrees of intramandibular bending and small gape angles (Fig. 3.7). The MRCA of the subgenus Psychropoecilia was herbivorous or omnivorous (cyanobacteria + diatoms + animals) and showed mid-range intramandibular bending and gape angles. The MRCA of the subgenus Allopoecilia was omnivorous (cyanobacteria + diatoms + animals) and had a low degree of intramandibular bending, but mid-range gape angles. 
The MRCA of the subgenus Micropoecilia was omnivorous (cyanobacteria + animals) based on MP analyses, with relatively low intramandibular bending and gape angles. However, ML analyses suggest that the ancestral condition of the subgenus Micropoecilia was carnivory. Finally, the MRCA of the subgenus Mollienesia displayed obligate herbivory (cyanobacteria + diatoms), with mid-range intramandibular bending and gape angles.

\section{Identifying Patterns of Diet Evolution in Response to Habitat Transitions}

Phylogenetic independent contrasts on salinity affiliation (percent of species occupying saline habitats) and diet characters revealed contrasting patterns. Despite the relationship between percent animal material in the gut and jaw morphology (IMB and GA), salinity affiliation did not predict IMB or GA (IMB: $y=0.001 x, r^{2}=-0.015, p=$

0.684; GA: $y=-3.8 \times 10^{4} x, r^{2}=-0.018, p=0.921$; Fig. 3.8a \& b). However, salinity affiliation explained $22 \%$ of percent of animal material in the gut $\left(y=-21.99 x, r^{2}=\right.$ $0.267, \mathrm{p}<0.0001)$, where increased salinity affiliation drives an increase in herbivory (decrease in animal material in the gut; Fig. 3.8c).

\section{Discussion}

Results revealed that herbivory may have evolved as an adaptation for invading less productive saline habitats, thereby supporting the Suboptimal Habitat Hypothesis (Sanchez and Trexler 2016). I found that the MRCAs of subgenera Acanthophacelus, Micropoecilia, Psychropoecilia and Allopoecilia had low salinity affiliations and were either omnivorous or carnivorous. 
Furthermore, the divergence of the subgenera Poecilia and Mollienesia resulted in MRCAs with brackish/ marine roots, and the transition from low to high salinity affiliation drove diet diversification favoring the appearance of obligate herbivory in these groups. Salinity affiliation explained $26 \%$ of the total variation in the diet of Poecilia species (measured by percent animal material in the gut), and jaw morphology (IMB and GA) was associated with percent animal material in the gut, but not with percent of species occupying saline habitats. These findings suggest that in this genus, herbivory evolved in response to habitat transitions between fresh and euryhaline habitats, and jaw morphology evolved in response to the appearance of herbivory.

Incorporating additional Poecilia species for phylogenetic analyses did not reveal any novel relationships compared to previous studies, but instead verified the relationships between subgenera within the tree, allowing us to estimate the ancestral diets and salinity affiliations of Poecilia species. Ancestral reconstructions revealed that the MRCA of the subgenus Mollienesia likely originated in freshwater and remained in these habitats until the divergence of the three species complexes (MP analyses). At this time, species of the P. mexicana and P. latipinna complexes transitioned into euryhaline habitats, and species belonging to the $P$. sphenops complex remained in freshwaters. Alternatively, the ML model suggests that before the divergence of the MRCA, this group likely originated in freshwater, transitioned into euryhaline waters, and either remained in euryhaline habitats ( $P$. mexicana and $P$. latipinna complexes), or crossed back into freshwaters ( $P$. sphenops complex). 
Dietary ancestral state reconstructions were more clear for the subgenus Mollienesia, as both MP and ML models suggest that all species belonging to this group displayed obligate herbivory, although the mode of herbivory varies throughout the clade. Three herbivorous strategies emerged ('green algae', 'cyanobacteria', and 'cyanobacteria + diatoms'), and these correspond to the salinity affiliations of each species, and the primary producer communities of the different habitat types. Tropical euryhaline primary producer communities are typically dominated by cyanobacteria (e.g., Flombaum et al. 2013), and these results show that the species with the highest salinity affiliations ( $P$. mexicana and $P$. orri) have diets comprised of these organisms. Furthermore, freshwater producer communities are dominated by diatoms, and I found that herbivorous species with low-medium salinity affiliations (P. latipinna, $P$. kykesis, $P$. gilli) consume both cyanobacteria and diatoms. The exception was $P$. butleri, which showed a high-salinity affiliation and consumed a high proportion of green algae. I only sampled $P$. butleri gut contents from one locality, so these results may not be representative for the entire species.

Despite the uncertainty in ancestral habitat and diet estimations, I found that increased salinity affiliation explained $26 \%$ of the decrease in animal material in the gut. Because the MRCA of the subgenus Mollienesia was herbivorous, this evidence suggests a freshwater $\rightarrow$ euryhaline $\rightarrow$ freshwater transition rather than a euryhaline $\rightarrow$ freshwater $\rightarrow$ euryhaline transition in this group. Similar to species of the subgenus Mollienesia, $P$. vivipara shows a high salinity affiliation and an herbivorous feeding strategy. 
But this species diverged from the MRCA of the subgenus Poecilia approximately 3 mya (Palacios et al. 2016), suggesting that both salinity affiliation and herbivory evolved multiple times before the appearance of the subgenus Mollienesia, which appeared approximately 0.25 mya (Palacios et al. 2017). In addition, P. picta (subgenus Micropoecilia) shows a high salinity affiliation with an omnivorous feeding strategy, and P. parae (subgenus Micropoecilia) inhabits mostly freshwater systems. These species appeared approx. 2.7 mya (Palacios et al. 2016) suggesting that a habitat transition might have occurred during the early evolution of the subgenus Micropoecilia, many years before the appearance of the subgenus Mollienesia.

Freshwater-to-marine transitions are relatively rare in fishes (McDowall 1997; Vermeij 2000; Betancur-R 2009), likely because of the decreased habitat heterogeneity offered by marine habitats (Bloom et al. 2013). In addition, herbivory is thought to be an energetically inferior diet compared to omnivory or carnivory, so coevolution of high salinity affiliation and an herbivorous feeding strategy seems maladaptive. The evolution of herbivory in Terapontid fishes is more intuitive, as this process was driven by the transition into heterogeneous freshwaters (Davis et al. 2012). In Cleupeoid fishes, the evolution of herbivory was not driven by habitat transitions, but was instead driven by latitude (Egan et al. 2018). These results support multiple transitions between freshwater and euryhaline habitats in the genus Poecilia (particularly in the subgenera Poecilia and Mollienesia), and I show that these transitions are related to the evolution of herbivory in the same species. 
The Suboptimal Habitat Hypothesis posits that herbivory may be an adaptive strategy to allow organisms to invade habitats with decreased resource quality, where animal prey are scarce and plant abundance is high (Sanchez and Trexler 2016). Under this definition, a euryhaline habitat may be considered "suboptimal" relative to a highly productive freshwater habitat. Therefore, these data support the Suboptimal Habitat Hypothesis as an explanation for the appearance of herbivory in this group. It is important to note, however, that there may be other explanations supporting the evolution of herbivory in other metazoan groups (see Sanchez and Trexler 2016 for alternative hypotheses), and that multiple mechanisms may be working simultaneously to explain the appearance and subsequent maintenance of herbivory in nature (see Sanchez and Trexler 2018).

\section{Conclusions}

This study suggests that high salinity affiliation and herbivory are derived characters in the genus Poecilia. In addition, I show that salinity affiliation and herbivory evolved together, where increased habitat salinity results in increased degree of herbivory. This result is surprising because there is ample evidence that freshwater-to-marine transitions generally result in decreased diversification relative to transitions in the opposite direction (e.g., McDowall 1997; Vermeij 2000; Betancur-R 2009). Although productive freshwater systems offer increased foraging opportunities compared to marine systems, I found that invading a 'suboptimal' habitat triggered diet diversification in the subgenera Poecilia and Mollienesia. The ability to cross ecosystem boundaries coupled with an adaptive diet strategy could allow Poecilia species to rapidly expand their range, thereby increasing opportunities for ecological diversification, ultimately resulting in species radiation. 


\section{Acknowledgments}

I wish to thank David Reznick (UC-Riverside), Juan Schmitter-Soto (ECOSUR), and Xavier Chiappa-Carrara (UNAM-Sisal) for assistance with field collections, Donovan German (UC-Irvine) for specimen collection/transportation advice, and Adeljean Ho (Chinese Academy of Sciences- South China Sea Institute of Oceanology) for sharing data that allowed me to construct the Poecilia phylogeny. In addition, I wish to thank the Florida Museum of Natural History and the University of Michigan Museum of Zoology for access to their ichthyology collections.

This material was developed in collaboration with the Florida Coastal Everglades Long-Term Ecological Research program under National Science Foundation Grant No. DEB-1237517. Animal use was approved by the Institutional Animal Care and Use Committee under protocol number IACUC-16-029. Funding for travel was provided by the Latin American and Caribbean Center at FIU through two Tinker Field Research Grants awarded to J. Sanchez. This is contribution number xxx from the Southeast Environmental Research Center in the Institute of Water \& Environment at Florida International University, and contribution number $\mathrm{xxx}$ from the Center for Coastal Oceans Research in the Institute for Water and Environment at Florida International University.

\section{References}

Alda, F., R. G. Reina, I. Doadrio and E. Bermingham. 2012a. Phylogeny and biogeography of Poecilia sphenops species complex (Actinopterygii, Poeciliidae) in Central America. Molecular Phylogenetics and Evolution 66 (2013): 110111026. 
Alda, F., R. G. Reina, I. Doadrio and E. Bermingham. 2012b. Data from: Phylogeny and biogeography of Poecilia sphenops species complex (Actinopterygii, Poeciliidae) in Central America. Molecular Phylogenetics and Evolution 66 (2013): 110111026. Deposited in Dryad: DOI: http://dx.doi.org/10.5061/dryad.fb280

Augusto, A., A. S. Pinheiro, L. J. Greene, H. J. Laure, and J. C. McNamara. 2009. Evolutionary transition to freshwater by ancestral marine palaemonids: evidence from osmoregulation in a tide pool shrimp. Aquatic Biology 7: 113-122.

Betancur-R, R. 2009. Molecular phylogenetics support multiple evolutionary transitions from marine to freshwater habitats in ariid catfishes. Molecular Phylogenetics and Evolution 55: 249-258.

Betancur-R, R., G. Orti, A. M. Stein, A. P. Marceniuk, and R. A. Pyron. 2012. Apparent signal of competition limiting diversification after ecological transitions from marine to freshwater habitats. Ecology Letters (2012) 15: 822-830.

Bloom, D. D., J. T. Weir, K. R. Piller, and N. R. Lovejoy. 2013. Do freshwater fishes diversify faster than marine fishes? A test using state-dependent diversification analyses and molecular phylogenetics of new world silversides (Atherinopsidae). Evolution 67(7): 2040-2057.

Bussing, W. A. 1998. Peces de las aguas continentales de Costa Rica-Freshwater fishes of Costa Rica. Editorial de la Universidad de Costa Rica, San José.

Colinvaux, P. 1980. Why big fierce animals are rare. Princeton University Press.

Cunningham, C. W., K. E. Omland, and T. H. Oakley. 1998. Reconstructing ancestral character states: a critical reappraisal. Trends in Ecology and Evolution 13: 361366.

Davis, A. M., P. J. Unmack, B. J. Pusey, J. B. Johnson and R. G. Pearson. 2012. Marine freshwater transitions are associated with the evolution of dietary diversification in terapontid grunters (Teleostei: Terapontidae). Journal of Evolutionary Biology 25(2012): 1163-1179.

Egan, J. P., D. D. Bloom, C. Kuo, M. P. Hammer, P. Tongnunui, S. P. Iglesias, M. Sheaves, C. Grudpan, and A. M. Simons. 2018. Phylogenetic analysis of trophic niche evolution reveals a latitudinal herbivory gradient in Clupeoidei (herrings, anchovies, and allies). Molecular Phylogenetics and Evolution 124 (2018): 151161.

Felsenstein, J. Phylogenies and the Comparative Method. 1985. The American Naturalist 125(1): 1-15. 
Ferraris, C.J., 2002. Aspredinidae. In: Carpenter, K.E. (Ed.), FAO Species Identification Guides for Fishery Purposes: The living Marine Resources of the Western Central Atlantic. FAO, Rome, pp. 859-861.

Fishnet, a computerized database management system for the national fish collection at the J.L.B. Smith Institute of Ichthyology. http://www.fishnet2.net/

Flombaum, P. J. L. Gallegos, R. A. Gordillo, J. Rincon, L. L. Zabala, N. Jiao, D. M. Karl, W. K. W. Li, M. W. Lomas, D. Veneziano, C. S. Vera, J. A. Vrugt, and A. C. Martiny. 2013. Present and future distributions of the marine Cyanobacteria Prochlorococcus and Synechococcus. Proceedings of the National Academy of Sciences 110(24): 9824-9829.

GenBank. Bethesda (MD): National Library of Medicine (US), National Center for Biotechnology Information; [1982] - [2017]. Available from: https://www.ncbi.nlm.nih.gov/nucleotide/.

Gibb, A., L. A. Ferry-Graham, L. P. Hernandez, R. Romansco, and J. Blanton. 2008. Functional significance of intramandibular bending in Poeciliid fishes. Environmental Biology of Fishes 83: 507-519.

Hernandez, L. P., L. A. Ferry-Graham, and A. C. Gibb. 2008. Morphology of a picky eater: A novel mechanism underlies premaxillary protrusion and retraction within cyprinodontiforms. Zoology 11(6): 442-454.

Hernandez, L. P., A. C. Gibb, and L. A. Ferry-Graham, and. 2009. Trophic apparatus in Cyprinodonitiform fishes: Functional specializations for picking and scraping behaviors. Journal of Morphology 270: 645-661.

Ho, A.L.F.C., C. L. Pruett and J. Lin. 2016a. Phylogeny and biogeography of Poecilia (Cyprinodontiformes: Poeciliinae) across Central and South America based on mitochondrial and nuclear DNA markers. Molecular Phylogenetics and Evolution 101: 32-45.

Ho, A.L.F.C., C. L. Pruett and J. Lin. 2016b. Data from: Phylogeny and biogeography of Poecilia (Cyprinodontiformes: Poeciliinae) across Central and South America based on mitochondrial and nuclear DNA markers. Molecular Phylogenetics and Evolution 101: 32-45. Deposited in Dryad: DOI: http://dx.doi.org/10.5061/dryad.bq70c.

Hrbek, T. J. Seckinger, and A. Meyer. 2007. A phylogenetic and biogeographic perspective on the evolution of poeciliid fishes. Molecular Phylogenetics and Evolution 43(3): 986-998. 
Huelsenbeck, J. P. and F. Ronquist. 2001. MRBAYES: Bayesian inference of phylogeny. Bioinformatics 17:754-755.

Kumar, S., G. Stecher, and K. Tamura. 2015. MEGA7: Molecular Evolutionary Genetics Analysis version 7.0. Molecular Biology and Evolution.

Lanfear, R., B. Calcott, S.Y.W. Ho, and S. Guindon. 2012. PartitionFinder: Combined selection of partitioning schemes and substitution models for phylogenetic analyses. Molecular Biology and Evolution 29(6): 1695-1701.

Lee, C. E. 1999. Rapid and repeated invasions of fresh water by the copepod Eurytemora affinis. Evolution 53(5): 1423-1434.

Lewis, P. O. 2001. A likelihood approach to estimating phylogeny from discrete morphological character data. Systematic Biology 50(6): 913-925.

Lovejoy, N. R. and B. B. Collette. 2001. Phylogenetic relationships of new world needlefishes (Teleostei: Belondiae) and the biogeography of transitions between marine and freshwater habitats. Copeia 2001(2): 324-338.

Lovejoy, N. R., E. Bermingham and A. P. Martin. 2006. Marine incursion into South America. Nature 396: 421-422.

Maechler, M., Rousseeuw, P., Struyf, A., Hubert, M., Hornik, K.(2017). cluster: Cluster Analysis Basics and Extensions. R package version 2.0.6.

Maddison, W. P., and D. R. Maddison. 2017. Mesquite: A modular system for evolutionary analysis. Version 3.2. http://mesquiteproject.org

May, R. M., and J. Godfrey. 1994. Biological Diversity: Differences between land and sea. Philosophical Transactions: Biological Sciences 343(1303): 105-111.

McDowall, R.M., 1997. The evolution of diadromy in fishes (revisited) and its place in phylogenetic analysis. Reviews in Fish Biology and Fish 7: 443-462.

Meffe, G. K., and E. E. Snelson. 1989. An ecological overview of Poeciliid fishes. In: Ecology and Evolution of Livebearing Fishes. Prentice Hall, NJ, pp. 13-32.

Miller, R.R. 2005. Freshwater Fishes of Mexico. University of Chicago Press, Chicago.

Nordlie, F. G.m D. C. Haney, and S. J. Walsh. 1992. Salinity tolerances and osmotic regulatory capabilities in populations of Sailfin Molly (Poecilia latipinna) from brackish and fresh waters. Copeia 1992(3): 741-746. 
Palacios, M., G. Voelker, L. A. Rodriguez, M. Mateos and M. Tobler. 2016. Phylogenetic analyses of the subgenus Mollienesia (Poecilia, Poeciliidae, Teleostei) reveal taxonomic inconsistencies, cryptic biodiversity, and spatio-temporal aspects of diversification in Middle America. Molecular Phylogenetics and Evolution 103: 230-244.

Paradis E., Claude J. \& Strimmer K. 2004. APE: analyses of phylogenetics and evolution in R language. Bioinformatics 20: 289-290.

Poeser, F. N. 2002. Poecilia kykesis nom. Nov., a new name for Mollienesia petenensis Gunther, 1866, and redescription, revalidation and the designation of a lectotype for Poecilia petenensis Gunther, 1866 (Teleostei: Poeciliidae). Contributions to Zoology 704: 243-246.

R Core Team. 2017. R: A language and environment for statistical computing. R Foundation for Statistical Computing, Vienna, Austria. <https://www.Rproject.org/>

Reznick, D. N., A. I. Furness, R. W. Meredith and M. S. Springer. 2017. The origin and biogeographic diversification of fishes in the family Poeciliidae. PLoS ONE 12(3): e0172546.doi:10.1371/journal.pone.0172546

Rambaut, A., M. A. Suchard, D. Xie, and A. J. Drummond. 2014. Tracer v1.6. Available from http://tree.bio.ed.ac.uk/software/tracer/.

Ronquist, F. and J. P. Huelsenbeck. 2003. MRBAYES 3: Bayesian phylogenetic inference under mixed models. Bioinformatics 19:1572-1574.

Royer-Carenzi, M., P. Pontarotti, and G. Didier. 2013. Choosing the best ancestral character state reconstruction method. Mathematical Biosciences 242: 95-109.

Sanchez, J. L., and J. C. Trexler. 2016. The adaptive evolution of herbivory in freshwater systems. Ecosphere, 7(7), e01414. 10.1002/ecs2.1414.

Sanchez, J. L., and J. C. Trexler. 2018. When is an herbivore not an herbivore? Detritivory facilitates herbivory in a freshwater system. Ecology and Evolution: doi 10.1002/ece3.4133

Schluter, D., T. Price, A. O. Mooers and D. Ludwig. 1997. Likelihood of Ancestor States in Adaptive Radiation. Evolution 51(6): 1699-1711.

Sullivan, J.P., Lundberg, J.G., Hardman, M., 2006. A phylogenetic analysis of the major groups of catfishes (Teleostei: Siluriformes) using rag1 and rag2 nuclear gene sequences. Molecular Phylogenetics and Evolution 41: 636-662. 
Trexler, J. C., and J. Travis. 1990. Phenotypic plasticity in the Sailfin Molly, Poecilia latipinna (Pisces: Poeciliidae). I. Field Experiments. Evolution 44(1): 143-156.

Vaidya, G., Lohman, D. J. and Meier, R. (2011), SequenceMatrix: concatenation software for the fast assembly of multi-gene datasets with character set and codon information. Cladistics, 27: 171-180. doi:10.1111/j.1096-0031.2010.00329.x

Vermeij, G. J. 2000. Why are there so few evolutionary transition between aquatic and terrestrial ecosystems? Biological Journal of the Linnean Society 70: 541-554.

Vermeij, G. J., and R. K. Grosberg. 2010. The great divergence: When did diversity on land exceed that in the sea? Integrative and Comparative Biology 50(4):675-682.

Warren D.L., A.J. Geneva, and R. Lanfear. 2017. RWTY (R We There Yet): An R package for examining convergence of Bayesian phylogenetic analyses. Molecular Biology and Evolution 34:1016-1020. doi: 10.1093/molbev/msw279.

Yamanoue, Y., M. Miya, H. Doi, K. Mabuchi, H. Sakai, and M. Nishida. 2011. Multiple invasions into freshwater by pufferfishes (Teleostei: Tetraodontidae): a mitogenomic pespective. PLoS One 6: e17410. Doi: 10.1371/journal.pone.0017410. 


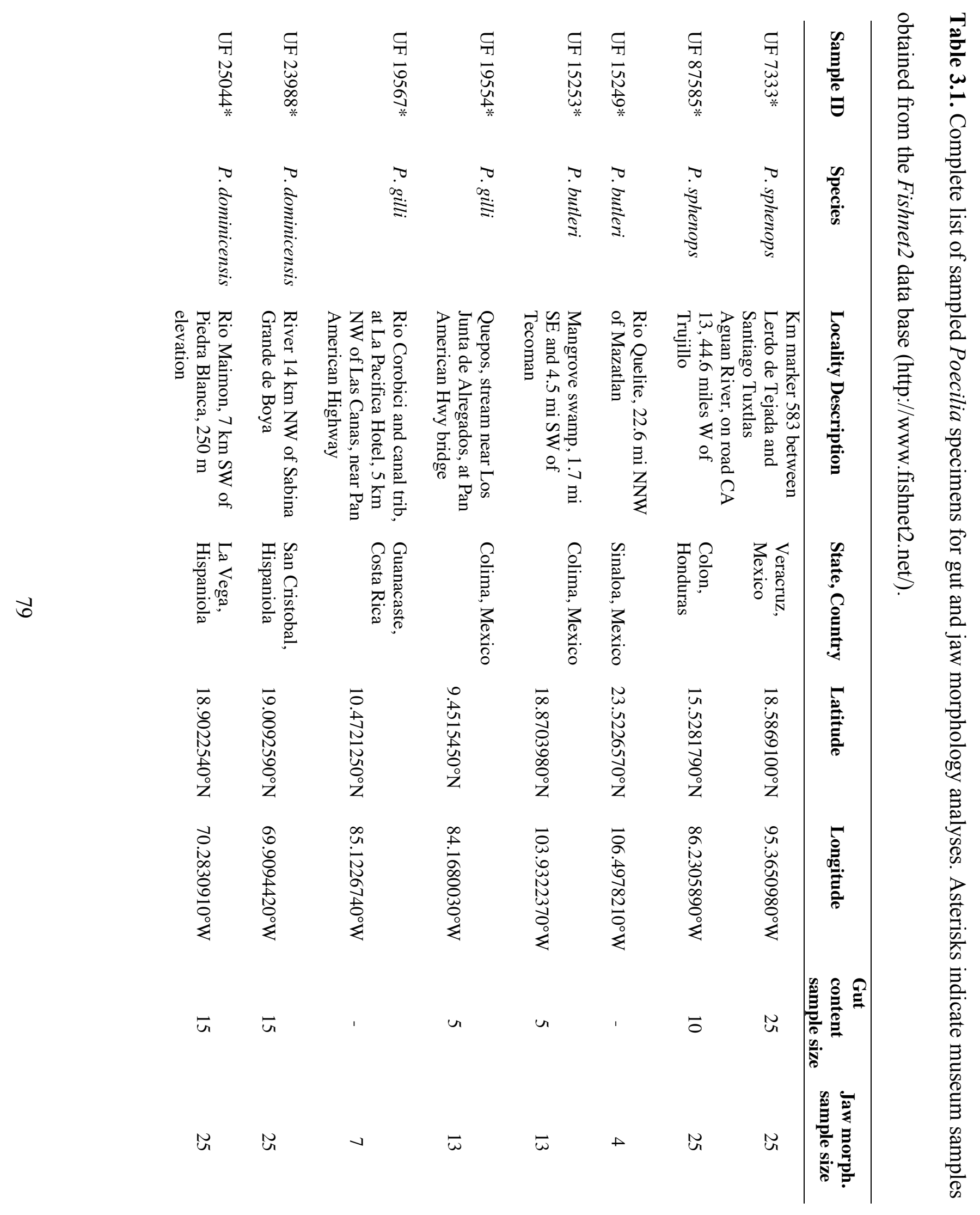




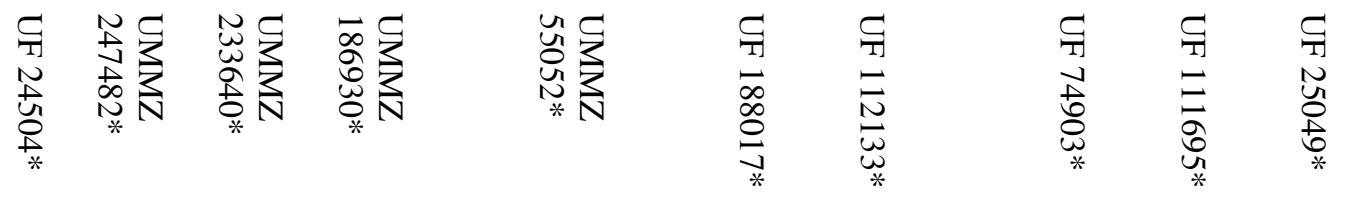

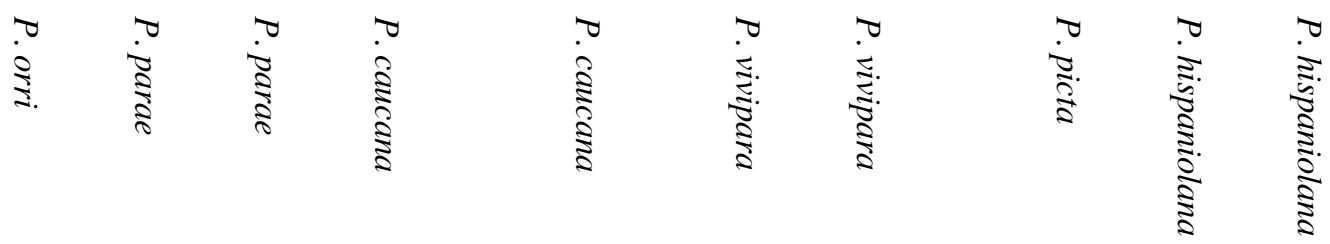

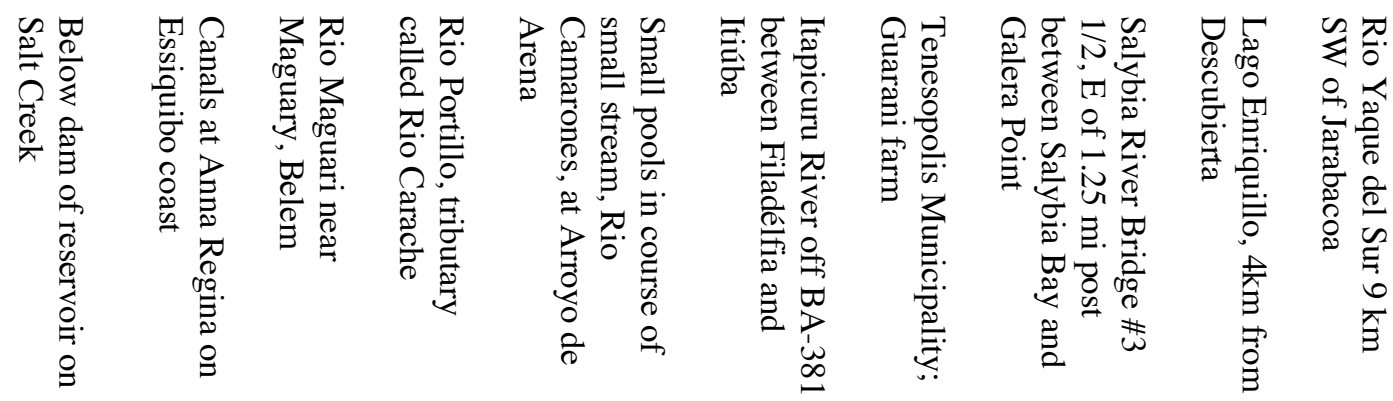

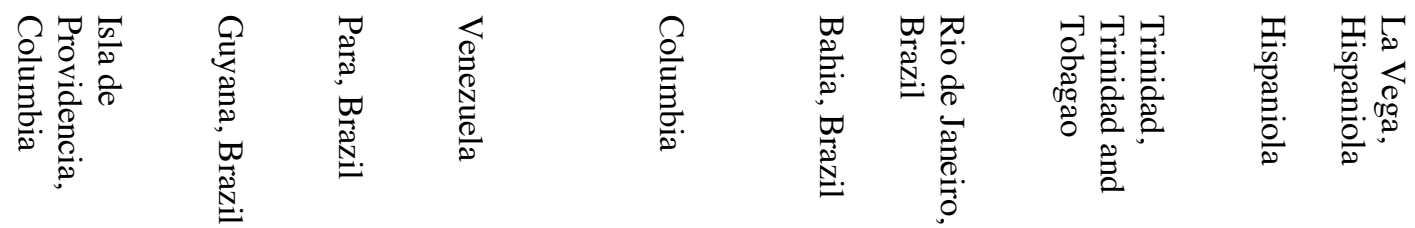

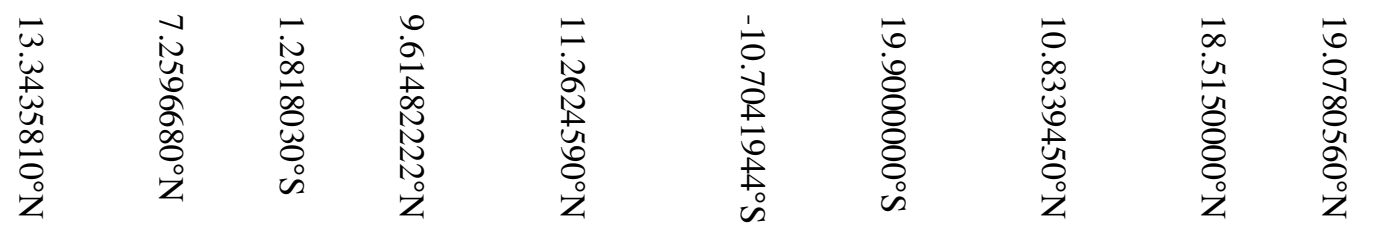

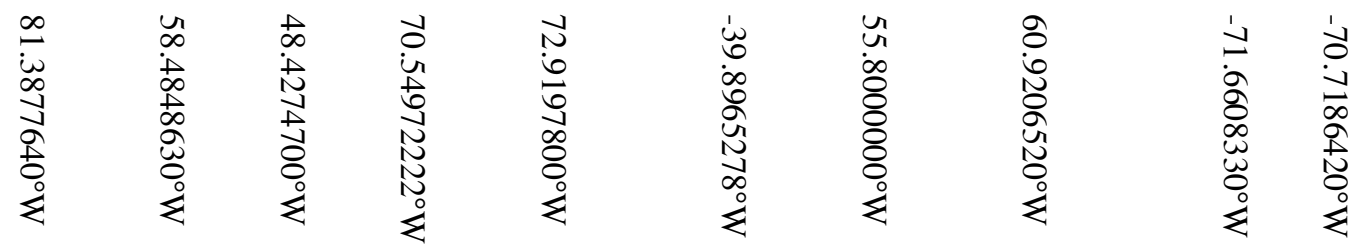

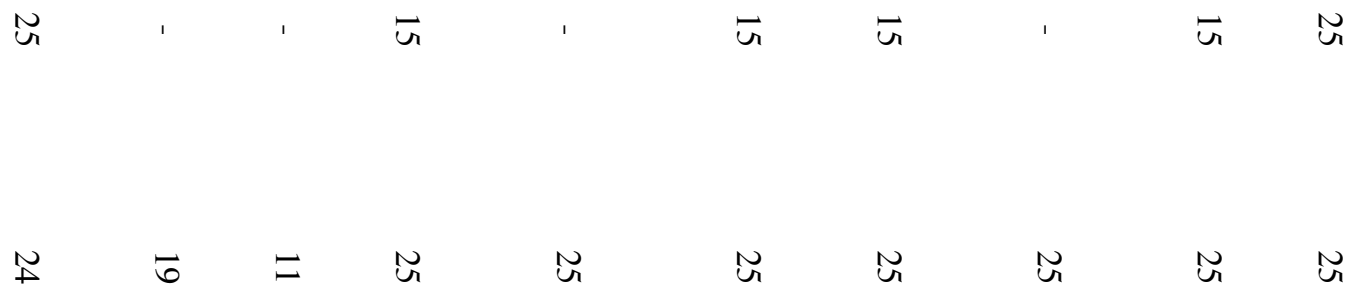




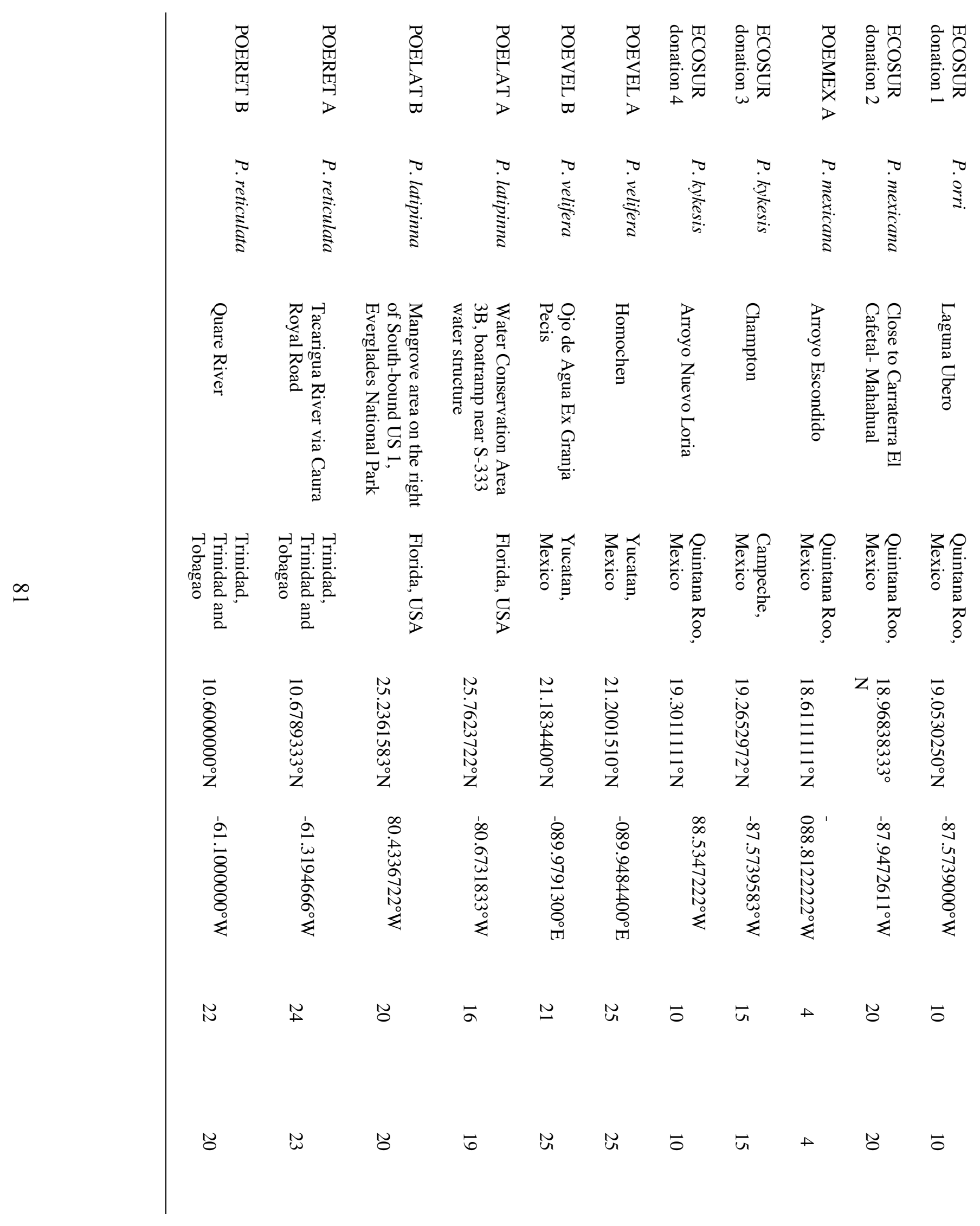


Table 3.2. Proportion of habitat types occupied by each species based on collections logged in the Fishnet2 data base (http://www.fishnet2.net/).

\begin{tabular}{llcccc}
\hline \multicolumn{7}{c}{ PrOPORTION OF COLLECTION SITES } \\
\hline & \multicolumn{1}{c}{ Species } & Freshwater & Brackish & Marine & Sample Size (N) \\
\hline 1 & P.reticulata & 100 & 0 & 0 & 25 \\
2 & P.parae & 100 & 0 & 0 & 9 \\
3 & P.picta & 67 & 17 & 17 & 12 \\
4 & P. vivipara & 84 & 8 & 8 & 25 \\
5 & P.dominicensis & 100 & 0 & 0 & 25 \\
6 & P. hispaniolana & 100 & 0 & 0 & 25 \\
7 & P. caucana & 100 & 0 & 0 & 16 \\
8 & P. kykesis & 68 & 24 & 8 & 25 \\
9 & P. latipinna & 58 & 21 & 21 & 25 \\
10 & P. sphenops & 100 & 0 & 0 & 25 \\
11 & P. gilli & 88 & 12 & 0 & 25 \\
12 & P. mexicana & 80 & 8 & 12 & 25 \\
13 & P. orri & 55 & 0 & 45 & 25 \\
\hline
\end{tabular}


Table 3.3. Measured jaw angles of each sampled Poecilia species. IMB= Intramandibular bending (angle subtracted from $180^{\circ}$ ), GA= Gape angle, $\mathrm{NCR}=$ Neurocranial rotation.

\begin{tabular}{|c|c|c|c|c|c|}
\hline & Species & IMB & GA & NCR & Sample Size (N) \\
\hline 1 & P.reticulata & $77.75 \pm 6.10$ & $66.48 \pm 13.40$ & $19.24 \pm 7.96$ & 43 \\
\hline 2 & P.parae & $78.81 \pm 6.87$ & $69.39 \pm 27.84$ & $12.34 \pm 4.81$ & 30 \\
\hline 3 & P.picta & $86.25 \pm 7.34$ & $50.76 \pm 12.06$ & $17.68 \pm 6.05$ & 25 \\
\hline 4 & P. vivipara & $85.96 \pm 11.72$ & $73.44 \pm 14.62$ & $14.30 \pm 5.47$ & 50 \\
\hline 5 & P.dominicensis & $89.52 \pm 8.49$ & $82.39 \pm 11.37$ & $9.41 \pm 4.24$ & 50 \\
\hline 6 & P. hispaniolana & $88.50 \pm 12.08$ & $72.69 \pm 12.17$ & $7.88 \pm 2.94$ & 50 \\
\hline 7 & P. caucana & $72.38 \pm 16.70$ & $81.16 \pm 18.27$ & $10.28 \pm 5.42$ & 50 \\
\hline 8 & P. kykesis & $89.17 \pm 10.00$ & $101.00 \pm 15.03$ & $16.14 \pm 3.86$ & 25 \\
\hline 9 & P. latipinna & $87.98 \pm 15.89$ & $95.43 \pm 9.30$ & $11.91 \pm 4.96$ & 39 \\
\hline 10 & $P$. velifera & $84.40 \pm 15.10$ & $96.36 \pm 29.53$ & $4.73 \pm 4.16$ & 50 \\
\hline 11 & P. butleria & $85.98 \pm 7.86$ & $74.98 \pm 14.02$ & $8.79 \pm 2.59$ & 17 \\
\hline 12 & P. sphenops & $84.55 \pm 11.00$ & $108.54 \pm 14.47$ & $13.36 \pm 3.29$ & 50 \\
\hline 13 & P. gilli & $80.03 \pm 11.27$ & $78.79 \pm 25.11$ & $12.73 \pm 4.34$ & 20 \\
\hline 14 & P.mexicana & $89.60 \pm 13.35$ & $84.68 \pm 14.28$ & $16.16 \pm 5.49$ & 24 \\
\hline 15 & P.orri & $82.80 \pm 14.78$ & $78.22 \pm 14.99$ & $13.01 \pm 3.29$ & 34 \\
\hline
\end{tabular}




\section{Figure Legends}

Fig. 3.1. Bayesian phylogenetic tree (50\% majority-rule) derived from concatenated mitochondrial Cytochrome Oxidase subunit I, ATPase 8/6, NADH dehydrogenase subunit 2, and Ribosomal Protein S7 genes for 36 Poecilia and 2 Limia species. Bullets at each node represent the Posterior Probability (PP). Nodes with posterior probabilities $\geq 99 \%$ are considered highly supported, those with posterior probabilities $\geq 95 \%$ are well-supported, nodes with posterior probabilities $\geq 75 \%$ are moderately supported, and those with posterior probabilities $\geq 75 \%$ have no support. Genbank ID for each species is listed in parentheses. Species are colored by subgenus.

Fig. 3.2. Pruned Bayesian phylogenetic tree (50\% majority-rule) derived from concatenated mitochondrial Cytochrome Oxidase subunit I, ATPase 8/6, NADH dehydrogenase subunit 2, and Ribosomal Protein S7 genes for the 15 subsampled Poecilia species. Bullets at each node represent the Posterior Probability (PP). Nodes with posterior probabilities $\geq 99 \%$ are considered highly supported, those with posterior probabilities $\geq 95 \%$ are well-supported, nodes with posterior probabilities $\geq 75 \%$ are moderately supported, and those with posterior probabilities $\geq 75 \%$ have no support. Genbank ID for each species is listed in parentheses. Species are colored by subgenus.

Fig. 3.3. Classification of Poecilia diets using Sorensen (Bray-Curtis) distance measures with flexible beta linkage. Hierarchical Cluster analysis identified 6 diet categories. 
Fig. 3.4. (A) Relationship between degree of intramandibular bending (IMB) and percent animal material in the diet for 15 Poecilia species plotted as phylogenetically independent contrasts. (B) Relationship between gape angle (GA) and percent animal material in the diet for 15 Poecilia species plotted as phylogenetically independent contrasts.

Fig. 3.5. Maximum Parsimony (left cladogram) and Maximum Likelihood (right cladogram) ancestral character reconstruction for the evolution of habitat (salinity affiliation) in the Poecilia group. Circles at terminal nodes represent the observed character states for extant species, and pie charts for ancestral nodes show estimated probabilities for reconstructed character states. Species are colored by subgenus and nodes with large circles indicate the most recent common ancestor for that subgenus. Genbank ID for each species is listed in parentheses.

Fig. 3.6. Maximum Parsimony (left cladogram) and Maximum Likelihood (right cladogram) ancestral character reconstruction for the evolution of diet in the Poecilia group. Circles at terminal nodes represent the observed character states for extant species, and pie charts for ancestral nodes show estimated probabilities for reconstructed character states. Species are colored by subgenus and nodes with large circles indicate the most recent common ancestor for that subgenus. Genbank ID for each species is listed in parentheses. 
Fig. 3.7. Maximum Parsimony ancestral character reconstruction for the evolution of intramandibular bending (left cladogram) and gape angle (right cladogram) in the Poecilia group. Circles at terminal nodes represent the observed character states for extant species, and pie charts for ancestral nodes show estimated probabilities for reconstructed character states. Maximum likelihood could not be performed because jaw metrics are continuous data. Species are colored by subgenus and nodes with large circles indicate the most recent common ancestor for that subgenus. Genbank ID for each species is listed in parentheses.

Fig. 3.8. (A) The relationship between salinity affiliation and intramandibular bending (plotted as phylogenetically independent contrasts) suggests that IMB did not evolve as an adaptation to saline habitats. (B) The relationship between salinity affiliation and gape angle (plotted as phylogenetically independent contrasts) suggests that GA did not evolve as an adaptation to saline habitats. (C) The relationship between salinity affiliation and $\%$ animal material in the gut (plotted as phylogenetically independent contrasts) suggests that herbivory evolved in response to increased salinity. 
Fig. 3.1.

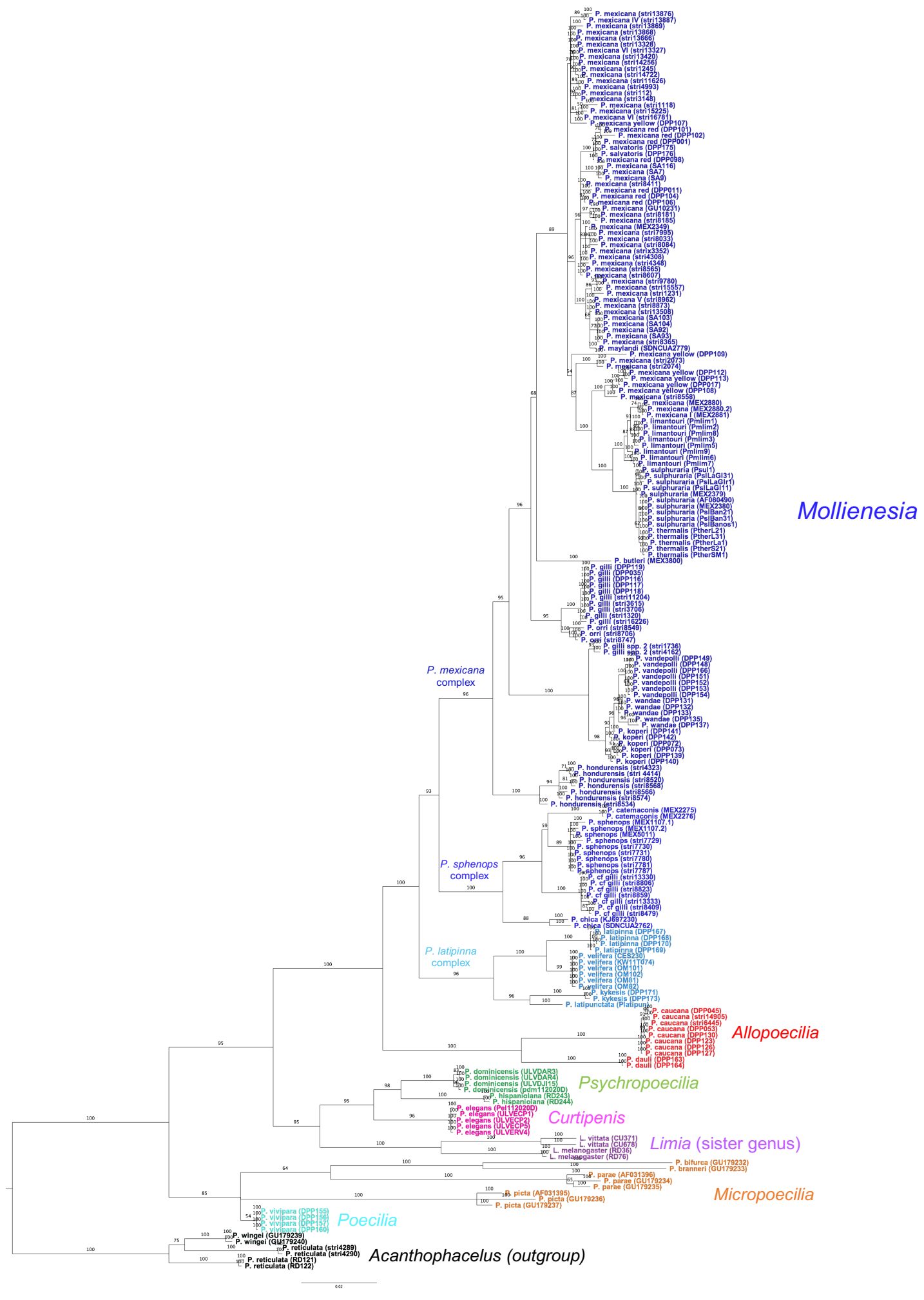


Fig. 3.2.

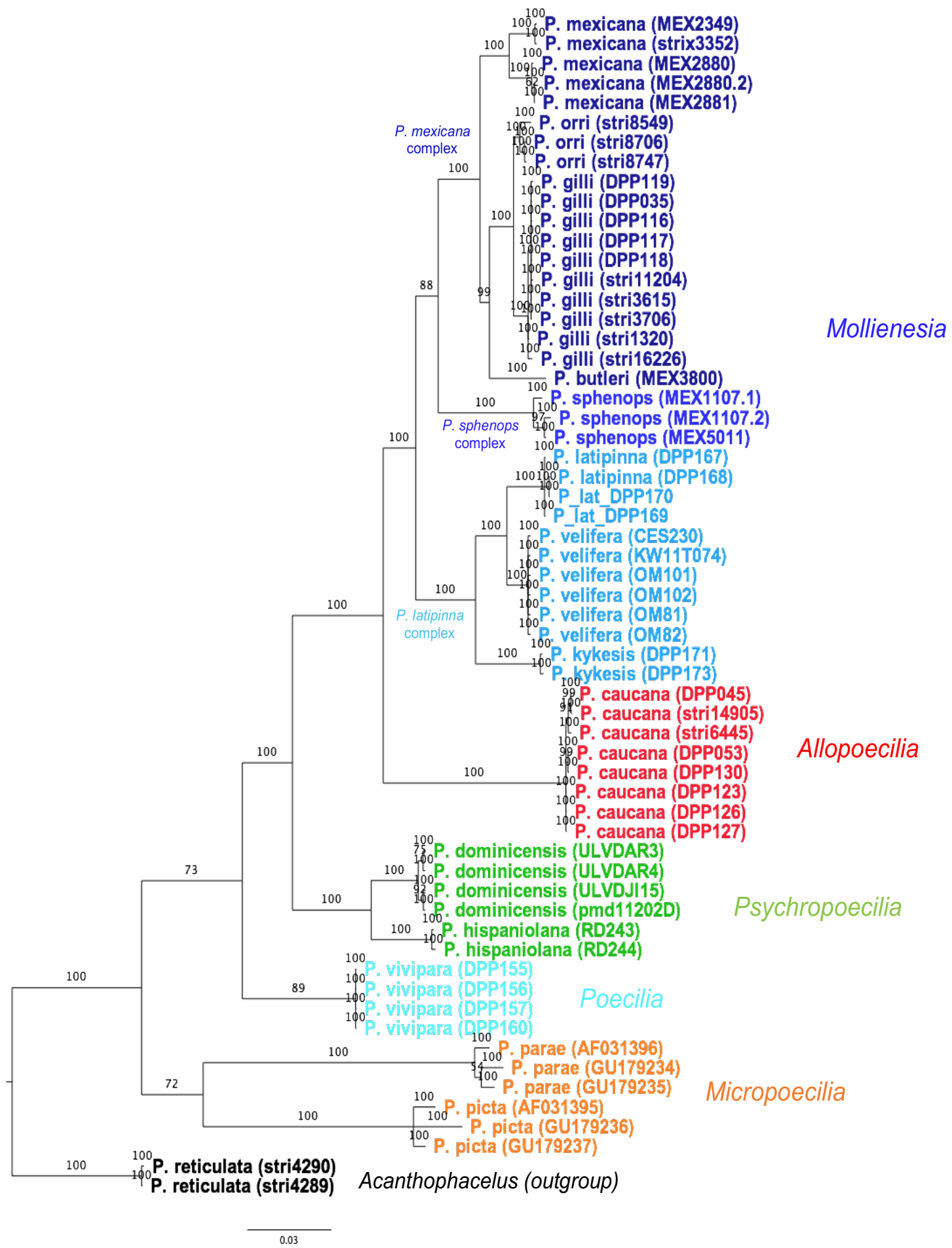


Fig. 3.3.

\section{Height}

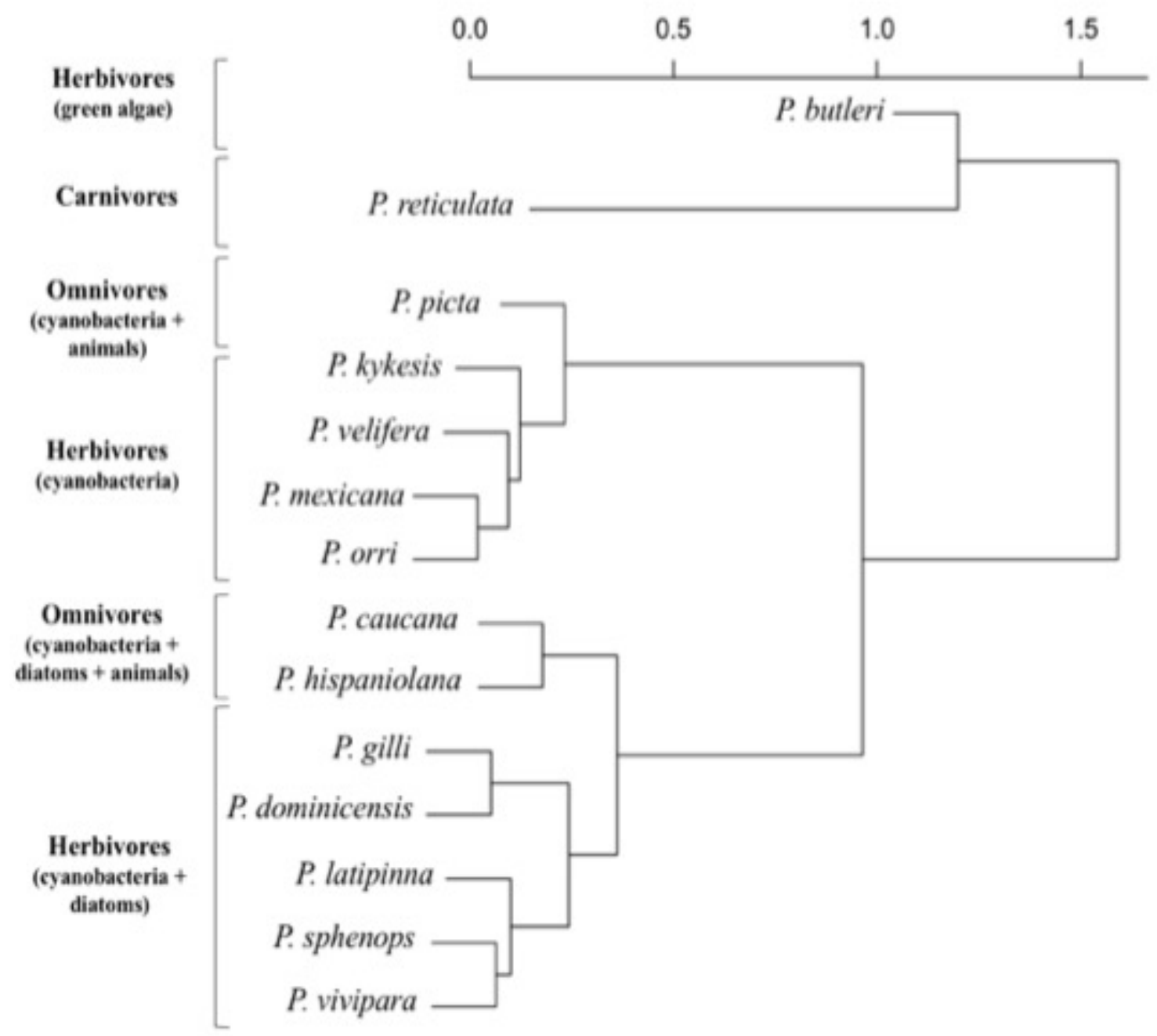


Fig. 3.4.
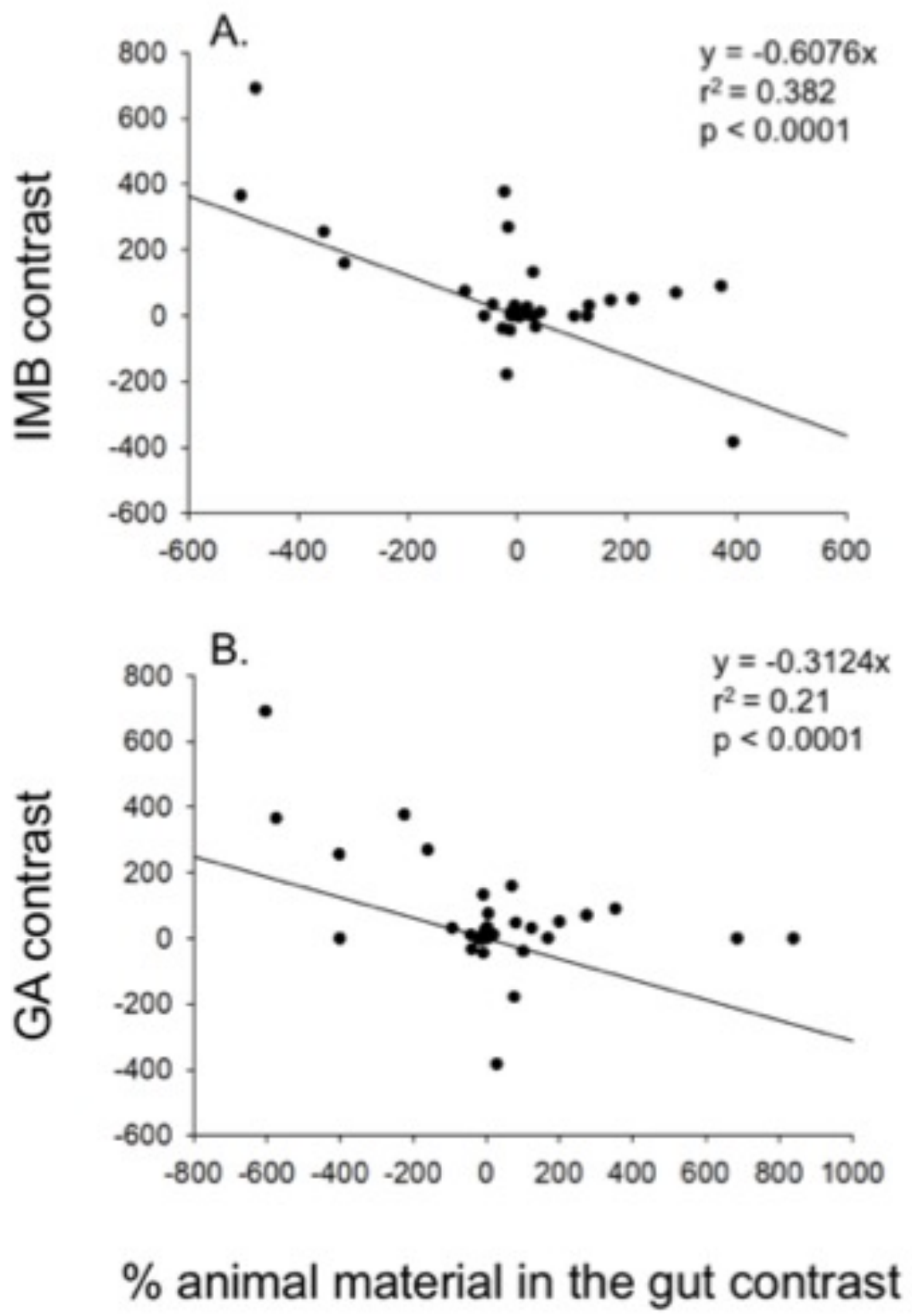

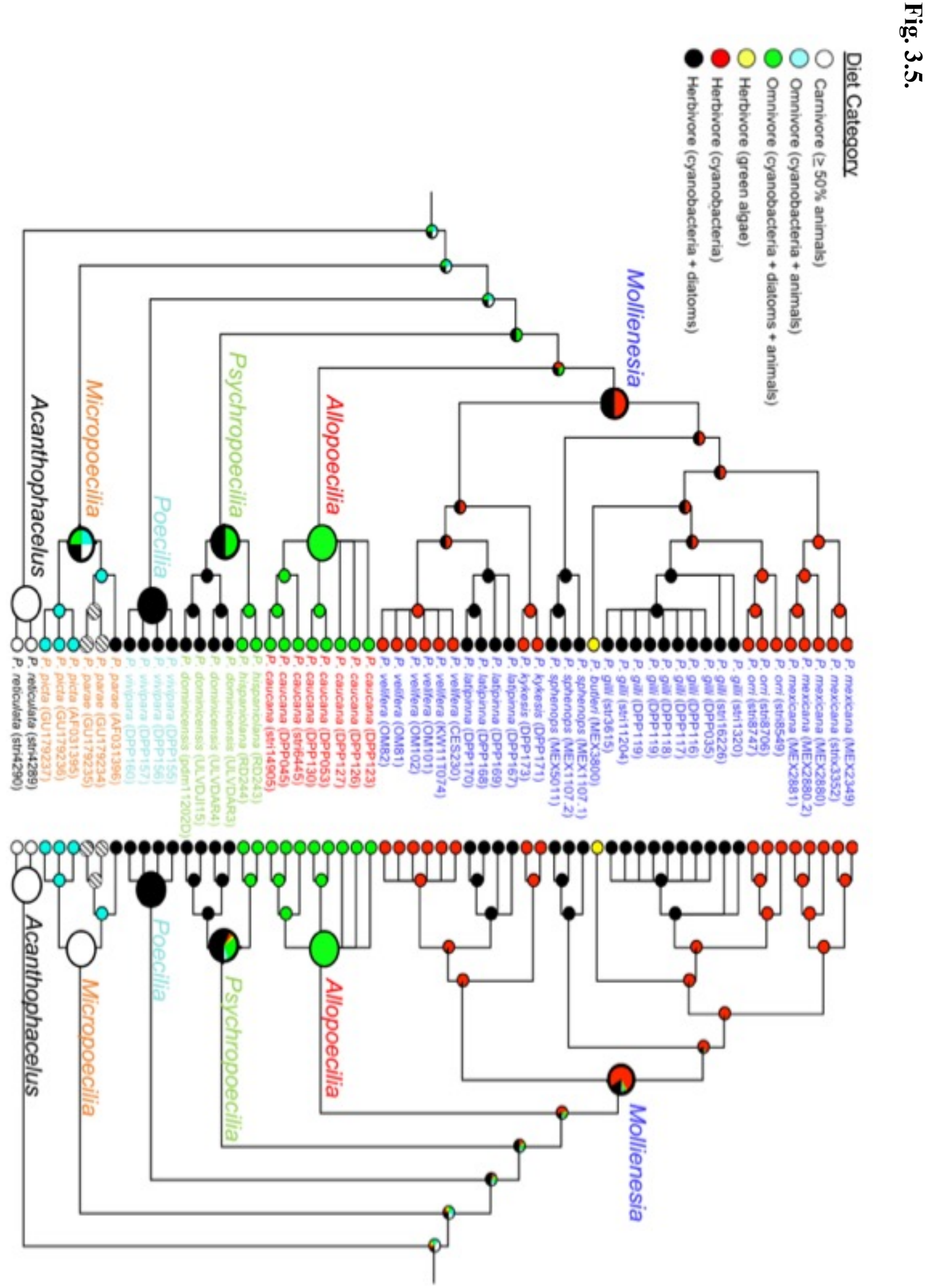
هִ
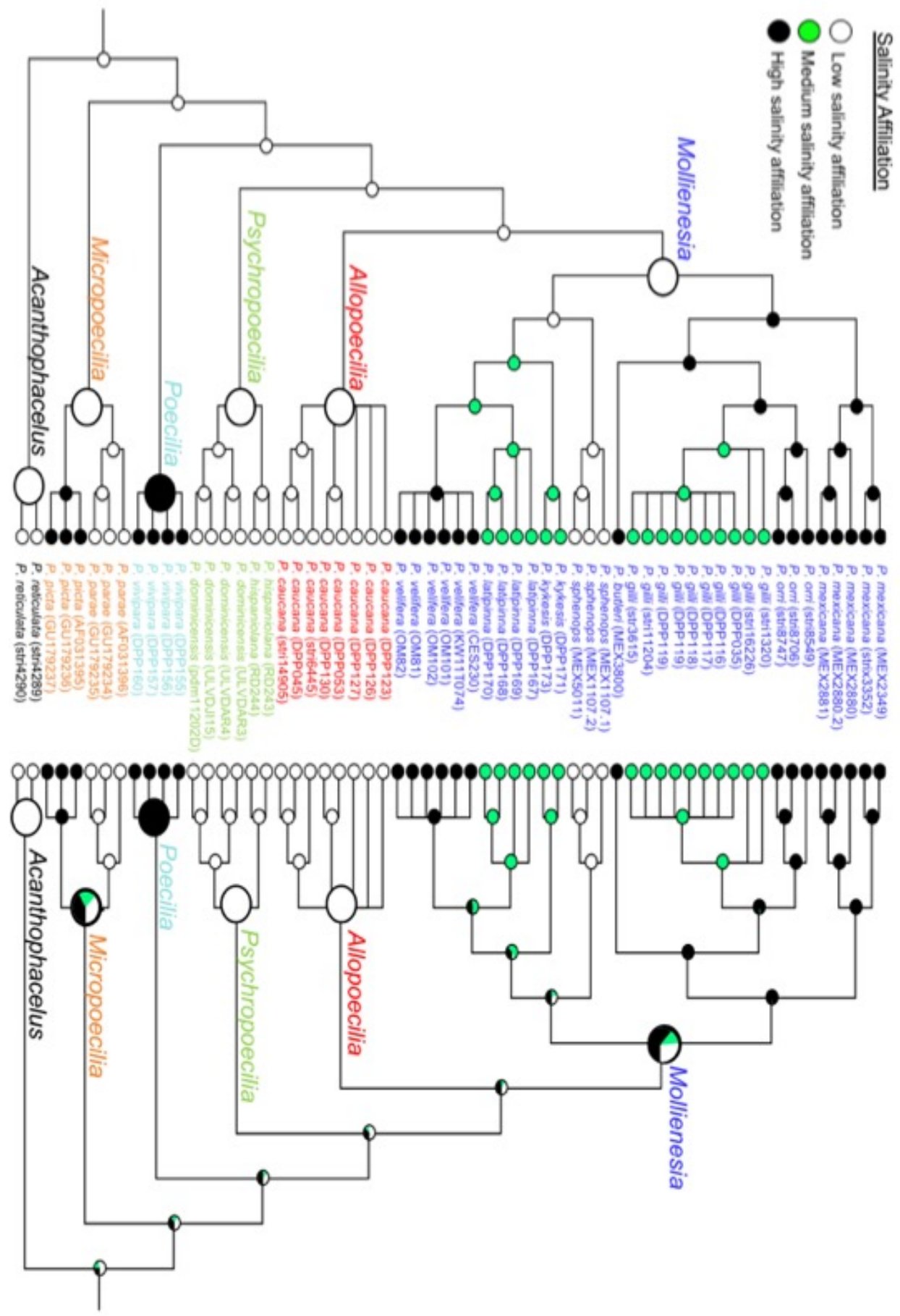


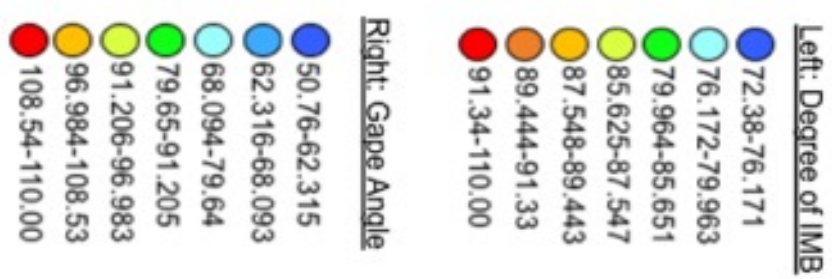

هُ
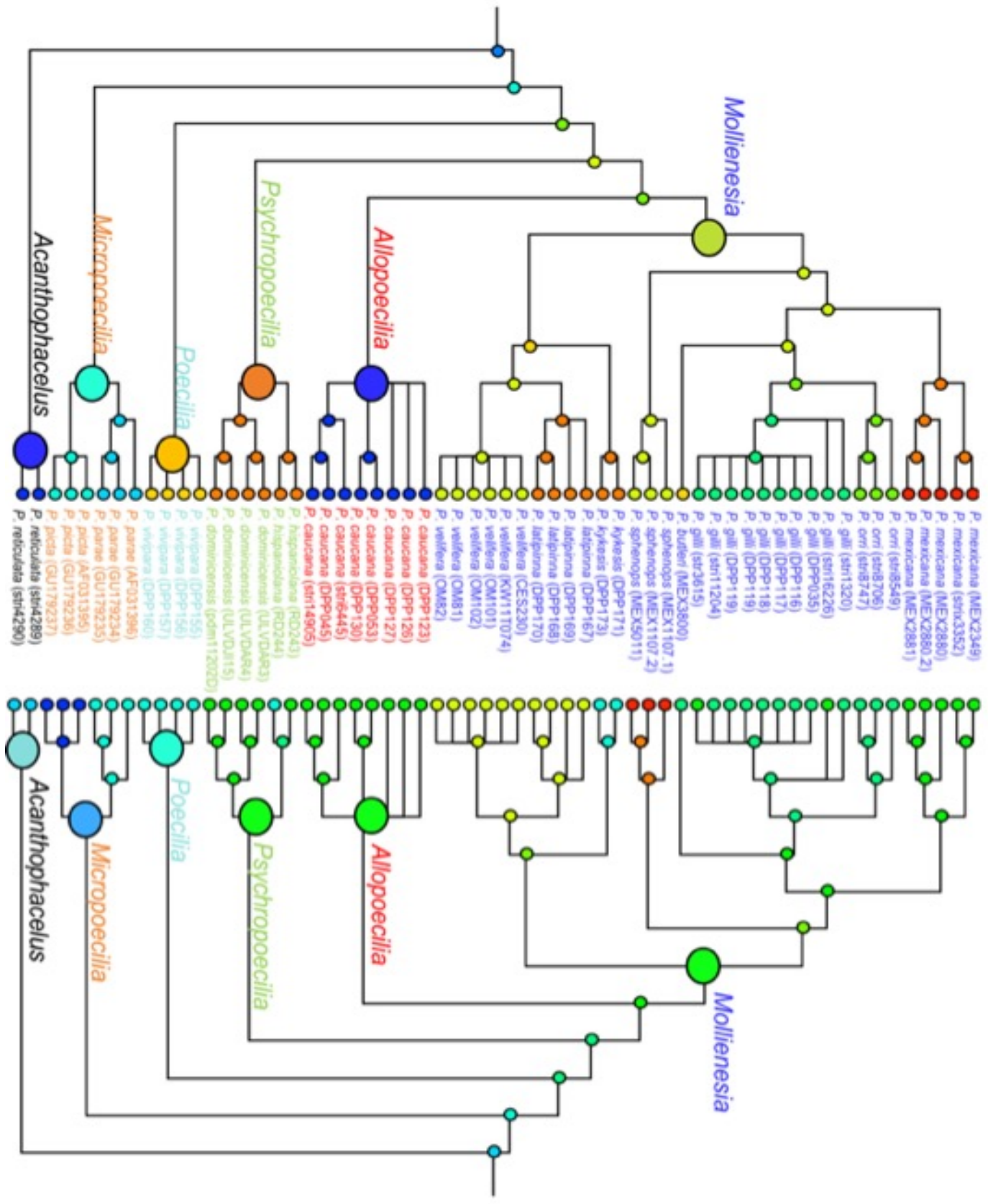
Fig. 3.8.
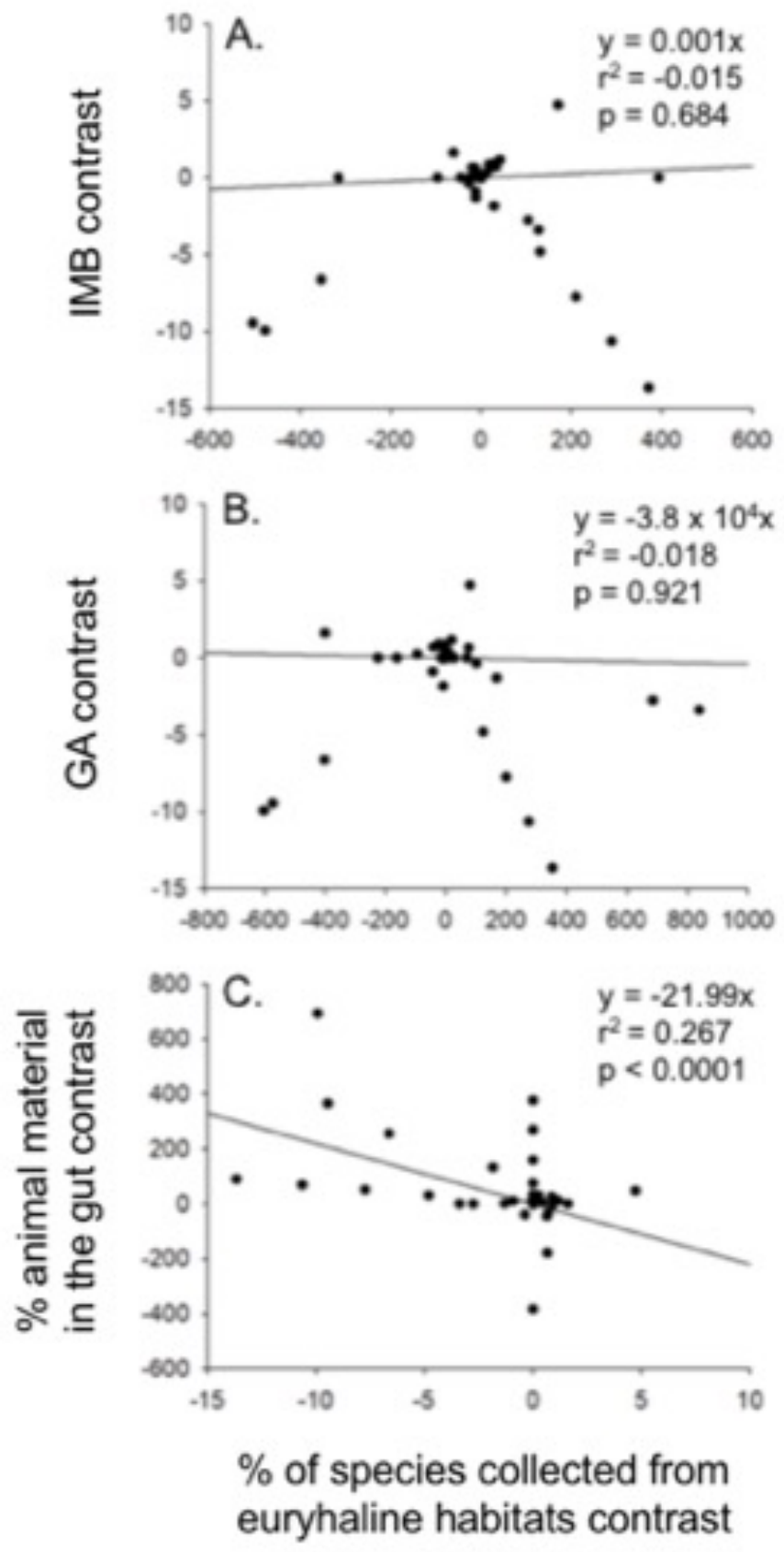
Supplementary Information 
Table S.3.1. GenBank accession numbers for genes used to reconstruct Poecilia phylogeny.

\begin{tabular}{|c|c|c|c|c|c|c|}
\hline Sample ID & $\begin{array}{l}\text { Species } \\
\text { (mtDNA OTU) }\end{array}$ & $\mathrm{COI}$ & ATPase $8 / 6$ & ND2 & 57 & Reference \\
\hline stri8479 & P. cf. gilli & & JX968594 & & & Alda et al. 2013 \\
\hline stri8409 & P. cf. gilli & & JX968593 & & & Alda et al. 2013 \\
\hline stri13333 & P. cf. gilli & & JX968613 & & & Alda et al. 2013 \\
\hline stri8859 & P. cf. gilli & JX968665 & JX968592 & JX968711 & JX968760 & Alda et al. 2013 \\
\hline stri8823 & P. cf. gilli & & & & JX968761 & Alda et al. 2013 \\
\hline stri8806 & P. cf. gilli & JX968664 & JX968591 & JX968710 & JX968759 & Alda et al. 2013 \\
\hline stri13330 & P. cf. gilli & & & & JX968776 & Alda et al. 2013 \\
\hline GU179240 & P. wingei & & & GU179240 & & Meredith et al. 2010 \\
\hline GU179239 & P. wingei & & & GU179239 & & Meredith et al. 2010 \\
\hline DPP-137 & P. wandae & KP761885 & KP761835 & & KP761935 & Ho et al. 2016 \\
\hline DPP-135 & P. wandae & KP761884 & KP761834 & & KP761934 & Ho et al. 2016 \\
\hline DPP-133 & P. wandae & KP761883 & KP761833 & & KP761933 & Ho et al. 2016 \\
\hline DPP-132 & P. wandae & KP761882 & KP761832 & & KP761932 & Ho et al. 2016 \\
\hline DPP-131 & P. wandae & KP761881 & KP761831 & & KP761931 & Ho et al. 2016 \\
\hline DPP-160 & P. vivipara & KP761880 & KP761830 & & KP761930 & Ho et al. 2016 \\
\hline DPP-157 & P. vivipara & KP761879 & KP761829 & & KP761929 & Ho et al. 2016 \\
\hline DPP-156 & P. vivipara & KP761878 & KP761828 & & KP761928 & Ho et al. 2016 \\
\hline DPP-155 & P. vivipara & KP761877 & KP761827 & & KP761927 & Ho et al. 2016 \\
\hline OM82 & P. velifera & JQ667582 & & & & Khedkar et al. 2012 \\
\hline OM81 & P. velifera & JQ667581 & & & & Khedkar et al. 2012 \\
\hline OM102 & P. velifera & JQ667583 & & & & Khedkar et al. 2012 \\
\hline OM101 & P. velifera & JQ667585 & & & & Khedkar et al. 2012 \\
\hline KW11T074 & P. velifera & KU568973 & & & & Van der Walt et al. 2016 \\
\hline CES230 & P. velifera & KJ669591 & & & & Hardy 2014 \\
\hline DPP-166 & P. vandepolli & KP761869 & KP761819 & & KP761919 & Ho et al. 2016 \\
\hline DPP-154 & P. vandepolli & KP761875 & KP761825 & & KP761925 & Ho et al. 2016 \\
\hline DPP-153 & P. vandepolli & KP761874 & KP761824 & & KP761924 & Ho et al. 2016 \\
\hline DPP-152 & P. vandepolli & KP761873 & KP761823 & & KP761923 & Ho et al. 2016 \\
\hline DPP-148 & P. vandepolli & KP761870 & KP761820 & & KP761920 & Ho et al. 2016 \\
\hline DPP-151 & P. vandepolli & KP761872 & KP761822 & & KP761922 & Ho et al. 2016 \\
\hline DPP-149 & P. vandepolli & KP761871 & KP761821 & & KP761921 & Ho et al. 2016 \\
\hline PtherSM1 & P. thermalis & & & KF276678 & & Palacios et al. 2016 \\
\hline PtherS2 1 & P. thermalis & & & KF276679 & & Palacios et al. 2016 \\
\hline PtherLa1 & P. thermalis & & & KF276675 & & Palacios et al. 2016 \\
\hline PtherL31 & P. thermalis & & & KF276677 & & Palacios et al. 2016 \\
\hline
\end{tabular}




\begin{tabular}{|c|c|c|c|c|c|c|}
\hline PtherL21 & P. thermalis & & & KF276676 & & Palacios et al. 2016 \\
\hline Psul1 & P. sulphuraria & & & HQ677863 & & Tobler et al. 2010 \\
\hline PsILaGIr1 & P. sulphuraria & & & KF276684 & & Palacios et al. 2016 \\
\hline PsILaGI31 & P. sulphuraria & & & KF276686 & & Palacios et al. 2016 \\
\hline PsILaGI11 & P. sulphuraria & & & KF276685 & & Palacios et al. 2016 \\
\hline PsIBanos1 & P. sulphuraria & & & KF276681 & & Palacios et al. 2016 \\
\hline PsIBan31 & P. sulphuraria & & & KF276683 & & Palacios et al. 2016 \\
\hline PsIBan21 & P. sulphuraria & & & KF276682 & & Palacios et al. 2016 \\
\hline AF080490 & P. sulphuraria & & & AF080490 & & Ptacek and Breden 199 \\
\hline stri7787 & P. sphenops & & & & JX968756 & Alda et al. 2013 \\
\hline stri7781 & P. sphenops & & & & JX968755 & Alda et al. 2013 \\
\hline stri7780 & P. sphenops & JX968661 & JX968583 & JX968707 & JX968754 & Alda et al. 2013 \\
\hline stri7731 & P. sphenops & JX968660 & JX968582 & JX968706 & JX968753 & Alda et al. 2013 \\
\hline stri7730 & P. sphenops & & & & JX968752 & Alda et al. 2013 \\
\hline stri7729 & P. sphenops & & & & JX968751 & Alda et al. 2013 \\
\hline MEX5011 & P. sphenops & & JX968565 & & & Alda et al. 2013 \\
\hline MEX1107.2 & P. sphenops & & JX968574 & & & Alda et al. 2013 \\
\hline MEX1107.1 & P. sphenops & & JX968573 & & & Alda et al. 2013 \\
\hline DPP-176 & P. salvatoris & & KR707737 & & & Ho et al. 2016 \\
\hline DPP-175 & P. salvatoris & & KR707736 & & & Ho et al. 2016 \\
\hline stri4290 & P. reticulata & JX968696 & JX968650 & JX968742 & JX968799 & Alda et al. 2013 \\
\hline stri4289 & P. reticulata & JX968695 & JX968649 & JX968741 & JX968798 & Alda et al. 2013 \\
\hline RD122 & P. reticulata & JX968694 & JX968648 & JX968740 & JX968797 & Alda et al. 2013 \\
\hline RD121 & P. reticulata & & JX968647 & & & Alda et al. 2013 \\
\hline GU179237 & P. picta & & & GU179237 & & Meredith et al. 2010 \\
\hline GU179236 & P. picta & & & GU179236 & & Meredith et al. 2010 \\
\hline AF031395 & P. picta & & & AF031395 & & Breden et al. 1999 \\
\hline GU179235 & P. parae & & & GU179235 & & Meredith et al. 2010 \\
\hline GU179234 & P. parae & & & GU179234 & & Meredith et al. 2010 \\
\hline AF031396 & P.parae & & & AF031396 & & Breden et al. 1999 \\
\hline stri8747 & P. orri & & JX968605 & & & Alda et al. 2013 \\
\hline stri8706 & P. orri & JX968671 & JX968606 & JX968717 & JX968771 & Alda et al. 2013 \\
\hline stri8549 & P. orri & JX968670 & JX968603 & JX968716 & JX968770 & Alda et al. 2013 \\
\hline strix 3352 & P. mexicana & & JX968566 & & & Alda et al. 2013 \\
\hline stri8962 & P. mexicana & JX968672 & JX968607 & JX968718 & JX968772 & Alda et al. 2013 \\
\hline stri8873 & P. mexicana & & JX968608 & & & Alda et al. 2013 \\
\hline stri8607 & P. mexicana & & JX968604 & & & Alda et al. 2013 \\
\hline stri8565 & P. mexicana & & JX968600 & & & Alda et al. 2013 \\
\hline stri8558 & P. mexicana & & & & JX968764 & Alda et al. 2013 \\
\hline stri8365 & P. mexicana & & JX968609 & & & Alda et al. 2013 \\
\hline stri8185 & P. mexicana & & JX968581 & & & Alda et al. 2013 \\
\hline stri8181 & P. mexicana & & JX968580 & & & Alda et al. 2013 \\
\hline
\end{tabular}




\begin{tabular}{|c|c|c|c|c|c|c|}
\hline stri8084 & P. mexicana & JX968659 & JX968578 & JX968705 & JX968750 & Alda et al. 2013 \\
\hline stri8033 & P. mexicana & & JX968577 & & & Alda et al. 2013 \\
\hline stri7995 & P. mexicana & & JX968576 & & & Alda et al. 2013 \\
\hline stri4993 & P. mexicana & & JX968623 & & & Alda et al. 2013 \\
\hline stri4348 & P. mexicana & JX968666 & JX968596 & JX968712 & JX968762 & Alda et al. 2013 \\
\hline stri4308 & P. mexicana & & JX968597 & & & Alda et al. 2013 \\
\hline stri3148 & P. mexicana & & JX968627 & & & Alda et al. 2013 \\
\hline stri2074 & P. mexicana & JX968678 & JX968622 & JX968724 & JX968782 & Alda et al. 2013 \\
\hline stri2073 & P. mexicana & JX968677 & JX968621 & JX968723 & JX968781 & Alda et al. 2013 \\
\hline stri16781 & P. mexicana & JX968679 & JX968630 & JX968725 & JX968783 & Alda et al. 2013 \\
\hline stri15557 & P. mexicana & & JX968629 & & & Alda et al. 2013 \\
\hline stri15225 & P. mexicana & & JX968631 & & JX968784 & Alda et al. 2013 \\
\hline stri14722 & P. mexicana & & JX968618 & & & Alda et al. 2013 \\
\hline stri14256 & P. mexicana & JX968673 & JX968610 & JX968719 & JX968773 & Alda et al. 2013 \\
\hline stri13887 & P. mexicana & JX968676 & JX968615 & JX968722 & JX968778 & Alda et al. 2013 \\
\hline stri13876 & P. mexicana & JX968675 & JX968615 & JX968721 & JX968777 & Alda et al. 2013 \\
\hline stri13869 & P. mexicana & & & & JX968780 & Alda et al. 2013 \\
\hline stri13868 & P. mexicana & & & & JX968779 & Alda et al. 2013 \\
\hline stri13666 & P. mexicana & & JX968617 & & & Alda et al. 2013 \\
\hline stri13508 & P. mexicana & & JX968616 & & & Alda et al. 2013 \\
\hline stri13420 & P. mexicana & & JX968611 & & & Alda et al. 2013 \\
\hline stri13328 & P. mexicana & & & & JX968775 & Alda et al. 2013 \\
\hline stri13327 & P. mexicana & JX968674 & JX968612 & JX968720 & JX968774 & Alda et al. 2013 \\
\hline stri1245 & P. mexicana & & JX968620 & & & Alda et al. 2013 \\
\hline stri1231 & P. mexicana & & JX968619 & & & Alda et al. 2013 \\
\hline stri1 1626 & P. mexicana & & JX968624 & & & Alda et al. 2013 \\
\hline stri112 & P. mexicana & & JX968625 & & & Alda et al. 2013 \\
\hline stri1118 & P. mexicana & & JX968628 & & & Alda et al. 2013 \\
\hline SA93 & P. mexicana & & JX968587 & & & Alda et al. 2013 \\
\hline SA92 & P. mexicana & & JX968586 & & & Alda et al. 2013 \\
\hline SA9 & P. mexicana & JX968663 & JX968585 & JX968709 & JX968758 & Alda et al. 2013 \\
\hline SA7 & P. mexicana & JX968662 & JX968584 & JX968708 & JX968757 & Alda et al. 2013 \\
\hline SA104 & P. mexicana & & JX968590 & & & Alda et al. 2013 \\
\hline MEX2881 & P. mexicana & JX968653 & JX968564 & JX968699 & JX968745 & Alda et al. 2013 \\
\hline MEX2880.2 & P. mexicana & JX968652 & JX968563 & JX968698 & JX968744 & Alda et al. 2013 \\
\hline MEX2880 & P. mexicana & & JX968562 & & & Alda et al. 2013 \\
\hline MEX2380 & P. sulphuraria & JX968656 & JX968571 & JX968702 & JX968749 & Alda et al. 2013 \\
\hline MEX2379 & P. sulphuraria & & JX968570 & & JX968748 & Alda et al. 2013 \\
\hline MEX2349 & P. mexicana & & JX968567 & & & Alda et al. 2013 \\
\hline GU10231 & P. mexicana & & JX968579 & & & Alda et al. 2013 \\
\hline DPP-113 & P. mexicana VI & KP761911 & KP761811 & & KP761911 & Ho et al. 2016 \\
\hline DPP-109 & P. mexicana VII* & KP761859 & KP761809 & & KP761909 & Ho et al. 2016 \\
\hline
\end{tabular}




\begin{tabular}{|c|c|c|c|c|c|c|}
\hline DPP-108 & P. mexicana VI & KP761858 & KP761808 & & KP761908 & Ho et al. 2016 \\
\hline DPP-106 & P. mexicana $V$ & KP761868 & KP761818 & & KP761918 & Ho et al. 2016 \\
\hline DPP-104 & P. mexicana $V$ & KP761867 & KP761817 & & KP761917 & Ho et al. 2016 \\
\hline DPP-102 & P. mexicana $V$ & KP761866 & KP761816 & & KP761916 & Ho et al. 2016 \\
\hline DPP-098 & P. mexicana $V$ & KP761864 & KP761814 & & KP761914 & Ho et al. 2016 \\
\hline DPP-017 & P. mexicana VI & KP761856 & KP761806 & & KP761906 & Ho et al. 2016 \\
\hline DPP-011 & P. mexicana $V$ & KP761863 & KP761813 & & KP761913 & Ho et al. 2016 \\
\hline DPP-001 & P. mexicana $V$ & KP761862 & KP761812 & & KP761912 & Ho et al. 2016 \\
\hline stri9780 & P. mexicana & & JX968626 & & & Alda et al. 2013 \\
\hline stri8411 & P. mexicana & & JX968595 & & & Alda et al. 2013 \\
\hline SA116 & P. mexicana & & JX968588 & & & Alda et al. 2013 \\
\hline SA103 & P. mexicana & & JX968589 & & & Alda et al. 2013 \\
\hline DPP-112 & P. mexicana VI & KP761860 & KP761810 & & KP761910 & Ho et al. 2016 \\
\hline DPP-107 & P. mexicana VI & KP761857 & KP761807 & & KP761907 & Ho et al. 2016 \\
\hline DPP-101 & P. mexicana & KP761865 & KP761815 & & KP761915 & Ho et al. 2016 \\
\hline SDNCUA2779 & P. maylandi & LC153119 & & & & $\begin{array}{l}\text { Suzuki-Matsubara et al. } \\
2016\end{array}$ \\
\hline Pmlim9 & P. limantouri & & & HQ677848 & & Tobler et al. 2010 \\
\hline Pmlim8 & P. limantouri & & & HQ677847 & & Tobler et al. 2010 \\
\hline Pmlim7 & P. limantouri & & & HQ677846 & & Tobler et al. 2010 \\
\hline Pmlim6 & P. limantouri & & & HQ677845 & & Tobler et al. 2010 \\
\hline Pmlim5 & P. limantouri & & & HQ677844 & & Tobler et al. 2010 \\
\hline Pmlim3 & P. limantouri & & & HQ677843 & & Tobler et al. 2010 \\
\hline Pmlim2 & P. limantouri & & & HQ677842 & & Tobler et al. 2010 \\
\hline Pmlim1 & P. limantouri & & & HQ677841 & & Tobler et al. 2010 \\
\hline PTR105 & P. latipunctata & JQ935927 & & & & Mejia et al. 2012 \\
\hline Platipun & P. latipunctata & KP700519 & & & & Bagley et al. 2015 \\
\hline DPP-170 & P. latipinna & KR707741 & KR707733 & & KR707749 & Ho et al. 2016 \\
\hline DPP-169 & P. latipinna & KR707740 & KR707732 & & KR707748 & Ho et al. 2016 \\
\hline DPP-168 & P. latipinna & KR707739 & KR707731 & & KR707747 & Ho et al. 2016 \\
\hline DPP-167 & P. latipinna & KR707738 & KR707730 & & KR707746 & Ho et al. 2016 \\
\hline DPP-173 & P. kykesis & KR707743 & KR707735 & & KR707751 & Ho et al. 2016 \\
\hline DPP-171 & P. kykesis & KR707742 & KR707734 & & KR707750 & Ho et al. 2016 \\
\hline DPP-142 & P. koperi & KP761855 & KP761805 & & KP761905 & Ho et al. 2016 \\
\hline DPP-140 & P. koperi & KP761853 & KP761803 & & KP761903 & Ho et al. 2016 \\
\hline DPP-139 & P. koperi & KP761852 & KP761802 & & KP761902 & Ho et al. 2016 \\
\hline DPP-073 & P. koperi & KP761851 & KP761801 & & KP761901 & Ho et al. 2016 \\
\hline DPP-072 & P. koperi & KP761850 & KP761800 & & KP761900 & Ho et al. 2016 \\
\hline DPP-141 & P. koperi & KP761854 & KP761804 & & KP761904 & Ho et al. 2016 \\
\hline stri8574 & P. hondurensis & & & & JX968768 & Alda et al. 2013 \\
\hline stri8568 & P. hondurensis & JX968668 & JX968601 & JX968714 & JX968765 & Alda et al. 2013 \\
\hline stri8534 & P. hondurensis & & & & JX968766 & Alda et al. 2013 \\
\hline
\end{tabular}




\begin{tabular}{|c|c|c|c|c|c|c|}
\hline stri8520 & P. hondurensis & JX968669 & JX968602 & JX968715 & JX968769 & Alda et al. 2013 \\
\hline stri4414 & P. hondurensis & JX968667 & JX968598 & JX968713 & JX968763 & Alda et al. 2013 \\
\hline stri4323 & P. hondurensis & & JX968599 & & & Alda et al. 2013 \\
\hline stri8566 & P. hondurensis & & & & JX968767 & Alda et al. 2013 \\
\hline RD244 & P. hispaniolana & JX968691 & JX968644 & JX968737 & JX968794 & Alda et al. 2013 \\
\hline RD243 & P. hispaniolana & JX968690 & JX968643 & JX968736 & JX968793 & Alda et al. 2013 \\
\hline stri16226 & P. gillii & & JX968632 & & & Alda et al. 2013 \\
\hline stri4162 & P. gillii_spp 2 & JX968685 & JX968638 & JX968731 & JX968789 & Alda et al. 2013 \\
\hline stri1736 & P.gillii_spp 2 & JX968684 & JX968637 & JX968730 & JX968788 & Alda et al. 2013 \\
\hline stri3706 & P. gillii & JX968682 & JX968635 & JX968728 & & Alda et al. 2013 \\
\hline stri3615 & P. gillii & JX968683 & JX968636 & JX968729 & JX968787 & Alda et al. 2013 \\
\hline stri1320 & P. gillii & JX968680 & JX968633 & JX968726 & JX968785 & Alda et al. 2013 \\
\hline stri1 1204 & P. gillii & JX968681 & JX968634 & JX968727 & JX968786 & Alda et al. 2013 \\
\hline DPP-118 & P. gillii & KP761848 & KP761798 & & KP761898 & Ho et al. 2016 \\
\hline DPP-117 & P. gillii & KP761847 & KP761797 & & KP761897 & Ho et al. 2016 \\
\hline DPP-116 & P. gillii & KP761846 & KP761796 & & KP761896 & Ho et al. 2016 \\
\hline DPP-035 & P. gillii & KP761844 & KP761794 & & KP761894 & Ho et al. 2016 \\
\hline DPP-119 & P. gillii & KP761849 & KP761799 & & KP761899 & Ho et al. 2016 \\
\hline ULVECP1 & P. elegans & & & KX024009 & & Weaver et al. 2016 \\
\hline ULVERV4 & P. elegans & & & KX024012 & & Weaver et al. 2016 \\
\hline ULVECP5 & P. elegans & & & KX024011 & & Weaver et al. 2016 \\
\hline ULVECP2 & P. elegans & & & KX024010 & & Weaver et al. 2016 \\
\hline Pel11202D & P. elegans & & & KP943309 & & Palacios et al. 2016 \\
\hline ULVDJI15 & P. dominicensis & & & KX023981 & & Weaver et al. 2016 \\
\hline ULVDAR4 & P. dominicensis & & & KX023979 & & Weaver et al. 2016 \\
\hline ULVDAR3 & P. dominicensis & & & KX023978 & & Weaver et al. 2016 \\
\hline Pdm11202D & P. dominicensis & & & KP943308 & & Palacios et al. 2016 \\
\hline DPP-164 & P. dauli & KP761843 & KP761793 & & KP761893 & Ho et al. 2016 \\
\hline DPP-163 & P. dauli & KP761842 & KP761792 & & KP761892 & Ho et al. 2016 \\
\hline SDNCUA2762 & P. chica & LC153110 & & & & $\begin{array}{l}\text { Suzuki-Matsubara et al. } \\
2016\end{array}$ \\
\hline KJ697230 & P. chica & & & KJ697230 & & Pollux et al. 2014 \\
\hline stri6445 & P. caucana & JX968687 & JX968640 & JX968733 & JX968790 & Alda et al. 2013 \\
\hline stri14905 & P. caucana & JX968686 & JX968639 & JX968732 & & Alda et al. 2013 \\
\hline DPP-130 & P. caucana & KP761841 & KP761791 & & KP761891 & Ho et al. 2016 \\
\hline DPP-127 & P. caucana & KP761840 & KP761790 & & KP761890 & Ho et al. 2016 \\
\hline DPP-126 & P. caucana & KP761839 & KP761789 & & KP761889 & Ho et al. 2016 \\
\hline DPP-123 & P. caucana & KP761838 & KP761788 & & KP761888 & Ho et al. 2016 \\
\hline DPP-053 & P. caucana & KP761837 & KP761787 & & KP761887 & Ho et al. 2016 \\
\hline DPP-045 & P. caucana & KP761836 & KP761786 & & KP761886 & Ho et al. 2016 \\
\hline MEX2276 & P. catemaconis & JX968655 & JX968569 & JX968701 & JX968747 & Alda et al. 2013 \\
\hline MEX2275 & P. catemaconis & JX968654 & JX968568 & JX968700 & JX968746 & Alda et al. 2013 \\
\hline
\end{tabular}




\begin{tabular}{lllllll} 
MEX3800 & P. butleri & JX968651 & JX968561 & JX968697 & JX968743 & Alda et al. 2013 \\
GU179233 & P. branneri & & & GU179233 & & Meredith et al. 2010 \\
GU179232 & P. bifurca & & GU179232 & & Meredith et al. 2010 \\
CU678 & L. vittata & JX968689 & JX968642 & JX968735 & JX968792 & Alda et al. 2013 \\
CU371 & L. vittata & JX968688 & JX968641 & JX968734 & JX968791 & Alda et al. 2013 \\
RD76 & L. melanonotata & JX968693 & JX968646 & JX968739 & JX968796 & Alda et al. 2013 \\
RD36 & L. melanonotata & JX968692 & JX968645 & JX968738 & JX968795 & Alda et al. 2013 \\
\hline
\end{tabular}


Table S.3.2. Relative abundance of diet items in the gut of each sampled Poecilia species.

\begin{tabular}{lccccc} 
Species & Diatoms & $\begin{array}{c}\text { Green } \\
\text { Algae }\end{array}$ & Cyanobacteria & $\begin{array}{c}\text { Animals } \\
\text { Sample Size } \\
\text { (N) }\end{array}$ \\
\hline P. reticulata & 0.18 & 0.02 & 0.12 & 0.68 & 46 \\
P. parae & NA & NA & NA & NA & 0 \\
P. picta & 0.17 & 0.01 & 0.76 & 0.06 & 10 \\
P. vivipara & 0.41 & 0.03 & 0.50 & 0.06 & 30 \\
P. dominicensis & 0.57 & 0.01 & 0.40 & 0.02 & 30 \\
P. hispaniolana & 0.31 & 0.09 & 0.42 & 0.18 & 40 \\
P. caucana & 0.48 & 0.09 & 0.24 & 0.19 & 15 \\
P. kykesis & 0.01 & 0.12 & 0.85 & 0.02 & 25 \\
P. latipinna & 0.34 & 0.04 & 0.56 & 0.06 & 36 \\
P. velifera & 0.08 & 0.03 & 0.88 & 0.01 & 47 \\
P. butleri & 0.00 & 1.00 & 0.00 & 0.00 & 5 \\
P. sphenops & 0.45 & 0.04 & 0.51 & 0.00 & 35 \\
P. gilli & 0.54 & 0.00 & 0.46 & 0.00 & 5 \\
P. mexicana & 0.01 & 0.01 & 0.95 & 0.03 & 24 \\
P. orri & 0.02 & 0.02 & 0.95 & 0.01 & 35 \\
\hline
\end{tabular}


Fig. S.3.1.

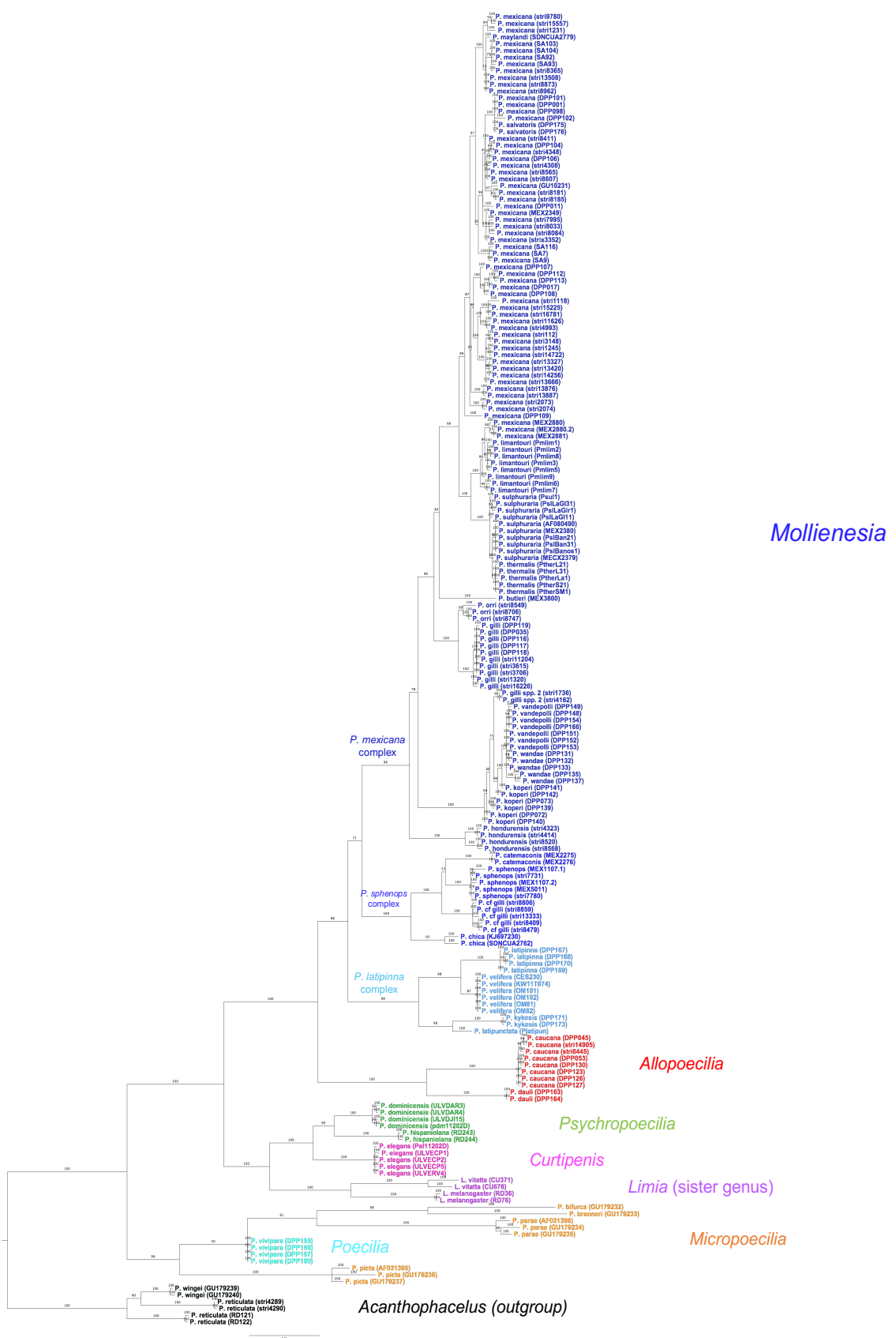

Fig. S.3.1. Bayesian phylogenetic tree (50\% majority-rule) derived from mitochondrial genes Cytochrome Oxidase subunit I, ATPase 8/6, and NADH dehydrogenase subunit 2 from 36 Poecilia and 2 Limia species. Genbank ID for each species is listed in parentheses. Species are colored by subgenus. 
Fig. S.3.2.

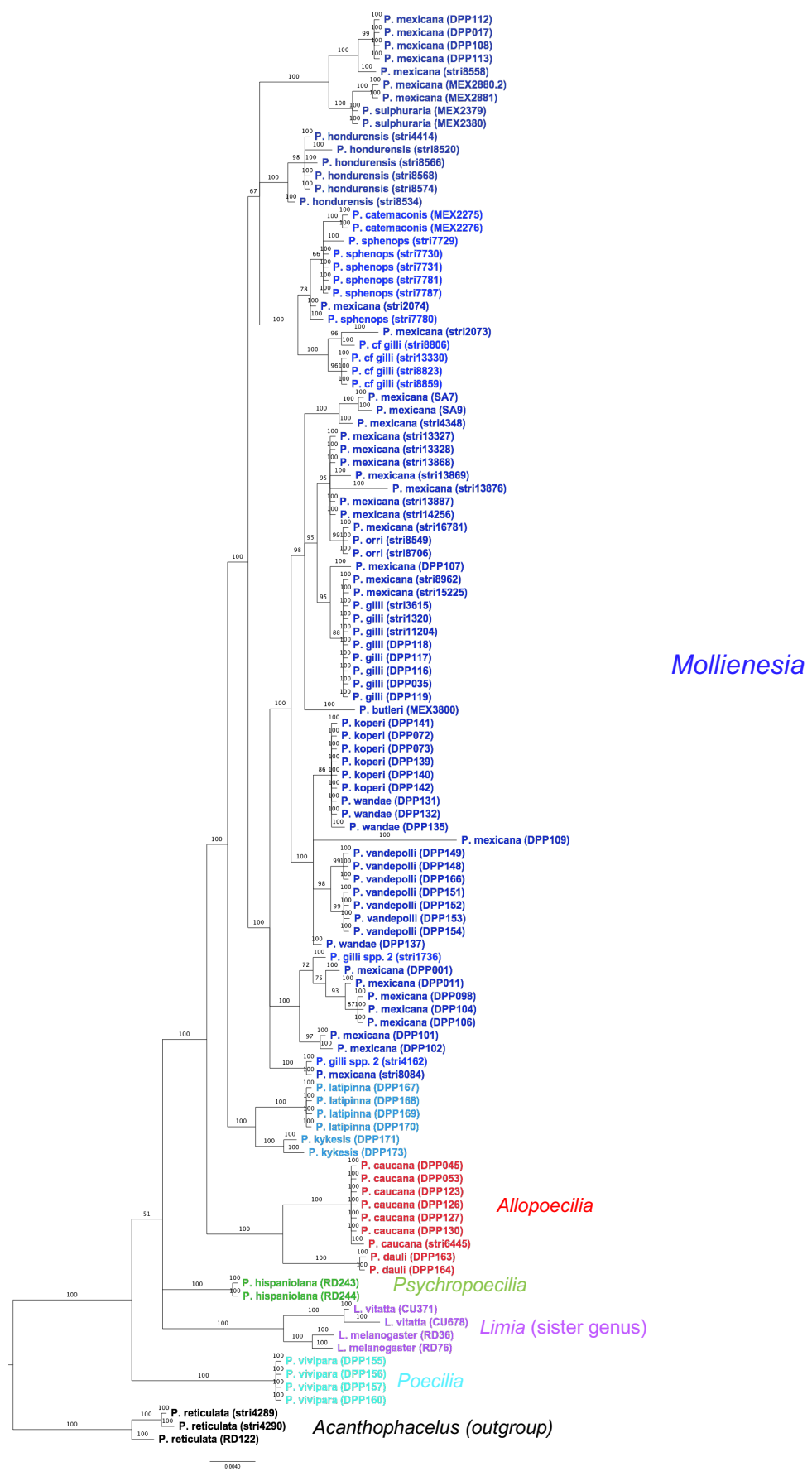

Fig. S.3.2. Bayesian phylogenetic tree (50\% majority-rule) derived from ribosomal gene, S7, from 36 Poecilia and 2 Limia species. Genbank ID for each species is listed in parentheses. Species are colored by subgenus. 


\section{Fig. S.3.3.}

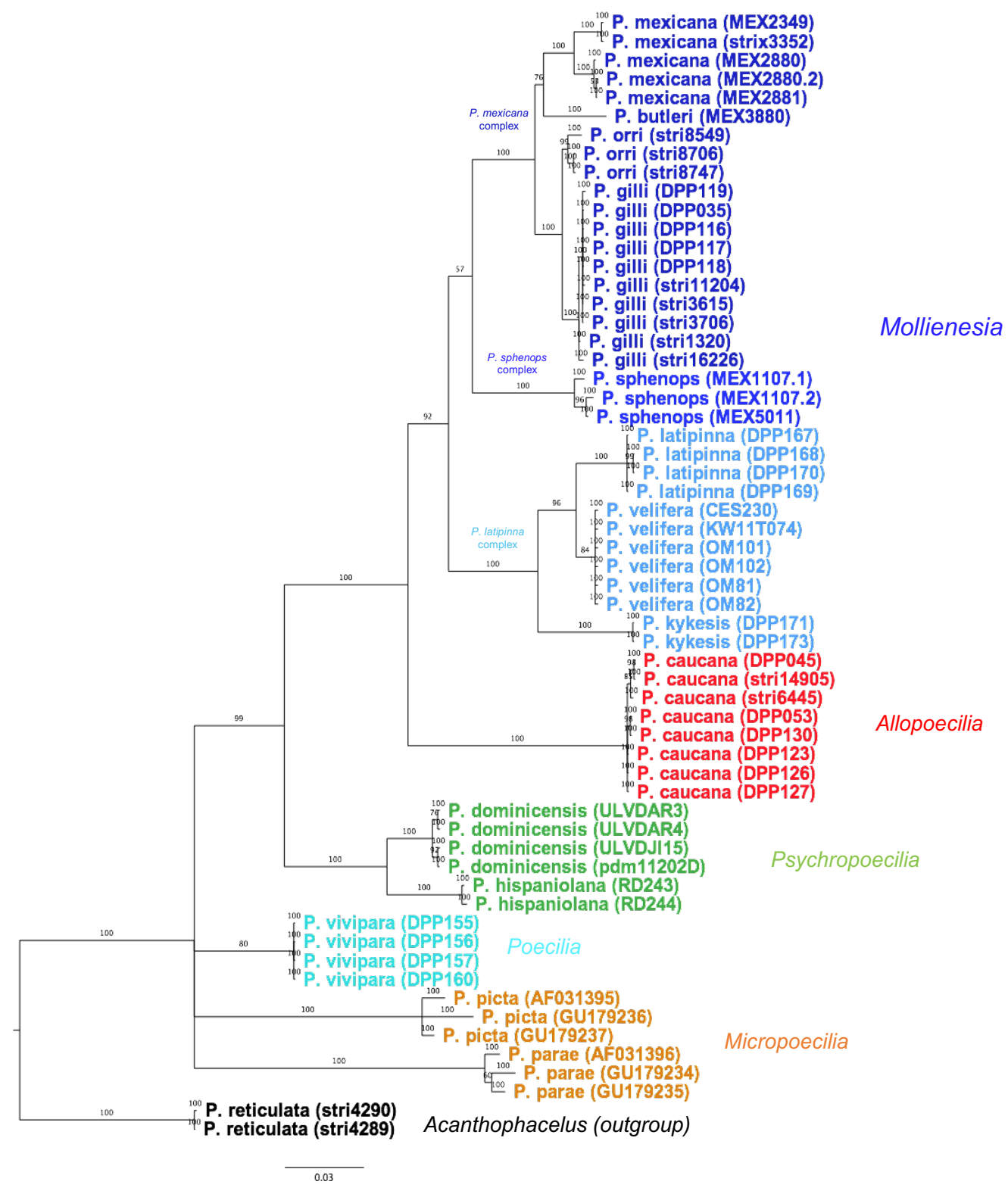

Fig. S.3.3. Pruned Bayesian phylogenetic tree (50\% majority-rule) derived from mitochondrial genes Cytochrome Oxidase subunit I, ATPase 8/6, and NADH dehydrogenase subunit 2 from 15 Poecilia species. Genbank ID for each species is listed in parentheses. Species are colored by subgenus. 
Fig. S.3.4.

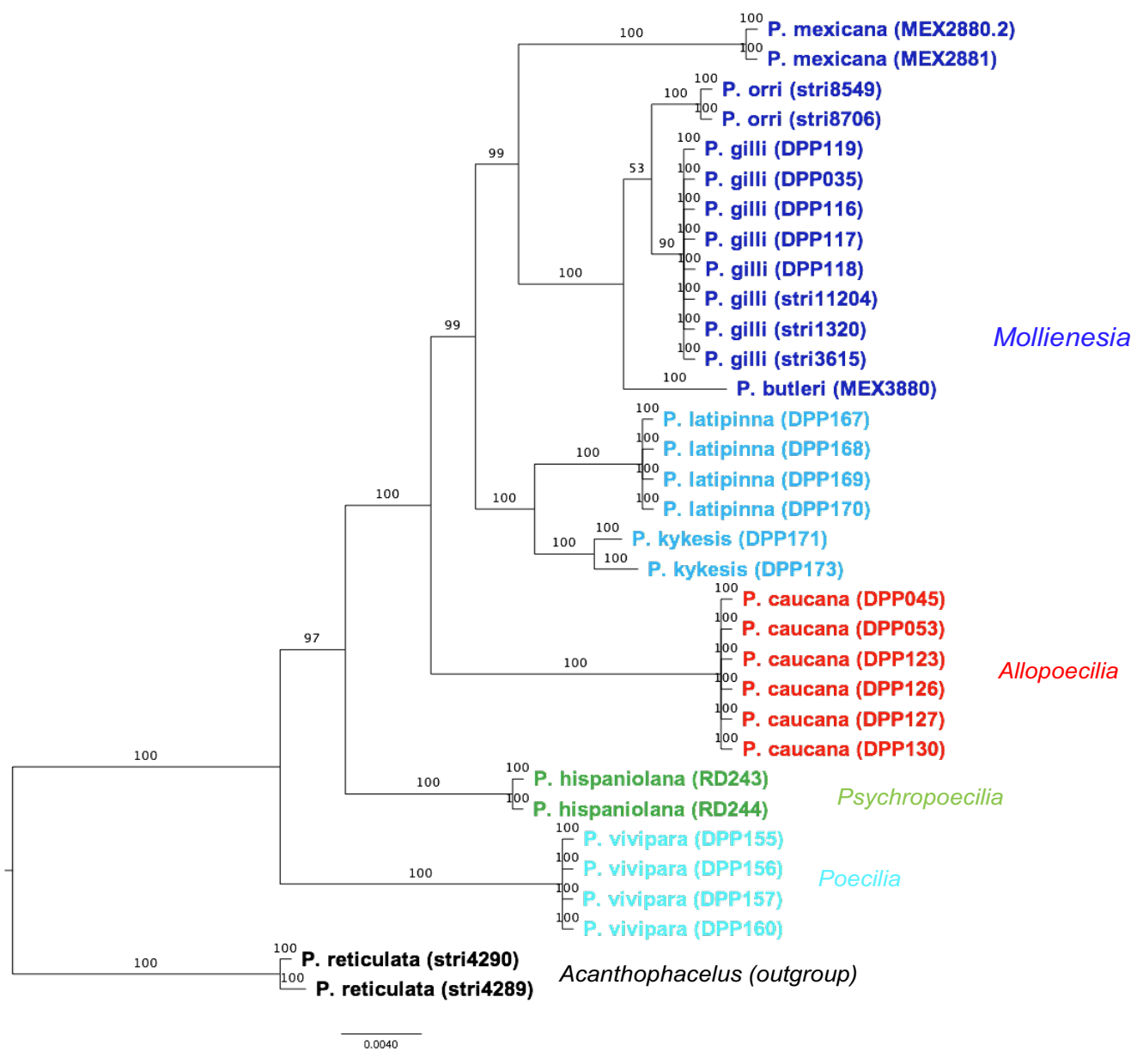

Fig. S.3.4. Pruned Bayesian phylogenetic tree (50\% majority-rule) derived from ribosomal gene, $S 7$, from 15 Poecilia species. Genbank ID for each species is listed in parentheses. Species are colored by subgenus. 


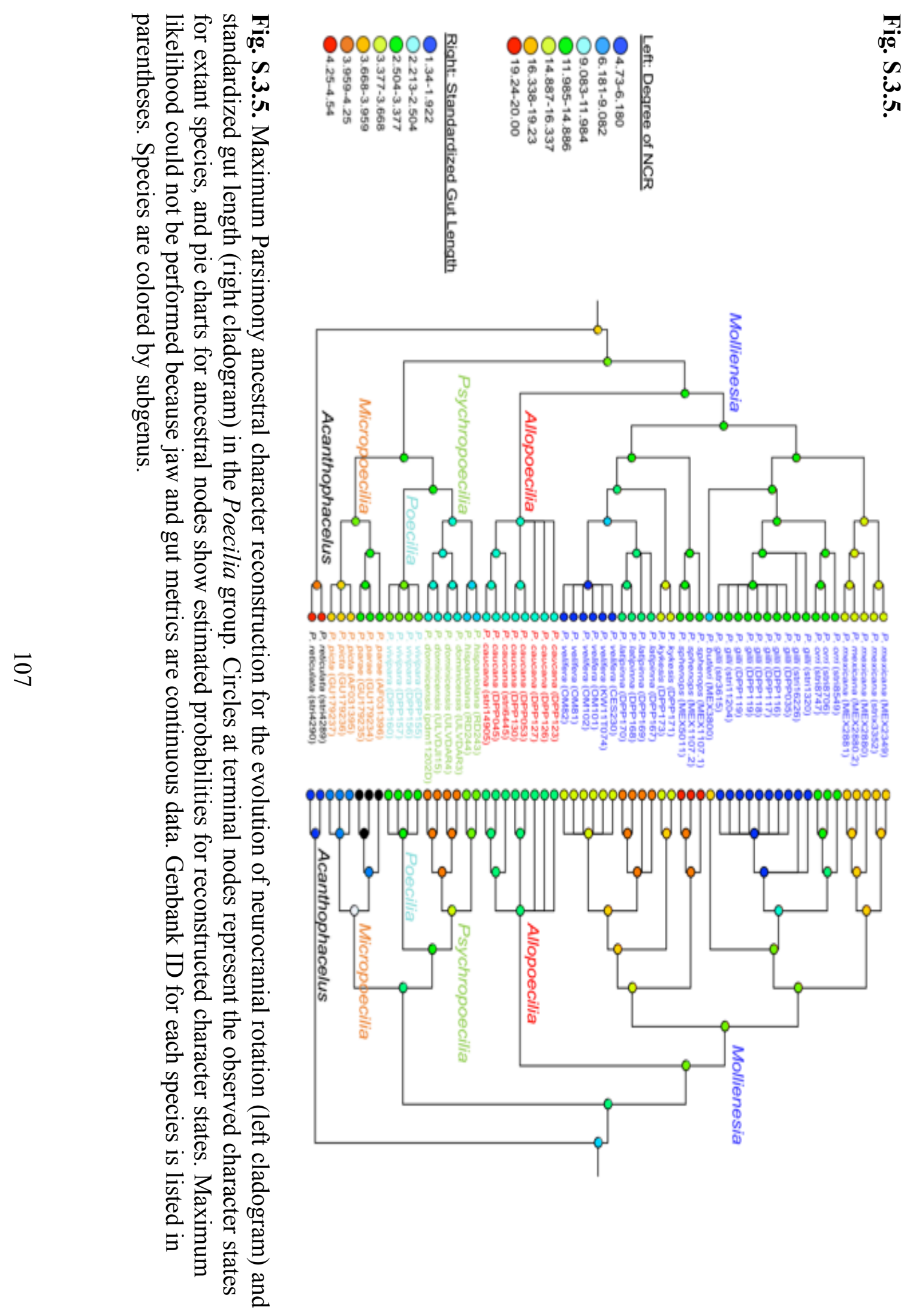


CHAPTER 4

WHEN IS AN HERBIVORE NOT AN HERBIVORE? DETRITIVORY FACILITATES

HERBIVORY IN A FRESHWATER SYSTEM

As published in Ecology and Evolution

April 2018

DOI:10.1002/ece3.4133

Available for reproduction with appropriate citation 


\begin{abstract}
Herbivory is thought to be an inefficient diet, but it independently evolved from carnivorous ancestors in many metazoan groups, suggesting that plant-eating is adaptive in some circumstances. In this study, I tested two hypotheses to explain the adaptive evolution of herbivory: 1) the Heterotroph Facilitation hypothesis (herbivory is adaptive because herbivores supplement their diets with heterotrophic microbes); and 2) the Lipid Allocation hypothesis (herbivory is adaptive because algae, which have high lipid concentrations, are nutritionally similar to carnivory). I tested these hypotheses using enclosure cages placed in the Everglades and stocked with Sailfin Mollies (Poecilia latipinna), a native herbivore. Using shading and phosphorus addition (P), I manipulated the heterotrophic microbe and lipid composition of colonizing epiphyton and examined the effects of varying food quality on Sailfin Molly life history.Epiphyton grown in 'shade only' conditions had a 55\% increase in bacterial fatty acids and 34\% lower ratios of saturated + monounsaturated to polyunsaturated fatty acids relative to the other treatments. Biovolume of heterotrophic microbes varied throughout the experiment, with a $697 \%$ increase at 3 weeks and $98 \%$ decrease at 6 weeks compared to the other treatments. Gut contents revealed that fish fed selectively on epiphyton to compensate for apparent deficiencies in the available food. Fish raised in 'shade only' cages experienced the highest survival, which was best explained by autotrophic abundance and algal- and bacterial-derived fatty acids at 3 weeks (2-6x more likely than alternative models with $\triangle \mathrm{AICc}>2.00)$, and by percentage of bacterial fatty acids in the diet at 6 weeks $(3-8 \mathrm{x}$ more likely than alternative models with $\triangle \mathrm{AICc}>2.00)$.
\end{abstract}


There were no differences in fish growth among treatments. Autotrophic lipids play a role in early fish life history, but I did not find these to be the best predictors of life history later in the juvenile period. Instead, heterotrophic lipids facilitated the herbivorous diet and enhanced survival of juvenile fish in this experiment. Bacterial fatty acid content of the diet promoted herbivore survival, consistent with the Heterotroph Facilitation hypothesis. This is the first study to explicitly contrast Heterotrophic Facilitation and Lipid Allocation hypotheses for the adaptive evolution of herbivory in an aquatic system. Keywords Diet evolution, diet quality, fatty acids, freshwater herbivore, herbivory, detritivory, structural equation model

\section{Introduction}

Herbivory appears to be at an evolutionary disadvantage compared to omnivorous or carnivorous strategies (Sanchez \& Trexler, 2016). Omnivores and carnivores consume animal prey that are high in nutritional value (Mattson, 1980; Sterner \& Hessen, 1994; Choat \& Clements, 1998; Karban \& Agrawal, 2002), and omnivores have the additional advantage of supplementing their diets with abundant and easy to obtain plant items (Coll \& Guershon 2002; Diehl, 2003). Obtaining comparable energy from an exclusively herbivorous diet is difficult because food items are nutritionally variable and are usually accompanied by structural and/or biochemical barriers to assimilation (Mattson, 1980; Porter \& McDonough, 1984; Horn 1989, Chivers \& Langer, 1994; Sterner \& Hessen, 1994; Choat \& Clements, 1998; and others). 
Furthermore, herbivores may be limited by foraging time and/or space by predators and competitors, by the ability to produce digestive or detoxifying enzymes (see Karban \& Agrawal, 2002), or the amount of time it takes for food to pass through the gut (Horn, 1989; Bruggeman et al. 1994; Bellwood, 1995; Choat \& Clements 1998). Despite these difficulties, there is evidence from many metazoan groups that herbivores evolved from carnivorous ancestors and that herbivory has been maintained alongside these animalcontaining diets in the majority of these lineages (e.g. Vermeij, 1992; deMaintenon, 1999; Van Damme, 1999; Vermeij \& Lindberg, 2000; Bellwood, 2003; Eubanks, Styrsky \& Denno, 2003; Espinoza, Wiens \& Tracy, 2004; Pauls et al. 2008, Bellwood et al. 2014; Reisz \& Frobisch, 2014).

Because few studies have addressed the adaptive significance of the herbivorous diet, Sanchez and Trexler (2016) reviewed the freshwater herbivory literature to identify conditions where eating plants might be adaptive over eating animals. They defined freshwater "herbivory" as the consumption of algae and/or phytoplankton, and an "herbivore" as an organism that mainly eats these primary producers, but may indirectly consume detritus (consumes $>50 \%$ primary producers). Furthermore, they defined a "carnivore" as an organism that eats animals (consumes $>50 \%$ animal material) and refer to an "omnivore" as an organism that eats both plants and animals (see Sanchez and Trexler 2016 for a review). The term "food quality" is used to describe the nutritional worth of a diet item to a consumer and could be defined by macronutrient (e.g., nutritional ecology) or elemental (e.g., stoichiometry) composition, where food items are rich in protein or phosphorus, respectively. 
However, elements may not be ideal currencies to answer questions about organismal diets since they form the basis of the molecules that animals often select for (e.g., proteins, carbohydrates and lipids; e.g., Sperfeld et al. 2017), and thus, I use the stoichiometric definition of food quality with caution. Food quality may also be defined as the ratio of food energy content to that assimilated by consumers. Regardless of the convention used, "food quality" is a relative term and can only be interpreted relative to other diets (e.g., a diet item can be both high and low quality depending on the comparison diet), and respective of organismal diet adaptations (e.g., "high quality" is defined differently for carnivores vs. herbivores). Under these designations, they concluded that herbivory is favored when higher quality food is limiting, or when plants provide important dietary elements that are unavailable in carnivore diets, such as lipids (e.g. Martin-Creuzburg, Beck \& Freese, 2011) or antioxidants (e.g. Pike et al. 2007). Additionally, herbivores may overcome limiting resource quality by indirectly supplementing their diets with heterotrophic microbes that are associated with primary producers (see Sanchez \& Trexler, 2016 for a review).

The idea that herbivores obtain nutrients from supplementary sources is wellestablished (see White, 1985). In aquatic systems, herbivores (e.g. macroinvertebrates) are nutrient-limited, and their nutrition is likely supported by detrital inputs (Hall, Likens \& Malcolm, 2001). The heterotrophic microbes that decompose detritus promote higher growth in macroinvertebrate families, compared to algal diets in both lab (e.g. Fuller, Fry \& Roelofs, 1988; Fuller \& Fry, 1991; Fuller, Kennedy \& Nielsen, 2004) and field studies (e.g. Mulla \& Lacey, 1976; Edwards \& Meyer, 1990). 
Furthermore, growth rates of Daphnia spp. have been shown to increase when diets are supplemented with heterotrophic bacteria (e.g. Martin-Creuzburg, Beck \& Freese, 2011), emphasizing the importance of heterotrophs in the herbivorous diet. However, diets composed only of heterotrophic bacteria are of poor quality for herbivores (e.g. Daphnia magna), suggesting that they also rely on autotrophs for essential lipids like sterols or polyunsaturated fatty acids (e.g. Goulden, Henry \& Tessier, 1982; Tessier, Henry \& Goulden, 1983; Schmidt \& Jonasdottier, 1997; Weers \& Gulati, 1997; Martin-Creuzburg, Wacker \& von Elert, 2005; Martin-Cruezburg, von Elert \& Hoffman, 2008; MartinCreuzburg, Beck \& Freese, 2011). The nutritional requirements of freshwater herbivores blur the distinction between herbivory and detritivory and emphasizes the idea that there are few "true" herbivores in nature (White 1985).

Although previous studies have shown that aquatic herbivores rely heavily on nutrients originating from both heterotrophic microbes and autotrophic bacteria and algae (e.g. Bowen, 1984; Martin-Creuzburg, Wacker \& von Elert, 2005; Smoot \& Findlay, 2010; Martin-Creuzburg, Beck \& Freese, 2011; Belicka et al., 2012), none have explicitly identified these dietary elements as facilitators of the evolution of herbivory. Here, I test two alternative hypotheses for the adaptive evolution of the herbivorous diet: 1) Heterotroph Facilitation hypothesis, which states that herbivory may be adaptive by supplementing herbivory with heterotrophic microbes that are indirectly consumed along with primary producers; and 2) Lipid Allocation hypothesis, which states that autotrophic bacteria and algae, the primary source of essential fatty acids, may be as beneficial as a carnivorous diet (Sanchez \& Trexler, 2016). 
These hypotheses are not mutually exclusive, as the definition of heterotroph facilitation includes ingestion of autotrophic organisms. The key difference between these ideas lies in the nutritional source (heterotrophic vs. autotrophic microbes) that is the driver of life history.

The Florida Everglades is an ideal system to test these adaptive hypotheses because periphyton mats are the primary basal resource in this area (Browder, Gleason \& Swift, 1994; Trexler et al., 2015) and are composed of complex assemblages of autotrophs (green algae, diatoms and cyanobacteria) and heterotrophs (fungi and bacteria; Gaiser et al., 2004). Both autotroph and heterotroph components of Everglades periphyton communities respond rapidly to changes in water chemistry (Pan et al., 2000; Noe, Childers \& Jones, 2001; Gottlieb, Gaiser \& Lee, 2015), such as when phosphorus is added, because the Everglades ecosystem is naturally oligotrophic (Gaiser et al., 2004). Furthermore, lipid profiles of Everglades primary and secondary consumers are comprised of both algal and bacterial-specific fatty acids (Belicka et al., 2012), suggesting that both items are important in their diet. One of these species is the native Sailfin Molly (Poecilia latipinna), a small livebearing fish (Fig. 4.1). Most Poecilia fishes are omnivorous (P. vivipara, Andrade et al., 2000; P. mexicana, Tobler, 2008), but stable isotope and gut content studies indicate that Sailfin Mollies are primarily herbivorous (Loftus, 2000; pers. obs.) and incorporate prokaryotic resources into their diet (Belicka et al., 2012). I used Sailfin Mollies held in enclosures in an Everglades marsh to test the alternative hypotheses of the adaptive advantage of the herbivorous diet. 
I predict that Sailfin Mollies will show increased growth and/or survival in response to increased dietary heterotrophic bacteria if the Heterotroph Facilitation hypothesis is the mechanism supporting the evolution of herbivory in the Everglades. Alternatively, Sailfin Mollies will show increased growth and/or survival in response to algal-derived fatty acids if the Lipid Allocation hypothesis is supported by this study.

\section{Methods}

I maintained juvenile Sailfin Mollies in cages in the Everglades from September 17 , to October 29,2015 , to evaluate the effects of varying herbivorous diets on fish growth and survival. The 24 cages were $1-\mathrm{m}^{2}$ and had five surfaces covered in 1-mm mesh (sides and bottom) and were open at the top. The cages were randomly placed in a slough located in the central Everglades $\left(25^{\circ} 49^{\prime} 41.23^{\prime} \mathrm{N}, 80^{\circ} 37^{\prime} 53.41^{\prime \prime} \mathrm{W}\right)$, with an average depth of $30 \mathrm{~cm}$ and temperature of $29.4 \pm 1.2 \mathrm{C}$. Light and temperature were tracked throughout the experiment using $\mathrm{HOBO}{ }^{\circledR}$ data loggers. Artificial vegetation strips (2.54 $\mathrm{cm}$ wide) made of black plastic sheeting $(0.154 \mathrm{~mm}$ thick $)$ attached to wire frames for a total of 150 strips per frame, simulating natural stem density of this area (described in Chick et al. 2008), were added to each cage. The length of the strips was trimmed to water depth (approximately $28 \mathrm{~cm}$ ) in the field so that they did not float on the surface and shade the water column. Periphyton was collected from the slough, cleaned of invertebrates, and $2000 \mathrm{~mL}$ was placed into each cage to encourage growth of epiphytic algae on the artificial vegetation strips. An initial periphyton sample was brought back to the lab on ice and subsequently frozen for nutrient and lipid analyses (ambient periphyton). 
Sailfin Mollies were born in the lab and raised on Tetramin ${ }^{\circledR}$ flake food for 6 weeks prior to the start of the experiment. They were measured (average standard length, SL) and transplanted to the field cages ( $\mathrm{n}=6$ fish per cage; $\mathrm{N}=36$ total fish/treatment) 1 week following cage set-up. This lag-time allowed epiphyton to colonize the artificial vegetation strips prior to the addition of consumers. For detailed experimental set-up, refer to Figs. S.4.1-S.4.2 located in the supplementary material.

I manipulated colonizing epiphyton by adding phosphorus $(\mathrm{P})$ and manipulating light (shade or light) to create a gradient of food quality for herbivores. Because the Everglades is a naturally oligotrophic system, both autotrophic and heterotrophic species within Everglades periphyton mats can be easily manipulated by addition of phosphorus. Each cage was randomly assigned to one of four treatments: 1) light $+\mathrm{P}$;2) light only; 3) shade $+\mathrm{P} ; 4)$ or shade only. Phosphorus $\left(\mathrm{Na}_{2} \mathrm{HPO}_{4}\right)$ was added at a concentration of 15 $\mu \mathrm{g} / \mathrm{L}$ weekly to 'shade $+\mathrm{P}$ ' and 'light $+\mathrm{P}$ ' cages. Previous studies manipulated the concentration of $\mathrm{P}$ across the Everglades landscape to understand the resulting changes to basal resources (e.g. McCormick and O’dell 1996; McCormick et al. 1996; Noe et al. 2001; Gaiser et al., 2005). They found that low and intermediate P concentrations induced changes in Everglades primary producers, but high concentrations resulted in a phase shift (e.g. Gaiser et al., 2005). The lower and intermediate nutrient concentrations occur in nature, in areas where Sailfin Mollies are native. Therefore, I chose the intermediate concentration $(15 \mu \mathrm{g} / \mathrm{L})$ in order to manipulate epiphyton composition within the natural dietary range of Sailfin Mollies. 
Following dosing, these cages were wrapped with $3-\mathrm{mm}$ clear plastic to prevent $\mathrm{P}$ from seeping and potentially affecting nearby cages. Everglades periphyton incorporates $\mathrm{P}$ very quickly (Noe et al., 2003); therefore, plastic covers were removed after 24 hours to permit water circulation. Shading was accomplished by covering cages with 3 sheets of greenhouse shade cloth to achieve approximately $75 \%$ reduction in ambient light (modified methods of Fuller, Kennedy \& Nielsen, 2004).

Epiphyton, periphyton and biofilms growing on the mesh cages were all potential herbivorous diet items available to grazing by fish. At 3 and 6 weeks, a sample of periphyton, a $5 \times 5 \mathrm{~cm}$ scrape taken from the mesh wall inside the cage (herein referred to as 'biofilm'), and 30 plastic strips were removed from each cage and brought back to the lab. At 3 weeks, two fish from each cage were euthanized with an overdose of MS-222, and the remaining fish were returned to their respective cage. At 6 weeks, all remaining fish were measured, euthanized and brought back to the lab on ice. Fish lacking gonopodial development (gonopodium, the male sexual organ) were dissected to assess fecundity.

Potential food items were processed for molecular analyses in the laboratory. Because plastic strips were various lengths from field trimming, standardized $30.5 \mathrm{~cm}$ sections from each were scraped of epiphytic algae. Subsamples of epiphyton, periphyton, and biofilm scrapes were kept for heterotroph and autotroph abundance estimates. Known volumes of epiphyton, periphyton or biofilms were stained with either DAPI (4', 6-diamidino-2-phenylindole) for bacteria (Hobbie, Daley \& Jasper, 1977), or labelled lectin (fluorescien-labelled wheat germ agglutinin) for fungal counts (e.g. Wanchoo, Lewis \& Keyhani, 2009). 
Heterotrophs were counted under a microscope at 40x using epifluorescence and autotrophs were counted using standard light microscopy at 40x magnification. Counts were transformed into total cells $/ \mathrm{mL}$ of material. Volume of bacteria, fungi and common algal species were estimated by taking measurements from of 20-30 representative organisms for each from high-definition photos and multiplied by total cells $/ \mathrm{mL}$ to yield biovolume $\left(\mu \mathrm{m}^{3} / \mathrm{mL}\right)$ estimates.

The remaining samples (including fish) were freeze-dried and prepped for fatty acid (sent to Microbial ID laboratory, Newark, DE) and stoichiometric analyses (CNP; sent to Southeastern Research Center, Florida International University, Miami, FL). Elements (CNP) are likely not ideal currencies for nutrition, but I measured the ratio of carbon to phosphorus, $\mathrm{C}: \mathrm{P}$, and ratio of nitrogen to phosphorus, $\mathrm{N}: \mathrm{P}$ (molar ratios) to compare nutritional and stoichiometric methodologies. Fatty acid data were categorized by diet tracers (Table 4.1; Belicka et al., 2012) and further organized into polyunsaturated fatty acids (PUFAs), saturated fatty acids (SAFAs), and monounsaturated fatty acids (MUFAs). Fatty acids were also organized by common essential fatty acids that are known to affect fish growth and development: eicosapentaenoic acid (EPA), docosahexaenoic acid (DHA), and arachidonic (ARA) (see Saikia \& Nandi, 2010 for a review). In addition to fatty acid and nutrient analyses, algal, bacterial, and fungal biovolume were used to calculate a ratio of autotrophic to heterotrophic organisms (A:H biovolume ratio). These metrics were analyzed in fish tissues and potential food sources to evaluate their influence on fish life history. 


\section{Statistical analyses}

Growth curves of poeciliid fishes are more strongly asymptotic in males than females (Snelson, 1989), a phenomenon well-described for Sailfin Mollies (Snelson, 1982; Travis et al., 1989). There were a few mature males at the end of the experiment; however, there were no developing embryos found in the ovaries of the females, so growth curves were treated as if fish had not yet matured. Fish standard length (mm) measurements at 0,3 and 6 weeks were analyzed using 2-way analysis of variance (ANOVA). Fish standard length $(\mathrm{mm})$ measurements by week were analyzed using the quadratic equation. Growth rates were estimated by dividing the slope at $2 / 3$ of that curve by the number of days to obtain the growth of Sailfin Mollies per day in mm (following Trexler \& Travis, 1990). A logit model with maximum likelihood was fit to fish survival data to predict the probability of survival, $p$, where $\operatorname{logit}(p)=\log (p / 1-p)$. Temperature and light availability, potential influences on fish growth and survival, were analyzed for each treatment using one-way ANOVA.

Multiple potential diet items were present in the experimental cages (biofilm, epiphyton, and periphyton described above), therefore, it was important to determine which diet items had the strongest influence on fish size and survival. I assumed that items that best predict fish life history were those that dominated the diets of fish in the experimental cages. Several food-quality variables were measured for all potential diet types. 
These were: ratio of carbon to phosphorus $(\mathrm{C}: \mathrm{P})$, ratio of nitrogen to phosphorus $(\mathrm{N}: \mathrm{P})$, relative fatty acid content, percentage of algal- and bacterial- derived fatty acids, fatty acid class (PUFA, SAFA, MUFA, ratio of SAFA+MUFA: PUFA), essential fatty acids (EPA, DHA, ARA, ratio of EPA:DHA), A:H biovolume, and proportion of edible algae (proportion of green algae relative to cyanobacteria). Stoichiometry of algal types (C:P) was analyzed using one-way Analysis of Variance (ANOVA) and Tukey post hoc tests. Algal species from epiphyton, periphyton, and fish guts were analyzed using 2-way multivariate analysis of variance (MANOVA) with Tukey post-hoc tests. To determine the probability that a fish would eat a diet item based on its availability in the environment, I calculated Ivlev's Electivity Index, $E_{i}=\left(r_{i}-p_{i}\right) /\left(r_{i}+p_{i}\right)$, where $r_{i}=$ the proportion of the item found in the gut and $\mathrm{p}_{\mathrm{i}}=$ the proportion of the item found in the environment. Calculated indices were rounded to the nearest whole number. A value of $E_{i}$ $<0$ suggests that fish are avoiding the dietary item, $E_{i}>0$ suggests that the fish are actively selecting the item, and $\mathrm{E}_{\mathrm{i}}=0$ means that items are eaten in proportion to their availability in the environment. These were calculated for each treatment at both 3- and 6- weeks.

Relative fatty acid content of all samples was calculated by dividing the mass spectrometry peak area for each by the mg of dry weight of each sample. Although not a quantitative measure, it allowed us to compare relative fatty acid content across experimental treatments. These relative values were analyzed using two-way ANOVA with post-hoc tests. Two- way ANOVAs were also used to assess any differences in the percentage of algal and bacterial- derived fatty acids across treatments. 
Fatty acid classes (PUFA, SAFA, MUFA) and essential fatty acids (EPA, DHA, ARA) comprising each algal type were analyzed using MANOVA tests, followed by Tukey multivariate comparison tests (ln transformed). Ratios of fatty acid classes (SAFA+MUFA: PUFA, ln transformed) and essential fatty acids (EPA:DHA, log +1 transformed) were analyzed using two-way ANOVA. Biovolume of heterotrophs and autotrophs were converted to ratios (A:H biovolume), natural-log transformed (ln), and analyzed using 2-way ANOVA. Proportion of edible algal species comprising each of the diet type was analyzed using two-way ANOVA.

Epiphyton and biofilm were not statistically different from each other across all measured variables, so biofilm was dropped from future analyses. Of the 14 measured characteristics, variables that were statistically different $(\alpha \leq 0.05)$ between epiphyton and periphyton were used as independent variables in Discriminant Function Analysis, with diet type as the grouping variable. These were: $\mathrm{C}: \mathrm{P}, \mathrm{A}: \mathrm{H}$ biovolume, SAFA+MUFA:PUFA, EPA:DHA, and percent of bacterial fatty acids. Discriminant scores for the function explaining the most variance were used as input variables for Structural Equation Models (SEM; Grace, 2006), which were fit using AMOS (Arbuckle, 2014)). Using Principal Component Analysis, fish size and survival rates were collapsed into a single score that was also an input for SEMs.

I used SEMs to evaluate the information in alternative hypothesized pathways that the treatments (light and nutrient manipulation) may affect the consumers through their impact on primary producers. The first set of 3 models were designed to test the linkages between potential food items and fish life history. 
Paths were varied between epiphyton, periphyton and fish life history in each model. Models were compared using Akaike's Information Criterion (AIC) by calculating $\Delta \mathrm{AICc}\left(\triangle \mathrm{AICc}=\mathrm{AIC}_{\mathrm{i}}-\min \mathrm{AICc}\right.$, where $\mathrm{i}=$ model $\left.\mathrm{i}\right)$, Akaike weight $\left(\mathrm{AIC}_{\mathrm{w}}=\left(\mathrm{e}^{(-0.5}\right.\right.$

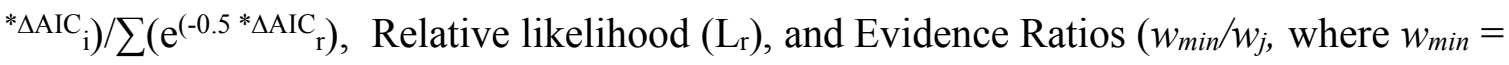
$\mathrm{AIC}_{\mathrm{w}}$ for the model with the smallest $\triangle \mathrm{AICc}$ and $w_{j}=\mathrm{AIC}_{\mathrm{w}}$ for the current model; Anderson \& Burnham, 2002). Path coefficients (regression weights) were assessed to determine which variables best predicted life history. Following Anderson \& Burnham (2002), models with $\Delta \mathrm{AICc}<2.0$ were considered equally explanatory. These models were fit for both 3- and 6-weeks.

I tested the alternative adaptive hypotheses by determining which food quality parameter influenced fish life history. The Heterotroph Facilitation hypothesis predicts that heterotrophs in the diet promote herbivore life history, and the Lipid Allocation hypothesis predicts that algal-derived fatty acids are driving herbivore success. Therefore, I chose to evaluate $\mathrm{A}: \mathrm{H}$ biovolume (measure of heterotroph and autotroph abundance), percentage of bacterial fatty acids (measure of bacterial quality), and SAFA+MUFA:PUFA ratios (algal-derived fatty acids; measure of algal quality) as independent variables in a second set of SEMs designed to test the adaptive hypotheses. Paths were varied between these 3 diet variables and fish life history to produce a total of 7 models. Similar to the first SEMs, models were compared using AIC. 


\section{Results}

\section{Epiphyton}

3 weeks. The cages differed in phosphorus availability, but this did not translate to differences in epiphyton stoichiometry at 3 weeks. Ratios of C:P and N:P were similar for epiphyton grown in all treatments $\left(\mathrm{F}_{3,8}=0.079, \mathrm{P}=0.970\right.$ and $\mathrm{F}_{3,8}=0.367, \mathrm{P}=0.779$, respectively).

Unlike stoichiometry, autotroph species composition was affected by light. Epiphyton samples collected at 3 weeks were comprised of similar algal species among treatments (Wilks' Lambda $=0.053, \mathrm{~F}_{15,11}=0.912, \mathrm{P}=0.588$ ), but differed in relative abundance of edible algal types. Specifically, light drove the proportion of edible algae comprising epiphyton (light: $\mathrm{F}_{1,8}=11.487, \mathrm{P}=0.010$ ), where epiphyton from the 'light only' treatments had $18 \%$ higher relative abundance of diatoms, solitary green, and filamentous green species than 'light $+\mathrm{P}$ ' epiphyton, and 94\% higher abundance of these species than the shaded treatments. Furthermore, the shaded treatments were comprised of $50 \%$ inedible species (filamentous and coccoid cyanobacteria), as compared to $3 \%$ and $18 \%$ for 'light only' and 'light $+\mathrm{P}$ ', respectively.

Biovolume differed between light and shade treatments. The biovolume of heterotrophs $\left(\mathrm{F}_{3,8}=0.415, \mathrm{P}=0.747\right)$ were not different between treatments, however, 'shade + P' and 'shade only' epiphyton was comprised of $238 \%$ and $887 \%$ greater autotrophs (respectively) compared to the other treatments (Light: $\mathrm{F}_{1,8}=5.430, \mathrm{P}=0.048$; P: $\left.\mathrm{F}_{1,8}=5.913, \mathrm{P}=0.041\right)$. 
Consequently, the ratios of A:H biovolume for 'shade $+\mathrm{P}$ ' and 'shade only' epiphyton were approximately $140 \%$ and $697 \%$ greater than the light treatments, respectively (Light: $\mathrm{F}_{1,8}=8.820, \mathrm{P}=0.018$ ).

The relative abundance of types of fatty acids was affected by the both light and $\mathrm{P}$ treatments. There were no differences the relative fatty acid content of epiphyton $\left(\mathrm{F}_{3,8}=\right.$ $1.348, \mathrm{P}=0.279)$, the percentage of algal-derived fatty acids $\left(\mathrm{F}_{3,8}=1.534, \mathrm{P}=0.279\right)$ or the percentage of bacterial-derived fatty acids $\left(\mathrm{F}_{3,8}=0.299, \mathrm{P}=0.825\right)$. The relative abundances of PUFA's and SAFA's comprising the 3-week epiphyton samples were driven by both light and nutrient addition (Wilks' Lambda $=0.162, \mathrm{~F}_{9,15}=10.31, \mathrm{P}=$ 0.009), where 'light only' epiphyton had approximately 59\% higher PUFAs and 'light + P' epiphyton had $8 \%$ higher SAFAs than the other treatments. However, only light drove the relative abundance of MUFAs (Wilks' Lambda $=0.135, \mathrm{~F}_{3,15}=12.811, \mathrm{P}=0.005$ ). The shaded treatments had 10\% higher MUFAs than the light treatments. Nutrient addition affected the SAFA+MUFA:PUFA ratios, where 'light $+\mathrm{P}$ ' and 'shade $+\mathrm{P}$ ' epiphyton had approximately $61 \%$ and $27 \%$ higher ratios relative to the other epiphyton types, respectively (phosphorus: $\mathrm{F}_{1,8}=28.946, \mathrm{P}=0.002$ ). Epiphyton grown in different treatments were not significantly different in EPA, DHA and ARA (Wilks' Lambda= $0.288, \mathrm{~F}_{9,15}=0.915, \mathrm{P}=0.543$ ). For a summary of results, refer to Table 4.2. 6 weeks. Stoichiometric differences between treatments were revealed at 6 weeks. The $\mathrm{C}: \mathrm{P}$ ratio of epiphyton was influenced by nutrient addition (phosphorus: $\mathrm{F}_{1,8}=5.316, \mathrm{P}=$ 0.05), where epiphyton grown in 'light $+\mathrm{P}$ ' and 'shade $+\mathrm{P}$ ' cages had $28 \%$ and $3 \%$ lower $\mathrm{C}: \mathrm{P}$ ratios than the other treatments. 
However, there were no differences in N:P ratios of epiphyton growing in the different treatments $\left(\mathrm{F}_{3,8}=2.703, \mathrm{P}=0.116\right)$.

Differences in autotroph species composition disappeared at 6 weeks. There were no differences in algal community structure (Wilks' Lambda $=0.004, \mathrm{~F}_{15,3}=1.407, \mathrm{P}=$ $0.433)$ or in edible algae proportions across treatments $\left(\mathrm{F}_{3,8}=1.125, \mathrm{P}=0.395\right)$.

Biovolume of autotrophs and heterotrophs was affected by both light and P at 6 weeks. Shaded treatments showed an $85 \%$ and $75 \%$ ('shade $+\mathrm{P}$ ' and 'shade only', respectively) decrease in heterotroph biovolume relative to light treatments $\left(\mathrm{F}_{3,8}=1.570, \mathrm{P}=0.271\right)$. Conversely, 'light $+\mathrm{P}$ ' treatments showed $65 \%$ decreased autotrophic biovolume (Light $\mathrm{x}$ $\left.\mathrm{P}: \mathrm{F}_{1,8}=36.72, \mathrm{P}<0.0001\right)$ relative to all other treatments. As a result, light treatments had relatively low A:H ratios (approx. 98\% decrease) compared to shaded treatments (Light: $\left.\mathrm{F}_{1,8}=5.088, \mathrm{P}=0.04\right)$. These ratios also increased in magnitude from 3-week epiphyton.

Similar to 3-week epiphyton, the relative abundance of types of fatty acids was affected by the both light and $\mathrm{P}$ treatments. There were no differences in the relative fatty acid content of 6-week epiphyton $\left(\mathrm{F}_{3,8}=0.254, \mathrm{P}=0.857\right)$ or the percentage of algal fatty acids $\left(\mathrm{F}_{3,8}=1.580, \mathrm{P}=0.269\right)$. Differences in bacterial fatty acid composition became evident at 6 weeks (Light: $\mathrm{F}_{1,8}=8.854, \mathrm{P}=0.018$ ), where the 'shade only' and 'shade $+\mathrm{P}$ ' treatments had 55\% and 28\% higher percentages than the other treatments, respectively. The relative abundance of PUFA's, SAFA's and MUFA's and the SAFA+MUFA:PUFA ratios were the same (Wilks' Lambda $=0.415, \mathrm{~F}_{9,15}=0.713, \mathrm{P}=$ 0.690 and $\mathrm{F}_{15,3}=0.075, \mathrm{P}=0.591$, respectively). 
In addition, epiphyton grown in different treatments were not significantly different in EPA, DHA and ARA (Wilks' Lambda $=0.234, \mathrm{~F}_{9,15}=1.337, \mathrm{P}=0.299$ ). For a summary of results, refer to Table 4.3. For detailed epiphyton results for both 3- and 6-week time periods, refer to Table S.4.1 located in the supplementary material.

\section{Periphyton}

3 weeks. At 3 weeks, stoichiometric ratios of periphyton were consistent across treatments. Ratios of C:P and N:P were not different across treatments or from ambient periphyton $\left(\mathrm{F}_{3,8}=0.551, \mathrm{P}=0.662\right.$ and $\mathrm{F}_{3,8}=0.231, \mathrm{P}=0.872$, respectively $)$. Periphyton $\mathrm{C}: \mathrm{P}$ and $\mathrm{N}: \mathrm{P}$ was different from that of epiphyton $\left(\mathrm{F}_{1,8}=142.32, \mathrm{P}<0.001\right.$ and $\mathrm{F}_{1,8}=$ 19.83, $\mathrm{P}<0.001$, respectively), as periphyton had $110 \%$ higher $\mathrm{C}: \mathrm{P}$ and $23 \%$ higher $\mathrm{N}: \mathrm{P}$ ratios. Autotroph species composition of 3-week periphyton was driven by light. Periphyton samples were similar in algal composition among treatments (Wilks' Lambda $\left.=0.514, \mathrm{~F}_{6,14}=0.920, \mathrm{P}=0.509\right)$, but differed in relative abundance of edible algal types. Light drove the proportion of edible algae comprising periphyton (Light: $\left.\mathrm{F}_{1,8}=5.23, \mathrm{P}=0.05\right)$, where the light treatments had approximately $63 \%$ higher abundance of edible species than the shaded treatments.

The A:H biovolume ratios of 3-week periphyton were driven by P-addition. Periphyton grown in the 'light $+\mathrm{P}$ ' and 'shade $+\mathrm{P}$ ' treatments had $24 \%$ and $425 \%$ higher A:H biovolume than 'light only' and 'shade only' periphyton, respectively (phosphorus: $\left.\mathrm{F}_{1,8}=0.129, \mathrm{P}=0.003\right)$. 
The relative abundance of types of fatty acids in periphyton was similar across treatments at 3 weeks. The percentage of algal and bacterial-derived fatty acids (Wilks' Lambda $\left.=0.743, \mathrm{~F}_{6,14}=0.411, \mathrm{P}=0.884\right)$, and the relative fatty acid content $\left(\mathrm{F}_{3,8}=0.919\right.$, $\mathrm{P}=0.474)$ were not different among treatments. The proportion of PUFAs, SAFAs and MUFAs (Wilks' Lambda $=0.452, \mathrm{~F}_{9,15}=0.633, \mathrm{P}=0.752$ ) as well as the SAFA+MUFA:PUFA ratios of 3- week periphyton were similar across treatments $\left(\mathrm{F}_{3,8}=\right.$ 1.392, $\mathrm{P}=0.314$ ). Essential fatty acid composition (EPA, DHA, ARA) of periphyton was not different across treatments (Wilks' Lambda $=0.635, \mathrm{~F}_{6,14}=0.595, \mathrm{P}=0.730$ ), but periphyton had non-detectable levels of DHA (i.e. $0.0 \%$ by weight), which was significantly lower than epiphyton $\left(\mathrm{F}_{1,8}=88.17, \mathrm{P}<0.0001\right)$. For a summary of results, refer to Table 4.2.

6 weeks. Similar to 3-week periphyton, stoichiometric ratios of periphyton were not different across treatments. Ratios of $\mathrm{C}: \mathrm{P}$ and $\mathrm{N}: \mathrm{P}$ were consistent across treatments $\left(\mathrm{F}_{3,8}=0.487, \mathrm{P}=0.701\right.$ and $\mathrm{F}_{3,8}=0.438, \mathrm{P}=0.732$, respectively), however, ambient periphyton was stoichiometrically different than 6-week periphyton from the experimental treatments $\left(\mathrm{F}_{4,9}=5.965, \mathrm{P}=0.013\right)$, with $64 \%$ and $2 \%$ greater $\mathrm{C}: \mathrm{P}$ and $\mathrm{N}: \mathrm{P}$ ratios, respectively.

Autotroph species composition of 6-week periphyton was not driven by light, in contrast to periphyton at 3 weeks. Periphyton samples collected at 6 weeks were similar in algal species composition among treatments (Wilks' Lambda $=0.191, \mathrm{~F}_{15,3}=0.980, \mathrm{P}=$ $0.510)$ and in the proportion of edible algal species $\left(\mathrm{F}_{3,8}=0.757, \mathrm{P}=0.549\right)$. The $\mathrm{A}: \mathrm{H}$ biovolume ratios of 6-week periphyton were driven by light and nutrients. 
Periphyton in the 'light $+\mathrm{P}$ ' cages had $96 \%$ lower A:H ratio than 'light only' periphyton, and $74 \%$ lower ratio than the shaded treatments (Light x P: $\mathrm{F}_{1,8}=5.211, \mathrm{P}=0.05$ ).

The relative abundance of types of fatty acids in periphyton were similar across treatments at 6 weeks. The percentage of algal and bacterial-derived fatty acids (Wilks' Lambda $\left.=0.679, \mathrm{~F}_{6,14}=0.499, \mathrm{P}=0.799\right)$ and the relative fatty acid content $\left(\mathrm{F}_{3,8}=0.170\right.$, $\mathrm{P}=0.913$ ) were not different among treatments. The proportion of PUFAs, SAFAs and MUFAs (Wilks' Lambda $=0.453, \mathrm{~F}_{9,15}=0.630, \mathrm{P}=0.755$ ) as well as the SAFA+MUFA:PUFA ratios were similar across treatments $\left(\mathrm{F}_{3,8}=0.961, \mathrm{P}=0.457\right)$. Essential fatty acid composition (EPA, DHA, ARA) of 6-week periphyton was not different across treatments (Wilks' Lambda $=0.703, \mathrm{~F}_{3,15}=1.125, \mathrm{P}=0.395$ ), but periphyton was significantly lower in DHA than epiphyton $\left(\mathrm{F}_{1,8}=50.01, \mathrm{P}<0.001\right)$. For a summary of results, refer to Table 4.3. For detailed periphyton results for both 3- and 6week time periods, refer to Table S.4.2 located in the supplementary material.

Fish

3 weeks. Juvenile Sailfin Molly survival, but not growth rate, was affected by the treatments. There were no differences in the sizes of juvenile fish stocked in each cage at the start of the experiment $\left(\mathrm{F}_{3,8}=0.207, \mathrm{P}=0.891\right)$. The light cages were approximately 2 degrees warmer than the shaded cages $\left(\mathrm{F}_{3,51}=7.617, \mathrm{P}<0.0001\right)$, but this did not translate into differences in fish growth, as all fish were similar sizes at week $3\left(\mathrm{~F}_{3,8}=1.597, \mathrm{P}=\right.$ 0.265). However, there were differences in fish survival among treatments. Specifically, fish in the 'shade only' had the greatest survival compared to all other treatments $\left(X^{2}=\right.$ 14.979, $\mathrm{P}=0.001)$. 
Fish reared in the 'light $+\mathrm{P}$ ' treatment experienced the lowest survival, which was $30 \%$ less than fish in the 'shade only' treatment (Fig. 4.2b).

Stoichiometric differences in fish tissues were evident at 3 weeks. Fish reared in the experimental treatments had $81 \%$ greater C:P ratios and $73 \%$ greater N:P ratios in their tissues relative to initial, lab-reared fish fed commercial food (C:P, $F_{4,9}=5.293$, $\left.\mathrm{P}=0.018 ; \mathrm{N}: \mathrm{P}, \mathrm{F}_{4,9}=4.238, \mathrm{P}=0.034\right)$. Furthermore, fish in the light treatments showed $28 \%$ higher $\mathrm{C}: \mathrm{P}$ ratios than those reared in the shaded treatments (Light: $\mathrm{F}_{1,8}=6.557, \mathrm{P}=$ $0.034)$, but there were no differences in N:P ratios in fish reared in the different treatments $\left(\mathrm{F}_{3,8}=1.411, \mathrm{P}=0.309\right)$.

The experimental treatments did not affect autotrophic species composition of 3week fish guts. The algal composition of 3-week fish guts (Wilks' Lambda=0.253, $\mathrm{F}_{18,37}=1.297, \mathrm{P}=0.245 ;$ Fig $\left.4.3 \mathrm{a}\right)$ and the relative abundances of edible algae were similar across treatments $\left(\mathrm{F}_{3,8}=0.414, \mathrm{P}=0.748\right)$. There were some fish with invertebrate parts present in guts at both time periods $(<1 \%$ of total gut material), but these values were not significantly different across treatments. Although these values were similar, Ivlev's Electivity Index varied for fish eating the different epiphyton types because available food varied among treatments. Indices suggested that fish reared in the light treatments consumed green algal species in proportion to their availability in the environment, whereas those in the shaded treatments actively selected green algae. In addition, fish reared in the 'light only' treatment proportionally consumed cyanobacteria as they were available, and fish in the other treatments selectively fed on cyanobacterial species. 
Fish in all treatments selectively fed on diatoms, and consumed cyanobacterial filaments in proportion to their availability (Fig. 4.4a; Supplementary Table S.4.4).

The differences in relative abundance of fatty acids in fish tissues were subtle at 3 weeks. There were no differences in relative fatty acid content of fish tissues across treatments $\left(\mathrm{F}_{3,8}=1.362, \mathrm{P}=0.322\right)$, or in the relative abundance of algal and bacterialderived fatty acids in the fish tissues across experimental treatments (Wilks' Lambda= $\left.0.728, \mathrm{~F}_{6,14}=0.840, \mathrm{P}=0.533\right)$.

The relative amounts of PUFAs and SAFAs in fish tissues were marginally different (Wilks' Lambda $=0.102, \mathrm{~F}_{9,15}=2.549, \mathrm{P}=0.054$ ). The shaded treatments revealed a 10\% increase in PUFAs, whereas 'light only' fish had 36\% lower SAFA abundance in their tissues. Despite these differences, the SAFA+MUFA: PUFA ratios were the same for fish tissues at 3 weeks $\left(\mathrm{F}_{3,8}=2.658, \mathrm{P}=0.120\right)$. There were no differences in essential fatty acids (EPA, DHA, ARA) in fish tissues (Wilks' Lambda= $0.277, \mathrm{~F}_{9,15}=1.140, \mathrm{P}=0.396$ ), but initial fish tissues had $91 \%$ higher DHA than fish tissues from experimental treatments $\left(\mathrm{F}_{4,10}=3.940, \mathrm{P}=0.036\right)$. For a summary of results, refer to Table 4.2.

6 weeks. Similar to 3-week data, there were differences in Sailfin Molly survival, but not growth rate at 6 weeks. The light cages were still 2 degrees warmer than the shaded cages $\left(\mathrm{F}_{3,51}=4.376, \mathrm{P}=0.007\right)$, but all cage temperatures decreased by 2 degrees in the second half of the experiment. This temperature change did not affect fish growth, as all fish grew at similar rates during time period 3-6 weeks $\left(\mathrm{F}_{3,8}=1.877, \mathrm{P}=0.212\right.$; Fig. 4.2a) and achieved similar sizes at 6 weeks $\left(\mathrm{F}_{3,8}=1.425, \mathrm{P}=0.305\right)$. 
Fish raised in the 'shade only' treatment experienced 53\% higher survival relative to fish reared in the nutrient addition treatments $\left(X^{2}=15.837, \mathrm{P}<0.0001\right)$. Fish reared in the 'light only' treatments experienced the lowest survival (Fig. 4.2b).

There were stoichiometric differences in fish tissues at 6 weeks. Similar to 3week fish tissues, fish in the 'light $+\mathrm{P}$ ' and 'light only' treatments had 32\% and 45\% higher ratios of C:P than 'shade $+\mathrm{P}$ ' and 'shade only' fish, respectively $\left(\mathrm{F}_{4,9}=24.22\right.$, $\mathrm{P}<0.001)$. Fish raised in the light treatments also had higher tissue N:P ratios, at $27 \%$ higher than 'shade $+\mathrm{P}$ ' fish and $18 \%$ higher than 'shade only' fish $\left(\mathrm{F}_{4,9}=8.481\right.$, $\mathrm{P}=0.006)$.

The algal composition of 6-week fish guts was marginally different across treatments. Fish reared in 'light $+\mathrm{P}$ ' and 'light only' treatments had higher proportions of diatoms (200\% increase) and green algae (900\% increase) in their guts (Wilks' Lambda= $\left.0.179, \mathrm{~F}_{18,37}=1.774, \mathrm{P}=0.077\right)$. These fish reared in light treatments also had $99 \%$ lower abundances of both coccoid and filamentous cyanobacteria in their guts than fish from the shaded treatments (Fig. 4.3b). However, the proportion of edible algal species present in the guts were not different across treatments $\left(\mathrm{F}_{3,8}=0.810, \mathrm{P}=0.523\right)$. There were some fish with invertebrate parts present in guts at both time periods $(<1 \%$ of total gut material), but these values were not significantly different across treatments. Ivlev's Electivity Index $\left(\mathrm{E}_{\mathrm{i}}\right)$ reflected differences in fish guts at 6 weeks.

Indices suggested that fish reared in the 'light $+\mathrm{P}$ ' treatment avoided diatoms, consumed green algae in proportion to their availability in the environment and avoided all other algal types. 
Those in the 'light only' treatments consumed all algae in proportion to their availability, except cyanobacteria. Fish in both shaded treatments selectively consumed diatoms. 'Shade + P' also selectively chose green algae, and avoided cyanobacteria. But 'shade only' fish ate green and cyanobacterial species in proportion to their availability in the environment (Fig. 4.4b; Supplementary Table S.4.4).

Differences in relative abundance of fatty acids in fish tissues were revealed at 6 weeks. The abundance of fatty acids in fish tissues was influenced by light (Light: $\mathrm{F}_{1,8}=6.641, \mathrm{P}=0.033$ ), where 'light $+\mathrm{P}$ ' fish were comprised of $3 \mathrm{x}$ greater fatty acid abundance than 'shade only' fish. But, there were no differences between experimental treatments and fatty acid content of initial fish $\left(\mathrm{F}_{3,8}=1.362, \mathrm{P}=0.322\right)$, or in the relative abundance of algal and bacterial- derived fatty acids in the fish tissues across experimental treatments (Wilks' Lambda $=0.430, \mathrm{~F}_{6,14}=1.051, \mathrm{P}=0.441$ ). At 6-weeks, fish reared in the 'shade only' treatments had 19\% lower abundances of MUFAs, whereas initial fish tissues were 76\% higher in PUFAs compared to experimental fish (Wilks' Lambda $\left.=0.009, \mathrm{~F}_{12,15}=5.575, \mathrm{P}=0.002\right)$. Ratios of SAFA+MUFA: PUFAs were the same for experimental fish, but were $124 \%$ higher than those of initial fish $\left(\mathrm{F}_{4,9}=12.203\right.$, $\mathrm{P}=0.002)$. At 6 weeks, 'shade only' fish had higher abundances of both DHA (60\% increase) and ARA ( $71 \%$ increase) in their tissues relative to fish in other treatments (Wilks' Lambda $=0.082, \mathrm{~F}_{9,15}=2.931, \mathrm{P}=0.033$ ). Still, initial fish tissues were $84 \%$ higher in DHA compared to the experimental treatments at week $6\left(\mathrm{~F}_{4,10}=13.148\right.$, $\mathrm{P}=0.001$ ). For a summary of results, refer to Table 4.3. For detailed periphyton results for both 3- and 6-week time periods, refer to Table S.4.3. 


\section{Testing adaptive hypotheses}

Based on $\triangle \mathrm{AICc}$ values and evidence ratios, SEMs suggested that epiphtyon was the primary food source for Sailfin Mollies in this study (Fig. 4.5; Table 4.4). In addition, Akaike weights for the alternative models ('epiphyton + periphyton' and 'periphyton only') suggest that the best-fit model is 3x more likely than the others. Path coefficients for the linkages between periphyton and fish life history were negative in all models, and those between epiphyton and life history were positive in all models, suggesting that epiphyton positively influenced fish life history and periphyton did not. Based on this evidence, I concluded that epiphyton, and not periphyton, was the preferred food source for fish in this study. This information was used to inform the second group of structural equation models that were designed to test the Heterotroph Facilitation and Lipid Allocation hypotheses.

To test the alternative hypotheses, I varied the paths between diet metrics (A:H biovolume, the percentage of bacterial-derived fatty acids, SAFA+MUFA:PUFA ratio) and fish life history to produce 7 models for each time period, and an additional set of models that linked 3-week epiphyton characteristics to 6-week fish. Based on $\triangle \mathrm{AICc}$ values and evidence ratios, the best fit model suggests that all 3 diet metrics influence fish life history at 3 weeks. There are several equally supported models (Table 4.5), but based on the path coefficients, they all suggest that fish life history trait values increase in proportion to A:H biovolume ratio. Path coefficients also show that fish size and survival decrease with increasing bacterial fatty acid percentage and SAFA+MUFA:PUFA ratio at 3 weeks (Fig. 4.6). 
According to their evidence ratios, these supported models are between 3-6x more likely than those with poor fit $(\triangle \mathrm{AICc}>2.00)$. However, at 6 weeks, 'A:H + Bac. FA \%', 'Bac. FA \% + FA ratio' and 'Bac. FA \%' models were the best supported based on $\triangle \mathrm{AICc}$ values. Evidence ratios and path coefficients suggest that bacterial fatty acid percentage alone predicts fish life history $3 \mathrm{x}$ better than the other supported models, and 3-9x better than the models with no support (Fig. 4.7; Table 4.5). Models comparing 3-week diets to diets of 6-week fish, have similar support as 6-week models, and also suggest that increased bacterial fatty acid percentage best predicted fish life history. (Fig. 4.8; Table 4.5).

\section{Discussion}

I found evidence that detritivory facilitates herbivory, supporting the suggestion that "true" herbivory is rare in nature (White 1985). This study indicated that herbivorous Sailfin Mollies benefit from a diet supplemented with heterotrophic microbes, consistent with the Heterotroph Facilitation hypothesis. In this experiment, increased algal biovolume, increased proportion of monounsaturated fatty acids, and decreased percentage of bacterial fatty acids in the diet best predicted early Sailfin Molly life history (6-9 weeks of age). However, later in development (9-12 weeks of age), cages with high heterotroph fatty acid production yielded the highest juvenile survival. These results indicate that prior to maturation, Sailfin Mollies benefit from a mixed diet of autotrophic and heterotrophic food sources. The Lipid Allocation hypothesis focuses on algal-derived lipids as the main driver of herbivore success, and was therefore not supported in this study. 
Rather, I show that heterotrophs supplement algal diets, and the quality (e.g. fatty acid abundance) of these microbes strongly influences herbivore life history by increasing survival by up to $53 \%$. However, because Sailfin Mollies did not reach sexual maturity at the end of this experiment, I am unable to determine any potential trade-offs between survival and reproductive output, or if heterotrophic bacteria are important in the reproductive phase. Furthermore, these findings do not explain why herbivory exists as an alternative to a carnivorous diet, although I do provide a justification for how herbivory is sustained in a natural setting. Finally, these findings confirm that "herbivory" in aquatic systems may routinely include detritivory and that 'green' food webs may be less common than thought (Moore et al. 2004).

Although some authors have examined the influence of dietary heterotrophs on herbivore life history (e.g. Bowen, 1984; Smoot \& Findlay, 2010; Belicka et al., 2012), it is not typically recognized as a fundamental part of the herbivorous diet (White, 1985). Many studies have assessed diet quality effects on life history using stoichiometry, polyunsaturated fatty acids, or indices like algal edibility, but, these diet measures were not retained in the model that best fit these data. The ecological stoichiometry literature assumes that diets with lower C:P ratios are the highest quality for consumers, and consumer tissues will reflect these diets by having high C:P levels (Sterner \& Elser, 2002). This was not the case in this study as fish with the highest survival ('shade only') were consuming epiphyton with high $\mathrm{C}: \mathrm{P}$ ratios and had tissues with low $\mathrm{C}: \mathrm{P}$ ratios, although $\mathrm{P}$ did not appear to be limiting in the diet of fish in the field cages. 
This finding was not surprising because animals catabolize and metabolize molecules, not individual elements (Raubenheimer et al. 2009; Sperfeld et al. 2017). The nutritional ecology literature suggests that food items with high PUFA content are of higher quality (e.g. Müller-Navarra et al., 2004; Persson \& Vrede, 2006), but I show that the highest surviving fish ('shade only') consumed epiphyton with low SAFA+MUFA: PUFA ratios, similar to 'light only' fish who showed relatively low survival. Edibility indices have also been used as a simple measure of food quality (e.g. Geddes \& Trexler, 2003; Trexler et al., 2015), where higher proportion of green algae and diatoms relative to cyanobacteria indicates a higher quality food source (Lamberti, 1996; Steinman, 1996; Sullivan \& Currin, 2000). In this study, fish with high survival ('shade only') were in cages with epiphyton with relatively high abundances of both filamentous and coccoid cyanobacteria. However, Ivlev's Electivity index showed that fish were feeding selectively on higher quality food items when they were not abundant in the environment. This suggests that estimations of food quality that are derived from edibility indices are compromised by feeding strategies, and are thus not reliable indicators of food quality. If this study had been conducted with a higher density of fish, increasing competition and precluding selective feeding, these results may have differed. The density used was reflective of ambient densities in the study area.

While this study did not find support for the Lipid Allocation hypothesis, algalderived fatty acids are important to herbivores. Fatty acids originating from primary producers fuel growth, survival and reproduction of herbivores. 
However, these results emphasize that life history characteristics are optimized when these diets are supplemented with heterotrophs (e.g. Martin-Creuzburg, Wacker \& von Elert, 2005; Martin-Creuzburg, Beck \& Freese, 2011). I found that diets with high levels of both bacterial-derived fatty acids and PUFAs (e.g. 'shade + P' epiphyton) were suboptimal for herbivore survival. Similarly, diets with intermediate levels of PUFAs, and decreased bacterial-derived fatty acids (e.g. 'light only'), or diets with decreased levels of both fatty acid types (e.g. 'light + P') are not ideal for herbivores. Diets with intermediate levels of PUFAs (e.g. 'shade only') were the best available diets in this study, providing evidence that detritivory represents an important part of the herbivorous diet as predicted by the Heterotroph Facilitation hypothesis.

I began this research to explore the conditions that would favor the evolution of an herbivorous diet from a carnivorous or omnivorous one. This study suggests that including heterotrophic microbes in the diet can compensate for the generally poor quality of aquatic plant foods. However, this study does not address how other nutritional components (e.g., macronutrients, algal starch, etc.) may have changed in response to the experimental manipulations, or their interactive effects on herbivore life history. Furthermore, I am unable to conclude why carnivory would be largely abandoned in herbivore-detritivores like Sailfin Mollies. Other adaptive hypotheses outlined by Sanchez \& Trexler (2016) may fill this gap. For example, ancestral herbivores may have invaded habitats with few predators and animal prey, but high in microbial and autotrophic biofilms. 
Because the mechanisms supporting the evolution of herbivory remain unknown, I hope this study is a step in establishing a research framework that will allow us to more fully understand herbivory from an adaptation perspective.

\section{Acknowledgements}

Animal use was approved by the Institutional Animal Care and Use Committee under protocol number IACUC-16-017 and was funded by NSF (Grant No. DEB-1237517).

\section{References}

Anderson, D., and Burnham, K. (2002). Avoiding Pitfalls When Using InformationTheoretic Methods. The Journal of Wildlife Management, 66(3), 912-918. doi: $10.2307 / 3803155$

Andrade, H. T. A., R. S. S. Nascimento, H. C. B. Gurel and J. F. Medeiros. (2000) Simuliidae (Diptera) in the diet of Poecilia vivipara Block \& Schneider, 1801 (Atheriniformes; Poecilidae) at the Ceará-Mirim river, state of Rio Grande do Norte, Brazil. Entomologia y Vectores, 7 (1), 119-122.

Arbuckle, J. L. (2014). Amos (Version 23.0) [Computer Program]. Chicago: IBM SPSS.

Belicka, L.L., Sokol, E.R., Hoch, J.M., Jaffe, R. and J. C. Trexler. (2012) A molecular and stable isotopic approach to investigate algal and detrital energy pathways in a freshwater marsh. Wetlands, 32,531-542.

Bellwood, D. R. (1995) Direct estimate of bioerosion by parrotfish species, Chlorurus gibbus and C. sordidus, on the Great Barrier Reef, Australia. Marine Biology, 121,419-29.

Bellwood, D. R. (2003) Origins and escalation of herbivory in fishes: a functional perspective. Paleobiology, 29(1),71-83.

Bellwood, D.R., Goatley, C.H.R., Brandl, S.J, and O. Bellwood (2014) Fifty million years of herbivory on coral reefs: fossils, fish and functional innovations. Proceedings of the Royal Society B, 281, 2013-3046.

Bowen, S. (1984) Evidence of a detritus food-chain based on consumption of organic precipitates. Bulletin of Marine Science, 35,440-448. 
Browder, J. A., P. J. Gleason, and D. R. Swift. (1994). Periphyton in the Everglades: Spatial variation, environmental correlates, and ecological implications, pp. 379418. In S. M. Davis and J. C. Ogden. Everglades. The Ecosystem and Its Restoration. St. Lucie Press, Boca Raton, FL.

Bruggemann, J. H.,J. Begeman, E. M. Bosma, P. Verburg, and A. M. Breeman. (1994) Foraging by the stoplight parrotfish Sparisoma viride. II.Intake and assimilation of food, protein and energy. Marine Ecology Progress Series, 106,57-71.

Model Selection and Multimodel Inference: a practical information-theoretic approach, 2nd edition, 2002, (eds. Burnham, K. P., and D. R. Anderson). Springer-Verlag, New York.

The Digestive System in Mammals: Food, Form and Function, 1994, (eds. Chivers, D. J., and P. Langer). Cambridge Univ. Press, Cambridge.

Choat, J.H., and Clements, K.D (1998) Vertebrate herbivores in marine and terrestrial environments: A nutritional ecology perspective. Annual Review of Ecology and Systematics, 29,375-403.

Coll, M. and Guershon, M. (2002) Omnivory in terrestrial arthropods: Mixing plant and prey diets. Annual Review of Entomology, 47, 267-297.

deMaintenon, M. J. (1999) Phylogenetic analysis of the Columbellidae (Mollusca: Neogastropoda) and the evolution of herbivory from carnivory. Invertebrate Biology, 118(3),258-288.

Diehl, S. (2003) The evolution and maintenance of omnivory: Dynamic constraints and the role of food quality. Ecology, 84(10), 2557-2567.

Edwards, R. T. and J. L. Meyer. (1990) Bacterivory by deposit-feeding mayfly larvae (Stenonema spp.). Freshwater Biology, 24,453-462.

Espinoza, R.E., J. J. Wiens, and C. R. Tracy. (2004) Recurrent evolution of herbivory in small, cold-climate lizards: Breaking the ecophysiological rules of reptilian herbivory. Proceedings of the National Academy of Science, 101(48),1681916824.

Eubanks, M.D., Styrsky, J.D., and Denno, R.F. (2003) The evolution of omnivory in heteropteran insects. Ecology, 84(10),2549-2556.

Fuller, R. L., T. J. Fry and J. A. Roelofs. (1988) Influence of different food types on the growth of Simulium vittatum (Diptera) and Hydropsyche betteni (Tricoptera). Journal of the North American Benthological Society, 7,197-204. 
Fuller, R. L., and T. J. Fry. (1991) The influence of temperature and food quality on the growth of Hydropsyche betteni (Tricoptera) and Simulium vittatum (Diptera). Journal of Freshwater Ecology, 6,75-86.

Fuller, R. L., B. P. Kennedy, and C. Nielsen. (2004) Macroinvertebrate responses to algal and bacterial manipulations in streams. Hydrobiologia, 523,113-126.

Gaiser, E. E., L. J. Scinto, J. H. Richards, K. Jayachandran, D. L. Childers, J. C. Trexler and R. D. Jones. (2004) Phosphorus in periphyton mats provides best metric for detecting low level $\mathrm{P}$ enrichment in an oligotrophic wetland. Water Research, 38, 507-516.

Gaiser, E. E., J. C. Trexler, J. H. Richards, D. L. Childers, D. Lee, A. I. Edwards, L. J. Scinto, K. Jayachandran, G. B. Noe and R. D. Jones. (2005) Cascading ecological effects of low- level phosphorus enrichments in the Florida Everglades. Journal of Environmental Quality, 34, 717-723.

Geddes, P. and J.C. Trexler. (2003) Uncoupling of omnivore-mediated positive and negative effects on periphyton mats. Oecologia, 136,585-595.

Gottlieb, A. D., E. E. Gaiser, and S. S. Lee. (2015) Changes in hydrology, nutrient loading, and conductivity in the Florida Everglades, and concurrent effects on periphyton community structure and function, pp 131-154. In J. A. Entry, A. D. Gottlieb, K. Jayachandran, and A. Ogram. Microbiology of the Everglades Ecosystem. CRC Press, Boca Raton, FL.

Goulden, C.E., Henry, L.L and Tessier, A.J. (1982) Body size, energy reserves, and competitive ability in three species of cladocera. Ecology, 63(6), 1780-1789.

Grace, J. B. 2006. Structural Equation Modelling and Natural Systems. Cambridge University Press, Cambridge, UK.

Hall, R. O., G. E. Likens, and H. M. Malcolm. (2001) Trophic basis of invertebrate production in 2 streams at the Hubbard Brook Experimental Forest. Journal of the North American Benthological Society, 20,432-447.

Hobbie, J. E., R. J. Daley, and S. Jasper (1977) The use of Nuclepore filters for counting bacteria by fluorescence microscopy. Applied and Environmental Microbiology, 33,1225-1228.

Horn, M. H. (1989). Biology of Marine Herbivorous Fishes. Oceanography and Marine Biology Annual Review, 27, 167-272.

Ivlev, V. S. (1961). Experimental Ecology of the Feeding of Fishes. Yale University Press, New Haven. 
Karban, R., and A. A. Agrawal. (2002) Herbivore offense. Annual Review of Ecology, Evolution and Systematics, 33, 641-664.

Lamberti, G.A. (1996) The role of periphyton in benthic food webs. Algal Ecology (eds. Stevenson, R. J., Bothwell, M. L., and R.L. Lowe)., pp 553-564. Academic Press, San Diego.

Loftus, W. F. (2000) Accumulation and fate of mercury in an Everglades aquatic food web. Dissertation, Florida International University. Miami, FL.

Martin-Creuzburg, D., Beck, B., and H. M. Freese. (2011) Food quality of heterotrophic bacteria for Daphnia magna: evidence for a limitation by sterols. FEMS Microbiology Ecology, 76, 592-601.

Martin-Creuzburg, D., A. Wacker, and E. von Elert. (2005) Life history consequences of sterol availability in the aquatic keystone species Daphnia. Oecologia, 144, 362372.

Martin-Creuzburg, D., E. von Elert, and K. H. Hoffman. (2008) Nutritional constraints at the cyanobacteria-Daphnia magna interface: The role of sterols. Limnology and Oceanography, 53(2), 456-468.

Mattson, W.J. Jr. (1980) Herbivory in relation to plant nitrogen content. Annual Review of Ecology and Systematics, 11,119-161.McCune, B., and J. B. Grace. 2002. Analysis of Ecological Communities. MJM Software Design, Gleneden Beach, OR.

McCormick, P. V., and M. B. O’Dell. (1996) Quantifying periphyton responses to phosphorus in the Florida Everglades: A Synoptic-Experimental Approach. Journal of the North American Benthological Society, 15(4), 450-468.

McCormick, P. V., P. S. Rawlik, L. Lurding, E. P. Smith, and F. H. Sklar. (1996) Periphyton-water quality relationships along a nutrient gradient in the northern Florida Everglades. Journal of the North American Benthological Society, 15(4), 433-449.

Moore, J. C., E. L. Berlow, D. C. Coleman, P. C. de Ruiter, Q. Dong, A. Hastings, N. C. Johnson, K. S. McCann, K.K. Melville, P. J. Morin, K. Nadelhoffer, A. D., Rosemond, D. Mulla, M. S., and L. A. Lacey. (1976) Feeding rates of Simulium larvae on particulates in natural streams (Diptera: Simuliidae). Environmental Entomology, 5, 283-287.

Müller-Navarra D.C., M. T. Brett, S. Park, S. Chandra, A.P. Ballantyne, E. Zorita, and C. R. Goldman. (2004) Unsaturated fatty acid content in seston and trophodynamic coupling in lakes. Nature, 427, 69-72. 
Noe, G. B., Childers, D. L., and Jones, R. D. (2001) Phosphorus biogeochemistry and the impact of phosphorus enrichment: Why is the Everglades so unique? Ecosystems, 4,603-624.

Noe, G. B., Scinto, L. J., Taylor, J., Childers, D. L., and Jones, R. D. (2003) Phosphorus cycling and partitioning in an oligotrophic Everglades wetland ecosystem: a radioisotope tracing study. Freshwater Biology, 48, 1993-2008.

Pan, Y., Stevenson, R. J., Vaithiyanathan, P., Slate, J., and Richardson, C. J. (2000) Changes in algal assemblages along observed and experimental phosphorus gradients in a subtropical wetland, USA. Freshwater Biology, 44,339-353.

Pauls, S. U., Graf, W., Haase, P., Lumbsch, H. T., and Waringer, J. (2008) Grazers, shredder and filtering carnivores- The evolution of feeding ecology in Drusinae (Trichoptera: Limnephilidae): Insights from a molecular phylogeny. Molecular Phylogenetics and Evolution, 46,776-791.

Persson, J., and Vrede, T. (2006). Polyunsaturated fatty acids in zooplankton: variation due to taxonomy and trophic position. Freshwater Biology, 51, 887-900.

Pike, T. W., Blout, J. D., Bjerkeng, B., Lindstrom, J., and Metcalfe, N. B. (2007). Proceedings of the Royal Soeciety B, 274(1618), 1591-1596.

Porter, K. G., and McDonough, R. (1984) The energetic cost of response to blue-green algal filaments by cladocerans. Limnology and Oceanography, 29,365-369.

Post, M., Sabo, J. L., Scow, K. M., Vanni, M. J. and Wall, D. H. (2004) Detritus, trophic dynamics and biodiversity. Ecology Letters, 7, 584-600.

Raubenheimer, D., Simpson, S. J., and Mayntz, D. (2009) Nutrition, ecology and nutritional ecology: toward an integrated framework. Functional Ecology, 23(1), 4-16.

Reisz, R. R., and Frobisch, J. (2014) The Oldest Caseid Synapsid from the Late Pennsylvanian of Kansas, and the Evolution of Herbivory in Terrestrial Vertebrates. PLoS ONE, 9(4), e94518. doi:10.1371/journal.pone.0094518

Saikia, S. K., and Nandi, S. (2010). C and P in aquatic food chain: A review on C:P stoichiometry and PUFA regulation. Knowledge and Management of Aquatic Ecosystems, 398 (2010), 10.1051/kmae/2010024.

Sanchez, J. L., and Trexler, J. C. (2016) The adaptive evolution of herbivory in freshwater systems. Ecosphere, 7(7), e01414. 10.1002/ecs2.1414. 
Schmidt, K. and Jonasdottir, S.H. (1997) Nutritional quality of two cyanobacteria: How rich is 'poor' food? Marine Ecology Progress Series, 151, 1-10.

Smoot, J.C. and Findlay, R. H. (2010) Caloric needs of a detritivorous gizzard shad Dorosoma cepedianum are met with sediment bacterial and algal biomass. Aquatic Biology, 8,105-114.

Snelson, F. F., Jr. (1982) Indeterminate growth in males of the sailfin molly, Poecilia latipinna. Copeia, 1982,296-304.

Snelson, F. F., Jr. (1989) Social and environmental control of life history traits in Poeciliid fishes. Ecology and Evolution of Livebearing Fishes (Poeciliidae) (eds. Meffe, G. K., and F. F. Snelson, Jr.), pp 149-161. Prentice Hall, Englewood Cliffs.

Sperfeld, E., Wagner, N. D., Halvorson, H. M., Malishev, M., \& Raubenheimer, D. (2017). Bridging ecological stoichiometry and nutritional geometry with homeostasis concepts and integrative models of organism nutrition. Functional Ecology, 31(2), 286-296.

Ecological stoichiometry, 2002, (eds. Sterner, R.W. and J. J. Elser). Princeton University Press, Princeton.

Sterner, R.W. and Hessen, D.O. (1994) Algal nutrient limitation and the nutrition of aquatic herbivores. Annual Review of Ecology and Systematics, 25,1-29.

Stienman, A. D. (1996) Effects of grazers on freshwater benthic algae. Algal Ecology (eds. Stevenson, R. J., Bothwell, M. L., and R.L. Lowe), pp 341-373. Academic Press, San Diego.

Sullivan, M.J. and C.A. Currin (2000) Community structure and functional dynamics of benthic microalgae in salt marshes. Concepts and Controversies in Tidal Marsh Ecology, (eds. M.P. Weinstein and D.A. Kreeger), pp. 91-106. Kluwer Academic Publishers, South Holland.

Tessier, A.J., Henry, L.L., Goulden, C.E., and Durand, M.W. (1983) Starvation in Daphnia: Energy re- serves and reproductive allocation. Limnology and Oceanography, 28, 667-676.

Travis, J., J. A. Farr, M. McManus, and J. C. Trexler. (1989) Environmental effects on adult growth patterns in the male sailfin molly, Poecilia latipinna (Poeciliidae). Environmental Biology of Fishes, 26,119-127. 
Trexler, J. C., Gaiser, E. E., Kominoski, J., and J. L. Sanchez. (2015) The Role of Periphyton Mats in Consumer Community Structure and Function in Calcareous Wetlands: Lessons from the Everglades. Microbiology of the Everglades Ecosystem, (eds. Entry, J., Jayachandran, K., Gottlieb, A. D. and A. Ogram), pp. 155-179. CRC Press, Boca Raton.

Trexler, J. C., and J. Travis. (1990) Phenotypic plasticity in the Sailfin Molly, Poecilia latipinna (Pisces: Poeciliidae). I. Field experiments. Evolution, 44(1), 143-156.

Tobler, M. (2008). Divergence in trophic ecology characterizes colonization of extreme habitats. Biological Journal of the Linnean Society, 95, 517-528.

Van Damme, R. (1999) Evolution of herbivory in Lacertid lizards: Effects of insularity and body size. Journal of Herpetology, 33(4), 663-674.

Vermeij, G. (1992) Time of origin and biogeographical history of specialized relationships between Northern marine plants and herbivorous mollusks. Evolution, 46(3), 657-664.

Vermeij, G., and D. R. Lindberg. (2000) Delayed herbivory and the assembly of marine benthic ecosystems. Paleobiology, 26(3), 419-430.

Wanchoo, A., M. W. Lewis, and N. O. Keyhani (2009) Lectin mapping reveals stagespecific display of surface carbohydrates in in vitro and haemolymph-derived cells of the entomopathogenic fungus Beauveria bassiana. Microbiology, 155, 3121-3133.

Weers, P.M.M. and Gulati, R.D. (1997) Growth and reproduction of Daphnia galeata in resposnse to changes in fatty acids, phosphorus, and nitrogen in Chlamydomonas reinhardtii. Limnology and Oceanography, 42(7), 1584-1589.

White, T. C. R. (1985) When is a herbivore not a herbivore? Oecologia (Berlin), 67, 596597. 
Table 4.1. Sources of fatty acid tracers used in this study (modified from Belicka et al. 2012).

\section{Carbon Source (grouped by fatty acids used in this References study)}

Bacteria (15:0i, 15:0a, 15:0n, 17:0i, 17:0a, 17:0n, 18:1w7, 19:1)

Odd carbon number fatty acids, 15:0i, 15:0a, 17:0i, $\quad$ Findlay and Dobbs (1993); Napolitano (1999) 17:0a, 18:1w7 and references therein; Volkman et al. (1980)

\begin{tabular}{|c|c|}
\hline \multicolumn{2}{|c|}{ Algae $(16: 3,18: 3 w 3,18: 4,18: 3 w 6,20: 4 w 6,20: 5 w 3$ (EPA), 20:4, 22:4w6, 22:5w3, 22:5w6, 22:6w3) } \\
\hline $\begin{array}{l}\text { 14:0, 16:1w7: multiple sources, but high in diatoms } \\
\text { and some cyanobacteria }\end{array}$ & Napolitano (1999) and references therein \\
\hline $\mathrm{C}_{16}$ PUFA: green algae and diatoms & $\begin{array}{l}\text { Kates and Volcani (1966); Cranwell et al. } \\
\text { (1990); Napolitano (1999) }\end{array}$ \\
\hline 18:3w3: green algae, cyanobacteria & $\begin{array}{l}\text { Ahlgren et al. (1992); Dalsgaard et al. } \\
\text { (2003) }\end{array}$ \\
\hline 18:3w6: cyanobacteria & Napolitano (1999) \\
\hline 18:4w3, 18:5w3, 22:6w3: dinoflagellates & $\begin{array}{l}\text { Ahlgren et al. (1992); Dalsgaard et al. } \\
\text { (2003) }\end{array}$ \\
\hline $20: 5 w 3$, ratio of $20: 5 w 3$ to $22: 6 w 3:$ diatoms & Napolitano (1999); Dalsgaard et al. (2003) \\
\hline
\end{tabular}




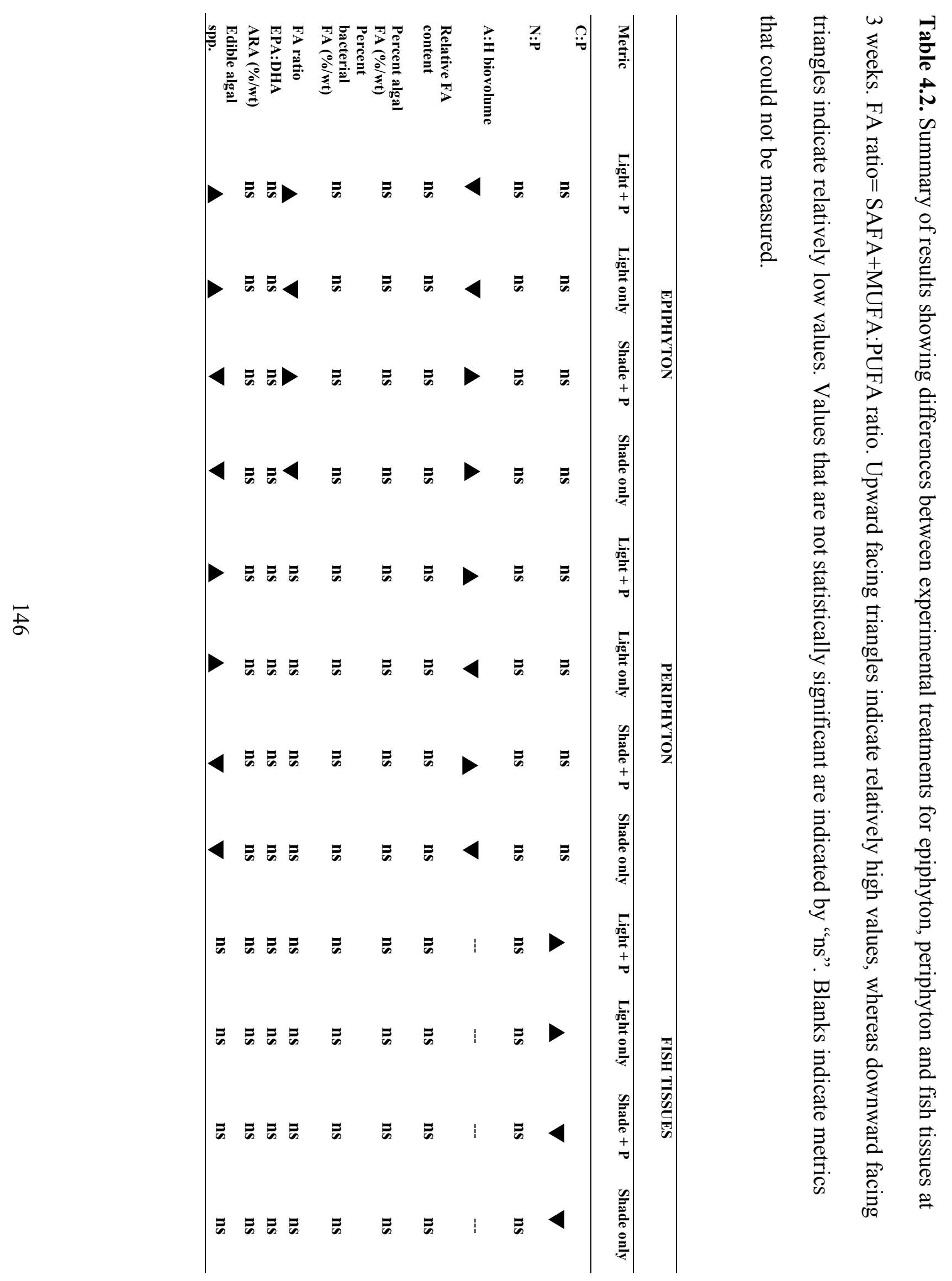




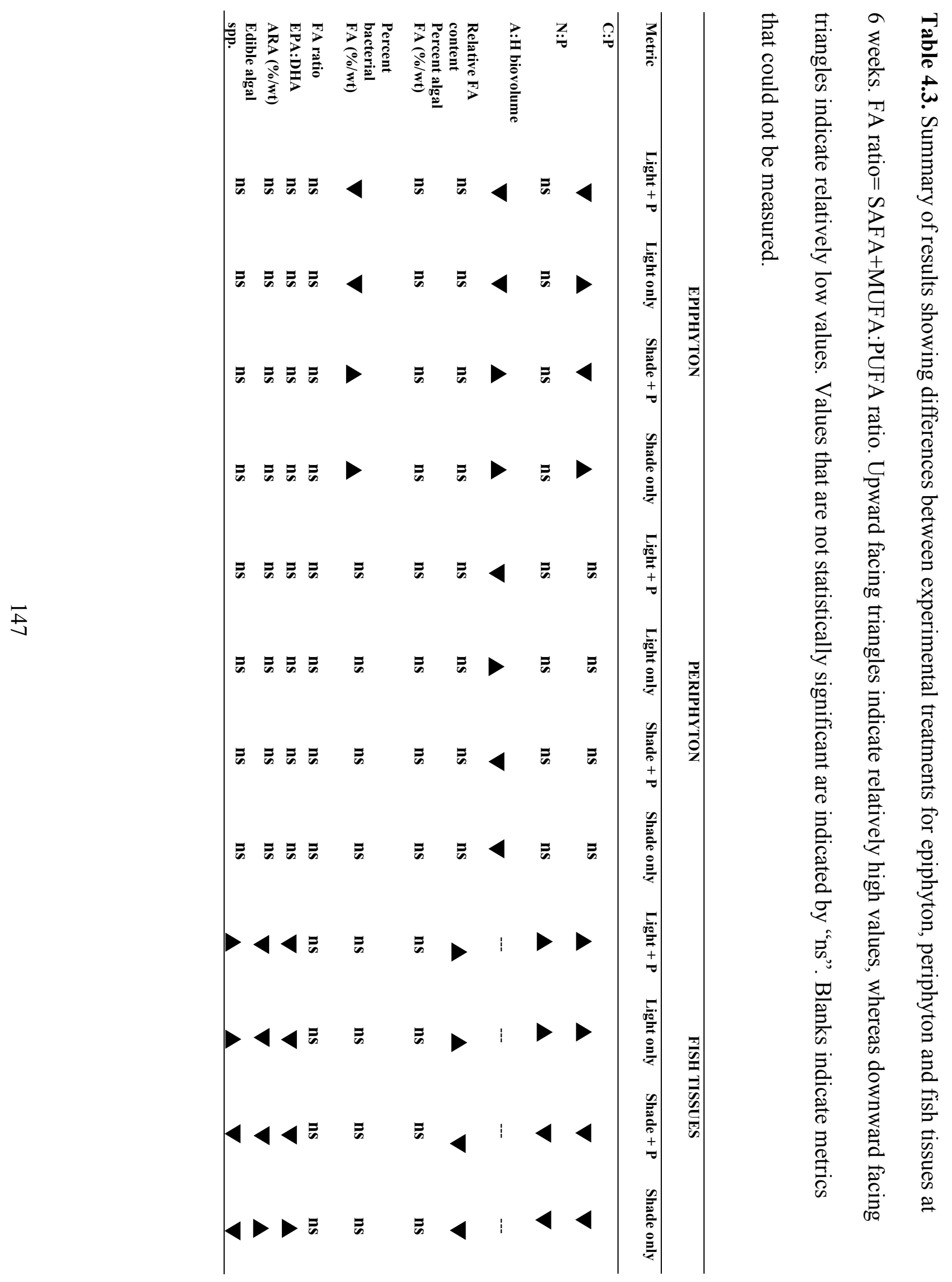


Table 4.4. Comparison of structural equation models used to predict diet type (epiphyton vs. periphyton). $\mathrm{AIC}_{\mathrm{w}}=$ Akaike weights, $w_{\min } / w_{j}=$ Evidence ratios. $\Delta \mathrm{AICc}$ values $\leq 2$ are highlighted in bold.

\begin{tabular}{lllll}
\hline Model & Description & $\Delta \mathbf{A I C c}$ & $\mathbf{A I C}_{\mathbf{w}}$ & $\boldsymbol{w}_{\boldsymbol{m i n}} / \boldsymbol{w}_{\boldsymbol{j}}$ \\
& & & & \\
\hline 1 & Epiphyton + Periphyton & 2.19 & 0.20 & 0.33 \\
2 & Epiphyton & $\mathbf{0 . 0 0}$ & $\mathbf{0 . 6 1}$ & $\mathbf{1 . 0 0}$ \\
3 & Periphyton & 2.38 & 0.19 & 0.30 \\
\hline
\end{tabular}


Table 4.5. Comparison of structural equation models used to test 'Heterotrophic facilitation' and 'Lipid allocation' hypotheses. $\mathrm{A}: \mathrm{H}=\mathrm{A}: \mathrm{H}$ biovolume, Bac. $\mathrm{FA}=$ percentage of bacterial fatty acids, $\mathrm{FA}$ ratio $=\mathrm{SAFA}+\mathrm{MUFA}: \mathrm{PUFA}$ ratio. $\mathrm{AIC}_{\mathrm{w}}=$ Akaike weights, $w_{\min } / w_{j}=$ Evidence ratios. $\Delta \mathrm{AICc}$ values $\leq 2$ are highlighted in bold.

\begin{tabular}{|c|c|c|c|c|c|c|c|c|c|}
\hline & \multicolumn{3}{|c|}{3 weeks } & \multicolumn{3}{|c|}{6 weeks } & \multicolumn{3}{|c|}{$3 \rightarrow 6$ weeks } \\
\hline $\begin{array}{l}\text { Model } \\
\text { Description }\end{array}$ & $\Delta \mathrm{AICc}$ & $\mathrm{AIC}_{\mathrm{w}}$ & $w_{\min } / w_{j}$ & $\triangle \mathrm{AICc}$ & $\mathrm{AIC}_{\mathrm{w}}$ & $w_{\min } / w_{j}$ & $\triangle \mathrm{AICc}$ & $\mathbf{A I C}_{\mathbf{w}}$ & $w_{\min } / w_{j}$ \\
\hline $\begin{array}{l}\text { A:H + Bac. } \\
\text { FA+ FA ratio }\end{array}$ & 0.00 & 0.26 & 1.00 & 3.95 & 0.05 & 0.14 & 3.28 & 0.07 & 0.19 \\
\hline $\mathrm{A}: \mathrm{H}+\mathrm{Bac} . \mathrm{FA}$ & 0.32 & 0.22 & 0.85 & 1.95 & 0.15 & 0.38 & 1.91 & 0.15 & 0.38 \\
\hline $\mathrm{A}: \mathrm{H}+\mathrm{FA}$ ratio & 0.62 & 0.19 & 0.73 & 4.36 & 0.04 & 0.11 & 4.16 & 0.05 & 0.12 \\
\hline $\begin{array}{l}\text { Bac. FA + FA } \\
\text { ratio }\end{array}$ & 2.36 & 0.08 & 0.31 & 2.00 & 0.14 & 0.37 & 1.32 & 0.20 & 0.51 \\
\hline $\mathrm{A}: \mathrm{H}$ & 1.77 & 0.11 & 0.41 & 2.36 & 0.12 & 0.31 & 2.23 & 0.12 & 0.33 \\
\hline Bac. FA & 2.15 & 0.09 & 0.34 & 0.00 & 0.39 & 1.00 & 0.00 & 0.38 & 1.00 \\
\hline FA ratio & 3.73 & 0.04 & 0.15 & 2.49 & 0.11 & 0.29 & 5.15 & 0.03 & 0.08 \\
\hline
\end{tabular}




\section{Figure Legends}

Fig. 4.1. (A) Male Sailfin Molly (Poecilia latipinna). (B) Female Sailfin Molly (Poecilia latipinna). Images retrieved from the Florida Museum Ichthyology Collection, University of Florida, Gainesville, FL, (c) George Burgess.

Fig. 4.2. (A) Standard length (mm) of juvenile Sailfin Mollies raised on biofilms grown in various treatments. (B) Probability of survival (p') of juvenile Sailfin Mollies showing high survival of those grown in 'shade only' treatments.

Fig. 4.3. (A) Relative abundance of algal species comprising fish guts reared in various treatments at 3 weeks. Guts are composed of similar proportions of diet items across treatments, and are dominated by diatoms and cyanobacteria. (B) Relative abundance of algal species comprising fish guts reared in various treatments at 6 weeks. Fish guts from light treatments are composed of similar proportions of diet items, and are dominated by cyanobacteria. Those from shaded treatments also contain a high proportion of cyanobacteria, but also have higher proportions of green filamentous algal species than fish guts from the light treatments.

Fig. 4.4. (A) Ivlev's Electivity Index $\left(\mathrm{L}_{\mathrm{i}}\right)$ calculated for fish reared in various treatments at 3 weeks. All fish expect those in 'Shade $+\mathrm{P}$ ' cages are actively avoiding filamentous cyanobacteria. (B) Ivlev's Electivity Index $\left(\mathrm{L}_{\mathrm{i}}\right)$ calculated for fish reared in various treatments at 6 weeks. Fish reared in 'Light $+\mathrm{P}$ ' cages are avoiding all diet types, whereas, all other fish are only avoiding coccoid cyanobacterial species. 
Fig. 4.5. The structural equation model with the best fit showing epiphyton at 3 weeks as the best predictor of fish life history at 3 weeks. Numbers indicate regression coefficients for each path analyzed.

Fig. 4.6. The structural equation model with the best fit showing A:H biovolume, the percentage of bacterial fatty acids and the ratio of SAFA+MUFA:PUFA (FA ratio) at 3 weeks as the best predictor of fish life history at 3 weeks. Numbers indicate regression coefficients for each path analyzed.

Fig. 4.7. The structural equation model with the best fit showing 6-week bacterial fatty acid percentage as the best predictor of fish life history at 6 weeks. Numbers indicate regression coefficients for each path analyzed.

Fig. 4.8. The structural equation model with the best fit showing 3 -week bacterial fatty acids percentage as the best predictor of fish life history at 6 weeks. Numbers indicate regression coefficients for each path analyzed. 
Figure 4.1.
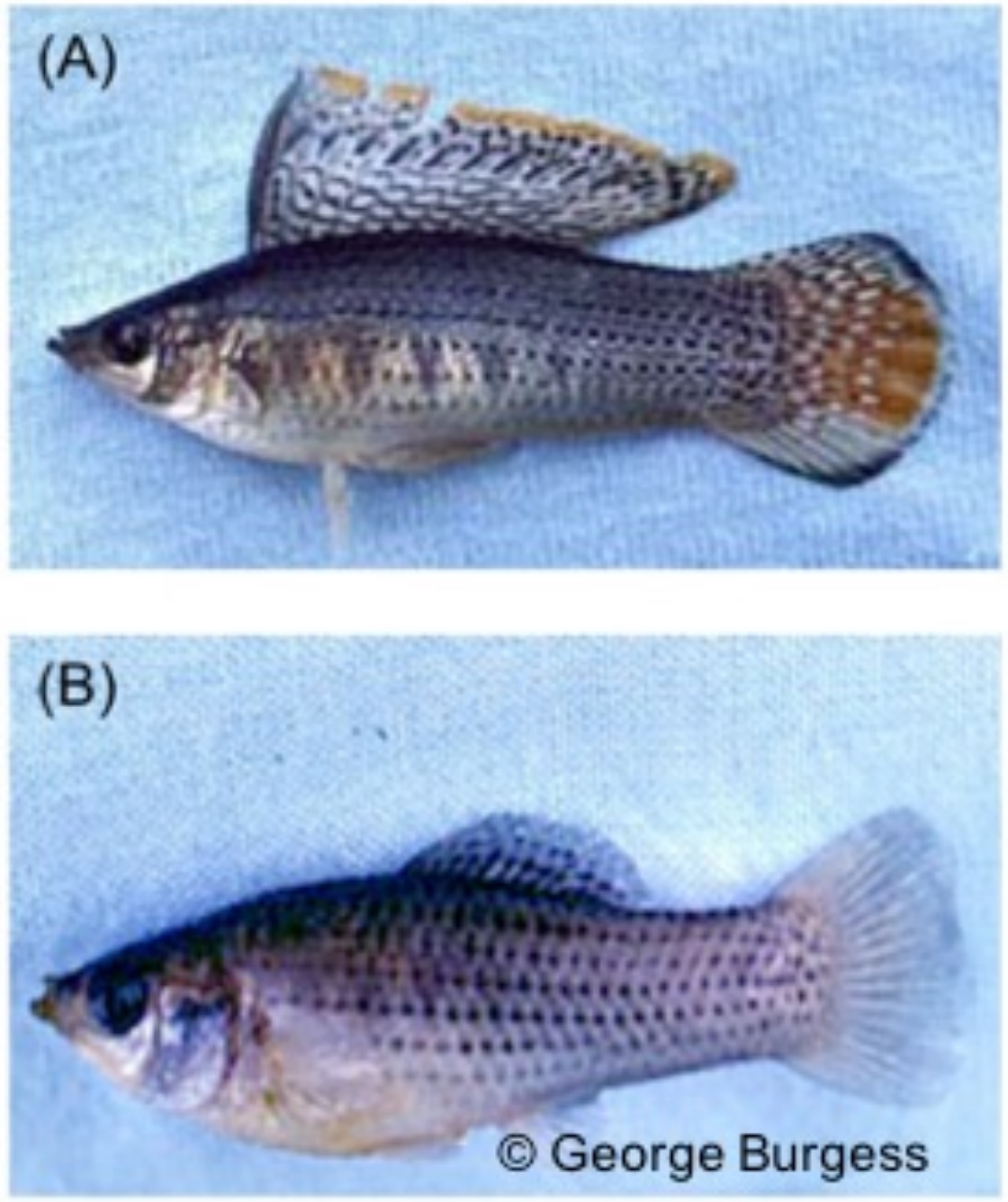
Figure 4.2.
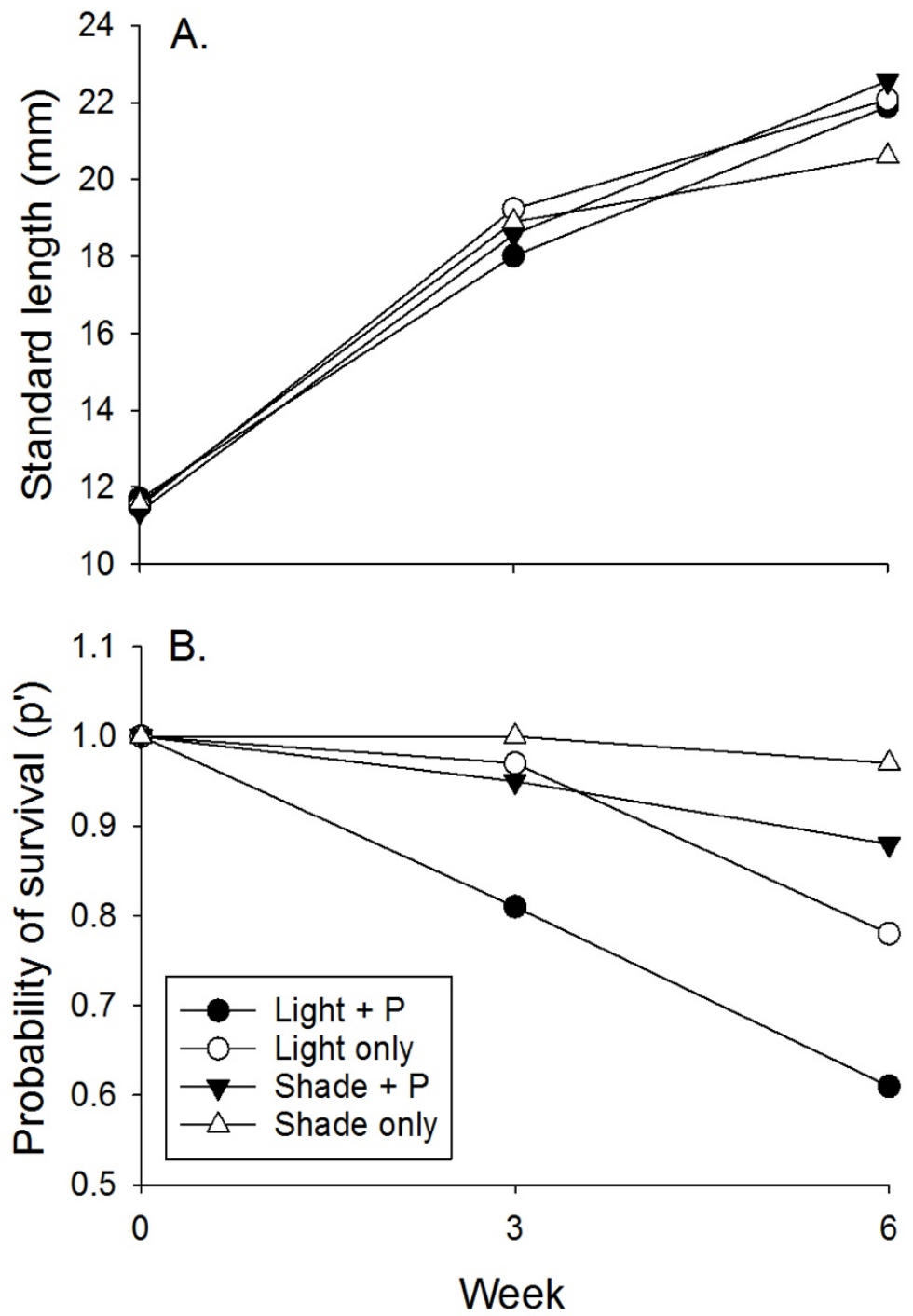
Figure 4.3.

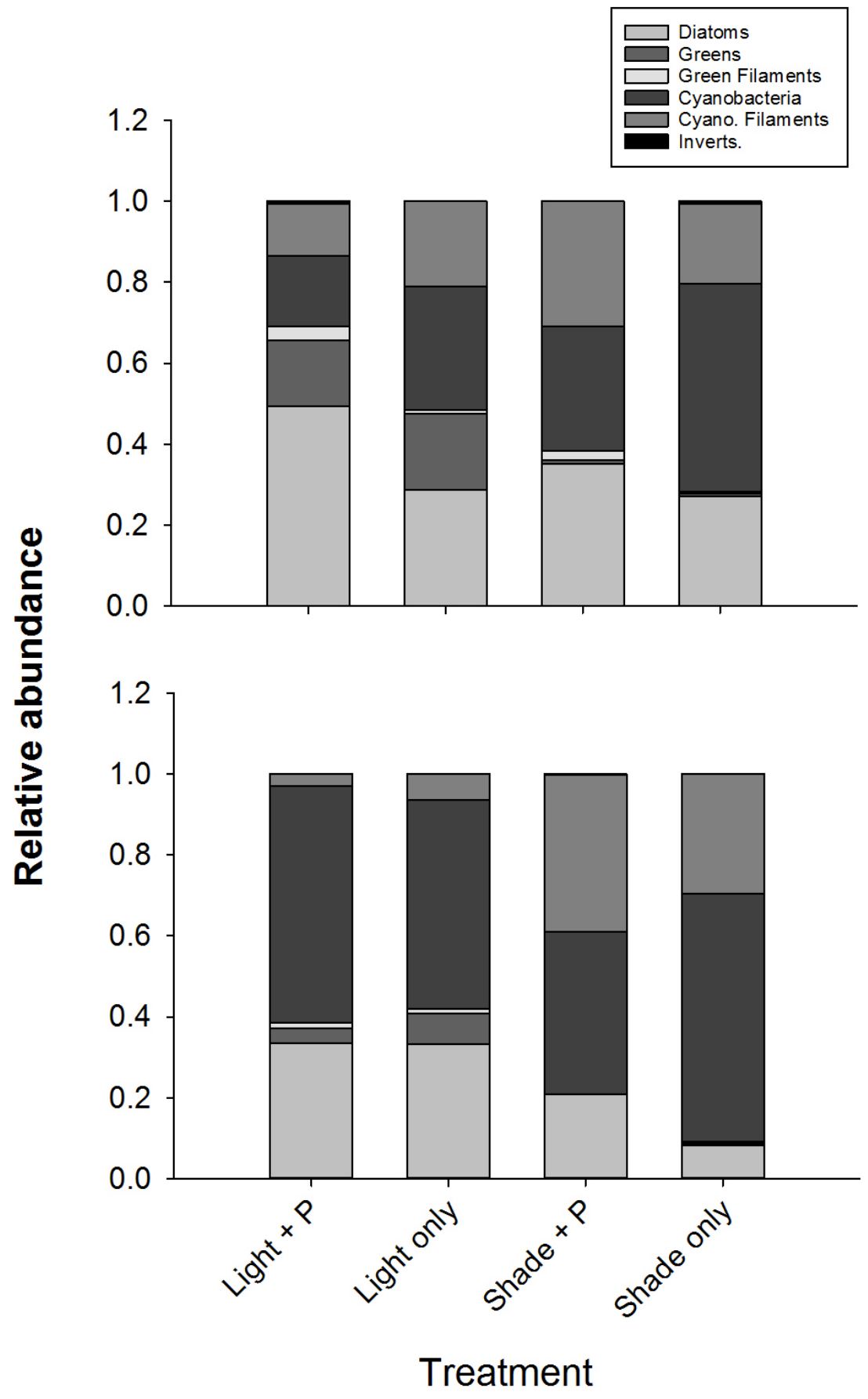


Figure 4.4.

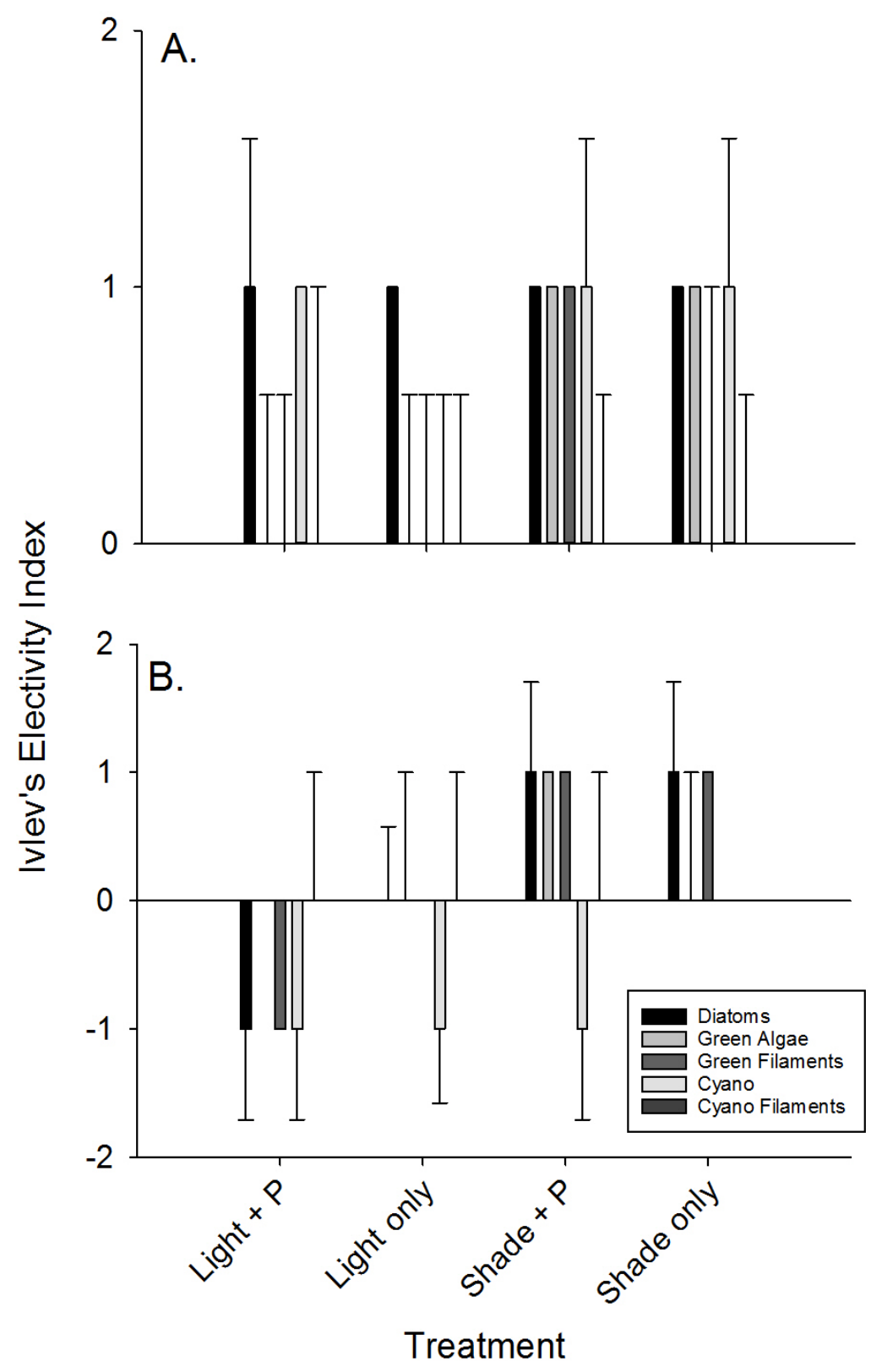


Figure 4.5.

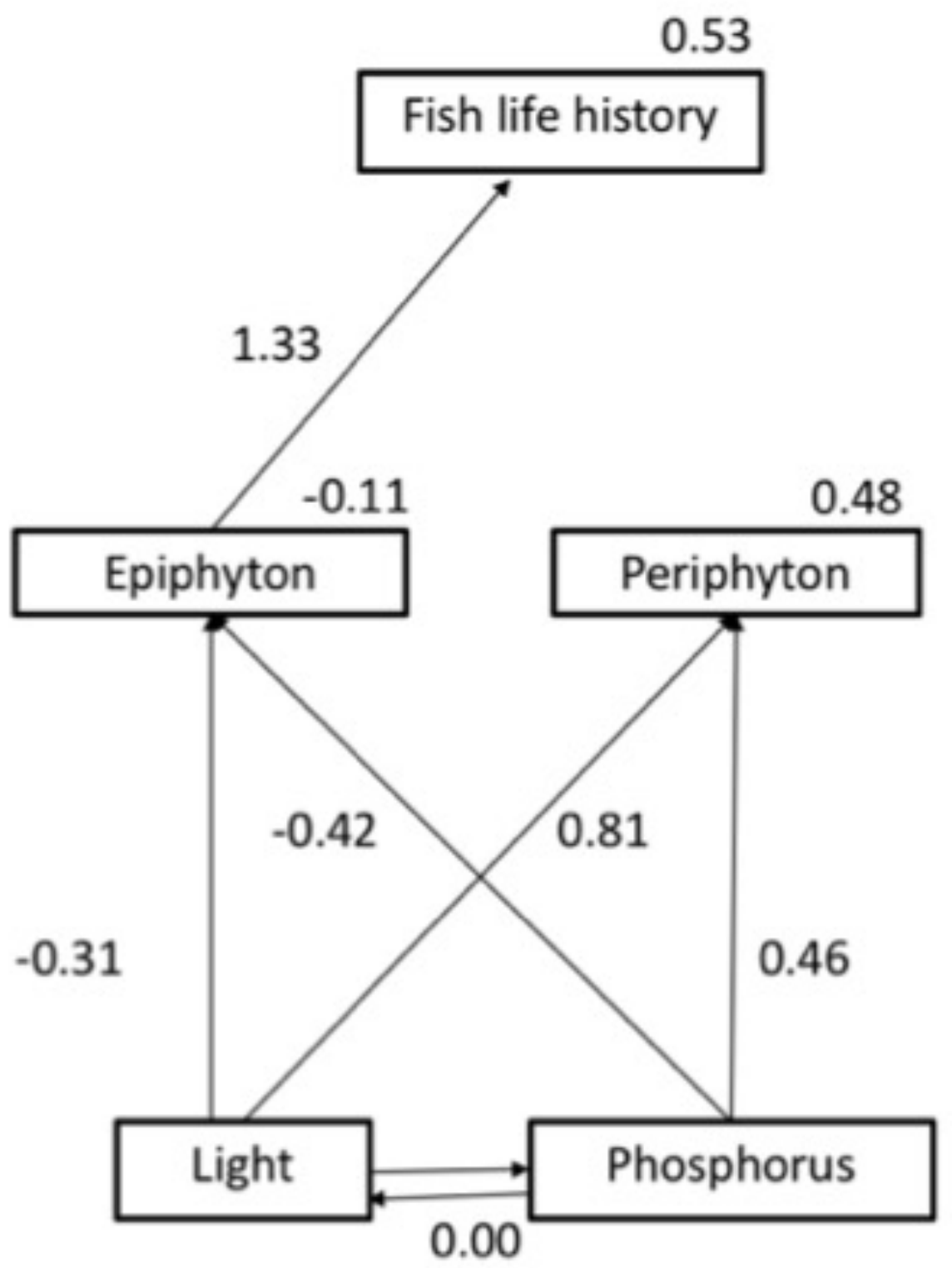


Figure 4.6.

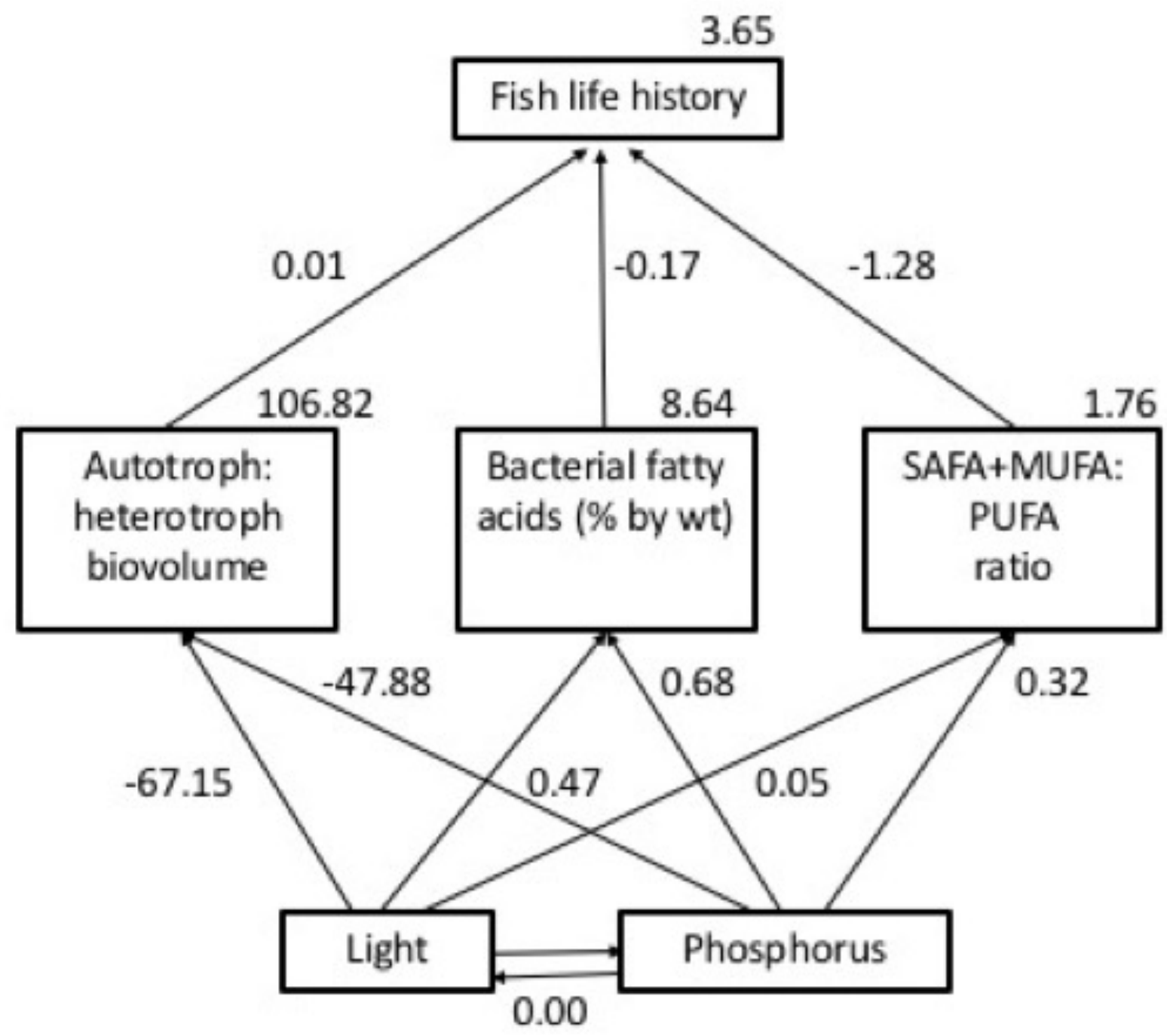


Figure 4.7.

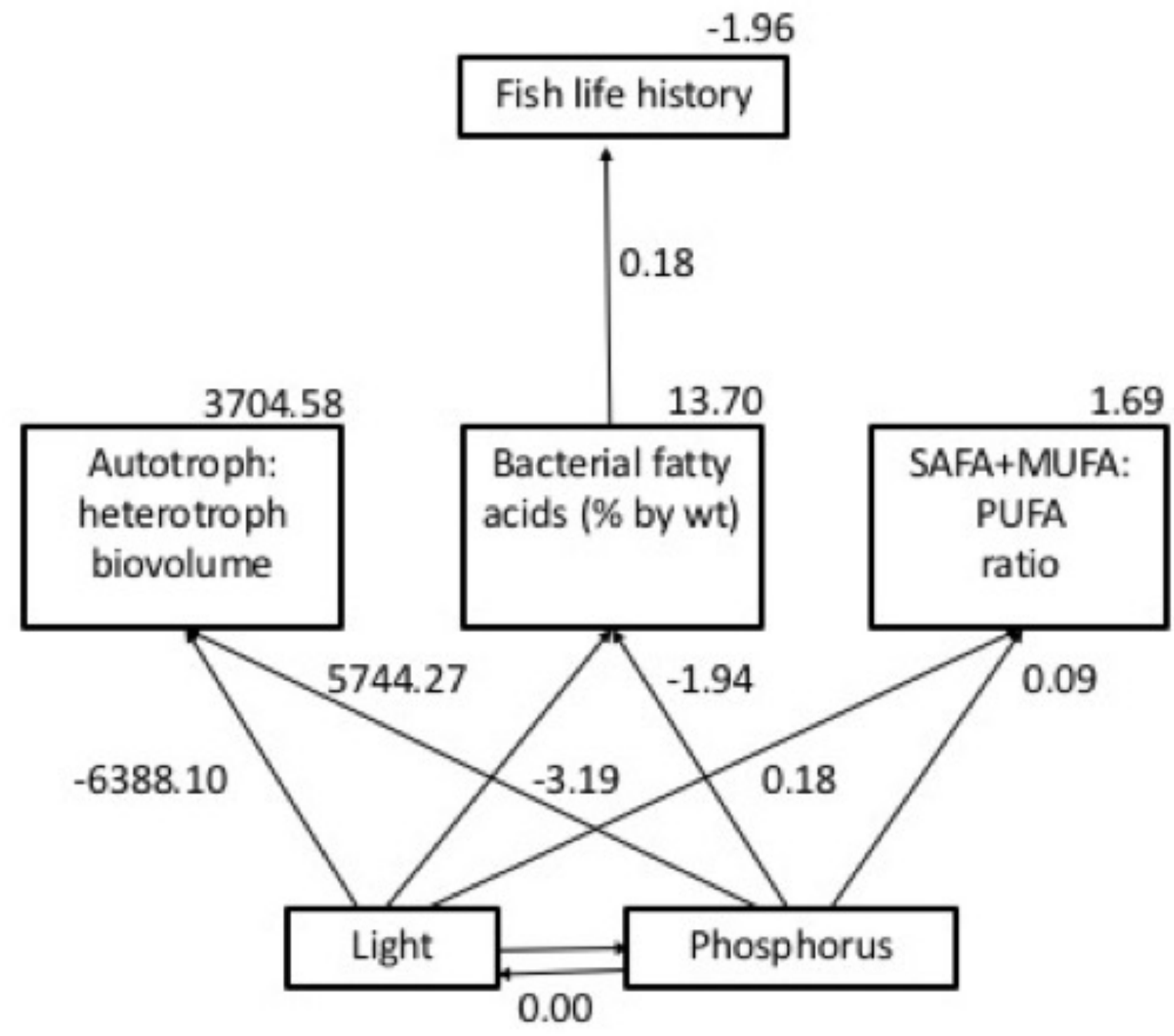


Figure 4.8.

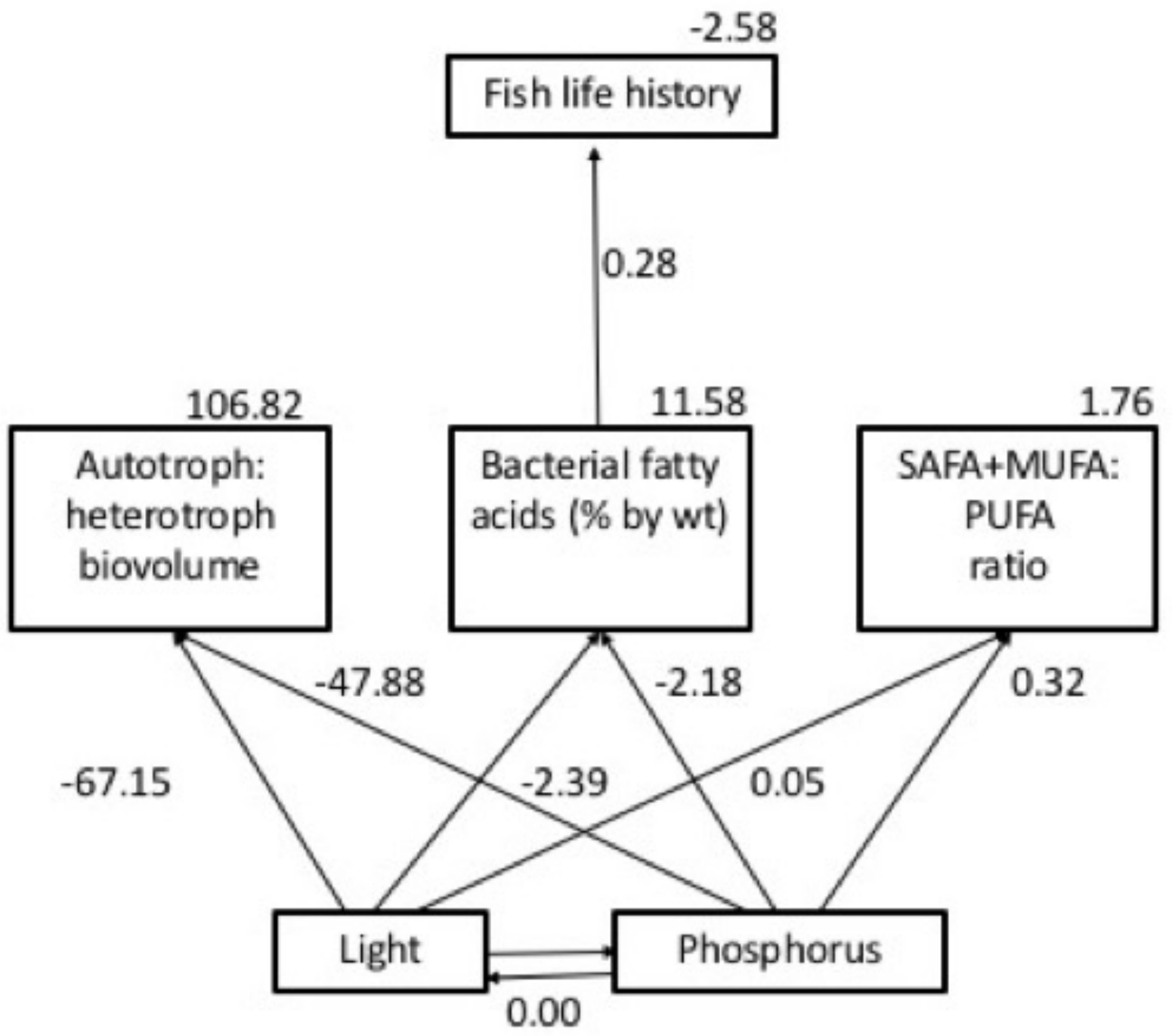


Supplementary Information 


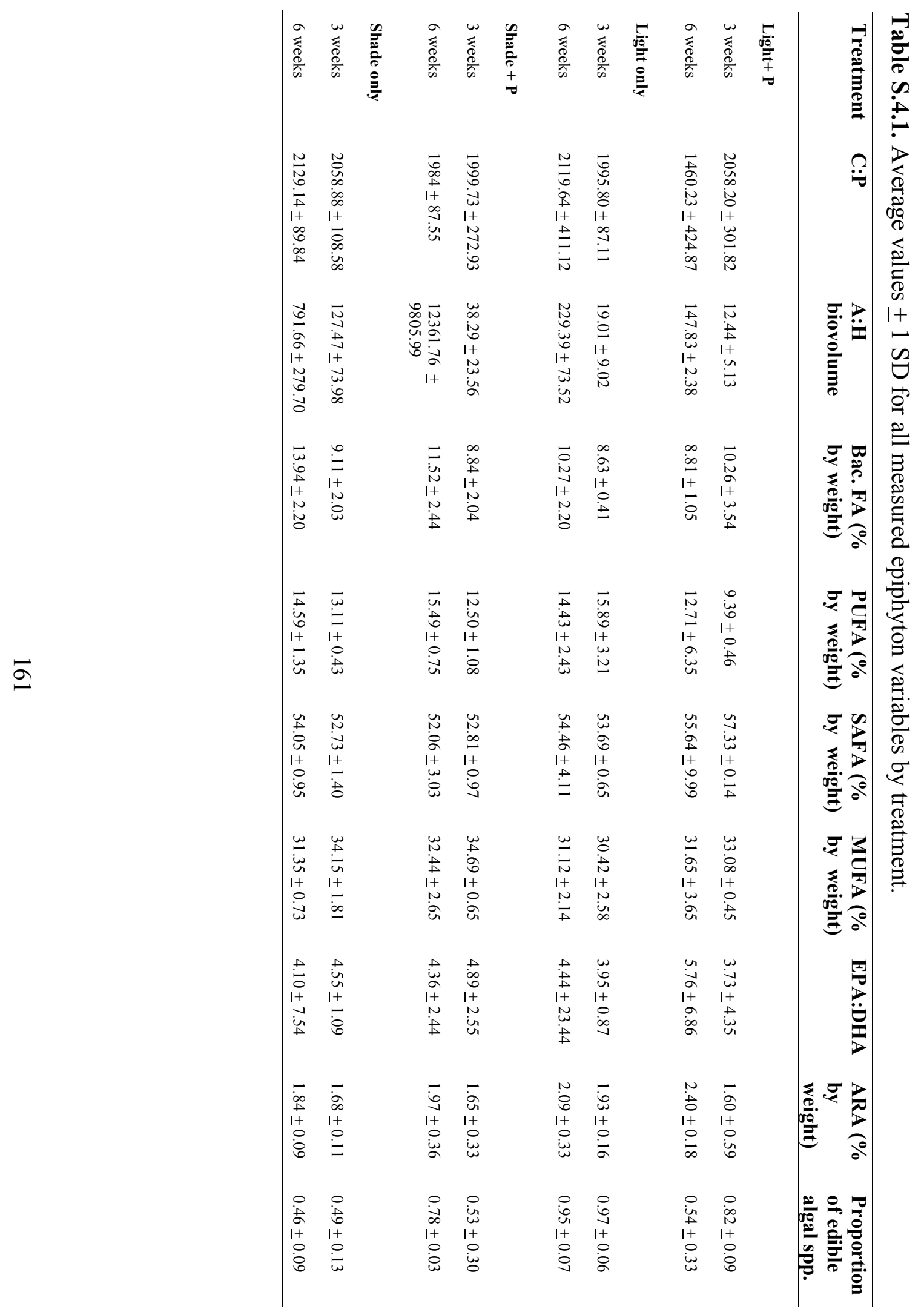




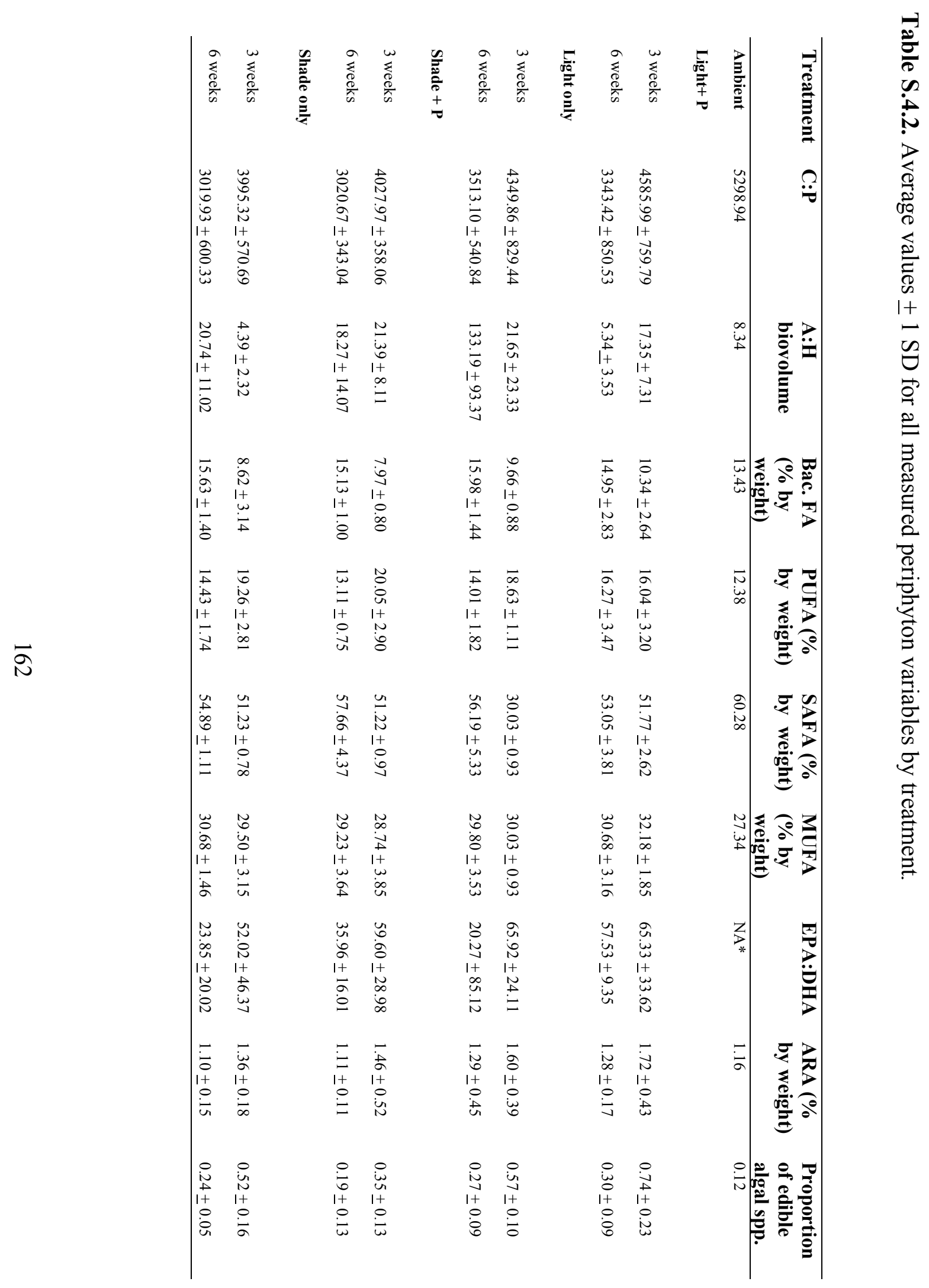




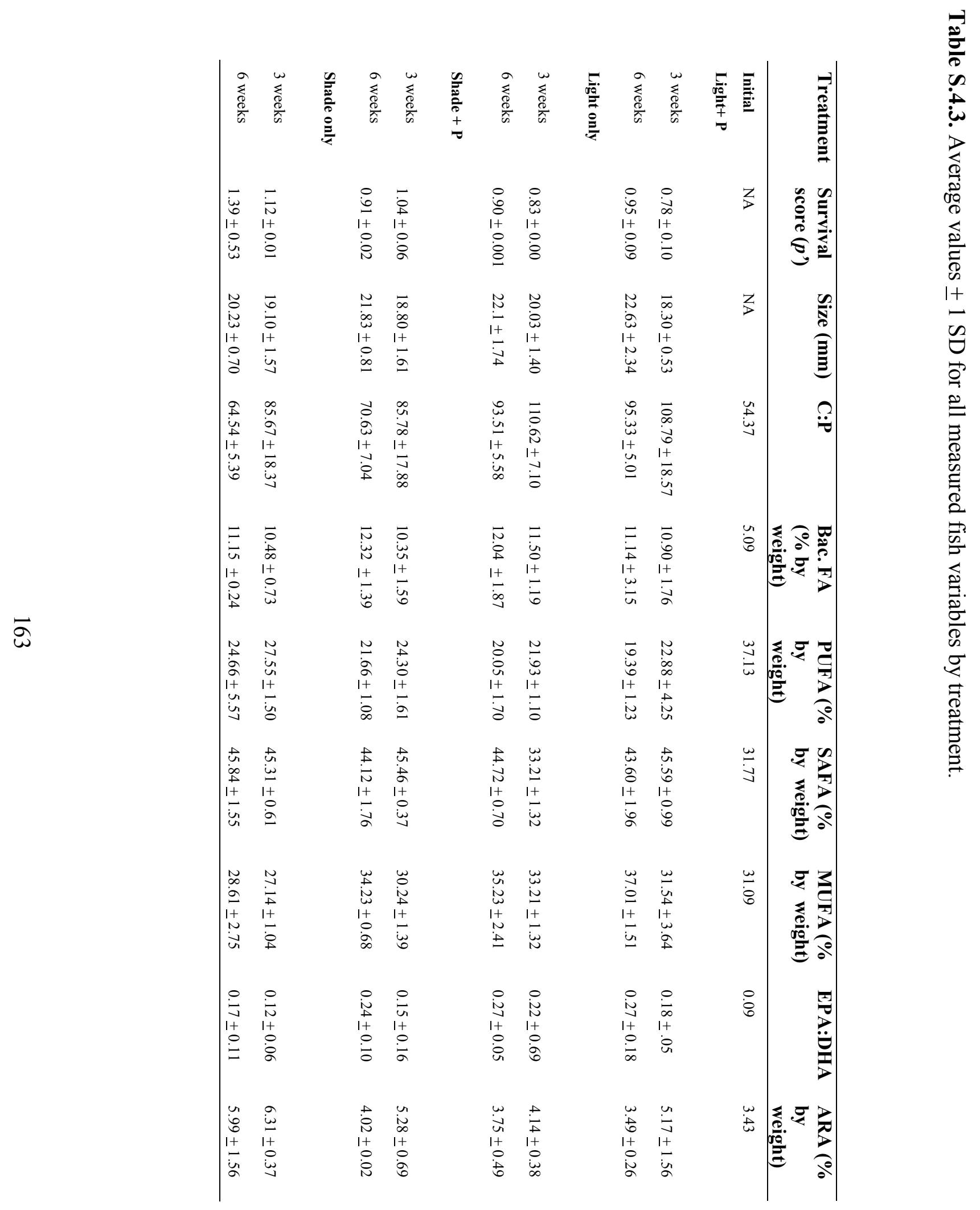


Table S.4.4. Average values \pm 1 SD for Ivlev's Electivity Index by treatment. NA= variables that could not be measured for that treatment.

\begin{tabular}{|c|c|c|c|c|c|}
\hline Treatment & Diatoms & Green Algae & Green Filaments & Cyano. & $\begin{array}{l}\text { Cyano. } \\
\text { Filaments }\end{array}$ \\
\hline \multicolumn{6}{|l|}{ Light + P } \\
\hline 3 weeks & $1.00 \pm 0.58$ & $0.00 \pm 0.58$ & $0.00 \pm 0.58$ & $1.00 \pm 0.00$ & $0.00 \pm 1.00$ \\
\hline 6 weeks & $-1.00 \pm 0.71$ & $0.00 \pm 0.00$ & $-1.00 \pm 0.00$ & $-1.00 \pm 0.71$ & $0.00 \pm 1.00$ \\
\hline \multicolumn{6}{|l|}{ Light only } \\
\hline 3 weeks & $1.00 \pm 0.00$ & $0.00 \pm 0.58$ & $0.00 \pm 0.58$ & $0.00 \pm 0.58$ & $0.00 \pm 0.58$ \\
\hline 6 weeks & $0.00 \pm 0.58$ & $0.00 \pm 1.00$ & $0.00 \pm 0.00$ & $-1.00 \pm 0.58$ & $0.00 \pm 1.00$ \\
\hline \multicolumn{6}{|l|}{ Shade $+\mathbf{P}$} \\
\hline 3 weeks & $1.00 \pm 0.00$ & $1.00 \pm 0.00$ & $1.00 \pm 0.00$ & $1.00 \pm 0.58$ & $0.00 \pm 0.58$ \\
\hline 6 weeks & $1.00 \pm 0.71$ & $1.00 \pm 0.00$ & $1.00 \pm 0.00$ & $-1.00 \pm 0.71$ & $0.00 \pm 1.00$ \\
\hline \multicolumn{6}{|l|}{ Shade only } \\
\hline 3 weeks & $1.00 \pm 0.00$ & $1.00 \pm 0.00$ & $0.00 \pm 1.00$ & $1.00 \pm 0.58$ & $0.00+0.58$ \\
\hline 6 weeks & $1.00 \pm 0.71$ & $0.00 \pm 1.00$ & $1.00 \pm 0.00$ & $0.00 \pm 0.00$ & $0.00 \pm 0.00$ \\
\hline
\end{tabular}


Fig. S.4.1.

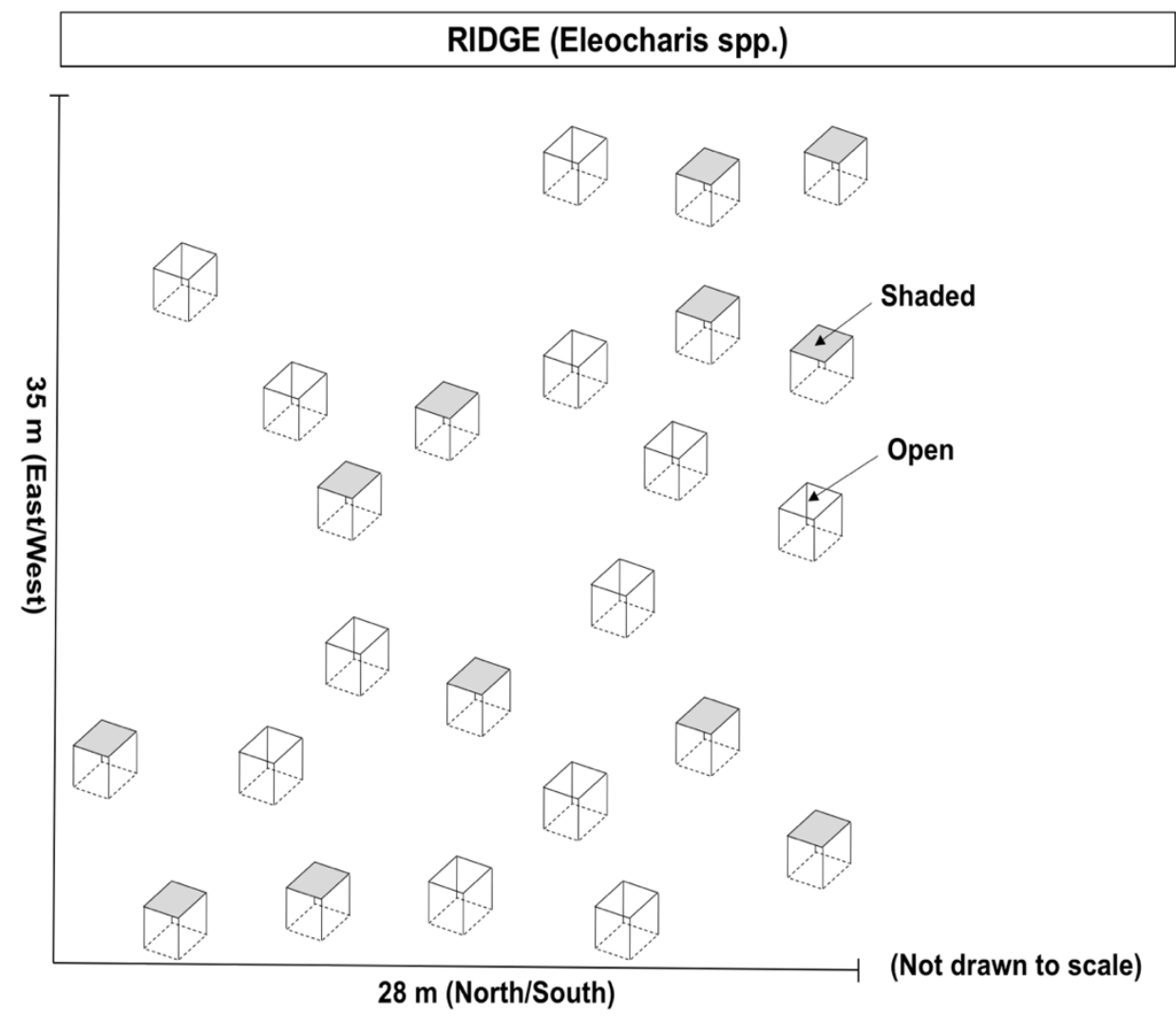

Figure S.4.1. Field experimental set-up. Boxes represent $1 \mathrm{~m}^{2}$ mesh cages (shaded and open) randomly distributed across a $980 \mathrm{~m}^{2}$ plot located in an open Everglades slough $\left(25^{\circ} 49^{\prime} 41.23\right.$ 'N, $\left.80^{\circ} 37^{\prime} 53.41^{\prime \prime} \mathrm{W}\right)$. Not drawn to scale. 


\section{Fig. S.4.2.}

(a)

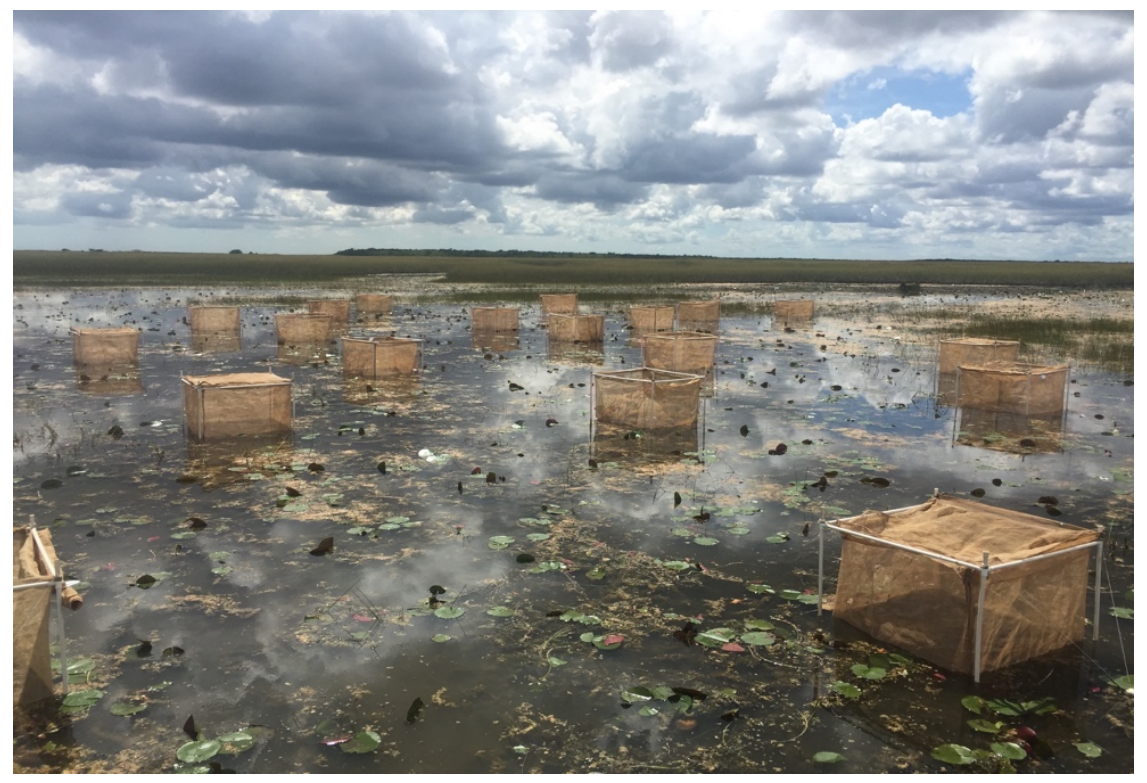

(b)

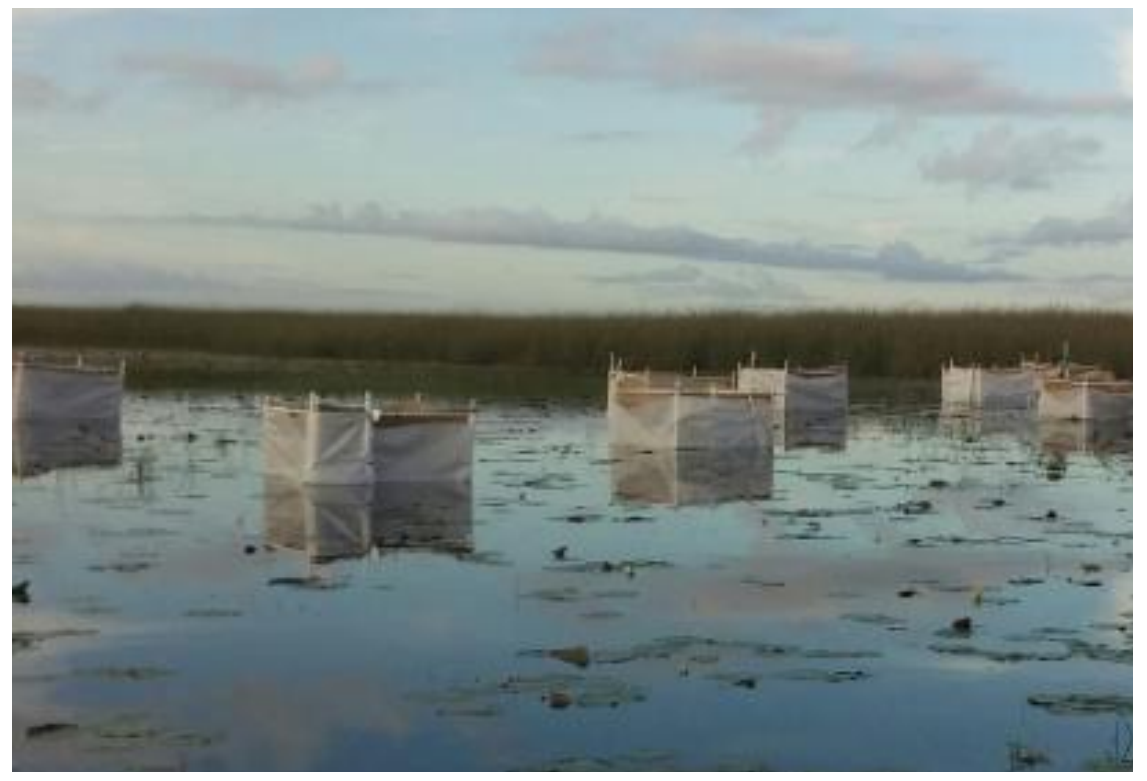

Figure S.4.2. (a) Photo showing mesh cages in the field. (b) Photo showing cages wrapped with $3 \mathrm{~mm}$ clear plastic following nutrient dosing. Phosphorus $\left(\mathrm{Na}_{2} \mathrm{HPO}_{4}\right)$ was added once per week and the cages remained wrapped for 24 hours to avoid seepage to cages without nutrient addition. 
CHAPTER 5

CARNIVORY IS BEST, BUT HERBIVORY IS GOOD ENOUGH: A TEST OF THE HETEROTROPH FACILITATION AND LIPID ALLOCATION HYPOTHESES FOR DIET EVOLUTION

In review: Freshwater Biology 


\begin{abstract}
Herbivorous diets are generally less nutritious than animal diets, but herbivory has evolved from carnivorous ancestors in many lineages, suggesting that herbivory can be adaptive. Using mesocosms stocked with periphyton from the Florida Everglades, I evaluated two hypotheses to explain the adaptive evolution of herbivory: 1) Heterotroph Facilitation (herbivores supplement their diet with nutrients derived from heterotrophic microbes); and 2) Lipid Allocation (herbivores consume algae that are similar in lipid concentration to animal prey). I manipulated the heterotrophic microbe and lipid composition of epiphyton using shading and phosphorus ('Light + P', 'Light only', 'Shade + P', and 'Shade only') and examined the effects of this varying food quality on growth and survival of juvenile Sailfin Mollies (Poecilia latipinna) compared to those raised on a reference carnivore diet.

I found that life history of Sailfin Mollies was driven by increased heterotrophic fatty acids in the diet $(2.5 \mathrm{x}$ more likely than alternative models with $\triangle \mathrm{AICc}>2.00)$. When comparing herbivorous Sailfin Mollies to those raised on a carnivore diet, I found that carnivores showed 24\%-34\% higher survival than fish eating shaded epiphyton, and 44$100 \%$ higher survival than fish eating epiphyton grown in the light. Shaded epiphyton and carnivore diets were both comprised of relatively high levels of heterotrophic-derived lipids, suggesting that these organisms are important for fish survival. Although carnivory is the best diet, mixing autotrophs and heterotrophs can result in a diet almost as good as a carnivorous one, consistent with the Heterotroph Facilitation Hypothesis.
\end{abstract}

Key-words Diet evolution, diet quality, fatty acids, herbivory, detritivory 


\section{Introduction}

Herbivory is a relatively inefficient feeding strategy compared to omnivory and carnivory (Mattson 1980, Sterner and Hessen 1994, Choat and Clements 1998, Sterner and Elser 2002, Laspoumaderes et al. 2010) because plants are nutritionally variable and often protected by structural and/or biochemical barriers to digestion (Mattson 1980, Montgomery and Gerking 1980, Porter and McDonough 1984, Hay and Fenical 1988, Horn 1989, Chivers and Langer 1994, Sterner and Hessen 1994, Choat and Clements 1998, and others). Furthermore, herbivores may be limited in foraging time and/or space by predators and competitors, in the ability to produce digestive or detoxifying enzymes (see Karban and Agrawal 2002), and in the amount of food they can process through their gut (Horn 1989, Bruggeman et al. 1994, Bellwood 1995, Choat and Clements 1998).

Despite these apparent disadvantages, there is evidence from many metazoan groups that herbivores evolved from carnivorous ancestors (e.g., Vermeij 1992, deMaintenon 1999, Van Damme 1999, Vermeij and Lindberg 2000, Bellwood 2003, Eubanks et al. 2003, Espinoza et al. 2004, Pauls et al. 2008, Bellwood et al. 2014, Reisz and Frobisch 2014). A review of the freshwater literature identified conditions where eating plants might be adaptive over eating animal prey (Sanchez and Trexler 2016). In this review, "herbivory" was defined as the consumption of aquatic primary producers (algae and/or phytoplankton), and an "herbivore" as an organism that mainly eats autotrophic organisms, but may indirectly assimilate nutrients from organisms that decompose detritus (consumes $>50 \%$ autotrophs). 
A "carnivore" was defined as an organism that consumes $>50 \%$ animal material, and an "omnivore" as an organism that eats both plants and animals in similar proportions (Sanchez and Trexler 2016, 2018). The term "food quality" describes the nutritional worth of a diet item to a consumer, or as the ratio of energy content of the food to energy assimilated by its consumers. Macronutrient (e.g., nutritional ecology) or elemental (e.g., stoichiometry) composition are commonly assessed as metrics of food quality, where high quality food items are rich in protein or phosphorus, respectively. Regardless of the convention used, "food quality" is a relative term and can only be interpreted relative to other diets, and respective of organismal diet adaptations (e.g., "high quality" is defined differently for carnivores and herbivores). Under these conditions, the review concluded that herbivory is favored when higher quality prey are limiting, or when plants provide important dietary elements that are limited in carnivore diets, such as essential fatty acids (e.g., Martin-Creuzburg et al. 2011) or antioxidants (e.g., Pike et al. 2007). Furthermore, herbivores may overcome limiting resource quality by passively supplementing their diets with heterotrophic microbes that are associated with primary producers (Sanchez and Trexler, 2016, 2018).

Many researchers recognize that herbivores obtain nutrients from supplementary sources, and as a result there are few "true" aquatic herbivores in nature (White 1985). In aquatic systems, primary consumers are nutrient-limited, and their diets depend on nutrients derived from both autochthonous and allochthonous inputs (Hall et al. 2001). 
The heterotrophic organisms that colonize decomposing autochthonous and allochthonous material provide a rich source of dietary nutrients and promote higher growth in some invertebrate families (e.g., Mulla and Lacey 1976, Fuller et al. 1988, Edwards and Meyer 1990, Fuller and Fry 1991, Fuller et al. 2004). However, diets composed only of heterotrophs are of poor quality for herbivores (e.g., Daphnia magna), suggesting that they also rely on autotrophs for essential nutrients (e.g., Goulden et al. 1982, Schmidt and Jonasdottier 1997, Weers and Gulati 1997, Martin-Creuzburg et al. 2005, Martin-Creuzburg et al. 2011). In a recent study (Sanchez and Trexler 2018), I evaluated the relative importance of autotroph-derived lipids and heterotroph diet supplementation on herbivore success by testing two alternative hypotheses for the adaptive evolution of herbivory: 1) the Heterotroph Facilitation hypothesis, which states that herbivory may be adaptive by supplementing herbivore diets with heterotrophic microbes (bacteria and/or fungi) that are indirectly consumed along with primary producers; and 2) the Lipid Allocation hypothesis, which states that consumption of primary producers with high lipid concentrations may be as beneficial to individual life history as a carnivorous diet (Sanchez and Trexler 2016). I tested these hypotheses using field enclosures stocked with the herbivorous Sailfin Molly (Poecilia latipinna) and found that autotrophic lipids play an important role in early development of Sailfin Mollies, but when energy is re-directed to reproduction, heterotrophic lipids become an important driver of herbivore survival. Sailfin Mollies assimilate nutrients from heterotrophs, which were not the target diet item, but were consumed as a consequence of their close association with primary producers. This result was consistent with the Heterotroph Facilitation hypothesis (Sanchez and Trexler 2016, 2018). 
Similar studies have shown that herbivores rely heavily on nutrients originating from heterotrophic microbes (see Sanchez and Trexler 2016), but no others have examined these diet components as potential mechanisms supporting the evolution of herbivory. Furthermore, it remains to be determined if a mixed herbivorous diet can be similarly nutritious for an herbivore as a carnivorous diet, as would be expected to facilitate a carnivorous ancestor giving rise to an herbivorous lineage.

I report a laboratory experiment designed to test the Heterotroph Facilitation and Lipid Allocation Hypotheses using a resource-consumer system that is native to the Florida Everglades, USA. The Everglades is an ideal system to test these hypotheses because periphyton mats, the primary basal resource in this area (Browder et al. 1994, Trexler et al. 2015), are composed of complex assemblages of autotrophs (green algae, diatoms and cyanobacteria) and heterotrophs (fungi, bacteria, protozoans and zooplankton) that are bound together by a calcium carbonate matrix (Gaiser et al. 2004). Because the Everglades is naturally oligotrophic, both autotroph and heterotroph components of periphyton mats are easily manipulated by nutrient addition (Gaiser et al., 2004, Bellinger et al. 2012). In addition, lipid profiles of Everglades primary and secondary consumers are comprised of both algal and bacterial fatty acids (Belicka et al. 2012), suggesting that both items are important in consumer diets. One of these native consumers is the Sailfin Molly (Poecilia latipinna), which is herbivorous (Scharnweber et al. 2011), but incorporates prokaryotic resources (Belicka et al. 2012) and sometimes small invertebrates (Harrington and Harrington 1961, 1982) into its diet. 


\section{Methods}

I kept juvenile Sailfin Mollies in tanks in the FIU Ecotoxicology Greenhouse Laboratory (North Miami, FL) from June- July 2015. The lab is covered by a clear canopy that blocks rain but allows exposure to sunlight with UV penetration, thus promoting growth of epiphytic algae, the food source for fish in this study. I constructed artificial vegetation strips $(2.54 \mathrm{~cm}$ wide $)$ made of black plastic sheeting $(0.154 \mathrm{~mm}$ thick) attached to $1 \mathrm{~m}^{2}$ wire frames for a total of 150 strips per $\mathrm{m}^{2}$, simulating the natural stem density of the Everglades (described in Chick et al. 2008). Frames were placed into large mesocosms along with 151 liters of filtered freshwater $(393.03 \pm 4.74 \mathrm{uS} / \mathrm{cm}, 0.02$ ppt). I collected periphyton from the Everglades $\left(25^{\circ} 54^{\prime} 11.0^{\prime} \mathrm{N}, 80^{\circ} 39^{\prime} 43.2^{\prime} \mathrm{W}\right)$, cleaned the periphyton of invertebrates, and stocked $2000 \mathrm{~mL}$ in each mesocosm. Periphyton was used to encourage growth of epiphytic algae on the artificial vegetation strips, and I manipulated the quality of colonizing epiphyton using phosphorus $(\mathrm{P})$ and/or shade. At low levels of light, diatoms and cyanophytes are expected to dominate periphyton communities (Thomas et al. 2006, Vadeboncoeur and Power 2017), resulting in an increase in polyunsaturated fatty acids (Hill et al. 2011). In increased light conditions, green algae are expected to dominate (Thomas et al. 2006, Vadeboncoeur and Power 2017) and bacterial-derived saturated and monounsaturated fatty acids are also expected to increase in abundance (Hill et al. 2011). When light levels interact with P-addition, PUFAs are favored in low light and high P conditions, and SAFAs + MUFAs are favored in high light and low P conditions (Hill et al. 2011). Although heterotrophic responses to light and $\mathrm{P}$ is not well-established for periphyton communities, it is believed that increased nutrient input results in increased heterotrophy (McCormick et al. 1997). 
Each mesocosm was randomly assigned to one of four treatments: 1) light + P; 2) light only; 3) shade + P; 4) or shade only. Light treatments were exposed to ambient sunlight. Phosphorus $\left(\mathrm{Na}_{2} \mathrm{HPO}_{4}\right)$ was added at a concentration of $15 \mu \mathrm{g} / \mathrm{L}$ weekly to 'shade $+\mathrm{P}$ ' and 'light $+\mathrm{P}$ ' mesocosms. This concentration was chosen based on previous P dosing studies in the Everglades (Noe et al. 2002, Gaiser et al. 2005). Shading was accomplished by covering 'shade $+\mathrm{P}$ ' and 'shade only' mesocosms with 2 sheets of greenhouse shade cloth to achieve approximately 50\% reduction in ambient light (modified methods of Fuller et al. 2004), which is within the natural range of shading experienced in the field (10-65\% reported by Armento et al. 2006). Light and temperature were tracked throughout the experiment using HOBO ${ }^{\circledR}$ data loggers. Mesocosm tanks were kept at approximately $28.72 \pm 2.00^{\circ} \mathrm{C}$.

Juvenile $(<12 \mathrm{~mm})$ Sailfin Mollies were born in the FIU indoor aquarium lab to wild-caught females, were separated by sib-groups, and were raised on Tetramin ${ }^{\circledR}$ flake food for 3 weeks prior to the start of the experiment. They were then measured (average standard length, SL) and transplanted to 18.9 liter aquaria (filled with treated freshwater) located in the greenhouse lab ( $n=6$ per tank; $N=24$ total fish/treatment) 3 weeks following mesocosm set-up (when fish were 6 weeks old). This allowed enough time for epiphyton to colonize the vegetation strips in mesocosms and to allow fish to acclimate to aquaria. I placed shade covers on top of the aquaria to keep them out of direct sunlight to prevent water from overheating ( $\sim 25 \%$ decrease in ambient light). Tanks were maintained at $30.92 \pm 2.64^{\circ} \mathrm{C}$, were topped off with clean freshwater twice per week, and were cleaned (full-water change, tank walls wiped) once per week throughout the experiment. Fish were assigned to one of the above treatments, or a fifth 'carnivore' treatment. 
Individual vegetation strips with newly colonized epiphyton were harvested from each mesocosm tank and provided to fish assigned to the same treatment (e.g., 'light only' epiphyton strips were provided to 'light only' fish tanks) for consumption. I provided fish 3 strips, 3 times per week; the number of strips provided was calculated based on how much epiphyton had grown on them, with a target goal of providing $20 \mathrm{mg}$ dry weight of food per tank based on preliminary studies to estimate the maximum ration. Fish in the 'carnivore' treatment were provided with $20 \mathrm{mg}$ of Tetra ${ }^{\circledR}$ Freeze-dried bloodworms 3x per week, along with 3 blank plastic vegetation strips to keep feeding trials as consistent as possible.

Multiple mesocosms with each epiphyton treatment ( 6 blocks of 4 tanks each) were maintained to create as consistent a "food supply" as possible throughout the study. For example, the first block was inoculated with stock periphyton on week 1 , the second on week 2 , the third on week 3 , etc. On week 3 , the artificial vegetation strips growing biofilms in the first block were ready to feed to fish. On week 4, strips from block 2 were ready; on week 5, strips from block 3 were ready, etc. Each block provided enough food to feed fish ( 4 replicates of 5 treatments, $\mathrm{N}=120$ fish) for one week (feedings on Monday, Wednesday and Friday). Stock periphyton was collected from the field and brought back to the lab every 2 weeks so that water chemistry in the greenhouse minimally affected species composition of periphyton (e.g., Ruehl and Trexler 2015) and so that I could capture the natural variation in periphyton quality over the course of a season. Samples for nutrient and lipid analyses were taken from the ambient periphyton before placing it into the mesocosm tanks with artificial vegetation and applying nutrient/shading treatments. 
Artificial strips were sampled at the beginning of the week they were fed to the fish (30 strips total per treatment).

The remaining samples (including carnivore diets and fish tissues) were freezedried and prepped for fatty acid analyses (sent to Microbial ID laboratory, Newark, DE). In addition, epiphyton, periphyton, bloodworms (carnivore diet), and fish tissues were processed for nutrient content (CNP; sent to Southeastern Research Center, Florida International University, Miami, FL). Stoichiometry data (CNP) were converted to molar ratios. Fatty acid data were categorized by diet tracers (Table 1; Sanchez and Trexler 2018) and further organized into polyunsaturated fatty acids (PUFAs), saturated fatty acids (SAFAs), and monounsaturated fatty acids (MUFAs). Fatty acid data were also organized by common Omega-3 and Omega-6 fatty acids (essential fatty acids) that are known to affect fish growth and development: eicosapentaenoic acid (EPA), docosahexaenoic acid (DHA), and arachidonic (ARA). These metrics were analyzed in fish tissues and the various diets to understand their influence on fish growth and survival.

\section{Statistical analyses}

Several food quality variables were measured for epiphyton and bloodworms: ratio of total carbon to phosphorus $(\mathrm{C}: \mathrm{P})$; ratio of nitrogen to phosphorus $(\mathrm{N}: \mathrm{P})$; relative fatty acid content; percentage of autotroph- and heterotroph- derived fatty acids; fatty acid class (PUFA, SAFA, MUFA; ratio of (SAFA + MUFA): PUFA); and essential fatty acids (EPA, DHA, ARA, ratio of EPA:DHA). 
In addition, the ratio of autotroph to heterotroph $(\mathrm{A}: \mathrm{H})$ biovolume, algal species composition and the proportion of edible algae (proportion of green algae relative to cyanobacteria) were analyzed in the epiphyton samples only. Carnivore diets were compositionally different than the epiphyton diets, so I statistically examined the experimental diets by excluding bloodworm data from the analyses. This allowed me to determine if any differences existed among treatments, without biasing the analyses towards differences between bloodworms and epiphyton. All epiphyton diet characters were first analyzed to determine if there were effects of mesocosm block on variation in diet I found no differences across treatments that were attributed to growing epiphyton in blocks, suggesting that any observed differences were in response to the treatments themselves.

Fatty acid classes (PUFA, SAFA, MUFA), fatty acid ratios ((SAFA+MUFA): PUFA), and essential fatty acids (EPA, DHA, ARA) comprising each diet type were analyzed separately using two-way ANOVA tests, followed by Tukey tests. Biovolume of autotrophs and heterotrophs were converted to ratios (A:H biovolume) and were analyzed using two-way ANOVA. Algal species composition was analyzed using twoway MANOVA with Tukey multivariate comparison tests. Proportion of edible algal species comprising each diet type was analyzed using two-way ANOVA. Once I determined if any differences existed between experimental diets, I ran the same analyses (with the exception of $\mathrm{A}: \mathrm{H}$ biovolume, algal species composition and edible algal abundance) with the bloodworm data. 
My next goal was to test the alternative hypotheses by determining which food parameter influenced herbivore size and survival. The Heterotroph Facilitation hypothesis predicts that diet supplementation with heterotrophic organisms promotes herbivore life history, and the Lipid Allocation hypothesis suggests that fatty acids derived from algae are influencing herbivore success. Therefore, I choose to evaluate variables describing heterotroph and autotroph quality/quantity as independent variables to predict fish life history: A:H biovolume (measure of heterotroph and autotroph quantity), percentage of heterotrophic fatty acids (measure of bacterial and fungal quality), and (SAFA + MUFA): PUFA ratios (measure of autotroph quality). Using Principal Component Analysis, fish size and survival rates were collapsed into a single score, collectively called "fish life history". These PCA scores were used as response variables for structural equation models (SEM) created using AMOS (Arbuckle, J. L. 2014). The models were designed to test the strength between the 3 independent variables and fish life history to determine which suite of diet characteristics most strongly influences herbivore growth and survival (i.e., to determine which alternative hypothesis is best supported by the data).

Paths were varied between diet variables and fish life history in each model to produce a total of 7 models (Table 4) that were compared using Akaike's Information Criterion (AIC). I calculated $\triangle \mathrm{AICc}(\triangle \mathrm{AICc}=\mathrm{AICi}-\min \mathrm{AICc}$, where $\mathrm{i}=$ model $\mathrm{i}) . \mathrm{I}$ also calculated Akaike weight $\left(\mathrm{AICw}=\left(\mathrm{e}(-0.5 * \Delta \mathrm{AICi}) / \sum(\mathrm{e}(-0.5 * \Delta \mathrm{AICr}),(\mathrm{Lr})\right.\right.$, and Evidence Ratios (wmin/wj, where wmin $=\mathrm{AICw}$ for the model with the smallest $\triangle \mathrm{AICc}$, and wj = AICw for the current model; Burnham and Anderson 2002) for each model. Following Burnham and Anderson (2002), models with $\Delta \mathrm{AICc}<2.0$ were equally supported by the data. 
I was only interested in the carnivore diets as references, therefore, I excluded them from these analyses.

\section{Results}

Bloodworm Diet

Carnivore diets were compositionally different than epiphyton diets (Table 2;

Table S1). Bloodworms had 84\% lower C:P and 59\% lower N:P ratios than the epiphyton with the lowest ratios ('shade $+\mathrm{P}$ ' and 'light $+\mathrm{P}$ '), and the relative fatty acid content of this diet was 2-4x less than that of the epiphyton diets. Bloodworms contained $36 \%$ and $48 \%$ more heterotrophic fatty acids than 'shade + P' and 'shade only' epiphyton, respectively. Carnivore diets had 52\% higher PUFAs and 51\% fewer MUFAs than 'shade + P' epiphyton, which had the highest PUFA and lowest MUFA percentage of all epiphyton types. Furthermore, bloodworms were $75 \%$ lower in SAFAs than all epiphyton types. Carnivore diets were 95\% higher in EPA, 98\% higher in DHA, and 90\% higher in ARA than the shaded diets.

\section{Epiphyton Diet}

Phosphorus addition influenced the stoichiometric ratios (C:P and N:P) of epiphyton in a predictable manner (Table 2; Table S1). Epiphyton grown in 'shade $+\mathrm{P}$ ' and 'light $+\mathrm{P}$ ' mesocosms had 52\% lower C:P and 40\% lower N:P ratios than the treatments without nutrient addition (Phosphorus: $\mathrm{F}_{1,16}=15.739, \mathrm{P}=0.001 ; \mathrm{F}_{1,16}=0.664, \mathrm{P}=0.012$, for $\mathrm{C}: \mathrm{P}$ and N:P, respectively). Epiphyton grown in 'shade only' and 'light only' treatments had 33-50\% lower relative abundance of green algal species than 'light $+\mathrm{P}$ ' epiphyton, which had the most (Wilks' Lambda $=0.120, \mathrm{~F}_{15,33}=2.586, \mathrm{P}=0.011$ ). 
Phosphorus addition drove the percent of edible species comprising the epiphyton (phosphorus: $\mathrm{F}_{1,16}=8.488, \mathrm{P}=0.010$ ). In addition, the ratios of $\mathrm{A}: \mathrm{H}$ biovolume for 'shade $+\mathrm{P}$ ' and 'shade only' epiphyton were higher than the light treatments, by $50 \%$ and $37 \%$, respectively (Light: $\mathrm{F}_{1,16}=4.503, \mathrm{P}=0.05$ ). There was no difference in the percentage of autotroph-derived fatty acids $\left(\mathrm{F}_{3,16}=1.534, \mathrm{P}=0.279\right)$ between treatments, but 'shade $+\mathrm{P}$ ' and 'shade only' treatments had $42 \%$ and $14 \%$ more heterotrophic fatty acids than the light treatments, respectively (Light: $\left.\mathrm{F}_{1,16}=11.208, \mathrm{P}=0.004\right)$. The quantity of heterotrophs (A:H biovolume) and quality of heterotrophs (fatty acid percentage) were not correlated $\left(\mathrm{R}^{2}=-0.009, \mathrm{t}_{1,16}=-0.910, \mathrm{P}=0.375\right)$. 'Shade $+\mathrm{P}$ ' epiphyton had $52 \%$ higher fatty acid content compared to the other treatments (Light: $F_{1,16}=15.48$, $\mathrm{P}<0.0001)$.

The relative abundances of PUFAs and SAFAs comprising the epiphyton samples were not different between treatments, but light was correlated with the relative abundance of MUFAs (Table 2; Table S1). 'Light only' treatments showed 14\% higher MUFAs than 'shade only', and 'light $+\mathrm{P}$ ' treatments and $32 \%$ higher MUFAs than the 'shade + P' epiphyton (PUFA, $\mathrm{F}_{3,16}=1.824, \mathrm{P}=0.183$; SAFA, $\mathrm{F}_{3,16}=0.071, \mathrm{P}=0.974$; MUFA, $\left.F_{1,16}=4.387, \mathrm{P}=0.02\right)$. But, the (SAFA+MUFA): PUFA ratios were not statistically different between the treatments $\left(\mathrm{F}_{3,16}=0.938, \mathrm{P}=0.445\right)$. Epiphyton grown in the 'shade $+\mathrm{P}$ ' treatments had the highest percent of EPA $\left(\mathrm{F}_{3,16}=13.093, \mathrm{P}<0.0001\right)$, but lowest percent of ARA $\left(\mathrm{F}_{3,16}=10.435, \mathrm{P}=0.005\right)$. Epiphyton grown in 'light $+\mathrm{P}$ ' mesocosms had the lowest EPA, which was $83 \%$ lower than 'shade + P'. 'Light only' epiphyton had 53\% higher ARA than 'shade + P' epiphyton. The different epiphyton types were not significantly different in DHA $\left(\mathrm{F}_{3,16}=0.481, \mathrm{P}=0.70\right)$. 


\section{Ambient Periphyton}

Periphyton varied in stoichiometry over the course of the experiment (Table 2; Table S1). Specifically, periphyton that stocked mesocosm blocks 1-3 had C:P ratios of approximately 4500 , and periphyton from blocks $4-6$ had C:P ratios of approximately 6000. Because stock periphyton for mesocosm blocks 1-2, 3-4, and 5-6, was collected on three separate occasions, variation in $\mathrm{C}: \mathrm{P}$ is likely attributed to the natural variation in the field. Ratios of N:P were consistently between 195 and 235 for all mesocosm blocks. There were differences in epiphyton stoichiometry independent of mesocosm block (confirmed by randomized block ANOVA); therefore, I assumed that the inter-block variation in periphyton C:P did not influence colonizing epiphyton. The proportion of edible species comprising periphyton was similar across blocks, but was different than that of epiphyton (Table 2; Tables S1 \& S2). Periphyton contained between $36 \%$ and $75 \%$ lower abundances of edible species than the experimentally manipulated epiphyton. Furthermore, periphyton contained 95\% less heterotrophic biovolume and $82 \%$ less autotrophic biovolume than epiphyton. However, the A:H biovolume ratio of periphyton was within the range of epiphyton A:H ratios, which was $11.01 \pm 5.86$ for 'light $+\mathrm{P}$ ' epiphyton (lowest ratio), $23.81 \pm 12.16$ for 'shade $+\mathrm{P}$ ' epiphyton (highest ratio), and $16.26 \pm 2.90$ for periphyton. The relative fatty acid content of periphyton did not vary by block. In addition, periphyton contained $62 \%$ fewer fatty acids than 'shade $+\mathrm{P}$ ' epiphyton, $36 \%$ fewer than 'shade only' epiphyton, and $16 \%$ fewer than epiphyton grown in the light treatments. Autotrophic fatty acid markers were present in similar amounts in periphyton and epiphyton. 
But, heterotrophic fatty acids were $28 \%$ higher in periphyton than 'shade $+\mathrm{P}$ ' epiphyton, which had the highest heterotrophic fatty acid content of the different epiphyton types. Periphyton had similar proportions of PUFAs compared to 'light only' epiphyton, but that amount was $49 \%$ lower than 'shade $+\mathrm{P}$ ' epiphyton. Periphyton contained similar SAFA and MUFA content as epiphyton. Periphyton did not contain any EPA or DHA and contained $40 \%$ less ARA than epiphyton grown in the light treatments. However, periphyton had $85 \%$ and $25 \%$ higher ARA than 'shade $+\mathrm{P}$ ' and 'shade only' epiphyton, respectively.

\section{Fish Life History}

There were no differences in the sizes of juvenile Sailfin Mollies stocked in each tank at the start of the experiment or at the end of the experiment. However, there were differences in growth rates between 0-3 weeks and 3-6 weeks. All fish were approximately $11.18 \pm 0.37 \mathrm{~mm}$ at the beginning of the experiment $\left(\mathrm{F}_{4,15}=2.141\right.$, $\mathrm{P}=0.126$ ). Fish eating 'light only' epiphyton were approximately $12 \%$ larger than fish eating other epiphyton types, and $11 \%$ larger than the carnivores at 3 weeks $\left(F_{4,15}=4.482\right.$, $\mathrm{P}=0.01$; Fig. 1a). These size differences disappeared by 6 weeks $\left(\mathrm{F}_{4,15}=0.662, \mathrm{P}=0.626\right.$;

Fig. 1a). As such, growth rates were different at both time periods, where 'light only' fish grew the fastest from $0-3$ weeks $\left(\mathrm{F}_{4,23}=6.847, \mathrm{P}=0.001\right)$, but slowed growth from 3-6 weeks $\left(\mathrm{F}_{4,23}=7.563, \mathrm{P}<0.0001\right)$. Carnivores showed the slowest growth at both time periods, and fish eating epiphyton grown in the shaded treatments displayed the fastest rates of growth from 3-6 weeks. Fish reared on 'light + P' epiphyton showed intermediate growth at both time periods. 
Survival differences between treatments were not yet evident at 3 weeks $\left(X^{2}=4.441, \mathrm{P}\right.$ $=0.350$; Fig. $1 \mathrm{~b}$ ), but at 6 weeks, carnivores showed $24 \%$ higher survival than 'shade only' fish, which were the highest surviving individuals of those eating epiphyton. Fish reared on 'light $+\mathrm{P}$ ' epiphyton had no surviving individuals at 6 weeks, followed by 'light only' and 'shade + P' fish with $28 \%$ and $14 \%$ lower survival rates than 'shade only’ fish (45\% and 34\% lower than carnivores). Because there were no surviving individuals from 'light $+\mathrm{P}$ ' treatments at the end of the experiment, we were unable to perform nutrient analyses on tissues from fish reared in this treatment. However, there were differences in fish tissues that were evident across the remaining treatments (Table 3; Table S3). Specifically, the relative fatty acid content of fish tissues was highest in fish eating bloodworms and 'shade $+\mathrm{P}$ ' epiphyton, and fish eating 'light only' and 'shade only' epiphyton had $14 \%$ fewer fatty acids comprising their tissues $\left(\mathrm{F}_{3,16}=3.564\right.$, $\mathrm{P}=0.038$ ). The percentage of autotroph- and heterotroph- derived fatty acids in the fish tissues across experimental treatments were not different (Autotroph: $\mathrm{F}_{3,16}=0.54$, $\mathrm{P}=0.662$; Heterotroph: $\left.\mathrm{F}_{3,16}=2.966, \mathrm{P}=0.063\right)$. The relative amounts of PUFAs and MUFAs in fish tissues were the same (PUFA: $F_{3,16}=1.169, \mathrm{P}=0.353$; MUFA: $\mathrm{F}_{3,16}=1.517$, $\mathrm{P}=0.248$ ); however, those reared in the 'shade $+\mathrm{P}$ ' and 'light only' treatments had $6 \%$ more SAFAs in their tissues than the other fish $\left(\mathrm{F}_{3,16}=3.356, \mathrm{P}=0.045\right)$. Despite these differences, the (SAFA+MUFA): PUFA ratios were the same for fish tissues $\left(\mathrm{F}_{3,16}=\right.$ $1.095, \mathrm{P}=0.380)$. There were no differences in essential fatty acids (EPA, DHA, ARA) in fish tissues (EPA: $\mathrm{F}_{3,16}=0.696, \mathrm{P}=0.568$; $\mathrm{DHA}: \mathrm{F}_{3,16}=0.946, \mathrm{P}=0.442$; $\mathrm{ARA}: \mathrm{F}_{3,16}=2.324$, $\mathrm{P}=0.114)$. For detailed results, refer to Table 3 and Supplementary Table 3. 


\section{Testing adaptive hypotheses}

To test the Heterotroph Facilitation and Lipid Allocation hypotheses, I varied the paths between diet metrics (A:H biovolume, the percentage of heterotroph-derived fatty acids, and (SAFA + MUFA): PUFA ratio) and fish life history to produce 7 models for each time period ( 3 and 6 weeks). Based on $\triangle \mathrm{AICc}$ values, and evidence ratios, low $\mathrm{A}: \mathrm{H}$ biovolume ratios (high heterotroph biovolume) and low heterotrophic fatty acid percentage best predicted fish size and survival at 3 weeks. However, 6-week models show that increased A:H biovolume (low heterotroph abundance) and increased heterotrophic fatty acids best predicted fish life history (Fig. 2; Table 4).

\section{Discussion}

These results supported the Heterotroph Facilitation hypothesis, which suggests that diet supplementation with heterotrophic microbes diminishes the nutritional discrepancy between an herbivorous and carnivorous diet. In our mesocosm experiment, juvenile Sailfin Mollies (6-12 weeks of age) had high survival when fed diets high in heterotrophic fatty acids (carnivores, 'shade only', 'shade + P'), indicating that Sailfin Mollies benefit from a diet that incorporates heterotrophic food sources. However, the quality of these dietary heterotrophs played a more important role in fish survival than the quantity. Furthermore, the carnivorous fish in this study experienced the greatest life history benefits in terms of survival, likely as a result of a diet rich in heterotrophic fatty acids. 
Although these results indicate that carnivory is a better diet than herbivory, herbivore survival increased with percent of dietary heterotrophic fatty acids, suggesting that an autotrophic diet rich in heterotrophic fatty acids can be adequate for fish growth and survival. It is important to note that I maintained these fish on a high-quality diet (Tetramin ${ }^{\circledR}$ flakes) for their first three weeks post-partum to standardize their condition prior to assigning diet treatments, which may have diminished treatment differences, at least for the first three-week experimental interval. However, this does not undermine the finding that heterotrophs supplement and improve the herbivorous diet in both field (Sanchez and Trexler 2018) and mesocosm settings.

I found that heterotroph biovolume and percentage of heterotrophic fatty acids in the diet could be useful metrics for predicting herbivore success in nature. At 3 weeks, increased heterotroph abundance and decreased percentage of heterotrophic fatty acids in the diet predicted herbivore growth and survival, but 6-week models revealed the opposite pattern, suggesting that low heterotroph abundance and high heterotroph-derived fatty acids support fish growth and survival. The usefulness of these diet metrics depends on the life history of the study organism. For example, Sailfin Mollies mature approximately 21-68 days after birth (Snelson et al. 1986), and at the end of this study the fish were 63-70 days old. Because I found a few mature males at the end of the experiment, it was apparent that these fish were beginning to transition from juveniles to reproductively-capable adults. As such, their energetic requirements were shifting from growth to reproduction, and this shift was evidenced by the change in dietary requirements suggested by the models at 3- (growth phase) and 6- (reproductive phase) weeks. 
Thus, heterotroph quantity in the diet may play a role in the early growth phase of Sailfin Mollies, but heterotroph quality (heterotrophic fatty acids) plays a larger role once fish approach the reproductive phase.

The (SAFA+MUFA): PUFA ratio was not found to be an important predictor of herbivore growth and survival in this study, although we found that an increase in PUFAs (autotroph-derived) promoted fish survival at 3 weeks in my field experiment. These results are not suggesting that autotroph-derived fatty acids are unimportant to herbivores, as several studies have proven the importance of these dietary elements for growth, survival and reproduction of aquatic organisms (e.g., Martin-Creuzburg et al. 2005, Martin-Creuzburg et al. 2011). Rather, I suggest that heterotrophs supplement autotrophic-based diets, and the quality (fatty acid abundance) of these microbes may influence herbivore life history.

The results from this mesocosm experiment are slightly different than the results from the previous field study, but both studies suggest that heterotrophs supplement the herbivorous diet in ways that benefit consumer life history, thereby supporting the Heterotroph Facilitation hypothesis. The Lipid Allocation hypothesis emphases autotrophic-derived lipids as the main driver of herbivore success, but this was not exclusively supported in either experiment. Previous studies support the idea that heterotroph supplementation is important for herbivore diets (e.g., Edwards and Meyer 1990, Fuller et al. 2004, Jäger et al. 2014) and have found that a diet consisting only of heterotrophs or autotrophs is suboptimal relative to a diet containing both in intermediate quantities (e.g., Martin-Creuzburg et al. 2005, Martin-Creuzburg et al. 2011). 
Here, I found that diets with increased autotrophs do not benefit herbivores, but instead, diets with increased heterotrophic fatty acids promote herbivore growth and survival. The increased heterotroph biovolume in the 3-week models may suggest otherwise, but when considering overall growth and survival of fishes at the end of the experiment, it is evident that those consuming epiphyton with these qualities do not experience high survival past this time period. Fish that continued to survive and grow through the end of the experimental period were those consuming food with low heterotroph abundance and high percentages of heterotrophic fatty acids, providing evidence that heterotrophic quality (fatty acids) and not quantity (heterotrophic biovolume) represent an important part of the herbivorous diet.

Although several studies have examined the influence of dietary heterotrophs on herbivore life history (e.g., Bowen 1984, Smoot and Findlay 2010, Belicka et al. 2012), it is not recognized as a fundamental part of the herbivorous diet (White, 1985). Studies that examine the effects of diet quality have historically used stoichiometry or nutritional ecology to describe consumer life history, but neither framework solely explains these results. The ecological stoichiometry framework predicts that diets with lower C:P ratios are the highest quality for consumers (Sterner and Elser 2002). While this was true for the carnivore diets, 'light $+\mathrm{P}$ ' epiphyton also had a low C:P ratio, and fish consuming epiphyton from this treatment experienced the lowest survival. The nutritional ecology framework predicts that high PUFA content represents a high-quality diet (e.g., MüllerNavarra et al. 2004, Persson and Vrede 2006), but variation in PUFAs (measured as (SAFA + MUFA): PUFA) was not retained in the models that best fit the data in this study, or in the field study. 
This suggests that estimations of food quality assessed by stoichiometric ratios or from autotroph-derived fatty acids (PUFAs) may not be the most reliable metrics for all study systems (Trexler et al. 2015). However, these studies do not address how other nutritional components (e.g., macronutrients, algal starch, etc.) may have varied in response to our experimental manipulations, or their interactive effects on Sailfin Molly life history.

My goal for this research was to explore the conditions that would favor the evolution of an herbivorous diet from a carnivorous or omnivorous diet. The fitness peak of carnivorous consumers was higher than all herbivorous consumers in this study. However, diets comprised of mixed autotroph and heterotroph diets were sufficient in supporting fish survival. Compared to algae, carnivorous prey are in low abundance (Sanchez and Trexler 2016) and require elevated risk to obtain (reviewed by Milinski 1985). Supplementing the herbivorous diet with heterotrophic microbes can compensate

for the generally poor quality of aquatic primary producers. This 'multichannel feeding' (Wolkovich et al. 2014) may allow consumers to expend less energy obtaining necessary nutrients to support growth and survival. Experimental tests of these hypotheses are valuable for establishing a research framework that will allow us to more fully understand the diet evolution and herbivory from an adaptation perspective.

\section{Acknowledgments}

Animal use was approved by the Institutional Animal Care and Use Committee under protocol number IACUC-16-017. This project was funded in part by the National Science Foundation through the Florida Coastal Everglades Long-Term Ecological Research program under Grant No. DEB-1237517. 
This is contribution number $\mathrm{xxx}$ from the Southeast Environmental Research Center in the Institute of Water \& Environment at Florida International University.

\section{References}

Ahlgren, G., Gustafsson, I.B., \& Boberg, M. (1992). Fatty-acid content and chemical composition of fresh-water microalgae. Journal of Phycology, $28,37-50$.

Andrade, H. T. A., Nascimento, R. S. S., Gurel, H. C. B., \& Medeiros, J. F. (2000). Simuliidae (Diptera) in the diet of Poecilia vivipara Block \& Schneider, 1801 (Atheriniformes; Poecilidae) at the Ceará-Mirim river, state of Rio Grande do Norte, Brazil. Entomologia y Vectores, 7(1), 119-122.

Arbuckle, J. L. (2014). Amos (Version 23.0) [Computer Program]. Chicago: IBM SPSS.

Armentano, T. V., Sah, J. P., Ross, M. S., Jones, D. T., Cooley, H. C. \& Smith, C. S. (2006). Rapid responses of vegetation to hydrological changes in Taylor Slough, Everglades National Park, Florida, USA. Hydrobiologia, 569, 293-309.

Belicka, L. L., Sokol, E. R., Hoch, J. M., Jaffe, R. \& Trexler, J. C. (2012). A molecular and stable isotopic approach to investigate algal and detrital energy pathways in a freshwater marsh. Wetlands, 32, 531-542.

Bellinger, B. J., Hagerthey, S. E., Newman, S., \& Cook, M. I. (2012). Detrital Floc and Surface Soil Microbial Biomarker Responses to Active Management of the Nutrient Impacted Florida Everglades. Microbial Ecology, 64, 893-908.

Bellwood, D. R. (1995). Direct estimate of bioerosion by parrotfish species, Chlorurus gibbus and C. sordidus, on the Great Barrier Reef, Australia. Marine Biology, 121, 419-29.

Bellwood, D. R. (2003). Origins and escalation of herbivory in fishes: a functional perspective. Paleobiology, 29(1), 71-83.

Bellwood, D. R., Goatley, C. H. R., Brandl, S. J., \& Bellwood, O. (2014). Fifty million years of herbivory on coral reefs: fossils, fish and functional innovations. Proceedings of the Royal Society B, 281, 2013-3046. 
Bowen, S. (1984). Evidence of a detritus food-chain based on consumption of organic precipitates. Bulletin of Marine Science, 35, 440-448.

Bruggemann, J. H., Begeman, J., Bosma, E. M., Verburg, P., \& Breeman, A. M. (1994). Foraging by the stoplight parrotfish Sparisoma viride. II.Intake and assimilation of food, protein and energy. Marine Ecology Progress Series, 106, 57-71.

Burnham, K. P., \& Anderson, D. R. (2002). Model Selection and Multimodel Inference: a practical information-theoretic approach (2nd ed.). New York, NY: SpringerVerlag,

Chick, J. H., Geddes, P., \& Trexler, J. C. (2008). Periphyton mat structure mediates trophic interactions in a subtropical marsh. Wetlands, 28(2), 378389.

Chivers, D. J., \& Langer, P. (1994). The Digestive System in Mammals: Food, Form and Function. New York, NY: Cambridge University Press.

Choat, J. H., \& Clements, K. D (1998). Vertebrate herbivores in marine and terrestrial environments: A nutritional ecology perspective. Annual Review of Ecology and Systematics, 29, 375-403.

Cranwell, P. A., Jaworski, G. H. M., \& Bickley, H. M. (1990). Hydrocarbons, sterols, esters, and fatty acids in 6 fresh-water chlorophytes. Phytochemistry, 29, 145-151.

Dalsgaard, J., St John, M., Kattner, G., Müller-Navarra, D., \& Hagen, W. (2003). Fatty acid trophic markers in the pelagic marine environment. Advances in Marine Biology, 46, 225-340.

deMaintenon, M. J. (1999). Phylogenetic analysis of the Columbellidae (Mollusca: Neogastropoda) and the evolution of herbivory from carnivory. Invertebrate Biology, 118(3), 258-288.

Edwards, R. T., \& Meyer, J. L. (1990). Bacterivory by deposit-feeding mayfly larvae (Stenonema spp.). Freshwater Biology, 24, 453-462.

Espinoza, R. E., Wiens, J. J., \& Tracy, C. R. (2004). Recurrent evolution of herbivory in small, cold-climate lizards: Breaking the ecophysiological rules of reptilian herbivory. Proceedings of the National Academy of Science, 101(48), 1681916824.

Eubanks, M. D., Styrsky, J. D., \& Denno, R. F. (2003). The evolution of omnivory in heteropteran insects. Ecology, 84(10), 2549-2556. 
Findlay, R. H., Dobbs, F. C. (1993). Quantitative description of microbial communities using lipid analysis. In: Kemp, P. F., Sherr, B. F., Sherr, E. B., \& Cole, J. J. (eds), Handbook of methods in aquatic microbial ecology. Boca Raton, FL: Lewis Publishers.

Fuller, R. L., Fry, T. J., \& Roelofs, J. A. (1988). Influence of different food types on the growth of Simulium vittatum (Diptera) and Hydropsyche betteni (Tricoptera). Journal of the North American Benthological Society, 7, 197-204.

Fuller, R. L., \& Fry, T. J. (1991). The influence of temperature and food quality on the growth of Hydropsyche betteni (Tricoptera) and Simulium vittatum (Diptera). Journal of Freshwater Ecology, 6, 75-86.

Fuller, R. L., Kennedy, B. P., \& Nielsen, C. (2004). Macroinvertebrate responses to algal and bacterial manipulations in streams. Hydrobiologia, 523, 113-126.

Gaiser, E. E., Childers, D. L., Jones, R., Richards, J. H., Scinto, L. J., \& Trexler, J. C. (2006). Periphyton responses to eutrophication in the Florida everglades: crosssystem patterns of structural and compositional change. Limnology and Oceanography, 617-630.

Gaiser, E. E., Scinto, L. J., Richards, J. H., Jayachandran, K., Childers, D. L., Trexler, J. C., \& and Jones, R. D. (2004). Phosphorus in periphyton mats provides best metric for detecting low level $\mathrm{P}$ enrichment in an oligotrophic wetland. Water Research, 38, 507-516.

Gaiser, E. E., Trexler, J. C., Richards, J. H., Childers, D. L., Lee, D., Edwards, A. I., ...Jones, R. D. (2005). Cascading ecological effects of low-level phosphorus enrichments in the Florida Everglades. Journal of Environmental Quality, 34, 717-723.

Geddes, P., \& Trexler, J. C. (2003). Uncoupling of omnivore-mediated positive and negative effects on periphyton mats. Oecologia, 136, 585-595.

Goulden, C. E., Henry, L. L., \& Tessier, A. J. (1982). Body size, energy reserves, and competitive ability in three species of cladocera. Ecology, 63(6), 1780-1789.

Hall, R. O., Likens, G. E., \& Malcolm, H. M. (2001). Trophic basis of invertebrate production in 2 streams at the Hubbard Brook Experimental Forest. Journal of the North American Benthological Society, 20, 432-447.

Harrington, R. W., \& Harrington, E. S. (1961). Food selection among fishes invading a high subtropical marsh: from onset of flooding through the progress of a mosquito brood. Ecology, 42, 646-666. 
Harrington, R. W., \& Harrington, E. S. (1982). Effects on fishes and their forage organisms of impounding a Florida salt marsh to prevent breeding by salt marsh mosquitoes. Bulletin of Marine Science, 32, 523-531.

Hay, M. E., \& Fenical, W. (1988). Marine plant-herbivore interactions: the ecology of chemical defense. Annual review of ecology and systematics, 19(1), 111-145.

Hill, W. R., Rinchard, J., \& Czesny, S. (2011). Light, nutrient and the fatty acid composition of stream periphyton. Freshwater Biology, 56, 1825-1836.

Hobbie, J. E., Daley, R. J., \& Jasper, S. (1977). The use of Nuclepore filters for counting bacteria by fluorescence microscopy. Applied and Environmental Microbiology, $33,1225-1228$.

Horn, M. H. (1989). Biology of marine herbivorous fishes. Oceanography and Marine Biology Annual Review, 27, 167-272.

Jäger, C. G., Vrede, T., Persson, L., \& Jansson, M. (2014). Interactions between metazoans, autotrophs, mixotrophs and bacterioplankton in nutrientdepleted high DOC environments: a long-term experiment. Freshwater Biology, 59, 1596-1607.

Karban, R., \& Agrawal, A. A. (2002). Herbivore offense. Annual Review of Ecology, Evolution and Systematics, 33, 641-664.

Kates, K., \& Volcani, B. E. (1966). Lipid components of diatoms. Biochimica et Biophysica Acta, 116, 264-278.

Laspoumaderes, C., Modenutti, B., \& Balseiro, E. (2010). Herbivory versus omnivory: Linking homeostasis and elemental imbalance in copepod development. Journal of Plankton Research, 32(11), 1573-1582.

Martin-Creuzburg, D., Beck, B., \& Freese, H. M. (2011). Food quality of heterotrophic bacteria for Daphnia magna: evidence for a limitation by sterols. FEMS Microbiology Ecology, 76, 592-601.

Martin-Creuzburg, D., von Elert, E., \& Hoffman, K. H. (2008). Nutritional constraints at the cyanobacteria-Daphnia magna interface: The role of sterols. Limnology and Oceanography, 53(2), 456-468.

Martin-Creuzburg, D., Wacker, A., \& von Elert, E. (2005). Life history consequences of sterol availability in the aquatic keystone species Daphnia. Oecologia, 144, 362372. 
Mattson, W. J. Jr. (1980). Herbivory in relation to plant nitrogen content. Annual Review of Ecology and Systematics, 11, 119-161.

Milinski, M. (1985). The patch choice model: no alternative to balancing. The American Naturalist, 125, 317-320.

McCormick, P. V., Chimney, M. J., \& Swift, D. R. (1997). Diel oxygen pro- files and water column community metabolism in the Florida Everglades, U.S.A. Archiv fur Hydrobiologie, 140, 117-29.

Montgomery, W. L., \& Gerking, S. D. (1980). Marine macroalgae as foods for fishes: an evaluation of potential food quality. Environmental Biology of Fishes, 5(2), 143153.

Mulla, M. S., \& Lacey, L. A. (1976). Feeding rates of Simulium larvae on particulates in natural streams (Diptera: Simuliidae). Environmental Entomology, 5, 283-287.

Napolitano, G. E. (1999). Fatty acids as trophic and chemical markers in freshwater ecosystems. In: Arts, M. T., \& Wainman, B. (eds), Lipids in freshwater ecosystems. New York, NY: Springer.

Noe, G. B., Childers, D. L, Edwards, A. L., Gaiser, E., Jayachandran, K., Lee, D., ...Jones, R. D. (2002). Short-term changes in phosphorous storage in an oligotrophic Everglades wetland ecosystem receiving experimental nutrient enrichment. Biogeochemistry, 59, 239-267.

Pauls, S. U., Graf, W., Haase, P., Lumbsch, H. T., \& Waringer, J. (2008). Grazers, shredder and filtering carnivores- The evolution of feeding ecology in Drusinae (Trichoptera: Limnephilidae): Insights from a molecular phylogeny. Molecular Phylogenetics and Evolution, 46, 776-791.

Pike, T., Blount, J. D., Lindstrom, J., \& Metcalfe, N. B. (2007). Dietary carotenoid availability influences a male's ability to provide parental care. Behavioral Ecology, 27(4), 1100-1105.

Porter, K. G., \& McDonough, R. (1984). The energetic cost of response to blue-green algal filaments by cladocerans. Limnology and Oceanography, 29, 365-369.

Reisz, R. R., \& Frobisch, J. (2014). The Oldest Caseid Synapsid from the Late Pennsylvanian of Kansas, and the Evolution of Herbivory in Terrestrial Vertebrates. PLoS ONE, 9(4), e94518. DOI:10.1371/journal.pone.0094518

Ruehl, C. B., \& Trexler, J. C. (2015). Reciprocal transplant reveals trade-off of resource quality and predation risk in the field. Oecologia, 179, 117-127. 
Sanchez, J. L., \& Trexler, J. C. (2016). The adaptive evolution of herbivory in freshwater systems. Ecosphere, 7(7), DOI: e01414. 10.1002/ecs2.1414

Sanchez, J. L., \& Trexler, J. C. (2018). When is an herbivore not an herbivore? Detritivory facilitates herbivory in a freshwater system. Ecology and Evolution, DOI:10.1002/ece3.4133

Scharnweber, K., M., Plath, M., Winemiller, K. O., \& Tobler, M. (2011). Dietary niche overlap in sympatric asexual and sexual livebearing fishes Poecilia spp. Journal of Fish Biology, 79, 1760-1773.

Schmidt, K. \& Jonasdottir, S. H. (1997). Nutritional quality of two cyanobacteria: How rich is 'poor' food? Marine Ecology Progress Series, 151, 1-10.

Smoot, J. C., \& Findlay, R. H. (2010). Caloric needs of a detritivorous gizzard shad Dorosoma cepedianum are met with sediment bacterial and algal biomass. Aquatic Biology, 8, 105-114.

Snelson, F. F., Jr. (1982). Indeterminate growth in males of the sailfin molly, Poecilia latipinna. Copeia, 1982, 296-304.

Snelson, F. F., Jr., Wetherington, J. D., \& Large, H. L. (1986). The relationship between interbrood interval and yolk loading in a generalized poeciliid fish, Poecilia latipinna. Copeia, 1986(2), 295-304.

Sterner, R. W., \& Elser, J. J. (2002). Ecological stoichiometry. Princeton, NJ: Princeton University Press.

Sterner, R. W., \& Hessen, D. O. (1994). Algal nutrient limitation and the nutrition of aquatic herbivores. Annual Review of Ecology and Systematics, 25, 129.

Stevens, C. E., \&. Hume, I. D. (2004). Comparative physiology of the vertebrate digestive system ( $2^{\text {nd }}$ ed.). New York, NY: Cambridge University Press.

Thomas, S., Gaiser, E. E., \& Tobias, F. A. (2006). Effects of shading on calcareous benthic periphyton in a short-hydroperiod oligotrophic wetland (Everglades, FL, USA). Hydrobiologia, 569, 209-221.

Tobler, M. (2008). Divergence in trophic ecology characterizes colonization of extreme habitats. Biological Journal of the Linnaean Society, 95, 517-528.

Travis, J., Farr, J. A., McManus, M., \& Trexler, J. C. (1989). Environmental effects on adult growth patterns in the male sailfin molly, Poecilia latipinna (Poeciliidae). Environmental Biology of Fishes, 26,119-127. 
Trexler, J. C., Gaiser, E. E., Kominoski, J. S., \& Sanchez, J. L. (2015). The role of periphyton mats in consumer community structure and function in calcareous wetlands: Lessons from the Everglades. In: Entry, J. A., Gottlieb, A. D., Jayachandrahan, K., \& Ogram, A. (eds.), Microbiology of the Everglades Ecosystem, Science Publishers, Boca Raton, FL: CRC Press.

Trexler, J. C., \& Travis, J. (1990). Phenotypic plasticity in the Sailfin Molly, Poecilia latipinna (Pisces: Poeciliidae). I. Field experiments. Evolution, 44(1), 143-156.

Turner, A. M., Trexler, J.C., Jordan, C. F., Slack, S. J., Geddes, P., Chick, J. H., \&

Loftus, W. F. (1999). Targeting ecosystem features for conservation: Standing crops in the Florida Everglades. Conservation Biology, 13, 898-911.

Vadeboncoer, Y., \& Power, M. E. (2017). Attached Algae: The cryptic base of the inverted trophic pyramids in freshwaters. Annual Review of Ecology, Evolution, and Systematics, 48, 255-279.

Van Damme, R. (1999). Evolution of herbivory in Lacertid lizards: Effects of insularity and body size. Journal of Herpetology, 33(4), 663-674.

Vermeij, G. (1992). Time of origin and biogeographical history of specialized relationships between Northern marine plants and herbivorous mollusks. Evolution, 46(3), 657-664.

Vermeij, G., \& Lindberg, D. R. (2000). Delayed herbivory and the assembly of marine benthic ecosystems. Paleobiology, 26(3), 419-430.

Volkman, J. K., Johns, R. B., Gillan, F. T., Perry, G. J., \& Bavor, H. J. (1980). Microbial lipids of an inter-tidal sediment. 1. Fatty-acids and hydrocarbons. Geochimica et Cosmochimica Acta, 44, 1133- 1143.

Wang, J., Liu, L., Wang, X., Yang, S., Zhang, B., Li, P., ...Liu, W. (2017). High nighttime humidity and dissolved organic carbon content support rapid decomposition of standing litter in a semi-arid landscape. Functional Ecology, DOI:

$10.1111 / 1365-2435.12854$

Weers, P. M. M., \& Gulati, R. D. (1997). Growth and reproduction of Daphnia galeata in resposnse to changes in fatty acids, phosphorus, and nitrogen in Chlamydomonas reinhardtii. Limnology and Oceanography, 42(7), 1584-1589.

White, T. C. R. (1985). When is a herbivore not a herbivore? Oecologia (Berlin), 67, 596-597. 
Wolkovich, E. M., Allesina, S., Cottingham, K. L., Moore, J. C., Sandin, S. A., \& de Mazancourt, C. (2014). Linking the green and brown worlds: the prevalence and effect of multichannel feeding in food webs. Ecology (95)12, 3376-3386. 
Table 5.1. Sources of fatty acid tracers used in this study (modified from Sanchez and Trexler 2018).

\section{Carbon Source (grouped by fatty acids used in this References study)}

Bacteria (15:0i, 15:0a, 15:0n, 17:0i, 17:0a, 17:0n, 18:1w7, 19:1)

Odd carbon number fatty acids, 15:0i, 15:0a, 17:0i, $\quad$ Findlay and Dobbs (1993); Napolitano (1999) 17:0a, 18:1w7 and references therein; Volkman et al. (1980)

\begin{tabular}{|c|c|}
\hline Fungi (16:1w5, 18:3w9, 18:3w12) & Wang et al. (2017) \\
\hline \multicolumn{2}{|c|}{ Algae (16:3, 18:3w3, 18:4, 18:3w6, 20:4w6, 20:5w3 (EPA), 20:4, 22:4w6, 22:5w3, 22:5w6, 22:6w3) } \\
\hline $\begin{array}{l}\text { 14:0, 16:1w7: multiple sources, but high in diatoms } \\
\text { and some cyanobacteria }\end{array}$ & Napolitano (1999) and references therein \\
\hline $\mathrm{C}_{16}$ PUFA: green algae and diatoms & $\begin{array}{l}\text { Kates and Volcani (1966); Cranwell et al. } \\
\text { (1990); Napolitano (1999) }\end{array}$ \\
\hline 18:3w3: green algae, cyanobacteria & $\begin{array}{l}\text { Ahlgren et al. (1992); Dalsgaard et al. } \\
\text { (2003) }\end{array}$ \\
\hline 18:3w6: cyanobacteria & Napolitano (1999) \\
\hline 18:4w3, 18:5w3, 22:6w3: dinoflagellates & $\begin{array}{l}\text { Ahlgren et al. (1992); Dalsgaard et al. } \\
\text { (2003) }\end{array}$ \\
\hline $20: 5 w 3$, ratio of $20: 5 w 3$ to $22: 6 w 3$ : diatoms & Napolitano (1999); Dalsgaard et al. (2003) \\
\hline
\end{tabular}


Table 5.2. Summary of results showing differences between experimental treatments for diet types (epiphyton and bloodworms) and periphyton. FA ratio $=(\mathrm{SAFA}+\mathrm{MUFA})$ :

PUFA ratio. For epiphyton diets, upward facing triangles indicate relatively high values, whereas downward facing triangles indicate relatively low values. Because bloodworms and periphyton were significantly different in quality than epiphyton, triangles for these variables represent relative comparisons rather than statistical comparisons. Values that are not statistically significant are indicated by "ns". Blanks indicate metrics that could not be measured.

\begin{tabular}{|c|c|c|c|c|c|c|}
\hline & & & & \multicolumn{3}{|c|}{ EPIPHYTON } \\
\hline Metric & $\begin{array}{c}\text { Ambient } \\
\text { Periphyton }\end{array}$ & $\begin{array}{c}\text { Carnivore } \\
\text { Diet }\end{array}$ & Light + P & Light only & Shade $+\mathbf{P}$ & Shade only \\
\hline$C: P$ & $\Delta$ & $\nabla$ & $\nabla$ & $\Delta$ & $\nabla$ & $\Delta$ \\
\hline $\mathbf{N}: P$ & $\Delta$ & $\nabla$ & $\nabla$ & $\Delta$ & $\nabla$ & $\Delta$ \\
\hline $\begin{array}{l}\text { A:H } \\
\text { biovolume }\end{array}$ & ns & -- & $\nabla$ & $\nabla$ & $\Delta$ & $\Delta$ \\
\hline $\begin{array}{l}\text { Relative FA } \\
\text { content }\end{array}$ & $\nabla$ & $\nabla$ & $\nabla$ & $\nabla$ & $\Delta$ & $\Delta$ \\
\hline $\begin{array}{l}\text { Percent algal } \\
\text { FA }(\% / w t)\end{array}$ & ns & ns & ns & ns & ns & ns \\
\hline $\begin{array}{l}\text { Percent } \\
\text { heterotrophic } \\
\text { FA }(\% / \mathbf{w t})\end{array}$ & $\Delta$ & $\boldsymbol{\Delta}$ & $\nabla$ & $\nabla$ & $\Delta$ & $\Delta$ \\
\hline FA ratio & $\Delta$ & $\nabla$ & ns & ns & ns & ns \\
\hline EPA $(\% / w t)$ & $\nabla$ & $\Delta$ & $\nabla$ & $\boldsymbol{\Delta}$ & $\Delta$ & $\nabla$ \\
\hline DHA (\%/wt) & $\nabla$ & $\Delta$ & ns & ns & ns & ns \\
\hline ARA (\%/wt) & $\nabla$ & $\Delta$ & $\Delta$ & $\Delta$ & $\nabla$ & $\nabla$ \\
\hline $\begin{array}{l}\text { Edible algal } \\
\text { spp. }\end{array}$ & $\nabla$ & -- & $\Delta$ & $\nabla$ & $\Delta$ & $\nabla$ \\
\hline
\end{tabular}


Table 5.3. Summary of results showing differences between tissues from fish reared on different diets. FA ratio $=($ SAFA + MUFA $)$ : PUFA ratio. Upward facing triangles indicate relatively high values, whereas downward facing triangles indicate relatively low values. Values that are not statistically significant are indicated by "ns". There were no surviving fish from 'Light $+\mathrm{P}$ ' treatments at the end of the experiment, therefore, I was unable to analyze tissues from these fish.

\section{FISH TISSUES}

\begin{tabular}{lcccc}
\hline Metric & Carnivore & $\begin{array}{l}\text { Light } \\
\text { only }\end{array}$ & $\begin{array}{l}\text { Shade } \\
+ \text { P }\end{array}$ & $\begin{array}{l}\text { Shade } \\
\text { only }\end{array}$ \\
\hline $\begin{array}{l}\text { Relative FA } \\
\text { content }\end{array}$ & $\boldsymbol{\Delta}$ & $\boldsymbol{\nabla}$ & $\boldsymbol{\Delta}$ & $\boldsymbol{\nabla}$ \\
$\begin{array}{l}\text { Percent } \\
\text { autotrophic } \\
\text { FA (\%/wt) }\end{array}$ & ns & ns & ns & ns \\
$\begin{array}{l}\text { Percent } \\
\text { heterotrophic }\end{array}$ & ns & ns & ns & ns \\
$\begin{array}{l}\text { FA (\%/wt) } \\
\text { FA ratio }\end{array}$ & ns & ns & ns & ns \\
EPA (\%/wt) & ns & ns & ns & ns \\
DHA (\%/wt) & ns & ns & ns & ns \\
& & & & \\
ARA (\%/wt) & ns & ns & ns & ns \\
\hline
\end{tabular}


Table 5.4. Comparison of structural equation models used to test 'Heterotrophic facilitation' and 'Lipid allocation' hypotheses. A:H = A:H biovolume, Het. FA= percentage of heterotrophic fatty acids, FA ratio= $($ SAFA + MUFA $)$ : PUFA ratio. $\triangle \mathrm{AICc}$ values $\leq 2$ are highlighted in bold

\begin{tabular}{llllllll}
\hline & & \multicolumn{3}{c}{ 3 weeks } & & \multicolumn{3}{c}{ 6 weeks } \\
& & & & & & \\
\hline Model & Description & $\Delta$ AICc & $\mathbf{A I C}_{\mathrm{w}}$ & $\boldsymbol{w}_{\boldsymbol{m} \text { min }} / \boldsymbol{w}_{j}$ & $\Delta \mathbf{A I C}_{\mathbf{c}}$ & $\mathbf{A I C}_{\mathrm{w}}$ & $\boldsymbol{w}_{\boldsymbol{m} \text { in }} / \boldsymbol{w}_{j}$ \\
& & & & & & & \\
\hline 1 & A:H + Het. FA+ FA ratio & $\mathbf{1 . 8 1}$ & $\mathbf{0 . 2 4}$ & $\mathbf{2 . 4 7}$ & $\mathbf{1 . 8 7}$ & $\mathbf{0 . 2 0}$ & $\mathbf{2 . 5 5}$ \\
2 & A:H+ Het. FA & $\mathbf{0 . 0 0}$ & $\mathbf{0 . 5 8}$ & $\mathbf{1 . 0 0}$ & $\mathbf{0 . 0 0}$ & $\mathbf{0 . 5 2}$ & $\mathbf{1 . 0 0}$ \\
3 & A:H+ FA ratio & 7.57 & 0.01 & 44.04 & 3.85 & 0.08 & 6.86 \\
& & & & & & & \\
4 & Het. FA + FA ratio & 5.11 & 0.05 & 12.87 & 8.42 & 0.01 & 67.36 \\
5 & A:H & 5.58 & 0.04 & 16.28 & 2.28 & 0.17 & 3.13 \\
6 & Het. FA & 3.91 & 0.08 & 7.06 & 6.53 & 0.02 & 26.18 \\
7 & FA ratio & 9.42 & 0.01 & 111.05 & 9.20 & 0.01 & 99.48 \\
\hline
\end{tabular}




\section{Figure Legends}

Fig. 5.1. (A) Standard length (mm) of juvenile Sailfin Mollies raised on experimental diets showing increased growth of fish consuming epiphyton grown in 'Light only' and 'Light + P' conditions at 3 weeks. (B) Survival scores (p') of juvenile Sailfin Mollies showing low survival of fish consuming epiphyton grown in 'Light $+\mathrm{P}$ ' conditions.

Fig. 5.2. (A) The structural equation model with the best fit $(\triangle \mathrm{AICc}=0.00)$ showing autotroph: heterotroph $(\mathrm{A}: \mathrm{H})$ biolvolume and heterotrophic fatty acid percentage as the best predictors of fish life history at 3 weeks. Numbers indicate regression coefficients for each path analyzed, suggesting that decreased A:H biolvolume and decreased heterotrophic fatty acid percentage results in increased fish life history. (B) The structural equation model with the best fit $(\triangle \mathrm{AICc}=0.00)$ showing autotroph: heterotroph $(\mathrm{A}: \mathrm{H})$ biolvolume and heterotrophic fatty acid percentage as the best predictors of fish life history at 6 weeks. Numbers indicate regression coefficients for each path analyzed, suggesting that increased A:H biolvolume and increased heterotrophic fatty acid percentage results in increased fish life history. This is opposite of the 3 -week model results. 
FIG. 5.1.
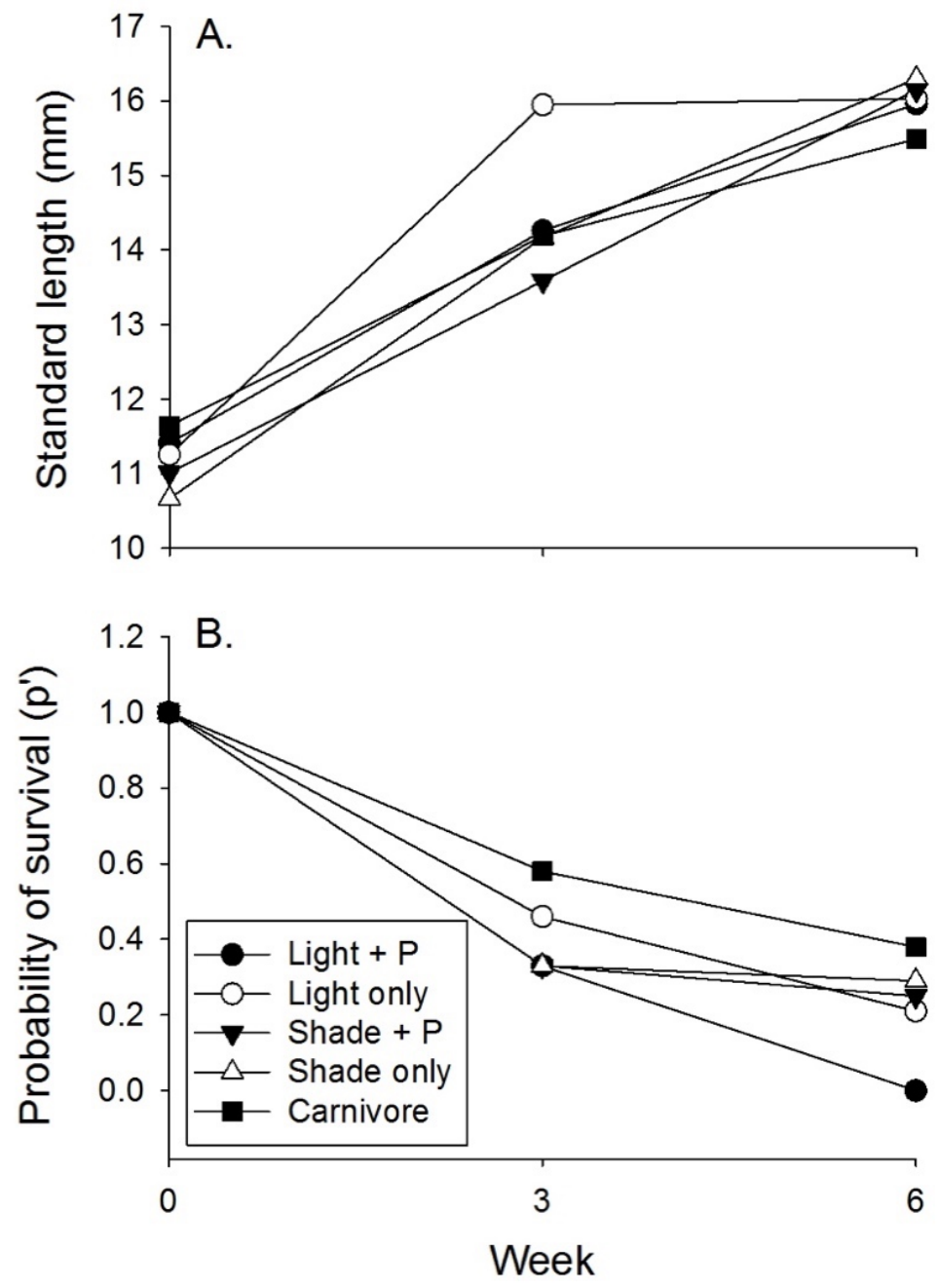


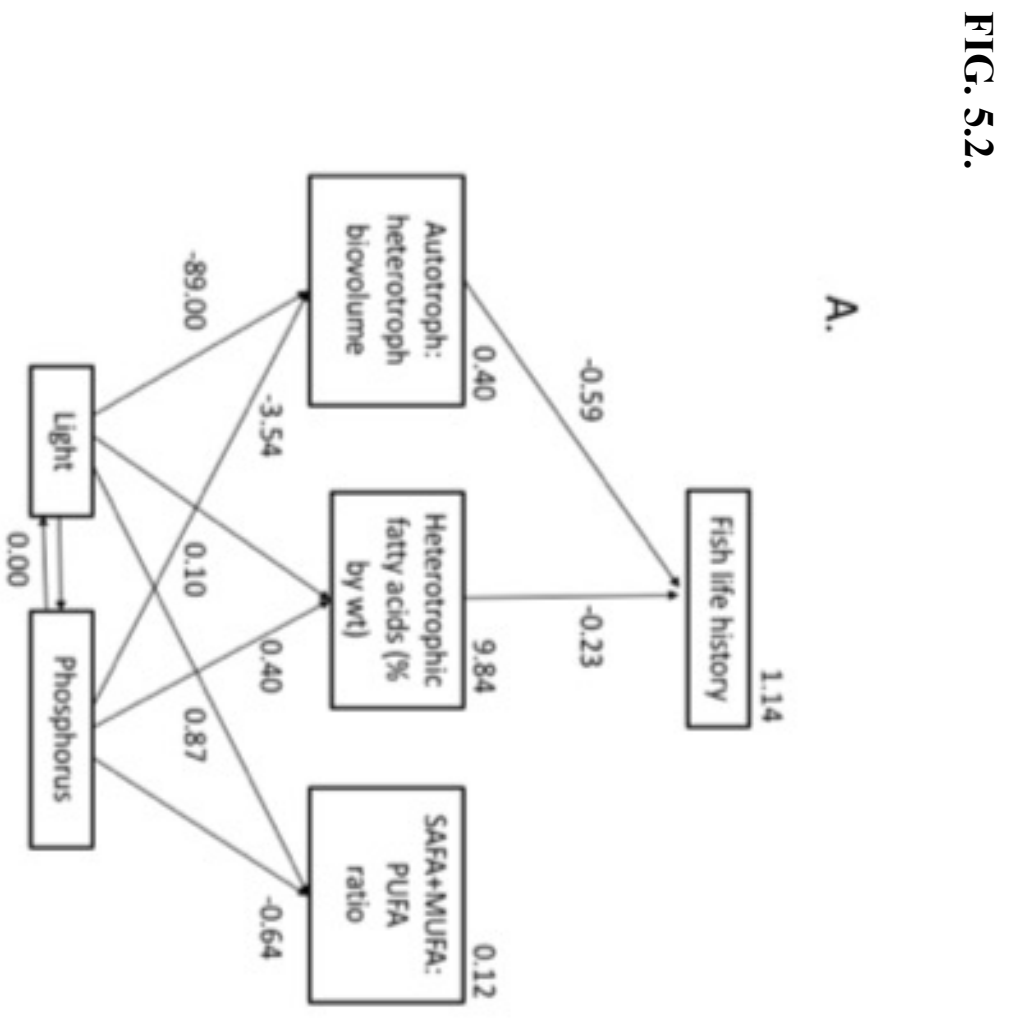

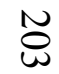

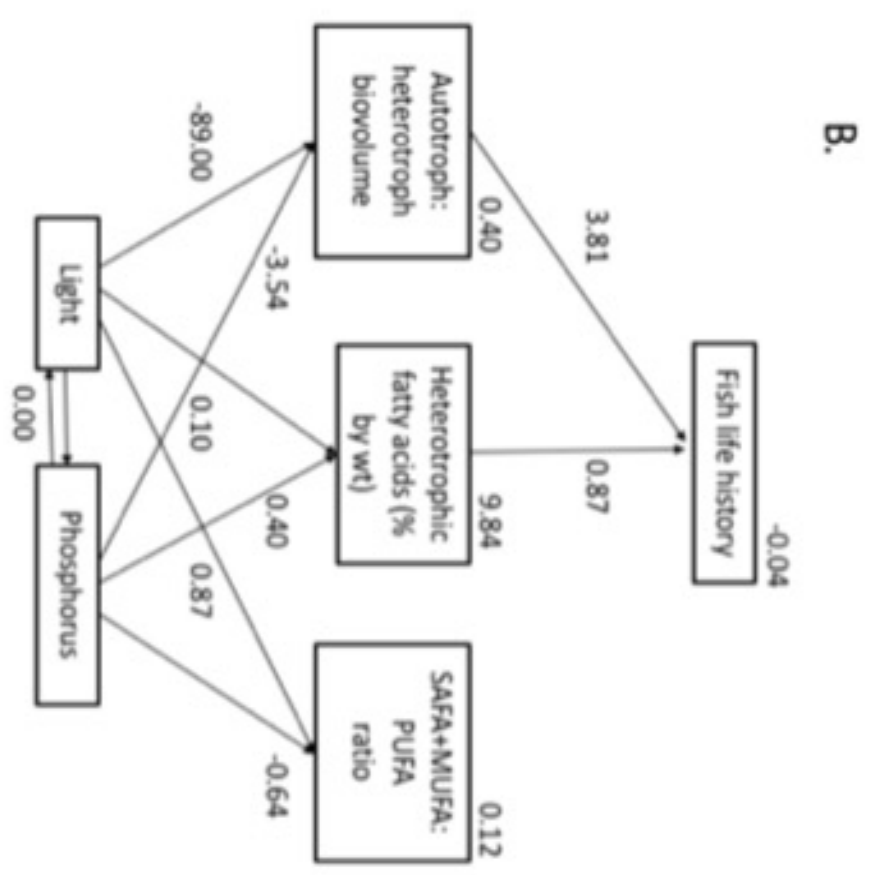


Supplementary Information 
웅

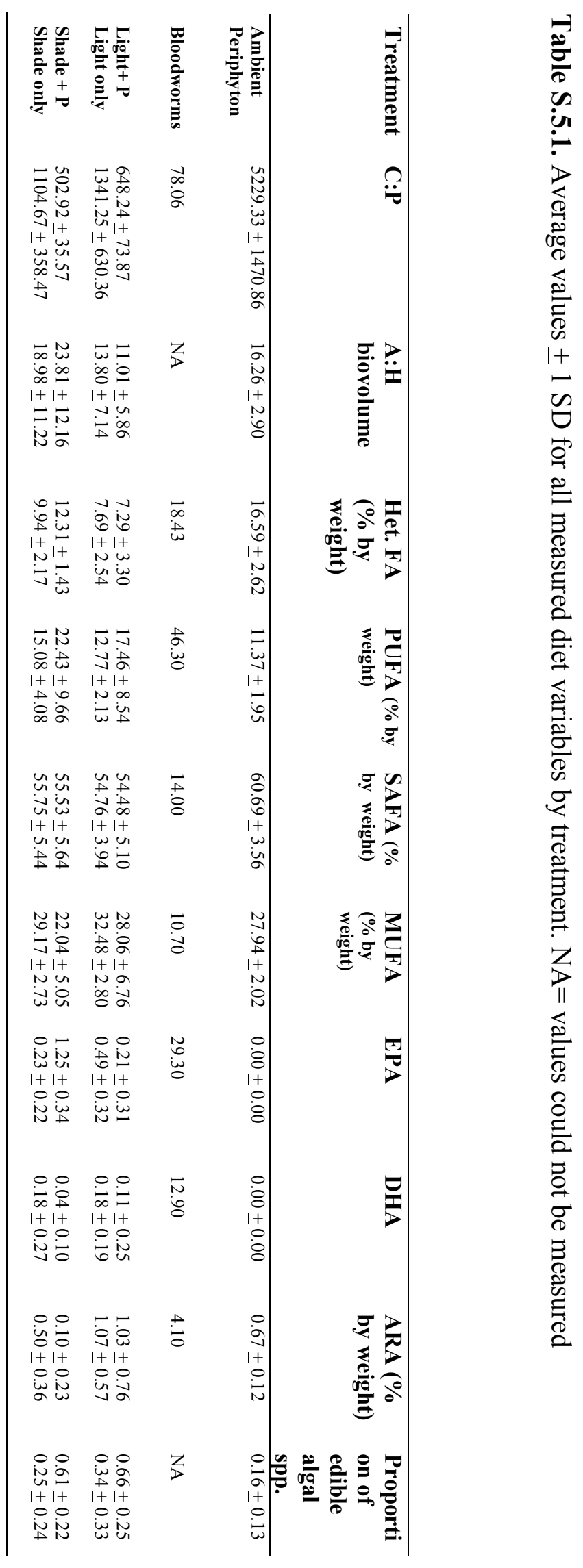




\section{CHAPTER 6}

NUTRITONAL LANDSCAPE OF THE EVERGLADES: MECHANISMS SHAPING

CONSUMER NICHE DIVERSITY ALONG THE BROWN-GREEN FOOD WEB

CONTINUUM

Formatted for: Oikos 


\begin{abstract}
Niche-based models assume that resource quality and availability interact with the physical environment to drive community assembly based on consumer diets and food web function. Conversely, dispersal-based models predict that community assembly is driven by stochastic colonization, independent from species traits. It has been suggested that resource quality/quantity drives diet evolution, which can in turn, influence consumer function in a food web. Therefore, invoking models that ignore the role of species traits in shaping communities limits our ability to understand the evolutionary consequences of ecological processes.

To better understand the mechanisms shaping consumer niche diversity, I determined if niche- or dispersal-based predictions best described consumer dynamics in the Florida Everglades based on the nutritional landscape. I sampled periphyton and consumers from 22 sites across the ecosystem and measured variables describing food quality (macronutrients, stoichiometry, edibility, fatty acid profiles) and food availability (periphyton volume, herbivore density) in both the wet and dry seasons. I used Structural Equation modelling to examine these variables as potential drivers of consumer density and to identify the conditions where herbivory and omnivory may be favored. I interpreted the results in the context two hypotheses about the maintenance of herbivorous diets in food webs, the Heterotroph Facilitation Hypothesis (herbivory is adaptive because herbivores supplement their diets with heterotrophic microbes) and the Suboptimal Habitat Hypothesis (herbivory may be an adaptive strategy to allow organisms to invade habitats with decreased resource quality).
\end{abstract}


My data revealed that herbivores track food quality when habitats are stable, but they can persist in a multitude of habitat types and survive on resources of varying quality when habitats are variable. These results suggest that herbivore diets follow niche-based predictions in the wet season, but dispersal-based predictions in the dry season. In contrast, omnivores rely on high-quality resources in both seasons, consistent with nichebased predictions. Taken together, these results partially support the Suboptimal Habitat Hypothesis as an explanation for the evolution and maintenance of herbivory in this system. By identifying an evolutionary mechanism that promotes herbivory, we are able to more fully describe the complex role of these consumers in functional food webs. Future trophic studies may benefit by using a framework that incorporates both ecology and evolution to predict how food webs are organized in nature.

Keywords Adaptive evolution, Everglades, diet evolution, food web, herbivory, omnivory, trophic dynamics, niche-based models, dispersal-based models, community assembly

\section{Introduction}

Consumers inhabit landscapes that vary spatially and temporally in resource quality and quantity (Hunter 2016). Until recently, ecologists predicted that community assembly resulted from local processes such as habitat filtering and biotic interactions, and species' ability to invade established communities was determined by their traits (Chase and Leibold 2003; McPeek 2017). Niche-based models assume robust dispersal to describe how resource quality and availability interact with environmental stress to drive community assembly (Chase and Leibold 2003; Chase 2007). 
When dispersal is assumed to be limited, neutral and patch dynamics models predict a role for stochastic colonization in community assembly, independent from species' traits (Hubbell 2001; Chase and Leibold 2003; Chase 2007). Some studies have shown that simplified dispersal-based models yield similar results to relatively complicated nichebased models (Condit et al. 2000; Bell 2001; Hubbell 2001, Volkov et al. 2003), challenging our ability to assign a single model to explain field data (Brown et al. 2017). There is no shortage of studies detailing the role of resource availability (e.g., Desilets and Houle 2005; Thompson and Townsend 2005) and environmental stress (e.g., Desilets and Houle 2005; Walters and Post 2011) in shaping communities via their effects on food webs. Therefore, inferring food web dynamics without considering the effects of both species' traits and environmental factors limits our ability to fully understand how communities are organized.

While these frameworks have allowed us to examine the underlying factors affecting food-web function, they do not consider the source of energy flow in their predictions. Determining the relative contribution of detrital and algal resources to aquatic food webs is an important goal in characterizing trophic structure (Moore et al. 2004; Belicka et al. 2012). Although studies on autotrophic food webs dominate the literature, it is becoming apparent that "brown" food webs play a key role in trophic structure, particularly in wetland ecosystems (Williams and Trexler 2006; Belicka et al. 2012; Sanchez and Trexler 2018). Models that link green and brown food webs have focused on nutrient cycling, where dead green matter transfers to a detrital pool that is mineralized. The mineralized nutrients then serve as sources of limiting nutrients for the primary producers comprising the algal pool (DeAngelis et al. 1989; DeAngelis 1992; 
Wolkovich et al. 2014). In addition to nutrient cycling, consumers can connect detrital and algal food webs by accessing the mineralized detritus directly (by eating it), by eating lower consumers that are detritivores (Wolkovich et al. 2014), or by consuming closely associated primary producers (Sanchez and Trexler 2016). Typically, brown and green pathways are studied independently, but there is evidence that "true" herbivory is rare in nature and instead, detritivory facilitates herbivory (Sanchez and Trexler 2018).

Herbivores and omnivores mobilize the captured energy from detrital and algal pools, but it is believed to be constrained by the vast variation in food quality at the base of both food webs. In nature, resources are distributed across a heterogeneous landscape, resulting in natural variation in consumer life history that drives species relative abundances and distributions (Kareiva 1990; Tilman 1994; Polis et al. 1997; Power and Dietrich 2002; McIntosh et al. 2004; Torres-Ruiz et al. 2007; Doi 2009; Guo et al. 2016). Recent evolutionary studies have found that variation in resources can also drive diet evolution (Diehl 2003; Krivan and Diehl 2005; Namba et al. 2008; Sanchez and Trexler 2016, 2018), suggesting that adaptive evolution can influence consumer function in a food web and shape community structure. The evolution of herbivory or omnivory from carnivory has been documented in several lineages (Vermeij 1992; deMaintenon 1999; Van Damme 1999; Vermeij and Lindberg 2000; Bellwood 2003; Espinoza et al. 2004; Pauls et al. 2008, Bellwood et al. 2014; Reisz and Frobisch 2014), and indicates that there is some adaptive advantage to eating plants. A few modelling studies found that the evolution of omnivory is favored when basal resources are high in abundance, and when higher-quality animal prey are rare (Diehl 2003; Krivan and Diehl 2005), but the evolution of herbivory is relatively understudied. 
Identifying the adaptive significance of herbivory may improve niche-based models by providing a mechanism that describes how resources and environments interact to drive community assembly. To better understand the mechanisms that shape consumer niche diversity, I evaluate the explanatory power of two hypotheses about the maintenance of herbivorous diets in food webs: 1) the Heterotroph Facilitation Hypothesis, which states that herbivory is adaptive because indirect detritivory supplements the herbivorous diet (i.e., assimilating nutrients from heterotrophs that were not the target diet item, but consumed as a consequence of their close association with primary producers), 2) and the Suboptimal Habitat hypothesis, which states that herbivory is adaptive because it allows organisms to invade and persist in 'suboptimal' habitats (Sanchez and Trexler 2016). I found evidence supporting both of these hypotheses in previous studies focusing on herbivorous members of the genus Poecilia. In both a lab and field study, I found that heterotroph-derived fatty acids supplement the diet of juvenile Sailfin Mollies $(P$. latipinna) and play an important role in their growth and survival (Sanchez and Trexler 2018), consistent with the Heterotroph Facilitation Hypothesis. An ancestral state reconstruction of diet and habitat across a phylogeny of the genus Poecilia revealed that herbivory evolved in response to habitat transitions across the freshwater-marine boundary (Sanchez et al., in review). This finding supports the Suboptimal Habitat Hypothesis as a mechanism behind the evolution of herbivory in the subgenus Mollienesia (includes P. latipinna). 
Although these studies provide alternative explanations for the evolution of herbivory, the key distinction between these hypotheses is that heterotroph facilitation is a mechanism to overcome poor food quality, and invasion of suboptimal habitats allows passage into habitats with varying resource bases. The bases of these findings is the same, however; resource quality and/or availability is responsible for the evolution and/or maintenance of herbivory in nature and the relative green. Therefore, I predict that these adaptive hypotheses may be able to explain variation in consumer trophic dynamics using niche-based and dispersal-limited frameworks.

The Florida Everglades is an ideal system to study trophic dynamics because food quality varies greatly across the landscape. The Everglades ecosystem has been impacted by urban and agricultural activities that have resulted in water diversions and nutrient enrichment (Noe et al. 2001; Gaiser et al 2005). The wetlands in the northern region are managed by a series of water control structures that divert water from developed areas and maintain water in 'water conservation areas' (WCA) that serve as a supply for South Florida (Light and Dineen 1994). Because these marshes are heavily managed and in close proximity to agricultural lands, they are impacted by nutrient input. The marshes in the southern region are relatively oligotrophic and hydrology is driven by rainfall, unlike the WCAs (Noe et al. 2001). As a result, these areas experience a wet season (JuneNovember), followed by drying events (December-May). Periphyton, the primary basal resource in Everglades (Browder et al. 1994; Radar and Richardson 1994; Williams and Trexler 2006), is composed of assemblages of autotrophs (green algae, diatoms and cyanobacteria) and heterotrophs (fungi and bacteria; Gaiser et al., 2004). 
The complexity of these assemblages has resulted in oversimplifications about the relative contribution of green and brown energy channels to wetlands food webs (Taylor and Batzer 2010), but several studies have shown that both autotrophs and heterotrophs are sources of energy for consumers in the Everglades (Williams and Trexler 2006; Belicka et al. 2012; Sanchez and Trexler 2018). Both of these periphyton components respond rapidly to changes in hydrology and water chemistry (Pan et al. 2000; Noe et al. 2001; McCormick et al. 2002; Gottlieb et al. 2015), thus creating variation in the nutritional quality at the base of the Everglades food web. In addition to variation in food quality, the Everglades has an unusual Eltonian biomass pyramid, where there is an extremely high abundance of periphyton relative to consumers (Turner et al. 1999; Gaiser et al. 2005). The typical Everglades food web is dominated by omnivorous and herbivorous macroinvertebrates and small fishes (Chick et al. 2008), and there is significant heterogeneity in the distribution of consumers across the landscape. These food web characteristics combined with the longitudinal variation in resource quality suggests that bottom-up transfer of energy is not very efficient in the Everglades (Turner et al. 1999; Geddes and Trexler 2003).

The impacts of nutrients and hydrology on Everglades periphyton communities have been extensively studied as part of the Everglades restoration plan (e.g., Gaiser 2009; Gaiser et al, 2011), and researchers have gained interest in the resulting trophic dynamics in light of these studies (e.g., Williams and Trexler 2006; Belicka et al. 2012; Trexler et al. 2015). 
In this study, I take advantage of the high producer biomass and natural variation in resources (brought about by hydrological disturbance and nutrient enrichment) in the Everglades to determine if hypotheses describing the evolution of herbivory can predict consumer dynamics across the landscape using niche-based and dispersal-limited frameworks.

\section{Methods}

\section{Field Collection}

I collected periphyton and fish samples from 22 sites across the Everglades (Fig. 6.1) landscape during the peak of the dry season (June-July 2016) and the wet season (January-February 2017). These sites span much of the freshwater Everglades ecosystem, thus capturing the longitudinal environmental gradient. In addition, these marshes vary in hydroperiod, where some experience annual dry-downs and others are constantly flooded (Table 6.1). I measured $\mathrm{pH}$ and conductivity from each site using a YSI meter and $\mathrm{pH}$ probe. Using a throw trap (Jordan et al. 1997), a random $1 \mathrm{~m}^{2}$ plot was surveyed for periphyton cover $(\%)$, percentage cover of emergent macrophytes, total periphyton volume $(\mathrm{mL})$, estimates of percentage of dominant submerged plant species (Table 6.1), and floating-mat and soil type (Table S.6.1). Hydrological data were obtained from the Everglades Depth Estimation Network (EDEN, United States Geological Survey; Table 6.1). I focused on days since dry (DSD; the number of days since the depth measured $<5$ $\mathrm{cm}$ ), and hydroperiod (the number of days in the 365 before sampling that the depth at the site measured $>5 \mathrm{~cm}$ ) as hydrology metrics. 
Because South Florida experiences a wet and dry season, hydroperiod was calculated by water year, which runs from the start of the wet season (May through October) through the end of the follow dry season (November through April).

Consumer density data were taken from July 2016 and February 2017 collections. I focused on six native fish and four macroinvertebrate species: Sailfin Molly (Poecilia latipinna), Flagfish (Jordanella floridae), Bluefin Killifish (Lucania goodei), Eastern Mosquitofish (Gambusia holbrooki), Golden Topminnow (Fundulus chrysotus), Least Killifish (Heterandria formosa), riverine grass shrimp (Palaemonetes paludosus), scuds (Hyalella spp), mayflies (Ephemeroptera), and midge larvae (chironomid spp). Consumer density was estimated by calculating the average number of consumers per 1- $\mathrm{m}^{2}$ from 5-7 randomized throw-trap samples at each of the sites for each season. I estimated fish trophic groups using gut-content data from Everglades fishes collected in wet and dry seasons (Loftus 2000), and I used the trophic groups presented in Belicka et al. (2012) to categorize macroinvertebrate diets. There may be no "true" aquatic herbivores in the Everglades (Belicka et al. 2012, Sanchez and Trexler 2018), but rather herbivorous consumers that supplement their diet with microbes originating from detritus. Therefore, we grouped all consumers that subsist on the autotroph-detritus continuum into a group referred to as 'herbivores'. Trophic groups (herbivores and omnivores) were summed over each site to obtain consumer density (no. of consumers $/ \mathrm{m}^{2}$ ) for each season. 
I collected periphyton from each site and characterized samples into 4 specific types: 1) Floating mat-aggregation of floating mature periphyton. Might be found in homogeneous floating aggregations, in small clumps in association with Utricularia spp., or in an epiphytic growth on emergent vascular plant stems; 2) Benthic mat- submerged periphyton adjacent to the exposed sediment. Might be found in homogeneous aggregations, or in smaller clumps in association with flocculent matter; 3) Epiphytonnewly colonizing epiphyton that is collected from the submerged stems of aquatic macrophytes; or 4) Filamentous green algae- filamentous green algal species usually occupying the water column in colonies visible to the naked eye; occasionally loosely attached to aquatic vegetation. Percentages of each periphyton type were assigned based on their abundance in the $1-\mathrm{m}^{2}$ sample plot (Table 6.2). These percentages were multiplied by the total periphyton volume $(\mathrm{mL})$ in the sample plot to estimate the volume of each periphyton type in the $1-\mathrm{m}^{2}$ plot. For each periphyton type, $50 \mathrm{~mL}$ samples $(\mathrm{N}=3)$ were collected, placed in separate vials, and brought back to the lab on ice. Samples of 13 dominant fish consumers were also collected from each site by hand net or throw trap, euthanized using an overdose of MS-222, transported on ice and subsequently frozen. All collections were handled using gloves to prevent any nutrient input.

\section{Food Quality Assays}

Nutritional quality of periphyton for consumers was assessed by estimating edibility, macronutrient composition, stoichiometry, and fatty acid profiles. I use the definition of "high" food quality that is presented in my previous studies (Sanchez and Treler 2016 and 2018). 
Specifically, food with high essential fatty acid content (PUFAs, EPA, DHA, ARA), increased protein or lipids relative to carbohydrates, increased TP, and/or increased edible algal content relative to food with the opposite metrics is considered "highquality". In the lab, periphyton samples were homogenized directly in the sample vial using a hand-held biohomogenizer. Known volumes of each periphyton type from each site were placed onto a clean microscope slide and autotrophic species (algae, cyanobacteria, diatoms) were counted using standard light microscopy at 40x magnification. Counts were transformed into total cells $/ \mathrm{mL}$ of material, which were then used to estimate the proportion of edible (green algae and diatoms) and inedible (cyanobacteria) components. These percentages were multiplied by the volume of each periphyton type $\left(\mathrm{ml} / \mathrm{m}^{2}\right)$, summed by site, and converted to proportions to yield the proportion of edible and inedible species (\%) for each site (for each season). A subsample of each periphyton type (from each site/season) was dried to constant weight at $60^{\circ} \mathrm{C}$ and placed in a muffle furnace at $500^{\circ} \mathrm{C}$ for 1 hour to estimate ash-free dry mass (AFDM). I then estimated the organic and mineral components of each periphyton type $\left(\mathrm{mg} / \mathrm{m}^{2}\right)$.

The remaining samples (including fish) were freeze-dried and prepped for nutrient analyses. Total protein was measured using a modified Lowry technique (Markwell et al. 1978) by digesting $0.15 \mathrm{mg}$ of dried sample in $50 \mu \mathrm{L} \mathrm{NaOH}$ for 1 hour at $60 \mathrm{C}$. I then followed the standard 96-well assay protocol listed in the Pierce BCA Protein Assay Kit (Thermo Scientific). This kit yields the colorimetric determination of total protein through reduction of copper in an alkaline medium. Samples were read on a microplate reader (Biotek Synergy HT multi-well) at $562 \mathrm{~nm}$. 
Total carbohydrates were quantified by digesting $0.4 \mathrm{mg}$ of dried sample in Trichloroacetic acid for 3 hours at 90 C. Following sample digestion, I used the vanillinsulfuric acid method (Masuko et al. 2005) in a 96-well microplate preparation and read results at $490 \mathrm{~nm}$. Total lipid concentration was estimated by using the Folch method (Folch et al. 1956) to digest $0.25 \mathrm{mg}$ of dried sample in $0.2 \mathrm{ml}$ of chloroform: methanol $(2: 1 \mathrm{v} / \mathrm{v})$. I transferred $30 \mu \mathrm{L}$ of supernatant from each sample to microcentrifuge tubes and incubated uncovered for 30 minutes at $90 \mathrm{C}$. I then followed the methods of Cleveland and Montgomery (2003) to colorimetrically estimate total lipids and read these samples at $540 \mathrm{~nm}$. All macronutrients were calculated as mg macronutrient/sample. I divided these values by the dry weight of the sample (e.g., $0.4 \mathrm{mg}$ for carbohydrate estimation), and multiplied them by the dry weight of the organic portion of periphyton found in $1 \mathrm{~m}^{2}$ (estimated from AFDM) to yield $\mathrm{mg}$ macronutrient $/ \mathrm{m}^{2}$ for each periphyton type. These values were summed over all periphyton types to yield total macronutrient $/ \mathrm{m}^{2}$ for each site, by season.

Freeze-dried periphyton and fish samples were sent to the Southeastern Research Center (SERC) located at Florida International University for stoichiometric (C:N:P) analyses (approx. 20mg per sample) and were sent to Microbial ID (Newark, DE) for lipid profile analyses $(15 \mathrm{mg})$. Total nitrogen, carbon and phosphorus were converted from $\mathrm{ug} / \mathrm{g}$ to moles in order to estimate stoichiometric ratios (C:P and N:P) for each periphyton type and for fish tissues. These ratios were averaged across all periphyton types and fish species for each site and reported by ratio and TP (ug/g). 
Fatty acids were sorted by autotroph- and heterotroph-derived diet tracers (see Sanchez and Trexler 2018 for specific fatty acid tracers), by saturation (polyunsaturated, saturated, monounsaturated; PUFA, SAFA, MUFA, respectively) and by essential fatty acids (EPA, DHA, ARA). Values were returned as percentages of individual fatty acids in the total sample. For periphyton samples, saturation values were converted to a ratio (PUFA: (SAFA + MUFA), herein referred to as 'PUFA ratio'), and all others were converted to $\mathrm{mg}$ fatty acid $/ \mathrm{m}^{2}$ for each periphyton type by multiplying each percentage by periphyton volume $\left(\mathrm{mL} / \mathrm{m}^{2}\right)$. These values were summed over all periphyton types to yield total fatty $\mathrm{acid} / \mathrm{m}^{2}$ for each site, by season. For fish tissues, I averaged percentages of individual fatty acids (autotrophic, heterotrophic, EPA, DHA and ARA) by species and by site to determine any intra- and interspecific differences in tissue composition.

\section{Statistical analyses}

The effects of hydroperiod and season on nutritional quality of food (periphyton) and consumer density were analyzed. To meet the assumptions of analyses, I $(\log +1)$ transformed all non-normal data and converted hydroperiod (obtained from EDEN) to categorical variables using hierarchical cluster analysis with the Sorensen (Bray-Curtis) distance measure with flexible beta linkages (CLUSTER package in R; Maechler et al. 2017). Converting these values to categorical variables allowed us to group nutritional variables and consumer densities by hydroperiod, therefore increasing degrees of freedom. 
I then calculated z-scores for environmental variables $(\mathrm{pH}$, conductivity, hydroperiod, DSD, and percent emergent plants), variables describing periphyton availability (periphyton cover $\%$, floating mat volume, benthic mat volume, epiphyton volume, and filamentous algae volume), and variables describing periphyton food quality (protein, carbohydrate, lipid, heterotrophic fatty acid \%, PUFA ratio, EPA \%, TP, and edible algae). I reduced these variables using Principal Components Analyses (PC; using devtools package in R) with hydroperiod categories as grouping variables. I assessed variables for collinearity and those with Tolerance levels $<0.20$ and Variance Inflation Factors $>5.00$ were considered overlapping and were removed from the analyses. Variables that were highly collinear (mineral content, DHA, ARA, autotrophic fatty acid $\%, \mathrm{C}: \mathrm{P}$, and $\mathrm{N}: \mathrm{P}$ ) were excluded from the analyses.

I compared algal composition of different periphyton types among hydroperiod categories using Analysis of Similarity (ANOSIM) and Similarity Percentage Analysis (SIMPER) using Primer v7. I used one-way Analysis of Variance (ANOVA) and Tukey Post-hoc tests to compare PC scores for periphyton quality/availability and consumer density across hydroperiod categories for each season, and to compare fish tissue composition (fatty acids, macronutrients, stoichiometry) among species by hydroperiod and season.

I estimated trophic groups of the common Everglades fish species using hierarchical cluster analysis (Sorensen distance measure) with flexible beta linkages (CLUSTER package in R; Maechler et al. 2017). This analysis was performed using gut content data collected from consumers in the Everglades sampled during the wet and dry seasons (taken from Loftus 2000). 
The resulting diet clusters were used to categorize fish consumers in this study. The PC scores calculated from the environmental data (taken from the first two axes) were regressed with scores representing periphyton availability/quality and consumer density (omnivores and herbivores).

I used the residuals from these analyses as input variables for Structural Equation Models (SEM; Grace 2006), which were fit using the AMOS package in SPSS (Arbuckle 2014). Performing these analyses using residuals allowed us to determine patterns in consumer density that were uniquely attributed to periphyton availability and quality, independent of environment ( $\mathrm{pH}$, conductivity, hydroperiod, $\mathrm{DSD}$, and percent emergent plants). Paths were varied between basal resource variables (periphyton quality and periphyton availability) and consumer density (herbivore and omnivore density) in each model. For herbivore models, the linkage between omnivores and herbivores represents the direct effects of competition with omnivores and/or predation by omnivores. Conversely, the linkage between these trophic groups in the omnivore models represents the direct effects of herbivore predation by omnivores.

Models were compared using Akaike's Information Criterion (AIC) by calculating $\Delta \mathrm{AICc}\left(\Delta \mathrm{AICc}=\mathrm{AIC}_{\mathrm{i}}-\min \mathrm{AICc}\right.$, where $\mathrm{i}=$ model $\left.\mathrm{i}\right)$, Akaike weight $\left(\mathrm{AIC}_{\mathrm{w}}=\left(\mathrm{e}^{(-0.5}\right.\right.$

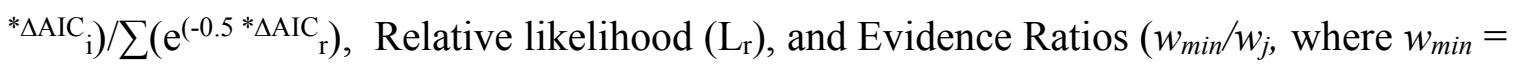
$\mathrm{AIC}_{\mathrm{w}}$ for the model with the smallest $\triangle \mathrm{AICc}$ and $w_{j}=\mathrm{AIC}_{\mathrm{w}}$ for the current model; Anderson and Burnham 2002). Path coefficients (regression weights) were assessed to determine which variables best predicted life history. Following Anderson \& Burnham (2002), models with $\Delta \mathrm{AICc}<2.0$ were considered equally explanatory. 


\section{Hypotheses Tests}

The Suboptimal Habitat hypothesis predicts that herbivore density will vary in proportion to food quantity (independent of other ecological interactions). The Heterotroph Facilitation hypothesis predicts that heterotrophic microbes (e.g., bacteria, fungi) supplement and compliment the herbivorous diet, therefore, herbivore density should increase in proportion to the percentage of heterotrophic fatty acids found in the basal resource (periphyton). I used linear regression to assess the relationship between periphyton quality (residuals of PC1 and PC2), periphyton availability (residuals of PC1 and PC2) and herbivore density (residuals). Furthermore, I determined the relationship between periphyton availability (residuals of PC1 and PC2) and periphyton quality (residuals of PC1 and PC2) for each season. I interpreted the results of the regression analyses in the context of the Suboptimal Habitat and Heterotroph Facilitation predictions to determine if herbivore density could be explained by either of these mechanisms.

\section{Results}

Hierarchical cluster analysis of hydroperiod data produced four hydroperiod categories $($ Cophenetic correlation $=0.827)$ : 1$)$ water depth is greater than $5 \mathrm{~cm}$ for less than 300 days per year, 2) water depth is greater than $5 \mathrm{~cm}$ for 300-324 days per year, 3) water depth is greater than $5 \mathrm{~cm}$ for 325-350 days per year, and 4) water depth is greater than $5 \mathrm{~cm}$ for greater than 350 days per year. See Table 6.1 for list of sites and hydroperiod classifications. 


\section{Wet Season}

There were few differences in environmental variables across hydroperiods in the wet season. Sites with $<300$ days of inundation had average depths of $18.75 \pm 4.65 \mathrm{~cm}$, sites with water 300-324 days were $43.6 \pm 7.83 \mathrm{~cm}$, sites with water 325-350 days were 49.86 $\pm 7.47 \mathrm{~cm}$, and sites with $>350$ days of inundation were $53.5 \pm 8.94 \mathrm{~cm}$ in the wet season. There were no differences in $\mathrm{pH}$ and conductivity among hydroperiods, but the shorter hydroperiods had more emergent vascular plants per $\mathrm{m}^{2}$ than the longer hydroperiods. Sites inundated $<300$ days had $82.4 \%$ greater emergent plant stem density than sites inundated with water $>350$ days $\left(F_{3,20}=5.71, P=0.007\right)$. There were no differences in periphyton $\mathrm{C}: \mathrm{P}$ and $\mathrm{N}: \mathrm{P}$ ratios across sites in the wet season $\left(\mathrm{CP}: \mathrm{F}_{3,18}=\right.$ $\left.1.61, \mathrm{P}=0.228 ; \mathrm{NP}: \mathrm{F}_{3,18}=0.722, \mathrm{P}=0.554\right) . \mathrm{I}$ was unable to statistically compare stoichiometric ratios of the different periphyton types due to variation in the types of periphyton available among sites, but filamentous green forms had the lowest $\mathrm{C}: \mathrm{P}$ and $\mathrm{C}: \mathrm{N}$ ratios, which were $49 \%$ lower than benthic mats (the highest ratios). Similarly, periphyton TP could not be statistically compared by periphyton type among sites, but filamentous green algae had the highest concentration of TP, which was $62 \%$ higher than floating mats, $45 \%$ higher than epiphyton, and $22 \%$ higher than benthic mats. Periphyton TP was not different among hydroperiods $\left(\mathrm{F}_{3,21}=1.17, \mathrm{P}=0.347\right)$ during the wet season, and there were no differences in algal community composition of periphyton by hydroperiod $(\mathrm{R}=-0.059, \mathrm{P}=0.902)$ at that time.

Environmental and periphyton quality/availability variables were reduced using Principal Components Analysis using correlation matrices. All variables loaded strongly on the first two axes (loading $\geq 0.30$; Table 6.3) and these data were used in further 
analyses. Environmental PC axis 1 and 2 explained $49.9 \%$ and $27.8 \%$ of the variance in the data, respectively. Hydroperiod (+), DSD (+), and plant cover (-) loaded strongly ( $\geq$ $0.30)$ on axis 1 , whereas $\mathrm{pH}(+)$ and conductivity (-) loaded strongly on axis 2. Multivariate Analysis of Variance corroborated these findings and suggested that sites with $<300$ days of inundation had greater plant density than sites with $>350$ days in the wet season $\left(\gamma=0.054, \mathrm{~F}_{15,45}=4.53, \mathrm{P}<0.0001\right)$. The first $\mathrm{PC}$ axis describing periphyton quality contained strong loadings (all +) for macronutrients (protein, carb, lipid), heterotrophic fatty acid $\%$ and edible algae (55.3\% explained variation). Principal Components food quality axis 2 contained strong loadings for PUFA ratio (-), EPA \% (+) and TP (-), and explained $15.4 \%$ of the total variation. Periphyton cover \% (-), benthic mat (-), epiphyton (-) and floating mat volume (-) loaded on periphyton availability PC axis 1 (35.4\% explained variation), and floating mat (+), epiphyton volume (-) and filamentous algae volume $(+)$ loaded on PC axis 2 (23.5\% explained variation).

Periphyton quality varied among hydroperiods in the wet season. Sites that were inundated for $<300$ days had higher periphyton quality in terms of increased macronutrients, heterotrophic fatty acid \%, and edible algae $\left(\mathrm{PC} 1: \mathrm{F}_{3,21}=5.53, \mathrm{P}=\right.$ 0.008). Furthermore, short-hydroperiod sites had floating mats with $99 \%$ more protein $\left(\mathrm{mg} / \mathrm{m}^{2}\right), 86 \%$ more carbohydrates $\left(\mathrm{mg} / \mathrm{m}^{2}\right)$, and $94 \%$ more lipids $\left(\mathrm{mg} / \mathrm{m}^{2}\right)$ than floating mats growing in long-hydroperiod sites (Protein: $F_{3,19}=3.86, P=0.03$; Carb: $F_{3,19}=4.00$, $\mathrm{P}=0.027$; Lipid: $\mathrm{F}_{3,19}=4.15, \mathrm{P}=0.024$; Figs. $\left.6.3 \mathrm{a} \& \mathrm{~b}\right)$. Short hydroperiods also had epiphyton with $96 \%$ greater lipid composition $\left(\mathrm{mg} / \mathrm{m}^{2}\right)$ than long hydroperiod sites $\left(\mathrm{F}_{3,11}\right.$ $=4.27, \mathrm{P}=0.045)$. 
Sites did not vary in availability of floating mat or benthic mat $\left(\mathrm{FM}: \mathrm{F}_{3,19}=1.31, \mathrm{P}=\right.$ 0.305; $\mathrm{BM}: \mathrm{F}_{1,4}=0.64, \mathrm{P}=0.48$ ), but long-hydroperiod sites had $91 \%$ less epiphyton than sites with $<300$ water inundation $\left(\mathrm{F}_{3,11}=4.04, \mathrm{P}=0.05\right)$.

The hierarchical cluster analysis of consumer gut-content data collected in the wet season produced two diet categories: 1) herbivore-detritivore (referred to as "herbivore"); 2) and omnivore (Cophenetic correlation $=0.996)$. In the wet season, Sailfin mollies and Flagfish were classified as herbivores, and the remaining four fish species were classified as omnivores (Fig. 6.2a). During this time, there were more 53\% more herbivores than omnivores $\left(\mathrm{F}_{1,43}=7.66, \mathrm{P}=0.008\right)$. However, there were no differences in herbivore and omnivore density by hydroperiod (Herb: $F_{3,21}=0.45, P=0.722 ;$ Omni: $F_{3,21}=0.69, P=$ 0.571; Fig. 6.3a).

Based on $\triangle \mathrm{AICc}$ values and evidence ratios, SEMs suggested that herbivore density best explained density of omnivores in the wet season (Fig 6.5a; Table 6.4). There were several equally supported Structural Equation Models (on $\Delta \mathrm{AICc}<2.00$ ), but path coefficients for the linkages between herbivore and omnivore density were positive in all models, suggesting that increased herbivore density resulted in increased omnivore density. In addition, Akaike weights suggest that the best-fit model $(\triangle \mathrm{AICc}=0)$ is $6 \mathrm{x}$ more likely than the least supported model $(\triangle \mathrm{AICc}=3.579)$. Because linkages between periphyton variables and omnivore density were not statistically significant and dropping these linkages from the model did not improve the $\triangle \mathrm{AICc}$ value, I inferred that omnivores are not directly influenced by periphyton quality and/or availability in the wet season. 
Similar to omnivore models, there were several equally supported herbivore SEMs (on $\Delta \mathrm{AICc}<2.00$ ), but they all suggest that herbivore density was best explained by increased PUFA ratio, increased TP, decreased EPA \% (negative PC2 axis values for periphyton quality), and increased omnivore density (Fig 6.6a; Table 6.5). Akaike weights suggest that the best-fit model $(\triangle \mathrm{AICc}=0)$ is $80 \mathrm{x}$ more likely than the model with the highest $\triangle \mathrm{AICc}$ value $(\triangle \mathrm{AICc}=8.779)$. Although linkages between herbivore and omnivore density were statistically significant, they occurred in the positive direction, suggesting that omnivore competition and/or predation did not directly affect herbivore density.

Consumer tissues showed spatial variation in nutrient composition in the wet season. Omnivore tissues contained 18\% higher TP than herbivore tissues, but these values were also driven by hydroperiod. The mid-range hydroperiod sites (300-350 days inundation) had consumers with decreased tissue TP (Diet x Hydroperiod: $F_{2,49}=7.96, P=0.003$ ). Similarly, omnivore tissues had $83 \%$ more autotrophic fatty acids and $92 \%$ more heterotrophic fatty acids than herbivore tissues (Autotroph: $\mathrm{F}_{1,50}=7.41, \mathrm{P}=0.009$; Heterotroph: $\left.\mathrm{F}_{1,44}=4.81, \mathrm{P}=0.034\right)$. However, herbivores had tissues with the highest proportion of protein, which was $40 \%$ greater than omnivores $\left(\mathrm{F}_{1,50}=8.70, \mathrm{P}=0.005\right)$. Lipids varied among trophic group and hydroperiod, with herbivore tissues having $60 \%$ more total lipids than omnivores $\left(\mathrm{F}_{1,50}=38.15, \mathrm{P}<0.0001\right)$. In addition, sites with $<300$ days of inundation had fish with a $32 \%$ decrease in tissue lipid concentration $\left(\mathrm{F}_{3,50}=\right.$ 5.91, $\mathrm{P}=0.002)$. Carbohydrates did not vary between herbivore and omnivore tissues $\left(\mathrm{F}_{6,50}=1.38, \mathrm{P}=0.246\right)$. 
Tissue EPA was on average $96 \%$ higher in omnivores; however, in sites with $>325$ days inundation, EPA was $40 \%$ higher in herbivore tissues (Trophic group: $\mathrm{F}_{1,50}=10.46, \mathrm{P}=$ 0.002; Hydroperiod: $\mathrm{F}_{3,50}=3.25, \mathrm{P}=0.031$ ). Omnivores had tissues with $51 \%$ higher DHA and $71 \%$ higher ARA than herbivores (DHA: $F_{1,44}=42.84, \mathrm{P}<0.0001$; ARA: $\mathrm{F}_{1,44}$ $=50.08, \mathrm{P}<0.0001)$. Similarly, omnivore tissues had $40 \%$ higher PUFAs than herbivores $\left(\mathrm{F}_{1,50}=56.15, \mathrm{P}<0.0001\right)$, but herbivore tissues had $19 \%$ higher MUFAs $\left(\mathrm{F}_{1,44}=19.78\right.$, $\mathrm{P}<0.0001$; Figs. 6.4a\&b).

I did not find evidence supporting the Heterotroph Facilitation hypothesis, as increased heterotrophic fatty acid (\%) was not a main predictor of herbivore density in the wet season. Herbivore density was found to decrease with increasing periphyton quality as predicted by the Suboptimal Habitat hypothesis (macronutrients, heterotrophic fatty acid \%, edible algae, and EPA; Fig. 6.7a). But, herbivore density increased with increasing PUFA ratio and TP, which is inconsistent with predictions of the Suboptimal Habitat hypothesis. Furthermore, I found that periphyton availability and quality were not inversely related (Avail. PC1 x Quality PC2: $\mathrm{R}^{2}=0.14, \mathrm{t}=2.07, \mathrm{P}=0.050$; Avail. PC2 x Quality PC1: $\mathrm{R}^{2}=0.46, \mathrm{t}=4.15, \mathrm{P}=0.001$ ), which violates a main prediction of the Suboptimal Habitat hypothesis. Similar to herbivores, omnivore density was not driven by heterotrophic fatty acids. Furthermore, omnivore density was not driven by quality or availability of periphyton, as direct and indirect paths between these variables were not significant in the SEMs. Instead, I found that omnivore density was driven only by density of herbivores, suggesting that omnivore dynamics are not explained by either adaptive hypothesis in the wet season. 


\section{Dry Season}

There were several differences in environmental variables across hydroperiods in the dry season. Sites with $<300$ days of inundation had average depths of $11.75 \pm 8.62 \mathrm{~cm}$, sites with water 300-324 days were $19.8 \pm 6.72 \mathrm{~cm}$, sites with water 325-350 days were $35.00 \pm 10.02 \mathrm{~cm}$, and sites with $>350$ days of inundation were $48.67 \pm 9.09 \mathrm{~cm}$. There were no differences in $\mathrm{pH}$ among hydroperiods, but short hydroperiods $(<300$ days inundation) had $53 \%$ higher conductivity than sites with $>350$ days of water $\left(\mathrm{F}_{3,20}=\right.$ 4.04, $\mathrm{P}=0.026)$. There were no differences in periphyton $\mathrm{C}: \mathrm{P}$ and $\mathrm{N}: \mathrm{P}$ ratios across sites in the dry season $\left(\mathrm{CP}: \mathrm{F}_{3,18}=1.68, \mathrm{P}=0.214 ; \mathrm{NP}: \mathrm{F}_{3,18}=1.614, \mathrm{P}=0.228\right)$. Similar to the wet season, I was unable to statistically compare stoichiometric ratios of the different periphyton types as a result of the variation in the types of periphyton available among sites, but filamentous green forms had the lowest $\mathrm{C}: \mathrm{P}$ and $\mathrm{C}: \mathrm{N}$ ratios, which were $68 \%$ and $61 \%$ lower than floating mats (the highest ratios), respectively. Similarly, periphyton TP could not be statistically compared by periphyton type among sites, but benthic mats had the highest concentration of TP, which was $51 \%$ higher than filamentous green algae, $49 \%$ higher than floating mat, and 14\% higher than epiphyton. Periphyton TP was not different among hydroperiods $\left(\mathrm{F}_{3,19}=0.45, \mathrm{P}=0.722\right)$, but wet-season periphyton had $41 \%$ higher TP than dry-season periphyton $\left(\mathrm{F}_{1,41}=4.68, \mathrm{P}=0.037\right)$. Therefore, dryseason periphyton had 58\% and 73\% greater C:P and N:P ratios than wet-season periphyton, respectively $\left(\mathrm{CP}: \mathrm{F}_{1,36}=12.41, \mathrm{P}=0.001 ; \mathrm{NP}: \mathrm{F}_{1,36}=23.07, \mathrm{P}<0.0001\right)$. 
Emergent vascular-plant stem density was not different among hydroperiods in the dry season $\left(\mathrm{F}_{3,20}=0.594, \mathrm{P}=0.628\right)$, but long-hydroperiod sites ( $>350$ days $)$ had periphyton with $61 \%$ lower filamentous cyanobacteria density and $48 \%$ higher filamentous green algal density than short-hydroperiod sites $(41.95 \%$ dissimilarity, $\mathrm{R}=0.072, \mathrm{P}=0.043)$. There were no significant differences between wet and dry season algal composition (34.91\% dissimilarity, $\mathrm{R}=0.005, \mathrm{P}=0.317)$.

Similar to wet-season variables, all dry-season environmental and periphyton quality/availability variables loaded strongly on the first two PC axes and those data were used in further analyses. Environmental PC axis 1 and 2 explained $73.6 \%$ and $18.0 \%$ of the variance in the data, respectively (Table 6.3). Axis 1 contained loadings highly correlated (loading $\geq 0.30)$ to $\mathrm{pH}(-)$, conductivity (-), and DSD (-), whereas axis 2 was highly correlated with variation in hydroperiod (-) and emergent plant cover $(+)$. Macronutrients (protein, carbohydrate, lipid), heterotrophic fatty acid \%, EPA \% and edible algae $($ all +$)$ loaded strongly on periphyton quality PC axis $1(52.6 \%$ explained variation), whereas PUFA ratio (-) and TP (-) loaded on axis 2 (16.6\% explained variation). For the periphyton availability variables, periphyton cover, floating mat volume, benthic mat volume and epiphyton volume (all -) loaded strongly on PC axis 1 (37.8\% explained variation). Benthic mat (-), epiphyton (-) and filamentous algae (+) volume, and periphyton cover $(+)$ loaded on PC axis 2 (23.7\% explained variation). Multivariate Analysis of Variance did not reveal any differences in these variables by hydroperiod $\left(\gamma=0.445, F_{15,39}=0.89, P=0.582\right)$. 
Periphyton quality varied across hydroperiods in the dry season. The sites with the longest hydroperiod (inundated for $>350$ days) had higher periphyton quality in terms of increased PUFA ratio and TP $\left(\mathrm{PC} 2: \mathrm{F}_{3,22}=3.56, \mathrm{P}=0.035\right)$. Mid-range hydroperiod sites (inundated for 300-324 days or 325-350 days) had higher periphyton quality (PUFA ratio and TP) than the sites with the shortest hydroperiod ( $<300$ days), but lower periphyton quality than long-hydroperiod sites ( $>350$ days). But, short-hydroperiod sites (inundated for $<300$ days) had floating mats with $94 \%$ higher lipid composition than the sites with water for 300-324 days, and 86\% higher than sites with water for $>350$ days $\left(\mathrm{F}_{3,19}=\right.$ 5.07, $\mathrm{P}=0.012$ ). Furthermore, long-hydroperiod sites ( $>350$ days) had epiphyton with the lowest proportion of protein and carbohydrates (99\% less than 300-324 days of inundation; Protein: $\mathrm{F}_{2,8}=95.95, \mathrm{P}<0.0001$; Carb: $\mathrm{F}_{2,8}=26.26, \mathrm{P}=0.001$; Figs. $6.3 \mathrm{c} \& d)$. Sites did not vary in availability of floating mat or benthic mat $\left(\mathrm{FM}: \mathrm{F}_{3,19}=\right.$ 1.55, $\mathrm{P}=0.240 ; \mathrm{BM}: \mathrm{F}_{3,19}=1.48, \mathrm{P}=0.404$ ), but long-hydroperiod sites had $99 \%$ less epiphyton availability than sites with water inundation for 300-350 days $\left(F_{2,8}=10.06, \mathrm{P}\right.$ $=0.012$ ). A summary of changes in food quality and availability from the wet season to the dry season can be found in Table 6.6.

Hierarchical cluster analysis of consumer gut content data collected in the dry season produced two diet categories: 1$)$ herbivore; and 2$)$ omnivore $($ Cophenetic correlation $=$ 0.87). Similar to the wet season, Sailfin Mollies and Flagfish had diets comprised of basal resources, although Flagfish consumed more periphyton in the dry season and more detritus in the wet season. Least Killifish were primarily consuming invertebrates in the wet season but switched to periphyton in the dry season. 
Therefore, I classified this species as omnivorous (referred to as "diet-switching omnivores" in Fig. 6.2b) since they were not obligate herbivores. Eastern Mosquitofish were classified as omnivores, but consumed approximately $41 \%$ periphyton in the dry season compared to only $7 \%$ consumed in the wet season (Loftus 2000). Golden Topminnows and Bluefin Killifish were classified as omnivores in both seasons as their diets did not change (Fig. 6.2b). There were 93\% more herbivores and $47 \%$ more omnivores in the wet season than the dry season $\left(\right.$ Herb: $\mathrm{F}_{1,41}=35.86, \mathrm{P}<0.0001$; Omni: $\left.\mathrm{F}_{1,41}=3.90, \mathrm{P}=0.013\right)$. In addition, there were $69 \%$ more omnivores than herbivores in the dry season $\left(\mathrm{F}_{1,41}=13.45, \mathrm{P}=0.001\right)$; however, there were $44 \%$ more herbivores than omnivores in sites with $<300$ days of water. There were no statistical differences in herbivore density across hydroperiods $\left(\mathrm{F}_{3,21}=2.25, \mathrm{P}=0.118\right)$, but there were $82 \%$ more omnivores in sites that were inundated for 325-350 days than in sites with water for $<$ 300 days $\left(\mathrm{F}_{3,17}=4.49, \mathrm{P}=0.017\right.$; Fig. $\left.6.4 \mathrm{~b}\right)$.

SEMs suggested that increased periphyton quality best explained density of omnivores in the dry season (Fig 6.5b; Table 6.5). There were 4 equally supported Structural Equation Models (on $\triangle \mathrm{AICc}<2.00$ ), but path coefficients for the linkages between periphyton PC 2 and omnivore density were negative in all models, indicating that increased PUFA ratio and TP resulted in increased omnivore density. Akaike weights suggest that the best-fit model $(\triangle \mathrm{AICc}=0)$ was $66 \mathrm{x}$ more likely to be the best model than the model with the highest $\triangle \mathrm{AICc}$ value $(\triangle \mathrm{AICc}=8.382)$. Linkages between omnivore density and other periphyton variables, or between omnivore density and herbivore density, were not statistically significant and dropping these linkages from the model did not improve the $\triangle \mathrm{AICc}$ value. 
There were several equally supported herbivore SEMs (on $\triangle \mathrm{AICc}<2.00$ ), but there were no statistically significant path coefficients between periphyton variables and herbivore density, suggesting that herbivore density was not explained by food quality or availability in the dry season. Similar to wet season results, increased herbivore density was explained by increased omnivore density, suggesting that competition with omnivores and/or predation by omnivores also did not influence herbivore density in the dry season (Fig 6.6b; Table 6.5).

Consumer tissues varied in molecular composition in the dry season. Omnivore tissues contained $30 \%$ greater TP and $21 \%$ more heterotrophic fatty acid markers than herbivore tissues (TP: $\mathrm{F}_{1,48}=11.13, \mathrm{P}=0.002$; Heterotrophic $\mathrm{FA}: \mathrm{F}_{1,52}=5.99, \mathrm{P}=0.018$ ). However, herbivore tissues had 15\% more autotrophic-derived fatty acid markers than omnivore tissues $\left(\mathrm{F}_{1,52}=7.69, \mathrm{P}=0.008\right)$. Omnivores had $42 \%$ more DHA and $55 \%$ more ARA in their tissues than herbivores (DHA: $\mathrm{F}_{1,52}=4.33, \mathrm{P}=0.043$; ARA: $\mathrm{F}_{1,52}=$ $8.61, \mathrm{P}=0.005$ ). Furthermore, omnivore tissues had $18 \%$ more PUFAs than herbivore tissues $\left(\mathrm{F}_{1,52}=4.70, \mathrm{P}=0.035\right)$, but herbivore tissues had $12 \%$ more MUFAs $\left(\mathrm{F}_{1,52}=\right.$ 4.08, $\mathrm{P}=0.049)$. There were no differences in EPA or SAFA concentrations between omnivore and herbivore tissues (EPA: $\mathrm{F}_{1,52}=0.12, \mathrm{P}=0.733$; SAFA: $\mathrm{F}_{1,52}=0.00, \mathrm{P}=$ 0.999). Both herbivore and omnivore tissues had similar macronutrient composition during the dry season (Protein: $F_{1,51}=0.08, P=0.776$; Carb: $F_{1,51}=0.17, P=0.682$; Lipid: $F_{1,51}=0.13, P=0.725$ ); but, tissue lipids were highest in fish collected from sites with 324-350 days of inundation $\left(\mathrm{F}_{3,51}=4.11, \mathrm{P}=0.012\right)$. 
Body condition of both omnivores and herbivores were less robust in the dry season than in the wet season. Compared to omnivore tissues in the wet season, omnivores had $91 \%$ lower protein concentration, $71 \%$ higher carbohydrate concentration, and $51 \%$ lower lipid concentration (Protein: $\mathrm{F}_{1,84}=272.75, \mathrm{P}<0.0001$; Carb: $\mathrm{F}_{1,84}=123.19, \mathrm{P}<0.0001$; Lipid: $\left.\mathrm{F}_{1,84}=19.05, \mathrm{P}<0.0001\right)$. Herbivore tissues had $92 \%$ lower protein concentration and $65 \%$ higher lipid concentration than herbivore tissues in the wet season (Protein: $\mathrm{F}_{1,17}$ $=6.58, \mathrm{P}=0.02 ;$ Lipid: $\left.\mathrm{F}_{1,17}=15.57, \mathrm{P}=0.001\right)$. Herbivore tissues contained similar amounts of carbohydrates in both seasons $\left(\mathrm{F}_{1,17}=0.31, \mathrm{P}=0.583\right)$. A summary of changes in consumer diet and tissue composition from the wet season to the dry season can be found in Table 6.7 .

Similar to the wet-season results, increased $\%$ heterotrophic fatty acid was not a main predictor of herbivore density in the dry season $\left(\mathrm{R}^{2}=0.013, \mathrm{t}=1.131, \mathrm{P}=0.271\right)$ and thus, the results did not support the Heterotroph Facilitation hypothesis. Periphyton availability (periphyton cover \%, floating mat volume, benthic mat volume and epiphyton volume) was inversely related to periphyton quality (macronutrients, heterotrophic fatty acid $\%$, EPA $\%$ and edible algae), supporting one prediction of the Suboptimal Habitat hypothesis $\left(\mathrm{R}^{2}=0.45, \mathrm{t}=3.73, \mathrm{P}=0.001\right.$; Fig. $\left.6.7 \mathrm{~b}\right)$. However, herbivore density was not found to increase in proportion to periphyton availability or decrease in proportion to periphyton quality. Instead, I found that herbivore density did not change with changing periphyton quality. Omnivores became more herbivorous in the dry season, but similar to herbivores, their density was not dependent on heterotrophic fatty acids. 
Furthermore, I found that omnivores increased with increasing periphyton quality (PUFA ratio and TP), suggesting that omnivore dynamics are not explained by either adaptive hypothesis in the dry season.

\section{Discussion}

Results revealed that herbivores do not track resource quality or availability during environmental stress, such as the conditions experienced by consumers during the Everglades dry season. During this time, short-hydroperiod sites were either dry or receding, thus concentrating consumers in these shrinking habitats.

As a result, consumers were vulnerable to predators unless they migrated to longer hydroperiod refuges (DeAngelis et al. 2010). In addition, longer hydroperiod sites had higher quality periphyton than sites with $<300$ days of inundation, better to support larger consumer populations in the dry season. Omnivore density was largely driven by the higher quality basal resources offered by the longer hydroperiod sites (300-350 days of inundation), consistent with niche-based predictions. Higher periphyton quality in dryseason long-hydroperiods sites may result from nutrient regeneration (Geddes and Trexler 2003; Dorn et al. 2006) and/or consumer transport and deposition (Stevenson and Childers 2004) as they move into these refuge sites. Though the study sites varied in levels of periphyton availability and quality, herbivore density was consistent across all hydroperiods, suggesting that herbivore fitness is not hampered by variation in resources. These results are consistent with dispersal-limited predictions. 
In the wet season, newly inundated habitats ( $<300$ days of water) had the highest quality basal resources. At these sites, herbivores outnumbered omnivores by $83 \%$. However, herbivore density was predicted by decreased EPA, and by increased PUFA ratio and $\mathrm{TP}$, which were all characteristic of long-hydroperiod sites in the wet season. Omnivore density was also a strong predictor of herbivore density. I thereby inferred that predation or competition by omnivores was not a strong driver of herbivore dynamics in the wet season. Similar to the dry season, herbivore density did not vary consistently across hydroperiods. However, herbivore density was influenced by food quality and availability, suggesting that herbivore diets are consistent with niche-based predictions in the wet season. Omnivore density was best predicted by herbivore density (i.e., prey) and by periphyton quality, suggesting that omnivores more closely track the availability of higher quality resources than herbivores. Similar to herbivores, omnivore diets were consistent with niche-based predictions in the wet season.

Taken together, these results partially support the Suboptimal Habitat Hypothesis, which suggests that herbivory is adaptive because it allows organisms to invade and persist in 'suboptimal' habitats. However, these results do not clearly support each prediction of this hypothesis as outlined in Sanchez and Trexler (2016). Specifically, herbivore density was not inversely related with periphyton quality or density of omnivores in the dry season. Furthermore, in the wet season, I failed to obtain evidence that periphyton availability was inversely related to periphyton quality, or that herbivore density was inversely related to omnivore density. However, I found that herbivore density was similar across habitats with varying levels of disturbance, and when habitats were inundated, herbivore density was predicted by periphyton quality. 
I did not find evidence for the Heterotroph Facilitation Hypothesis in this study as heterotrophic fatty acids did not drive herbivore density; however, previous studies suggest that heterotrophic bacteria are important for consumers in this system (Belicka et al. 2012; Sanchez and Trexler 2018), so the explanatory power of this hypothesis remains unclear. Unlike herbivores, omnivore populations were driven by availability of highquality food items. In the dry season, when high quality prey items were rare, omnivores sought high-quality basal resources, but in the wet season when prey items were abundant, omnivores exploited this food source. This finding supports the current hypotheses on the adaptive evolution of omnivory (e.g., Diehl 2003; Krivan and Diehl 2005).

These results suggest that herbivory may have evolved as an adaptive strategy to deal with fluctuating conditions. In this study, herbivores track food quality when habitats are stable (wet season) but can survive in a multitude of habitat types during disturbance events (dry season). These results imply that herbivore density is driven by both species traits and dispersal. Conversely, omnivores were limited to quasi-permanent habitats (e.g., long-hydroperiod sites) and were outnumbered by herbivores at all sites in the wet season, and in short-hydroperiod sites in the dry season. Furthermore, omnivores rely on high quality resources in both wet and dry seasons, suggesting that they are less flexible than herbivores in their diet and habitat requirements. Previous studies of Everglades consumers have found that omnivore density increases with time since flooding, while herbivore density tends to decrease with time following drought (Sargeant et al. 2011). Other studies have found negative correlations between omnivore densities and measures of disturbance (Trexler et al. 2002, 2005; Liston 2006). 
These findings support food quality as a mechanism driving omnivore dynamics, and infer that herbivores are better adapted than omnivores to conditions with variable hydrology, food supply, and food quality.

Studying trophic dynamics in an evolutionary context allows researchers to better understand the forces driving species organization. Many studies have laid the groundwork for this type of research by describing the role of ecological influences on food webs. However, the current findings offer oversimplified predictions for how food webs are organized. For example, previous ecological studies have established that herbivores have such an integral role in food webs that their removal reveals a trophic cascade (Power 1992). In this study, I concluded that herbivores are better adapted to fluctuating resources than higher level consumers, suggesting that herbivory may "buffer" food webs from stressful environmental factors. By identifying an evolutionary mechanism that promotes herbivory, we are able to more fully describe the complex role of these consumers in food webs. Future trophic studies may benefit by using a framework that incorporates both ecology and evolution to predict how food webs are organized in nature.

\section{Acknowledgments}

Funding for this project was provided by Task Agreement P15AC01258 under Cooperative Agreement H5000-10-0104 between the National Park Service and Florida International University and by the U. S. National Science Foundation through the Florida Coastal Everglades Long-Term Ecological Research program under Grant No. DEB-1237517. 
This is contribution number XXX from the Southeast Environmental Research Center in the Institute of Water \& Environment at Florida International University.

\section{References}

Anderson, D., and K. Burnham. 2002. Avoiding Pitfalls When Using InformationTheoretic Methods. The Journal of Wildlife Management, 66(3), 912-918. doi: $10.2307 / 3803155$

Arbuckle, J. L. 2014. Amos (Version 23.0) [Computer Program]. Chicago: IBM SPSS.

Belicka, L. L., E. R. Sokol, J. M. Hoch, R. Jaffe, and J. C. Trexler. 2012. A molecular and stable isotopic approach to investigate algal and detrital energy pathways in a freshwater marsh. Wetland 32:531-542.

Bell, G. 2001. Neural Macroecology. Science 293:2413-2418.

Bellwood, D. R. 2003. Origins and escalation of herbivory in fishes: a functional perspective. Paleobiology 29(1):71-83.

Bellwood, D.R., Goatley, C.H.R., Brandl, S.J, and O. Bellwood. 2014. Fifty million years of herbivory on coral reefs: fossils, fish and functional innovations. Proceedings of the Royal Society B 281: 2013-3046.

Browder, J. A., P. J. Gleason, and D. R. Swift. 1994. Periphyton in the Everglades: Spatial variation, environmental correlates, and ecological implications, pp. 379418. In S. M. Davis and J. C. Ogden. Everglades. The Ecosystem and Its Restoration. St. Lucie Press, Boca Raton, FL.

Caceres, C. W., L. S. Fuentes, and F. P. Ojeda. 1994. Optimal feeding strategy of the temperate herbivorous fish Aplodactylus punctatus: the effects of food availability on digestive and reproductive patterns. Oecologia 99:118-123.

Cattin, M. F., L. F. Bersier, C. Banašek-Richter, R. Baltensperger, and J. P. Gabriel. 2004. Phylogenetic constraints and adaptation explain food-web structure. Nature, 427 (6977):835-839.

Chase, J. M. 2007. Drought mediates the importance of stochastic community assembly. PNAS 104(4): 17430-17434. 
Chase, J. M.., and M. A. Leibold. 2003. Ecological Niches: Linking Classical and Contemporary Approaches. The University of Chicago Press, Chicago and London.

Chick, J. H., P. Geddes, and J. C. Trexler. 2008. Periphyton mat structure mediated trophic interactions in a subtropical marsh. Wetlands 28(2): 378389.

Choat, J. H., and K. D. Clements. 1998. Vertebrate herbivores in marine and terrestrial environments: A nutritional ecology perspective. Annual Review of Ecology and Systematics 29:375-403.

Cleveland, A. and W. L. Montgomery. 2003. Gut characteristics and assimilation efficiencies in two species of herbivorous damselfishes (Pomacentridae: Stegastes dorsopunicans and S. planifrons). Marine Biology 142:35-44.

Condit, R., N. Pitman, E.G. Leigh, J. Chave Jr., J., Terborgh, R. B. Foster, P. Nunez, S. Aguilar, R. Valencia, G. Villa, H. C. Muller-Landau, E. Losos and S. P. Hubbell. 2002. Beta-Diversity in Tropical Forest Trees. Science 295:666-669.

DeAngelis, D. L. 1992. Dynamics of nutrient cycling and food webs. Population and Community Biology Series. Chapman and Hall, New York, New York, USA.

DeAngelis, D. L., S. M. Bartell, and A. L. Brenkert. 1989. Effects of nutrient recycling and food-chain length on resilience. American Naturalist 134:778-805.

DeAngelis, D. L., J. C. Trexler, C. Cosner, A. Obaza, and F. Jopp. 2010. Fish population dynamics in a seasonally varying wetland. Ecological Modelling 221(8): 1131-1137.

deMaintenon, M. J. 1999. Phylogenetic analysis of the Columbellidae (Mollusca: Neogastropoda) and the evolution of herbivory from carnivory. Invertebrate Biology 118(3): 258-288.

Desilets, P., and G. Houle. 2005. Effects of resource availability and heterogeneity on the slope of the species-area curve along a floodplainupland gradient. Journal of Vegetation Science 16(5): 487-496.

Diehl, S. 2003. The evolution and maintenance of omnivory: Dynamic constraints and the role of food quality. Ecology 84(10): 2557-2567. 
Doi, H. 2009. Spatial patterns of autochthonous and allochthonous resources in aquatic food webs. Population Ecology 52: 57-64.

Elser, J. J., K. Acharya, and M. Kyle. 2003. Growth rate-stoichiometry couplings in diverse biota. Ecology Letters 6:936-943.

Elser, J. J., W. F. Fagan, R. F. Denno, D. R. Dobberfuhl, A. Folarin, A. Huberty, S. Interlandi, S.S. Kilham, E. McCauley, K. L. Schulz, E. H. Siemann, and R. E. Sterner. 2000. Nutritional constrains in terrestrial and freshwater food webs. Nature 408:578-580.

Espinoza, R.E., J. J. Wiens, and C. R. Tracy. 2004. Recurrent evolution of herbivory in small, cold-climate lizards: Breaking the ecophysiological rules of reptilian herbivory. Proceedings of the National Academy of Science 101(48): 1681916824.

Eubanks, M.D., Styrsky, J.D., and Denno, R.F. 2003. The evolution of omnivory in heteropteran insects. Ecology 84(10): 2549-2556.

Folch, J., M. Lees, G. H., S. Stanley. 1957. A simple method for the isolation and purification of total lipids from animal tissues. Journal of Biological Chemistry 226(1): 497-509.

Gaiser, E. E. 2009. Periphyton as an indicator of restoration in the Florida Everglades. Ecological Indicators 9 (6): S37-S45.

Gaiser, E. E., P. V. McCormick, S. E. Hagerthy, and A. D. Gottlieb. 2011. Landscape patterns of periphyton in the Florida Everglades, pp 92-120. Critical Reviews in Environmental Science and Technology, 41:S1, 92120, DOI: $10.1080 / 10643389.2010 .531192$

Gaiser, E. E., J. C. Trexler, J. H. Richards, D. L. Childers, D. Lee, A. L. Edwards, L. J. Scinto, K. Jayachandran, G. B. Noe, and R. D. Jones. 2005. Cascading ecological effects of low- level phosphorus enrichment in the Florida Everglades. Journal of Environmental Quality 34:717-23.

Geddes, P., and J. C. Trexler. 2003. Uncoupling of omnivore-mediated positive and negative effects on periphyton mats. Oecologia 136:585-595.

Gottlieb, A. D., E. E. Gaiser, and S. S. Lee. 2015. Changes in hydrology, nutrient loading, and conductivity in the Florida Everglades, and concurrent effects on periphyton community structure and function, pp 131-154. In J. A. Entry, A. D. Gottlieb, K. Jayachandran, and A. Ogram. Microbiology of the Everglades Ecosystem. CRC Press, Boca Raton, FL. 
Grace, J. B. 2006. Structural Equation Modelling and Natural Systems. Cambridge University Press, Cambridge, UK.

Guo, F., M. Kainz, F. Sheldon, and S. E. Bunn. 2016. The importance of highquality algal food sources in stream food webs- current status and future perspectives. Freshwater Biology <doi: 10.1111/fwb.12755>.

Hanley, T. C., D. L. Kimbro, and A. R. Hughes. 2017. Stress and subsidy effects of seagrass wrack duration, frequency, and magnitude on salt marsh community structure. Ecology 98(7): 1884-1895.

Horn, M. H. 1989. Biology of marine herbivorous fishes. Oceanography and Marine Biology Annual Review 27:167-272.

Hubbell, S. P. 2001 The unified neutral theory of biodiversity and biogeography. Princeton, NJ: Princeton University Press.

Jordan, C. F., S. Coyne, and J. C. Trexler. 1997. Sampling fishes in heavily vegetated habitats: the effects of habitat structure on sampling characteristics of the $1-\mathrm{m}^{2}$ throw trap. Transactions of the American Fisheries Society 126:10121020.Karasov, W.H. and C. Martinez del Rio. 2007. Physiological Ecology: How Animals Process Energy, Nutrients, and Toxins. Princeton University Press, Princeton, New Jersey, USA.

Kareiva, P. 1990. Population dynamics in spatially complex environments: theory and data. Philosophical Transactions of the Royal Society, London, Series B 330: 175-190.

Krivan, V., and S. Diehl. 2005. Adaptive omnivory and species coexistence in tritrophic food webs. Theoretical Population Biology 67(2005): 85-99.

Laspoumaderes, C., B. Modenutti, and E. Balseiro. 2010. Herbivory versus omnivory:Linking homeostasis and elemental imbalance in copepod development. Journal of Plankton Research 32(11):1573-1582.

Light, S. S., and J. W. Dineen. 1994. Water control in the Everglades: a historical perspective. In: Everglades: The ecosystem and its restoration 5, pp. 4784.

Liston S.E. 2006. Interactions between nutrient availability and hydroperiod shape macroinvertebrate communities in Florida Everglades marshes. Hydrobiologia, 569, 343-357. doi: 10.1007/s10750-006-0141-0.

Maechler, M., Rousseeuw, P., Struyf, A., Hubert, M., Hornik, K. 2017. cluster: Cluster Analysis Basics and Extensions. R package version 2.0.6. 
Markwell M. A., S. M. Haas, L. L. Biever. And N. E. Tolbert.1978. A modification of the Lowry procedure to simplify protein determination in membrane and lipoprotein samples. Analytical Biochemistry 87:206-210.

Masuko, T., A. Minami, T. Majima, S. Nishimura, and Y. C. Lee. 2005. Carbohydrate analysis by a phenol-sulfuric acid method in microplate format. Analytical Biochemistry 339: 69-72.

Mattson, W. J. Jr., 1980. Herbivory in relation to plant nitrogen content. Annual Review of Ecology and Systematics 11:119-161.

McCormick, P. V., S. Newman, S. Miao, D. E. Gawlik, D. Marley, K. R. Reddy, and T. D. Fontaine. 2002. Effects of anthropogenic phosphorus inputs on the Everglades. In Porter, J. W \& K. G. Porter (eds), The Everglades, Florida Bay, and Coral Reefs of the Florida Keys: an Ecosystem Sourcebook. CRC, Boca Raton, pp. 83-126.

McPeek, M. A. 2017. Evolutionary Community Ecology. Princeton University Press, NJ.

McIntosh, A. R., B. L. Peckarsky, and B. W. Taylor. 2004. Predator-induced resource heterogeneity in a stream food web. Ecology 85(8): 2279-2290.

Moore, J. C., E. L. Berlow,D. C. Coleman, P. C., deRuiter, Q. Dong, A. Hastings, N. C. Johnson, K. S. McCann, K. Melville, P. J. Morin, K. Nadelhoffer, A. D. Rosemond, D. M. Post, J. L. Sabo, K. M. Scow, M. J., Vanni, and D. H. Wall. 2004. Detritus, trophic dynamics and biodiversity. Ecology Letters 7:584-600.

Namba, T., K. Tanabe, and N. Maeda. 2008. Omnivory and stability of food webs. Ecological Complexity: doi:10.1016/j.ecocom.2008.02.001

Noe, G. B., D. L. Childers, and R. D. Jones. 2001. Phosphorus biogeochemistry and the impact of phosphorus enrichment: Why is the Everglades so unique? Ecosystems 4(7): 603-624.

Pan, Y., R. J. Stevenson, P., Vaithiyanathan, J. Slate, and C. J. Richardson. 2000. Changes in algal assemblages along observed and experimental phosphorus gradients in a subtropical wetland, USA. Freshwater Biology 44:339-353.

Pauls, S. U., W. Graf, P. Haase, H. T. Lumbsch, and J. Waringer. 2008. Grazers, shredder and filtering carnivores- The evolution of feeding ecology in Drusinae (Trichoptera: Limnephilidae): Insights from a molecular phylogeny. Molecular Phylogenetics and Evolution 46:776-791. 
Polis, G. A. W. B. Anderson, and R. D. Holt. 1997. Toward and integration of landscape and food web ecology: The dynamics of spatially subsidized food webs. Annual Review of Ecology and Systematics 28(1997): 289316.

Power, M. E. 1992. Top-down and bottom-up forces in food webs: do plants have primacy? Ecology 73: 733-746.

Power, M. E., and W. E. Dietrich. 2002. Food webs in river networks. Ecological Research 17: 451-471.

R Core Team (2017). R: A language and environment for statistical computing. R Foundation for Statistical Computing, Vienna, Austria. URL https://www.R-project.org/.

Radar, R. B., and C. J. Richardson. 1994. Response of macro- invertebrates and small fish to nutrient enrichment in the northern Everglades. Wetlands 14: $134-146$.

Reisz, R. R., and J. Frobisch. 2014. The Oldest Caseid Synapsid from the Late Pennsylvanian of Kansas, and the Evolution of Herbivory in Terrestrial Vertebrates. PLoS ONE 9(4): e94518. doi:10.1371/journal.pone.0094518

Sanchez, J. L., and J. C. Trexler. 2016. The adaptive evolution of herbivory in freshwater systems. Ecosphere 7(7) doi e01414. 10.1002/ecs2.1414.

Sanchez, J. L., and J. C. Trexler. 2018. When is an herbivore not an herbivore? Detritivory facilitates herbivory in a freshwater system. Ecology and Evolution: doi 10.1002/ece3.4133

Sanchez, J. L., and J. C. Trexler. Carnivory is best, but herbivory is good enough: A test of the Heterotroph Facilitation and Lipid Allocation Hypotheses for diet evolution. In review.

Sanchez, J. L., H. D. Bracken-Grissom, and J. C. Trexler. Freshwater-to-marine transitions may explain the evolution of herbivory in the subgenus Mollienesia (genus Poecilia). In review.

Sargeant, B. L., E. E. Gaiser, and J. C. Trexler. 2011. Indirect and direct controls of macroinvertebrates and small fish by abiotic factors and trophic interactions in the Florida Everglades. Freshwater Biology 56(11): 23342346.

Sterner, R. W., and J. J. Elser. 2002. Ecological stoichiometry. Princeton University Press, Princeton. 
Sterner, R. W., and D. O. Hessen. 1994. Algal nutrient limitation and the nutrition of aquatic herbivores. Annual Review of Ecology and Systematics 25:129.

Stevenson, C., and D. L. Childers. 2004. Hydroperiod and seasonal effects on fish decomposition in an oligotrophic Everglades marsh. Wetlands 24:529-537.

Taylor, A. N., D. P. Batzer. 2010. Spatial and temporal variation in invertebrate consumer diets in forested and herbaceous wetlands. Hydrobiologia 651:145-159.

Thompson, R. M., and C. R. Townsend. 2005. Energy availability, spatial heterogeneity and ecosystem size predict food-web structure in streams. Oikos 108: 137-148.

Tilman, D. 1994. Competition and biodiversity in spatially structured habitats. Ecology 75: 2-16.

Torres-Ruiz, M., J. D. Wehr, and A. A. Perrone. 2007. Trophic relations in a stream food webs: Importance of fatty acids for macroinvertebrate consumers. Journal of the North American Benthological Society 26: 509522.

Trexler J. C., W. F. Loftus, F. Jordan, J. H. Chick, K. L. Kandl, T. C. McElroy, and O. L. Bass Jr. 2002. Ecological scale and its implications for freshwater fishes in the Florida Everglades. In: The Everglades, Florida Bay, and Coral Reefs of the Florida Keys: An Ecosystem Sourcebook (Eds. J.W. Porter \& K.G. Porter), pp. 153-181. CRC Press, Boca Raton, FL, USA.

Trexler J.C., W. F. Loftus, and S. Perry. 2005. Disturbance frequency and community structure in a twenty-five year intervention study. Oecologia, 145, 140-152. doi:10.1007/s00442-005-0094-4.

Turner, A. M., J. C. Trexler, C. F. Jordan, S. J. Slack, P. Geddes, J. H. Chick, and W. F. Loftus. 1999. Targeting ecosystem features for conservation: Standing crop in the Florida Everglades. Conservation Biology 13:989911.

Van Damme, R. 1999. Evolution of herbivory in Lacertid lizards: Effects of insularity and body size. Journal of Herpetology 33(4):663-674.

Vermeij, G. 1992. Time of origin and biogeographical history of specialized relationships between Northern marine plants and herbivorous mollusks. Evolution 46(3): 657664. 
Vermeij, G., and D. R. Lindberg. 2000. Delayed herbivory and the assembly of marine benthic ecosystems. Paleobiology 26(3): 419-430.

Volkov, I., J. R. Banavar, S. P. Hubbell, and A. Maritan. 2003. Neutral theory and relative species abundance in ecology. Nature 424: 1035-1037.

Walters, A. W., and D. M. Post. 2011. How low can you go? Impacts of a lowflow disturbance on aquatic insect communities. Ecological Applications 21(1): 163-174.

Wickham, H., and W. Chang. 2017. devtools: Tools to Make Developing R Packages Easier. R package version 1.13.3. https://CRAN.Rproject.org/package $=$ devtools

Williams, A. J., and J. C. Trexler. 2006. A preliminary analysis of the correlation of food-web characteristics with hydrology and nutrient gradients in the southern Everglades. Hydrobiologia 569: 493-504.

White, T. C. R. 1985. When is a herbivore not a herbivore? Oecologia (Berlin) 67: 596-597.

Wolkovich, E. M., S. Allesina, K. L. Cottingham, J. C. Moore, S. A. Sandin, and C. de. Mazancourt. 2014. Linking the green and brown worlds: the prevalence and effect of multichannel feeding in food webs. Ecology 95(12) 3376-3386. 


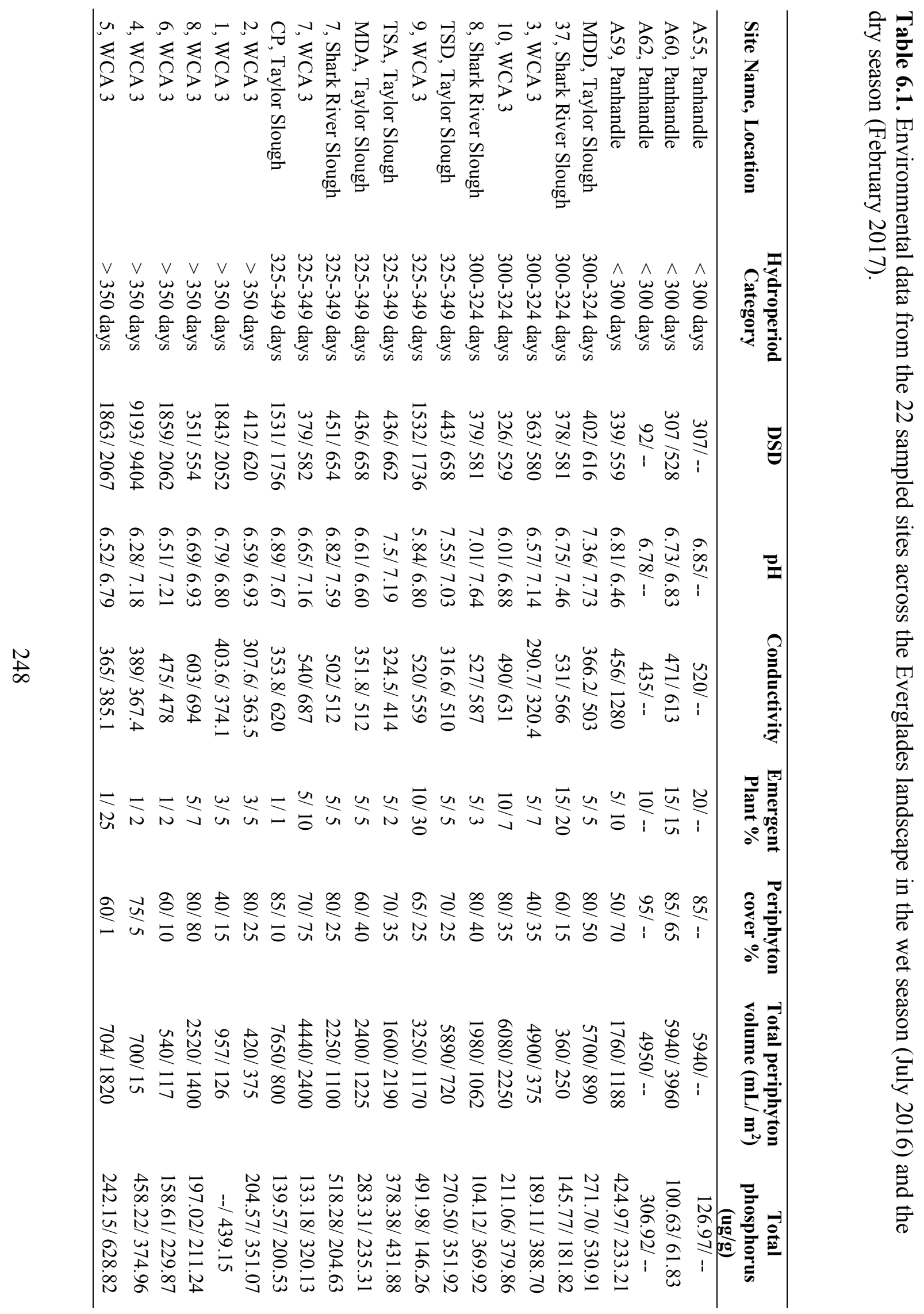


Table 6.2. Percentage of each periphyton type at each site in the wet season (July 2016) and the dry season (February 2017). Sites A55 and A60 were not able to be sampled in the dry season. Sorted in order from shortest to longest hydroperiod.

\begin{tabular}{|c|c|c|c|c|c|c|c|c|}
\hline & \multicolumn{4}{|c|}{ WET SEASON } & \multicolumn{4}{|c|}{ DRY SEASON } \\
\hline $\begin{array}{l}\text { Site Name, } \\
\text { Location }\end{array}$ & $\begin{array}{c}\text { Floating } \\
\text { Mat }\end{array}$ & $\begin{array}{l}\text { Benthi } \\
\text { c Mat }\end{array}$ & Epiphyton & $\begin{array}{c}\text { Fil. } \\
\text { Green } \\
\text { Algae }\end{array}$ & $\begin{array}{c}\text { Floating } \\
\text { Mat }\end{array}$ & $\begin{array}{c}\text { Benthic } \\
\text { Mat }\end{array}$ & Epiphyton & $\begin{array}{c}\text { Fil. } \\
\text { Green } \\
\text { Algae }\end{array}$ \\
\hline $\begin{array}{c}\text { A55, } \\
\text { Panhandle }\end{array}$ & 95 & 5 & -- & -- & -- & -- & -- & -- \\
\hline $\begin{array}{c}\text { A60, } \\
\text { Panhandle }\end{array}$ & 98 & 2 & -- & -- & 100 & -- & -- & -- \\
\hline $\begin{array}{c}\text { A62, } \\
\text { Panhandle }\end{array}$ & 73 & 2 & 25 & -- & -- & -- & -- & -- \\
\hline $\begin{array}{c}\text { A59, } \\
\text { Panhandle }\end{array}$ & 95 & -- & -- & 5 & 100 & & & \\
\hline $\begin{array}{l}\text { MDD, } \\
\text { Taylor } \\
\text { Slough }\end{array}$ & 100 & -- & -- & -- & 98 & -- & -- & 2 \\
\hline $\begin{array}{l}\text { 37, Shark } \\
\text { River Slough }\end{array}$ & 100 & -- & -- & -- & 100 & -- & -- & -- \\
\hline 3 , WCA 3 & 80 & -- & 20 & -- & 100 & -- & -- & -- \\
\hline 10, WCA 3 & 95 & -- & 5 & -- & 75 & 25 & -- & -- \\
\hline $\begin{array}{c}\text { 8, Shark } \\
\text { River Slough }\end{array}$ & 95 & -- & 5 & -- & 50 & -- & 50 & -- \\
\hline $\begin{array}{l}\text { TSD, Taylor } \\
\text { Slough }\end{array}$ & 98 & -- & -- & 2 & 90 & -- & 10 & -- \\
\hline 9, WCA 3 & 90 & 5 & 5 & -- & 100 & -- & -- & -- \\
\hline $\begin{array}{l}\text { TSA, Taylor } \\
\text { Slough }\end{array}$ & 70 & 20 & 10 & -- & 60 & 10 & 30 & -- \\
\hline $\begin{array}{l}\text { MDA, } \\
\text { Taylor } \\
\text { Slough }\end{array}$ & 65 & -- & 35 & -- & 80 & -- & 20 & -- \\
\hline $\begin{array}{l}\text { 7, Shark } \\
\text { River Slough }\end{array}$ & 90 & -- & 10 & -- & 100 & -- & -- & -- \\
\hline 7, WCA 3 & 98 & -- & 2 & -- & 90 & 5 & 5 & -- \\
\hline $\begin{array}{l}\text { CP, Taylor } \\
\text { Slough }\end{array}$ & 95 & -- & 5 & -- & 50 & 30 & 20 & -- \\
\hline 2, WCA 3 & 100 & -- & -- & -- & 98 & -- & 2 & -- \\
\hline 1, WCA 3 & 100 & -- & -- & -- & 99 & -- & 1 & -- \\
\hline 8, WCA 3 & 98 & -- & 2 & -- & 99 & 1 & -- & -- \\
\hline 6, WCA 3 & 100 & -- & -- & -- & 100 & -- & -- & -- \\
\hline 4, WCA 3 & 95 & -- & 5 & -- & 95 & -- & 5 & -- \\
\hline 5, WCA 3 & 100 & -- & -- & -- & 50 & -- & 50 & -- \\
\hline
\end{tabular}


Table 6.3. Principal components loadings for environmental, food availability, and food quality variables for the wet season (July 2016) and the dry season (February 2017).

Loadings $\geq 0.30$ (abs. value) are highlighted in grey. DSD = Days since last dry-down, $\mathrm{TP}=$ Total phosphorus

\begin{tabular}{|c|c|c|c|c|}
\hline & \multicolumn{2}{|c|}{ WET SEASON } & \multicolumn{2}{|c|}{ DRY SEASON } \\
\hline Variables & PC 1 & PC 2 & PC 1 & PC 2 \\
\hline \multicolumn{5}{|l|}{ ENVIRONMENTAL } \\
\hline Hydroperiod & 0.53 & -0.01 & -0.39 & -0.55 \\
\hline DSD & 0.53 & -0.23 & -0.50 & -0.14 \\
\hline Emergent plant $\%$ & -0.59 & -0.12 & -0.29 & 0.82 \\
\hline $\mathrm{pH}$ & -0.14 & 0.73 & -0.51 & -0.01 \\
\hline Conductivity & -0.26 & -0.63 & -0.50 & 0.09 \\
\hline \multicolumn{5}{|l|}{ FOOD AVAILABILITY } \\
\hline Periphyton cover $\%$ & -0.51 & 0.18 & -0.55 & 0.41 \\
\hline Floating mat volume & -0.42 & 0.55 & -0.67 & 0.13 \\
\hline Benthic mat volume & -0.46 & 0.24 & -0.39 & -0.43 \\
\hline Epiphyton volume & -0.41 & -0.38 & -0.31 & -0.56 \\
\hline $\begin{array}{l}\text { Fil. algae volume } \\
\end{array}$ & 0.41 & 0.68 & -0.05 & 0.56 \\
\hline \multicolumn{5}{|l|}{ FOOD QUALITY } \\
\hline Protein & 0.41 & -0.24 & 0.30 & -0.03 \\
\hline Carbohydrate & 0.41 & -0.14 & 0.41 & -0.07 \\
\hline Lipid & 0.47 & -0.06 & 0.37 & -0.13 \\
\hline Bacterial fatty acid $\%$ & 0.45 & 0.07 & 0.38 & -0.14 \\
\hline Edible algae (mg) & 0.39 & 0.29 & 0.41 & 0.27 \\
\hline $\mathrm{EPA} \%$ & -0.09 & 0.81 & 0.39 & 0.25 \\
\hline PUFA ratio & -0.19 & -0.37 & 0.27 & -0.64 \\
\hline TP & -0.19 & -0.30 & 0.25 & -0.50 \\
\hline
\end{tabular}


Table 6.4. Comparison of structural equation models used to predict omnivore density in the wet and dry seasons. Total model includes paths between Periphyton Quality PC 1 \& 2 (Q1 \& Q2), Periphyton Availability PC $1 \& 2$ (A1 \& A2), herbivores and omnivores. Paths between consumers were not varied. $\mathrm{AIC}_{\mathrm{w}}=$ Akaike weights, $w_{\min } / w_{j}=$ Evidence ratios. $\triangle \mathrm{AICc}$ values $\leq 2$ are highlighted in bold.

\begin{tabular}{|c|c|c|c|c|c|c|c|}
\hline & & & WET & & & DRY & \\
\hline Model & $\begin{array}{l}\text { Removed from } \\
\text { model }\end{array}$ & $\triangle \mathrm{AICc}$ & $\mathrm{AIC}_{\mathrm{w}}$ & $w_{\min } / w_{j}$ & $\triangle \mathrm{AICc}$ & $\mathbf{A I C}_{\mathbf{w}}$ & $w_{\min } / w_{j}$ \\
\hline 1 & None & 3.27 & 0.03 & 5.13 & 5.87 & 0.02 & 18.81 \\
\hline 2 & $\mathrm{Q} 1+\mathrm{Q} 2+\mathrm{A} 1$ & 1.27 & 0.09 & 1.88 & 8.57 & 0.005 & 72.49 \\
\hline 3 & $\mathrm{Q} 2+\mathrm{A} 1+\mathrm{A} 2$ & 1.93 & 0.06 & 2.62 & 7.12 & 0.01 & 35.16 \\
\hline 4 & $\mathrm{Q} 1+\mathrm{Q} 2+\mathrm{A} 2$ & 1.32 & 0.09 & 1.94 & 6.91 & 0.01 & 31058 \\
\hline 5 & $\mathrm{Q} 1+\mathrm{A} 1+\mathrm{A} 2$ & 0.16 & 0.13 & 1.08 & 0.00 & 0.36 & 1.00 \\
\hline 6 & $\mathrm{Q} 1+\mathrm{Q} 2$ & 1.97 & 0.06 & 2.68 & 8.66 & 0.005 & 75.75 \\
\hline 7 & $\mathrm{~A} 1+\mathrm{A} 2$ & 1.99 & 0.06 & 2.71 & 1.98 & 0.14 & 2.70 \\
\hline 8 & $\mathrm{Q} 2+\mathrm{A} 2$ & 3.23 & 0.03 & 5.02 & 8.66 & 0.005 & 75.98 \\
\hline 9 & $\mathrm{Q} 2+\mathrm{A} 1$ & 3.13 & 0.04 & 4.77 & 8.88 & 0.005 & 84.56 \\
\hline 10 & $\mathrm{Q} 1+\mathrm{A} 2$ & 1.88 & 0.07 & 2.57 & 1.93 & 0.14 & 2.62 \\
\hline 11 & $\mathrm{Q} 1+\mathrm{A} 1$ & 0.58 & 0.13 & 1.34 & 1.91 & 0.14 & 2.60 \\
\hline 12 & Q1 & 1.81 & 0.07 & 2.47 & 3.89 & 0.05 & 6.99 \\
\hline 13 & Q2 & 3.58 & 0.03 & 5.99 & 10.30 & 0.002 & 172.09 \\
\hline 14 & A1 & 2.28 & 0.05 & 3.13 & 3.91 & 0.05 & 7.07 \\
\hline 15 & A2 & 3.71 & 0.03 & 6.39 & 3.92 & 0.05 & 7.10 \\
\hline 16 & All & 0.00 & 0.17 & 1.00 & 6.57 & 0.01 & 26.70 \\
\hline
\end{tabular}


Table 6.5. Comparison of structural equation models used to predict herbivore density in the wet and dry seasons. Total model includes paths between Periphyton Quality PC 1 \& 2 (Q1 \& Q2), Periphyton Availability PC 1 \& 2 (A1 \& A2), herbivores and omnivores. Paths between consumers were not varied. $\mathrm{AIC}_{\mathrm{w}}=$ Akaike weights, $w_{\min } / w_{j}=$ Evidence ratios. $\triangle \mathrm{AICc}$ values $\leq 2$ are highlighted in bold.

\begin{tabular}{|c|c|c|c|c|c|c|c|}
\hline \multirow[b]{2}{*}{ Model } & \multirow[b]{2}{*}{$\begin{array}{l}\text { Removed from } \\
\text { model }\end{array}$} & \multicolumn{3}{|c|}{ WET } & \multicolumn{3}{|c|}{ DRY } \\
\hline & & $\triangle \mathrm{AICc}$ & $\mathbf{A I C}_{\mathbf{w}}$ & $w_{\min } / w_{j}$ & $\triangle \mathrm{AICc}$ & $\mathrm{AIC}_{\mathrm{w}}$ & $w_{\min } / w_{j}$ \\
\hline 1 & None & 1.49 & 0.10 & 2.10 & 4.63 & 0.02 & 45.77 \\
\hline 2 & $\mathrm{Q} 1+\mathrm{Q} 2+\mathrm{A} 1$ & 8.78 & 0.00 & 80.60 & 1.30 & 0.12 & 8.65 \\
\hline 3 & $\mathrm{Q} 2+\mathrm{A} 1+\mathrm{A} 2$ & 5.57 & 0.01 & 16.21 & 1.59 & 0.10 & 9.97 \\
\hline 4 & $\mathrm{Q} 1+\mathrm{Q} 2+\mathrm{A} 2$ & 4.14 & 0.03 & 7.92 & 0.00 & 0.22 & 4.51 \\
\hline 5 & $\mathrm{Q} 1+\mathrm{A} 1+\mathrm{A} 2$ & 2.84 & 0.05 & 4.15 & 0.62 & 0.14 & 7.14 \\
\hline 6 & $\mathrm{Q} 1+\mathrm{Q} 2$ & 3.19 & 0.04 & 4.93 & 2.68 & 0.06 & 17.22 \\
\hline 7 & $\mathrm{~A} 1+\mathrm{A} 2$ & 0.78 & 0.14 & 1.48 & 2.50 & 0.06 & 15.77 \\
\hline 8 & $\mathrm{Q} 2+\mathrm{A} 2$ & 2.37 & 0.06 & 3.27 & 3.07 & 0.05 & 20.97 \\
\hline 9 & $\mathrm{Q} 2+\mathrm{A} 1$ & 7.41 & 0.01 & 40.57 & 3.25 & 0.04 & 22.97 \\
\hline 10 & $\mathrm{Q} 1+\mathrm{A} 2$ & 2.16 & 0.07 & 2.95 & 1.37 & 0.11 & 8.94 \\
\hline 11 & $\mathrm{Q} 1+\mathrm{A} 1$ & 2.07 & 0.07 & 2.81 & 2.49 & 0.06 & 15.64 \\
\hline 12 & Q1 & 0.00 & 0.21 & 1.00 & 2.64 & 0.06 & 16.86 \\
\hline 13 & Q2 & 4.11 & 0.03 & 7.82 & 4.60 & 0.02 & 44.93 \\
\hline 14 & A1 & 2.62 & 0.06 & 3.70 & 4.11 & 0.03 & 35.30 \\
\hline 15 & A2 & 0.39 & 0.17 & 1.22 & 3.31 & 0.04 & 23.62 \\
\hline
\end{tabular}


Table 6.6. Summary of the changes (by hydroperiod) in food quality and availability from the wet season to the dry season. Upward facing triangles indicate relatively high values, whereas downward facing triangles indicate relatively low values. FA= fatty acid, $\mathrm{NC}=$ no change.

\begin{tabular}{|c|c|c|c|c|}
\hline & \multicolumn{4}{|c|}{ FOOD } \\
\hline & $<300$ days & 300-324 days & 325-350 days & $>350$ days \\
\hline \multicolumn{5}{|l|}{ Quality } \\
\hline Protein & $\nabla$ & $\nabla$ & $\nabla$ & $\nabla$ \\
\hline Carbohydrate & $\nabla$ & $\Delta$ & $\Delta$ & $\Delta$ \\
\hline Lipid & $\nabla$ & $\nabla$ & $\nabla$ & $\nabla$ \\
\hline Algal FAs & $\nabla$ & $\nabla$ & $\nabla$ & $\nabla$ \\
\hline Bact. FAs & $\nabla$ & $\nabla$ & $\nabla$ & $\nabla$ \\
\hline $\begin{array}{l}\text { Unsaturated FAs } \\
\text { (PUFA, SAFA, } \\
\text { MUFA) }\end{array}$ & $\nabla$ & $\nabla$ & $\nabla$ & $\nabla$ \\
\hline $\begin{array}{l}\text { Omega-3 FAs (EPA, } \\
\text { DHA) }\end{array}$ & $\Delta$ & $\Delta$ & $\Delta$ & $\Delta$ \\
\hline ARA & $\Delta$ & $\nabla$ & $\Delta$ & $\nabla$ \\
\hline Total phosphorus & $\nabla$ & $\Delta$ & $\nabla$ & $\Delta$ \\
\hline $\begin{array}{l}\text { Stoichiometry (C:P \& } \\
\mathrm{N}: \mathrm{P})\end{array}$ & $\Delta$ & $\Delta$ & $\Delta$ & $\Delta$ \\
\hline \multicolumn{5}{|l|}{ Availability } \\
\hline Edible algae \% & $\nabla$ & $\nabla$ & $\nabla$ & $\nabla$ \\
\hline $\begin{array}{l}\text { Total Periphyton } \\
\text { volume }\end{array}$ & $\nabla$ & $\nabla$ & $\nabla$ & $\Delta$ \\
\hline Floating mat \% & $\nabla$ & $\nabla$ & $\nabla$ & $\nabla$ \\
\hline Herbivore density & $\nabla$ & $\nabla$ & $\nabla$ & $\nabla$ \\
\hline
\end{tabular}


Table 6.7. Summary of the changes in consumer diet and tissue composition (herbivores and omnivores) from the wet season to the dry season. Values are averaged across all hydroperiods. Upward facing triangles indicate relatively high values, whereas downward facing triangles indicate relatively low values. $\mathrm{FA}=$ fatty acid, $\mathrm{NC}=$ no change.

\begin{tabular}{|c|c|c|}
\hline & HERBIVORES & OMNIVORES \\
\hline \multicolumn{3}{|l|}{ Diet } \\
\hline Algae & $\boldsymbol{\nabla}$ & \\
\hline Detritus & 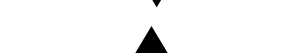 & $\hat{\mathbf{A}}$ \\
\hline Macroinverts. & $\mathrm{NC}$ & $\mathbf{\nabla}$ \\
\hline \multicolumn{3}{|l|}{ Tissues } \\
\hline Protein & $\boldsymbol{\nabla}$ & $\boldsymbol{\nabla}$ \\
\hline Carbohydrate & $\boldsymbol{\nabla}$ & $\boldsymbol{\nabla}$ \\
\hline Lipid & $\boldsymbol{\Delta}$ & $\boldsymbol{\Delta}$ \\
\hline Algal FAs & $\mathbf{\Delta}$ & $\Delta$ \\
\hline Bact. FAs & $\Delta$ & $\Delta$ \\
\hline Unsaturated FAs (PUFA, SAFA, MUFA) & $\Delta$ & $\boldsymbol{\Delta}$ \\
\hline EPA & $\boldsymbol{\Delta}$ & $\boldsymbol{\nabla}$ \\
\hline DHA & $\Delta$ & $\mathbf{\Delta}$ \\
\hline ARA & $\Delta$ & $\Delta$ \\
\hline Total phosphorus & $\mathbf{\Delta}$ & $\boldsymbol{\Delta}$ \\
\hline Stoichiometry (C:P \& N:P) & $\boldsymbol{\nabla}$ & $\boldsymbol{\nabla}$ \\
\hline
\end{tabular}




\section{Figure Legends}

Fig. 6.1. Map showing location of 22 sampled locations across the Everglades landscape Fig. 6.2. Classification of diets by gut contents using Sorensen (Bray-Curtis) distance measures with flexible beta linkage. Although some species showed seasonal diet shifts, Hierarchical Cluster analysis identified the same 2 diet categories in the wet season (A) and in the dry season (B). Pie charts represent amount of each food type present in the gut (estimated from Loftus 2000). White $=$ periphyton, grey= detritus, black= animal material Fig. 6.3. Seasonal variation of periphyton quality by hydroperiod. (A) Periphyton Quality PC1 represents macronutrients (protein, carb, lipid), edibility and $\%$ of heterotrophic fatty acids. These food quality variables decrease with increasing hydroperiod in the wet season. (B) Periphyton Quality PC2 represents PUFA Ratio (-), EPA and TP

(-). Periphyton Quality PC2 increased with increasing hydroperiod, suggesting that long hydroperiod sites have decreased PUFA ratios, increased EPA and decreased TP in the wet season. (C) Periphyton Quality PC1 represents macronutrients (protein, carb, lipid), edibility, EPA and \% of heterotrophic fatty acids in the dry season. These variables increase with increasing hydroperiod in the dry season, contrary to the pattern in the wet season. (D) Periphyton Quality PC2 represents PUFA ratio (-) and total phosphorus (-) in the dry season. Similar to the wet season, Periphyton Quality PC2 increased with increasing hydroperiod in the dry season, suggesting that long hydroperiod sites have decreased PUFA ratios and TP

Fig. 6.4. Number of consumers per $\mathrm{m}^{2}$ found in sites with different hydroperiods in the wet season (A) and dry season (B) 
Fig. 6.5. The structural equation models with the best fit $(\triangle \mathrm{AICc}=0.00)$ showing $(\mathrm{A})$ herbivore density as the best predictor of omnivore density in the wet season, (B) and PUFA ratio and $\mathrm{TP}$ as the best predictors of omnivore density in the dry season. Solid lines indicate statistically significant relationships and dashed lines indicate nonsignificant relationships. Numbers indicate regression (path) coefficients for each path analyzed

Fig. 6.6. The structural equation models with the best fit $(\triangle \mathrm{AICc}=0.00)$ showing $(\mathrm{A})$ PUFA ratio, TP, EPA \%, and omnivore density as the best predictors of herbivore density in the wet season, (B) and no statistically significant relationships between periphyton variables and herbivore density in the dry season. Solid lines indicate statistically significant relationships and dashed lines indicate non-significant relationships. Numbers indicate regression (path) coefficients for each path analyzed

Fig. 6.7. Verified predictions of the Suboptimal Habitat Hypothesis. (A) In the wet season, herbivore density decreases with periphyton quality (PC1: macronutrients, edibility and $\%$ of heterotrophic fatty acids). Herbivore residuals were taken from a regression with environmental variables and herbivore density to obtain the unique pattern attributable to periphyton quality.

(B) In the dry season, Periphyton Availability PC1 represents periphyton cover \% (-) and floating mat abundance (-) and Periphyton Quality PC1 represents macronutrients (protein, carb, lipid), edibility, EPA and \% of heterotrophic fatty acids. The relationship between these PC scores suggests that periphyton quality decreases with increasing periphyton cover estimations and floating mat abundance 
FIG. 6.1.

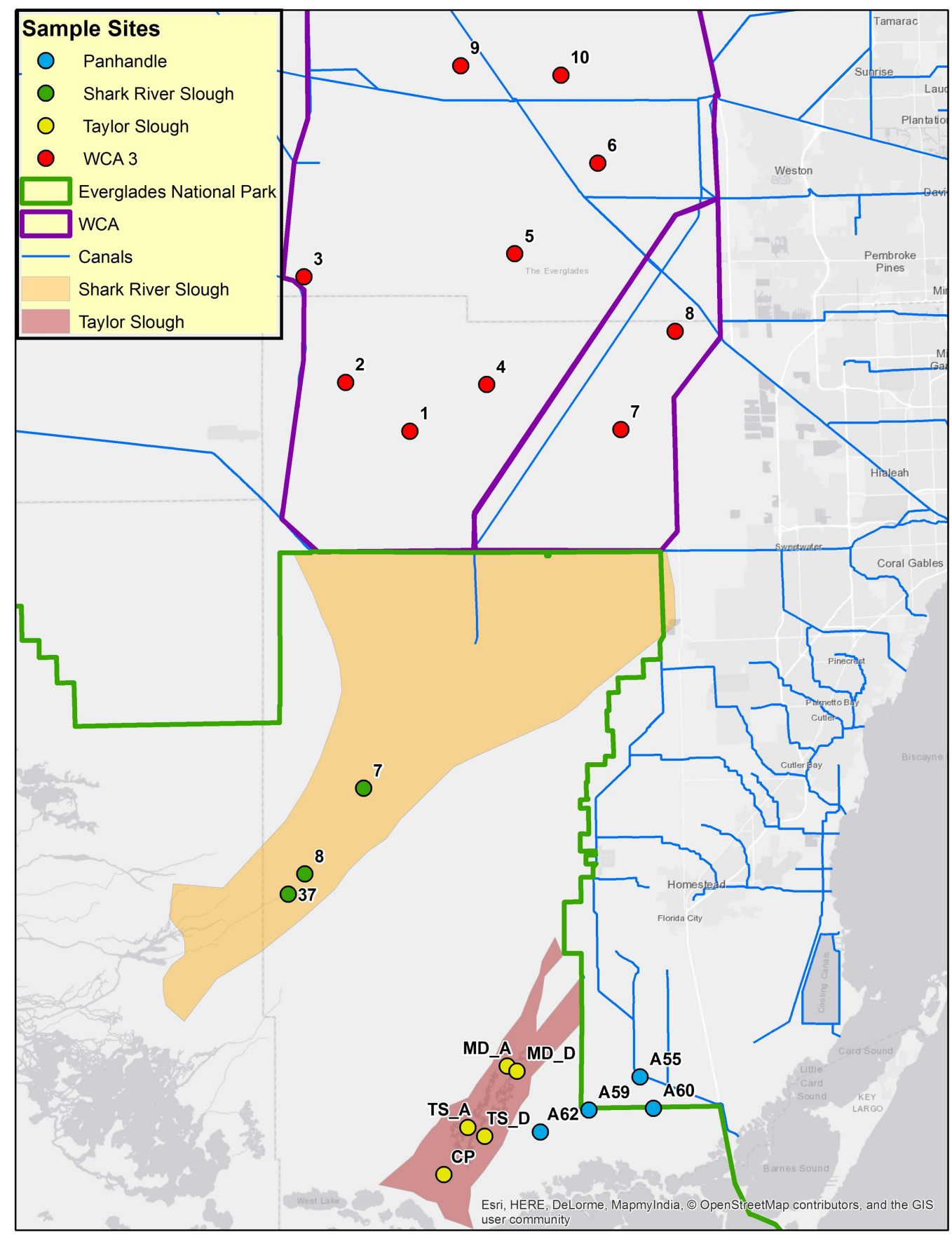


岕
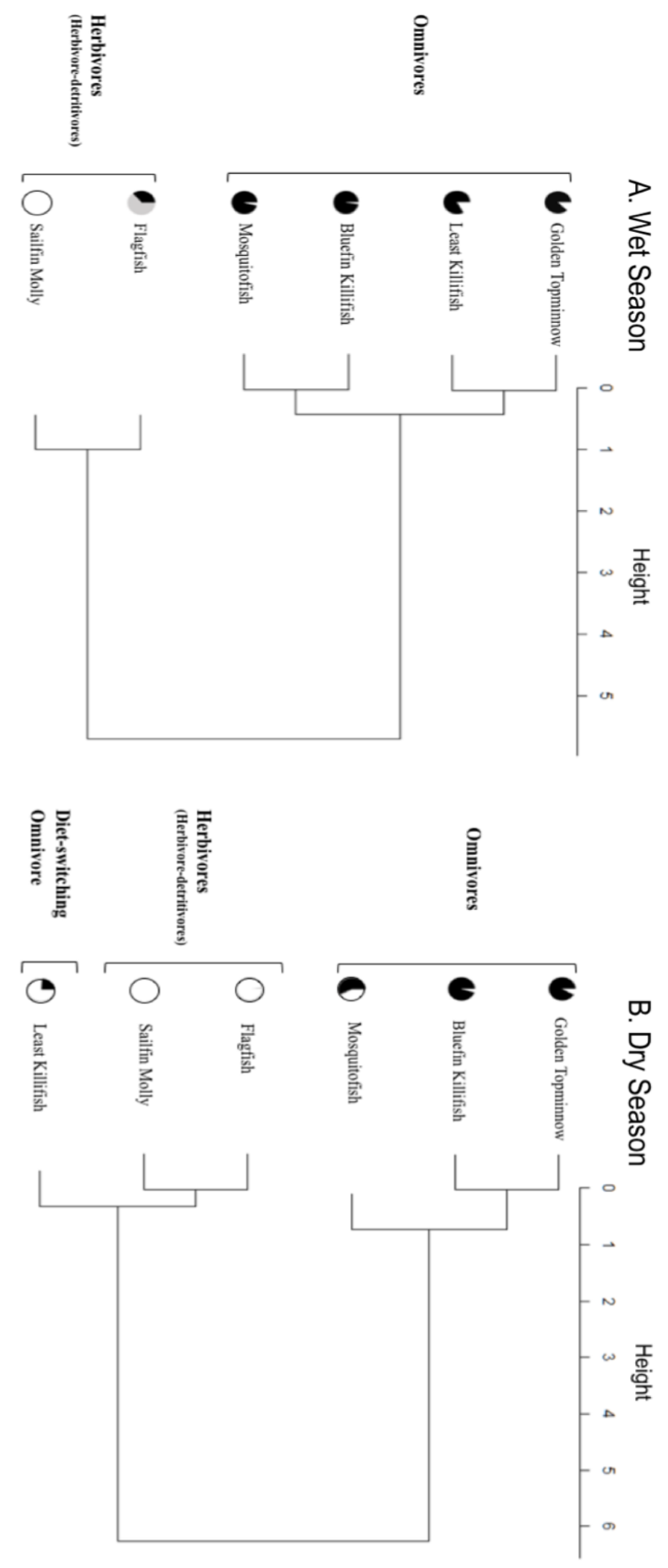


\section{Periphyton Quality PC1}

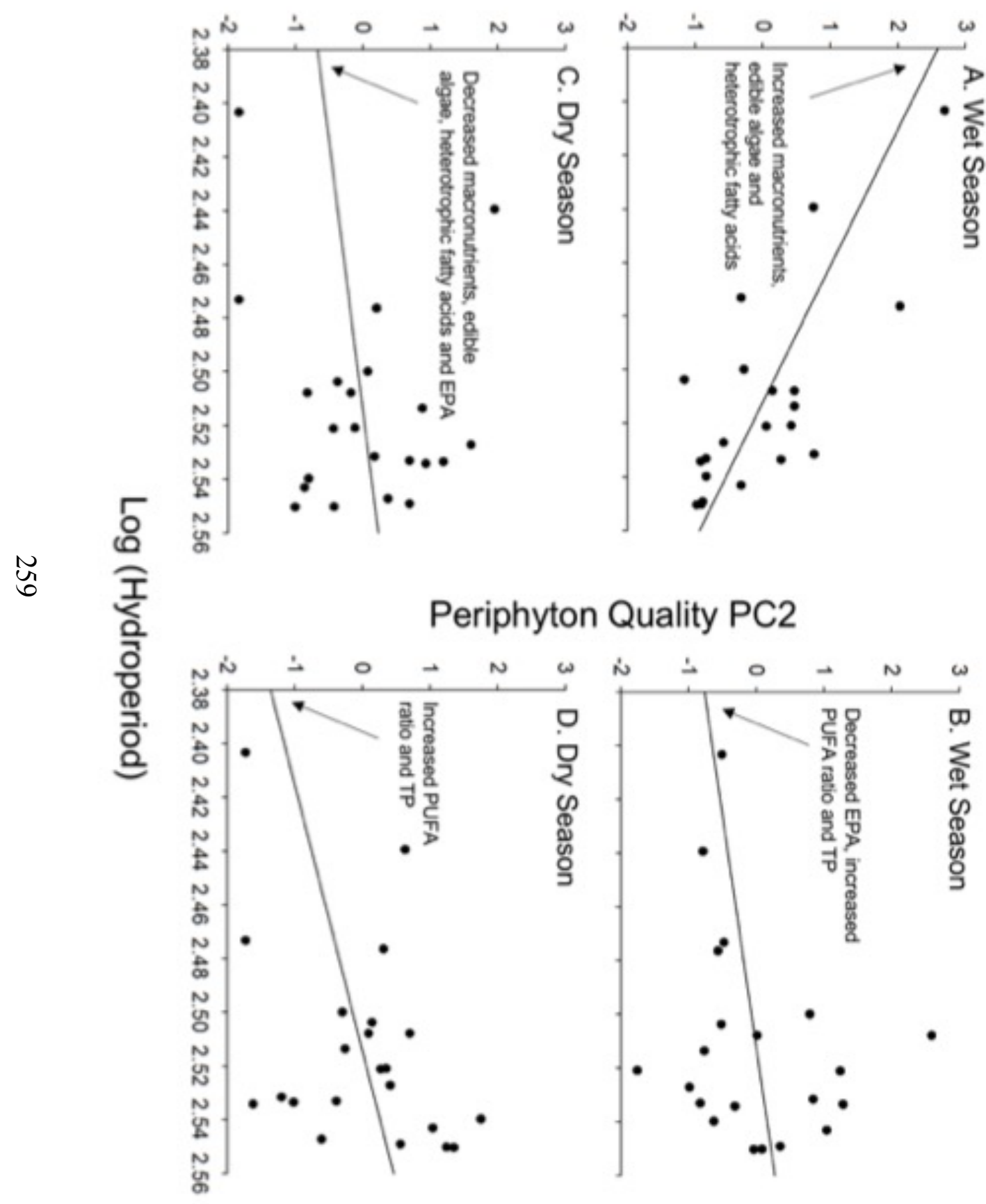


FIG. 6.4.

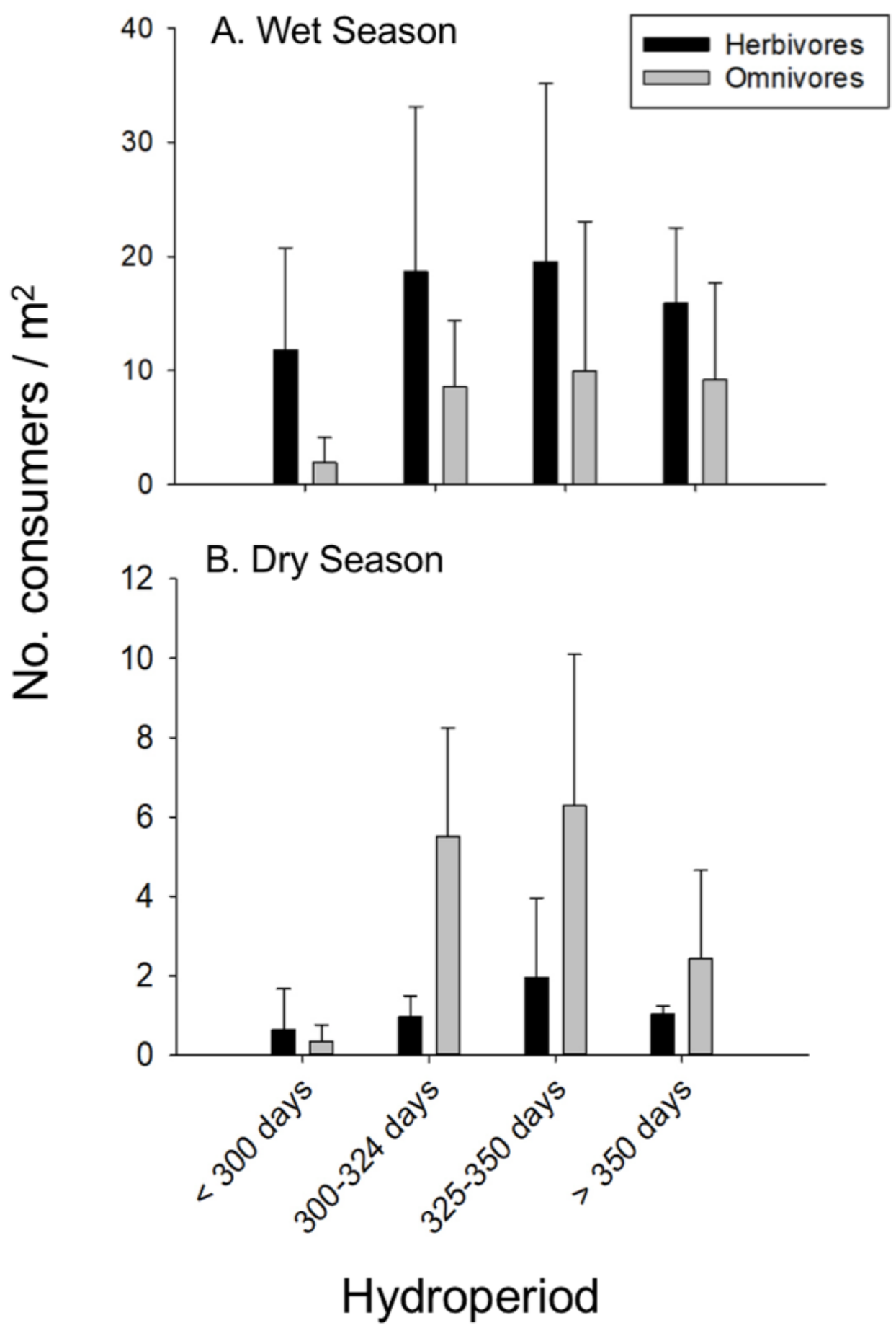


FIG. 6.5.
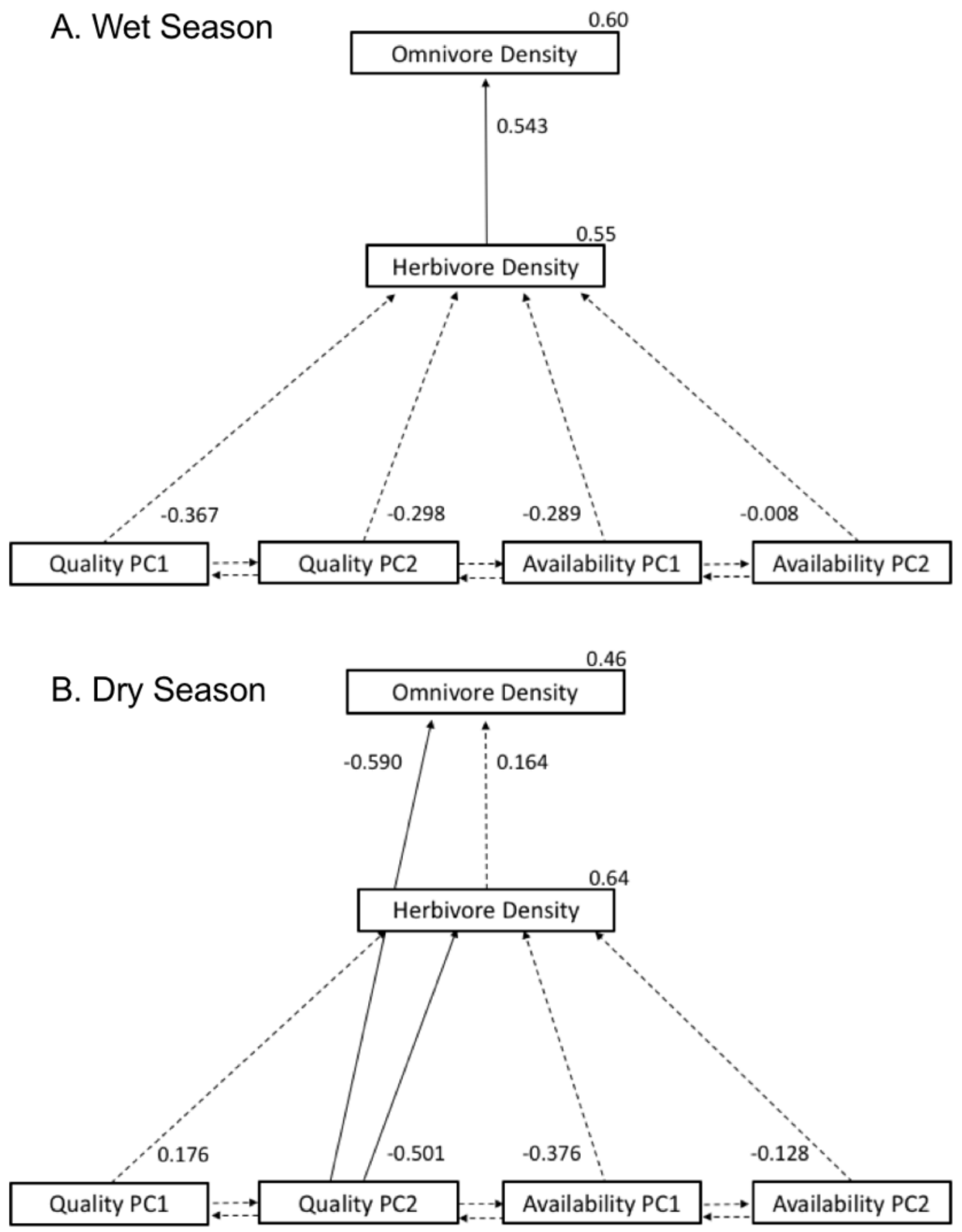
FIG. 6.6.
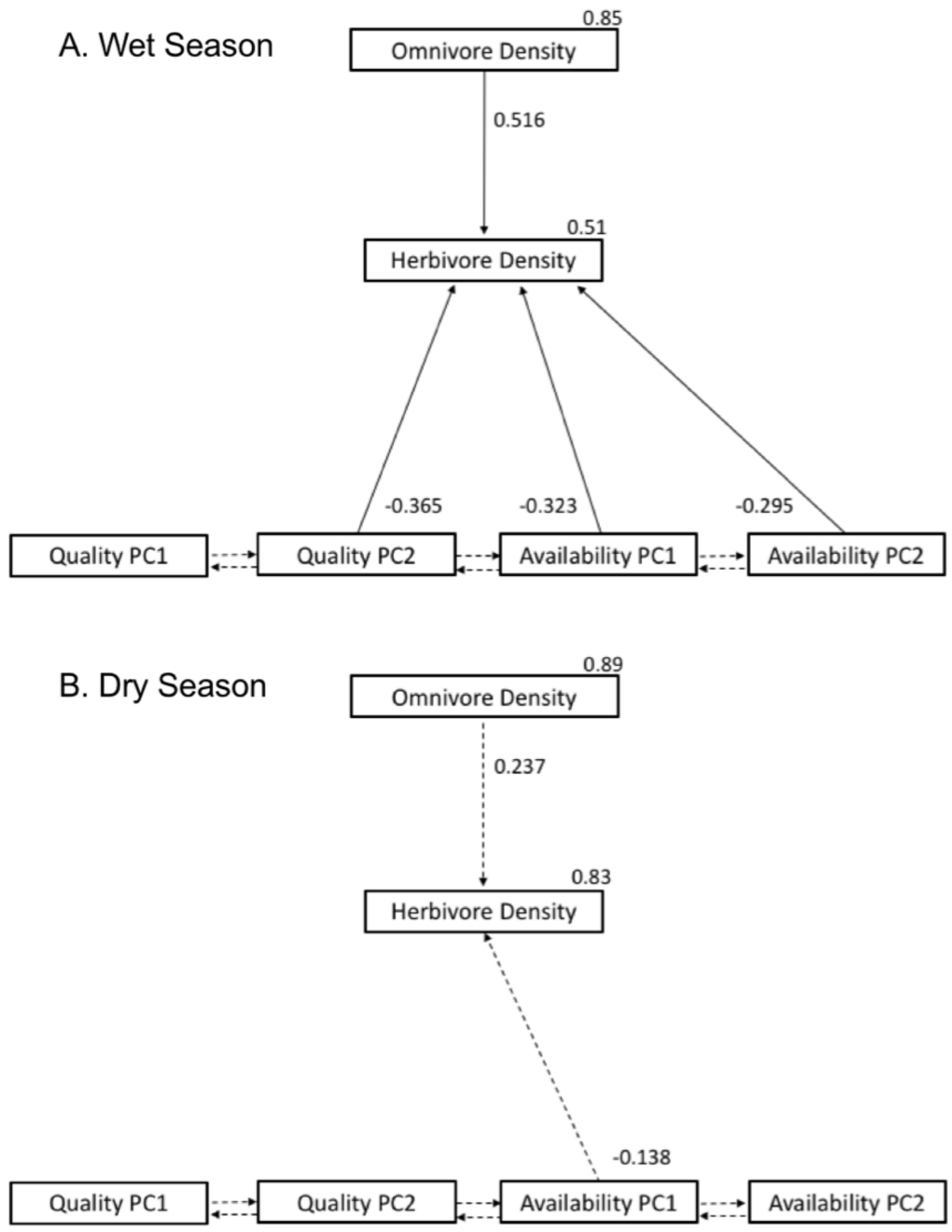
FIG. 6.7.
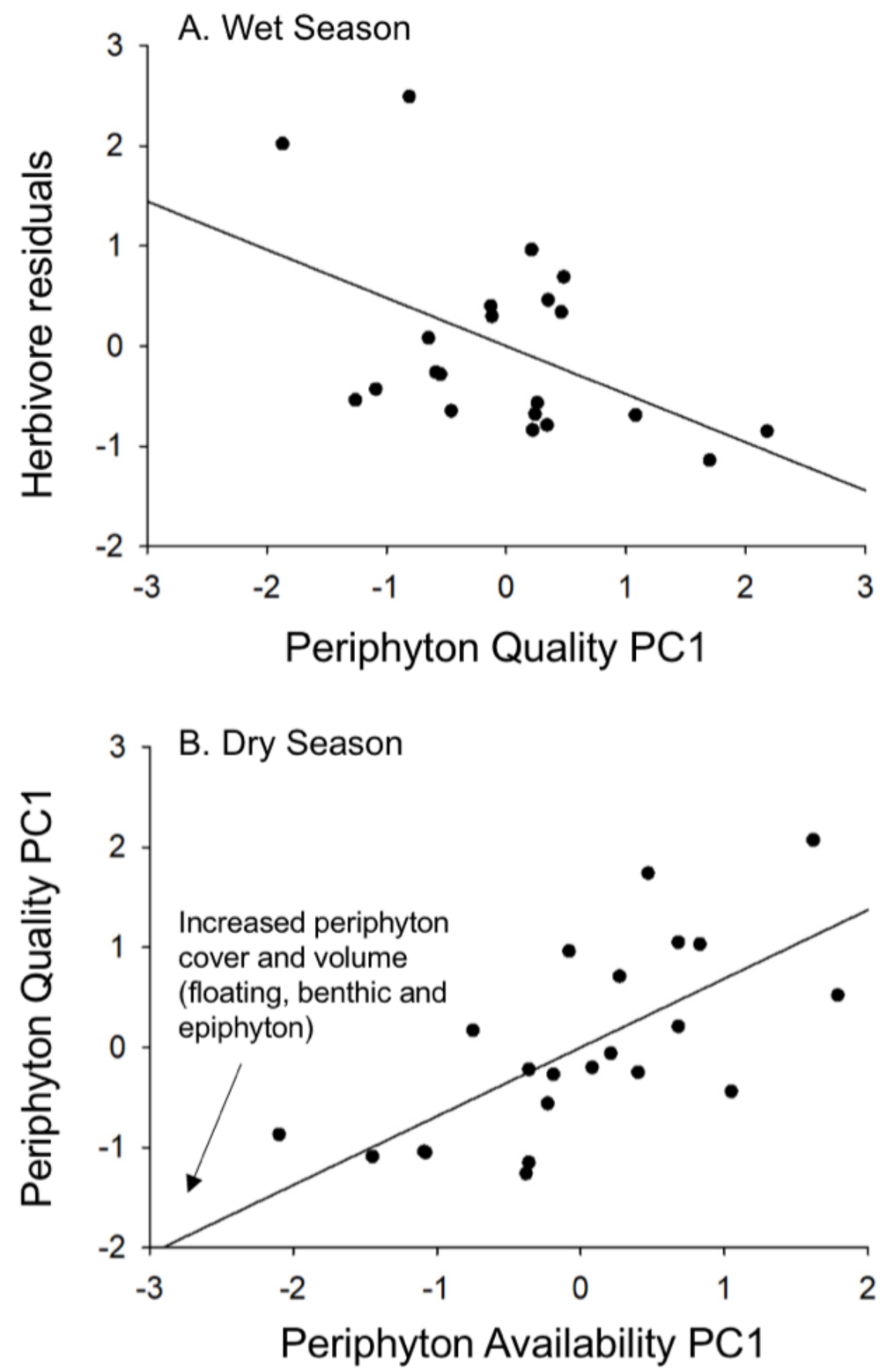
Supplementary Information 
Table S.6.1. Additional environmental characteristics of the 22 sampled sites across the Everglades landscape in the wet season (July 2016) and the dry season (February 2017). WCA 1 periphyton was not processed for nutrients in the wet season due to sample contamination, and sites A55 and A62 were inaccessible by boat in the dry season and thus not able to be sampled. Sorted in order from shortest to longest hydroperiod.

\begin{tabular}{|c|c|c|c|c|}
\hline Site Name, Location & UTM & Soil Type & Mat Type & $\begin{array}{l}\text { Dominant } \\
\text { plant genera }\end{array}$ \\
\hline A55, Panhandle & 17R 0548370,2799637 & Marl & Calcareous & Cladium \\
\hline A60, Panhandle & 17 R 0549633, 2796673 & Marl & Calcareous & Cladium \\
\hline A62, Panhandle & 17R 0538937,2794437 & Peat + Marl & Calcareous & Eleocharis \\
\hline A59, Panhandle & 17R 543522, 2796517 & Peat + Marl & Calcareous & Eleocharis \\
\hline MDD, Taylor Slough & 17R 0536563,2800183 & Peat & Calcareous & Eleocharis \\
\hline $\begin{array}{l}\text { 37, Shark River } \\
\text { Slough }\end{array}$ & 17R 0515124,2816895 & Peat & Organic & Eleocharis \\
\hline 3, WCA 3 & 17R 0516614, 2875215 & Peat & Organic & Eleocharis \\
\hline 10, WCA 3 & 17R 0540853,2894243 & Peat & $\begin{array}{c}\text { Calcareous + } \\
\text { Organic }\end{array}$ & Eleocharis \\
\hline 8, Shark River Slough & 17R 0516610, 2818861 & Peat + Marl & Organic & Eleocharis \\
\hline TSD, Taylor Slough & 17R 0533471, 2794060 & Peat & $\begin{array}{l}\text { Calcareous }+ \\
\text { Organic }\end{array}$ & Eleocharis \\
\hline 9, WCA 3 & 17R 0531411,2895129 & Peat & Organic & Eleocharis \\
\hline TSA, Taylor Slough & 17R 0532105, 2794861 & Peat & Calcareous & Eleocharis \\
\hline MDA, Taylor Slough & 17R 05355703,2800594 & Marl & Calcareous & Eleocharis \\
\hline 7, Shark River Slough & 17 R 0522246, 2826891 & Peat & Organic & Eleocharis \\
\hline 7, WCA 3 & 17R 0546523, 2860779 & Marl & Organic & Eleocharis \\
\hline CP, Taylor Slough & 17R 0529841, 2790479 & Marl & Calcareous & Eleocharis \\
\hline 2, WCA 3 & 17R 0520550,2865235 & Sand & Organic & Nymphaea \\
\hline 1 , WCA 3 & 17R 0526618,2860613 & Sand & Organic & Nymphaea \\
\hline 8, WCA 3 & 17R 0551663,2870064 & Marl & Organic & Eleocharis \\
\hline 6, WCA 3 & 17R 0544333,2885929 & Peat & Organic & Nymphaea \\
\hline 4, WCA 3 & 17R 0533854,2865022 & Peat & Organic & Nymphaea \\
\hline 5, WCA 3 & 17R 0536494,2877413 & Peat & Organic & Nymphaea \\
\hline
\end{tabular}




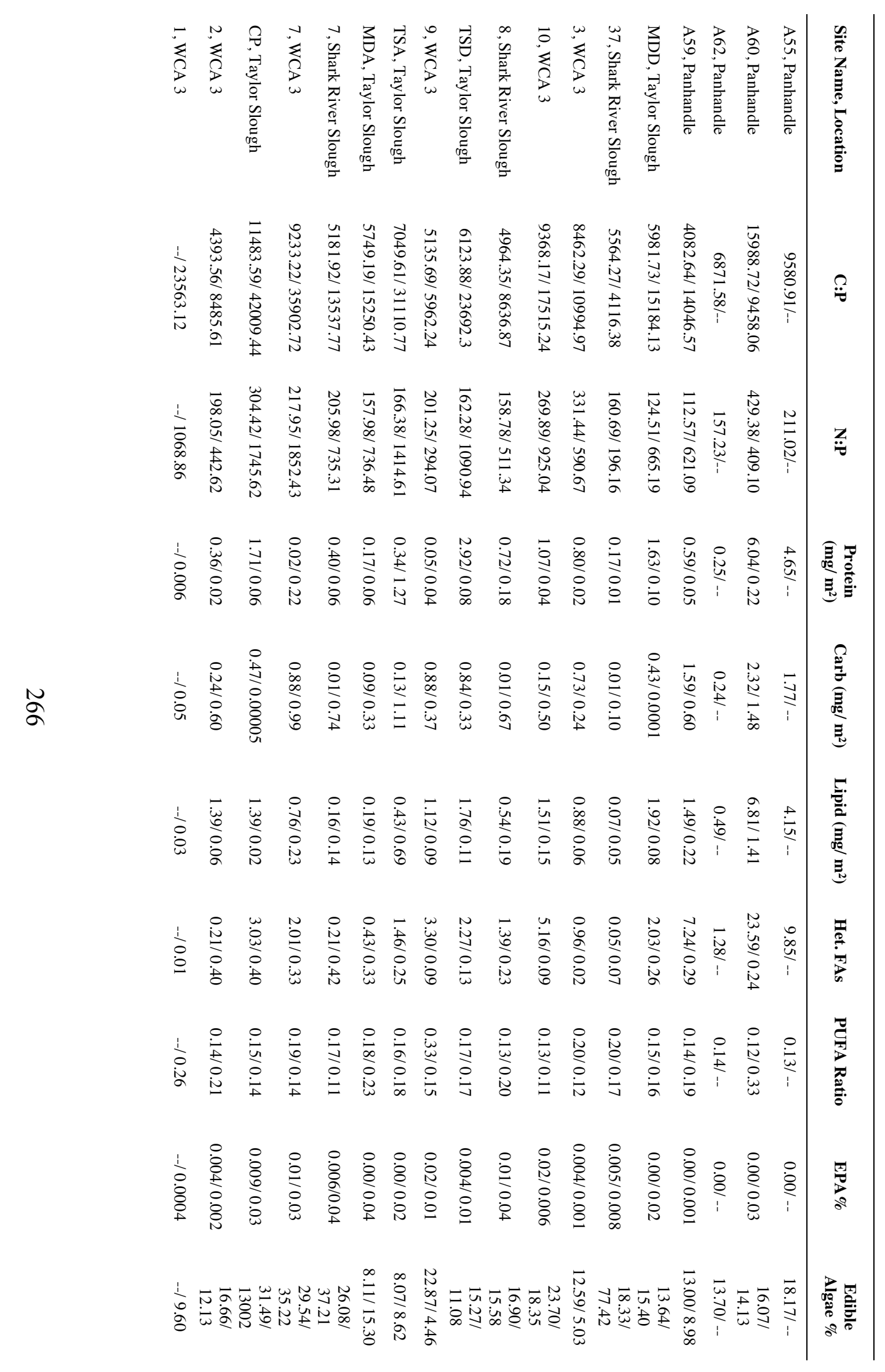

응

芑

官

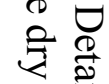

离

ญ

궁ㄷㄹ

ฏ

幽

크

8

ह

$\stackrel{\circ}{\stackrel{2}{5}}$

N

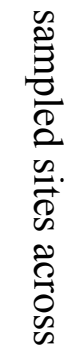

홍

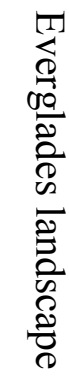

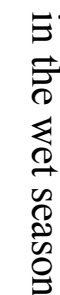

छ 


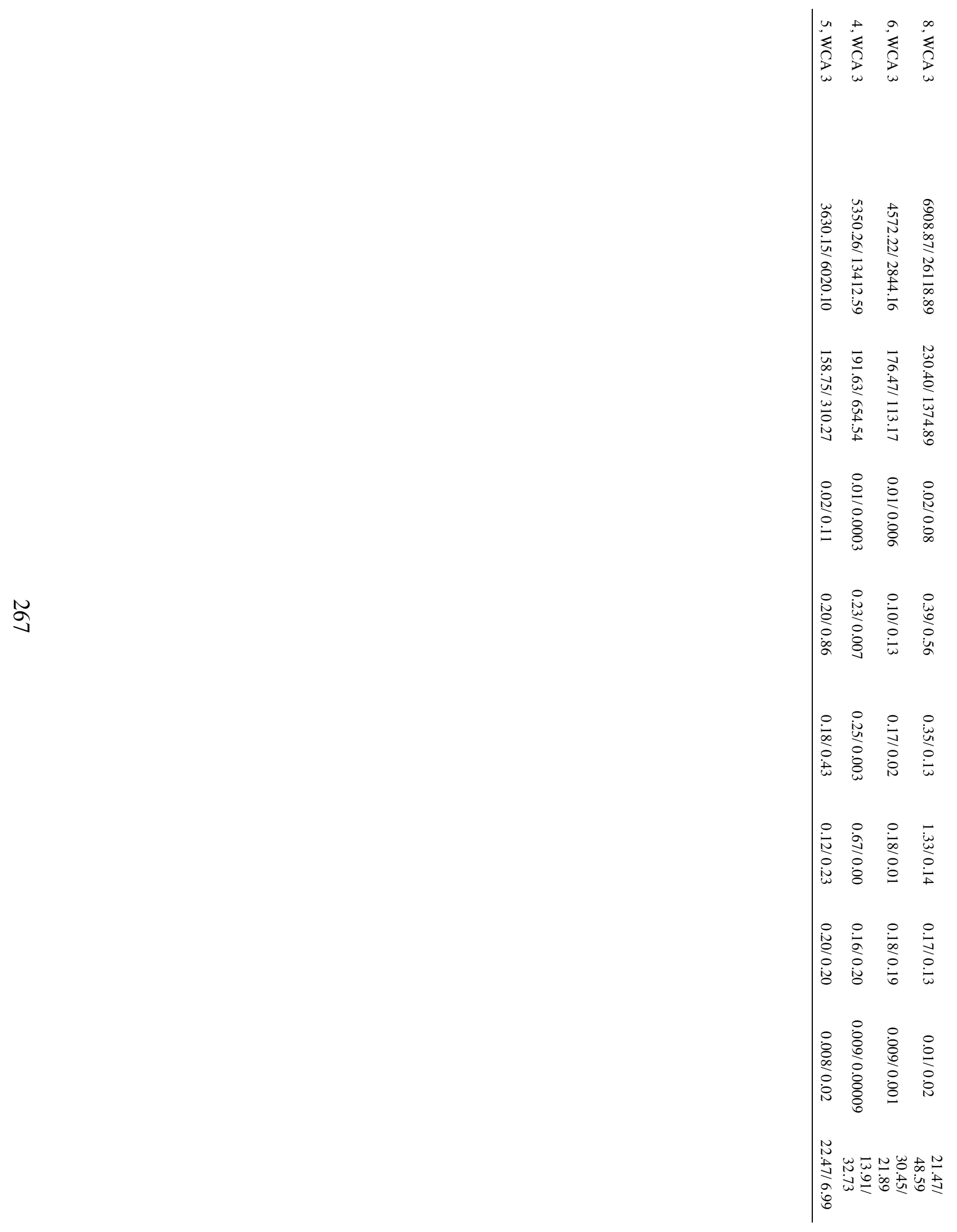


Fig. S.6.1
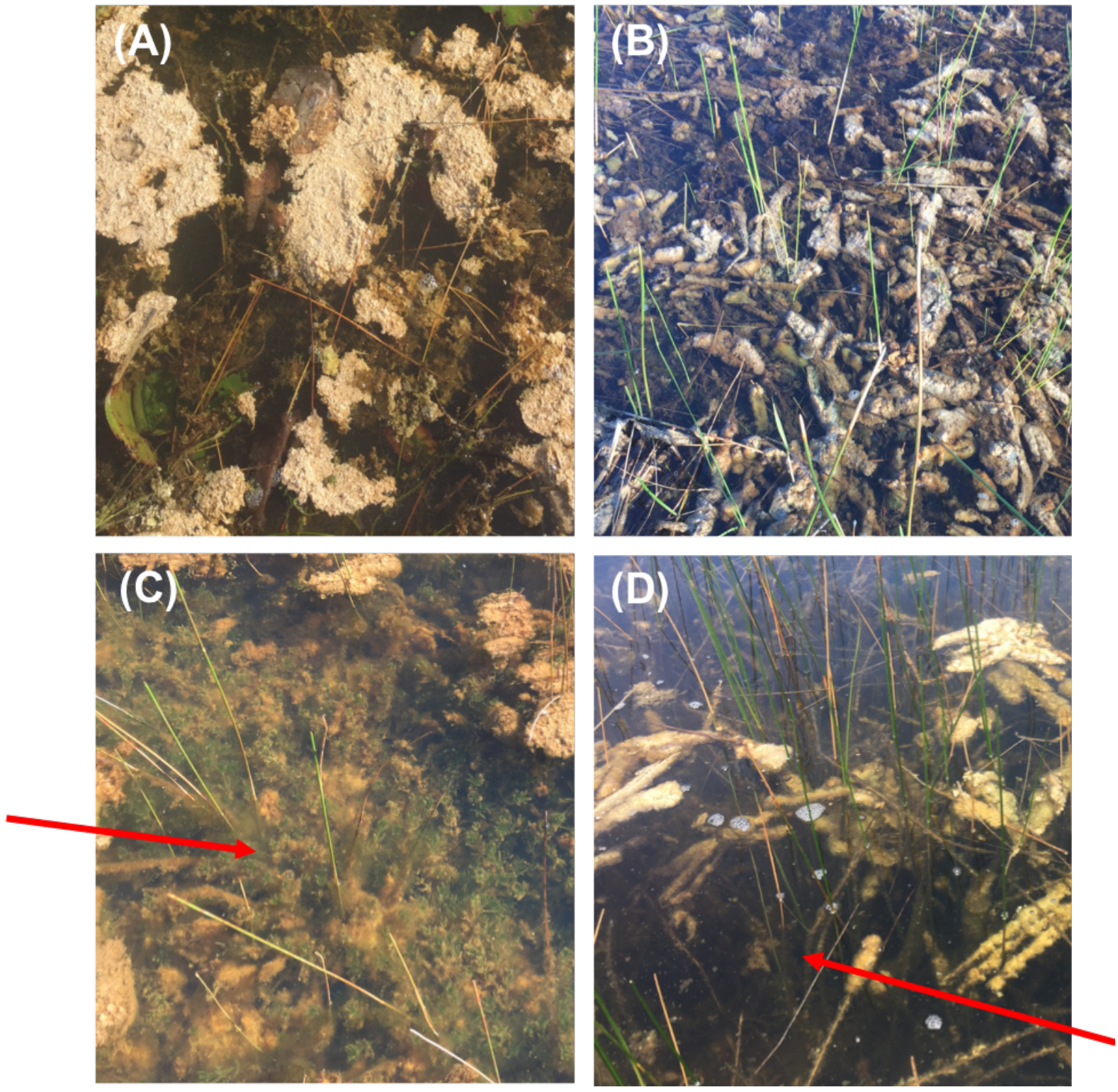

Fig. S.6.1. Examples of various periphyton types sampled in this study. (A) Floating mat aggregation (WCA 8, Dry season). (B) Alternative floating mat form: epiphytic growth on emergent vascular plant stems (WCA 3, dry season). (C) Filamentous green algae mass occupying the water column (see red arrow; PHD-A59, wet season). (D) Epiphyton collected from submerged stems of aquatic macrophytes (see red arrow; TSL-MDA, wet season). 
CHAPTER 7

CONCLUSION 
The objectives of my dissertation research were: 1) to propose testable hypotheses for the adaptive evolution of herbivory; 2) and to test several of these proposed hypotheses to understand the evolutionary and ecological consequences of adopting an herbivorous diet. I reviewed the herbivory literature and identified existing studies that could be interpreted in the context of adaptive evolution of diet. I used these studies to build a framework of five testable hypotheses and tested three of these hypotheses (Heterotroph Facilitation, Lipid Allocation, and Suboptimal Habitat) using a series of phylogenetic, experimental (lab and field), and community assembly studies. I found evidence supporting the Heterotroph Facilitation Hypothesis in my experimental work, but the Suboptimal Habitat Hypothesis had greater explanatory power when assessing the evolution of herbivory from a phylogenetic and community assembly perspective. Although these studies provide alternative explanations for the evolution of herbivory, the key distinction between these hypotheses is that heterotroph facilitation is a mechanism to overcome poor food quality, and invasion of suboptimal habitats allows passage into habitats with varying resource bases. The basis of these findings is the same, however; resource quality and/or availability is responsible for the evolution and/or maintenance of herbivory in nature. There were no explicit studies examining the adaptive significance of herbivory before I began this research, so I was interested in identifying the "gaps" in the current research that limit our knowledge of the evolution of $\operatorname{diet}$ (Ch. 2). 
Our previous understanding of herbivory was defined by studies focusing on herbivory from the perspective of the primary producers (e.g., Power 1992; Strong 1992; Pare and Tumlinson 1999; Howe and Jander 2008; and others), or by studies examining herbivore responses to diet (e.g., Sinclair et al. 1982; Targett and Targett 1990; Simpson and Simpson 1990; Pennings et al. 1993; Stachowicz and Hay 1996; Cruz-Rivera and Hay 2000b; Van der Wal et al. 2000; Fink and von Elert 2006, and others). A recent body of work has begun to identify patterns of diet evolution in related species using comparative analyses (e.g., Van Damme 1999; Espinoza et al. 2004; deMaintenon 1999; Eubanks et al. 2003; Pauls et al. 2008; Bellwood 2003; Bellwood et al. 2014, and others), which has brought us closer to understanding the adaptive significance of herbivory. In reviewing these works, I found evidence that eating plants is favored when higher quality food is limiting (e.g., Chubaty et al. 2014). Furthermore, I found that freshwater herbivore diets are not always inadequate as they can provide a different suite of important dietary elements such as plant-derived lipids and sterols (e.g., MartinCreuzburg et al. 2011), or heterotroph-derived nutrients (e.g., Bowen 1984, Smoot and Findlay 2010, Belicka et al. 2012) that are deficient in carnivorous diets. Exploring these already established ideas from an adaptive perspective has provided us with a better understanding of the conditions that promote the evolution of herbivory in nature.

In Chapter 3, I evaluated the Suboptimal Habitat Hypothesis by reconstructing ancestral states of habitat and diet across a phylogeny of the genus Poecilia (comprised of 7 subgenera). Species comprising the genus Poecilia exhibit a variety of diet preferences, with obligate herbivory concentrated in the subgenus Mollienesia. 
Extant species belonging to the subgenus Mollienesia inhabit both fresh and euryhaline habitat types (Meffe and Snelson 1989). I found that the most recent common ancestors (MRCA) of subgenera Acanthophacelus, Micropoecilia, Psychropoecilia and Allopoecilia had low salinity affiliations and were either omnivorous or carnivorous. Furthermore, the divergence of the subgenera Poecilia and Mollienesia resulted in MRCAs with euryhaline roots, and the transition from low to high salinity affiliation drove diet diversification favoring the appearance of obligate herbivory in these groups. Salinity affiliation explained $26 \%$ of the total variation in the diet of Poecilia species, and jaw morphology was associated with percent animal material in the gut, but not with percent of species occupying saline habitats. These findings suggest that in this genus, herbivory evolved in response to habitat transitions between fresh and euryhaline habitats, and jaw morphology evolved in response to the appearance of herbivory. These results are consistent with the Suboptimal Habitat Hypothesis.

I experimentally evaluated the Heterotroph Facilitation and Lipid Allocation hypotheses using field (Ch. 4) and lab (Ch. 5) studies. I found that herbivorous Sailfin Mollies (Poecilia latipinna) benefit from a diet supplemented with heterotrophic microbes, supporting the suggestion that "true" herbivory is rare in nature (White 1985). In my field cage experiment, increased autotroph biovolume, increased proportion of monounsaturated fatty acids, and decreased percentage of heterotrophic fatty acids in the diet best predicted early Sailfin Molly life history (6-9 weeks of age). However, later in development (9-12 weeks of age), cages with high heterotroph fatty acid production yielded the highest juvenile survival. 
Because autotroph-derived lipids were not the main influencer of herbivore success, the Lipid Allocation Hypothesis was not supported. Rather, I found that heterotrophs supplement herbivorous diets, and the quality (e.g. fatty acid abundance) of these microbes strongly influences herbivore life history by increasing survival by up to $53 \%$. My lab study yielded comparable results to those found in my field experiment and confirmed that Sailfin Mollies benefit from a diet that incorporates heterotrophic food sources. Both studies suggest that heterotrophs supplement the herbivorous diet in ways that affect consumer life history, thereby supporting the Heterotroph Facilitation Hypothesis.

In my final chapter (Chapter 6), I measured food quality and availability across the Everglades landscape and examined these variables as potential drivers of consumer density. I interpreted these results in the context of traditional niche theory (niche-based and dispersal-based models) and hypotheses about the maintenance of herbivorous diets in food webs (Heterotroph Facilitation and Suboptimal Habitat). I found that herbivores track food quality when habitats are stable (e.g., in the wet season), but they can persist in a multitude of habitat types and survive on resources of varying quality when habitats are variable (e.g., in the dry season). These results suggest that herbivore diets follow nichebased predictions in the wet season, but dispersal-based predictions in the dry season. In contrast, omnivores rely on high-quality resources in both seasons, consistent with nichebased predictions. Taken together, these results partially support the Suboptimal Habitat Hypothesis as an explanation for the evolution of herbivory in this system. 
My goal for this research was to explore the conditions that would favor the evolution of an herbivorous diet from a carnivorous or omnivorous diet. Overall, these studies suggest that herbivory may have evolved as an adaptive strategy to deal with variable/unproductive habitats, and is maintained in natural systems by supplemental detritivory. My results show that invading 'suboptimal' habitats has significant evolutionary consequences by enhancing the possibility for novel phenotypes to spread (i.e., herbivory), thereby promoting new ecological interactions between species. Once the diet strategy has appeared in a lineage, it is maintained as an alternative to carnivory or omnivory, as long as it provides the necessary nutrients to sustain herbivore life processes. Exploring these adaptive hypotheses has established a much-needed research framework, allowing us to more fully understand the evolution of diet in freshwater and other systems.

\section{References}

Belicka, L.L., Sokol, E.R., Hoch, J.M., Jaffe, R. and Trexler, J.C. (2012.) A molecular and stable isotopic approach to investigate algal and detrital energy pathways in a freshwater marsh. Wetlands 32:531-542.

Bellwood, D.R. (2003). Origins and escalation of herbivory in fishes: A functional perspective. Paleobiology 29(1): 71-83.

Bellwood, D.R., Goatley, C.H.R., Brandl, S.J, and Bellwood, O. (2014). Fifty million years of herbivory on coral reefs: fossils, fish and functional innovations. Proceedings of the Royal Society B 281: 20133046.

Bowen, S. (1984). Evidence of a detritus food-chain based on consumption of organic precipitates. Bulletin of Marine Science 35: 440-448.

Chubaty, A.M., Ma, B.O., Stein, R.W., Gillespie, D.R., Henry, L.M., Phelan, C., Palsson, E., Simon, F.W., and Roitberg, B.D. (2014). On the evolution of omnivory in a community context. Ecology and Evolution 4(3): 251-265. 
Cruz-Rivera, E. and Hay, M.E. (2000b). Can quantity replace quality? Food choice, compensatory feeding, and fitness of marine mesograzers. Ecology 81(1): 201219.

deMaintenon, M.J. (1999). Phylogenetics analysis of the Columbellidae (Mollusca:Neogastropoda) and the evolution of herbivory from carnivory. Invertebrate Biology 118(3): 258-288.

Espinoza, R.E., J. J. Wiens, and C. R. Tracy. (2004). Recurrent evolution of herbivory in small, cold-climate lizards: Breaking the ecophysiological rules of reptilian herbivory. Proceedings of the National Academy of Science 101(48):1681916824.

Eubanks, M.D., Styrsky, J.D., and Denno, R.F. (2003). The evolution of omnivory in heteropteran insects. Ecology 84(10): 2549-2556.

Fink, P. and von Elert, E. (2006). Physiological responses to stoichiometric constraints: nutrient limitation and compensatory feeding in a freshwater snail. Oikos 115: 484-494.

Howe, G. A., and G. Jander (2008). Plant immunity to insect herbivores. Annual Review of Plant Biology 59:41-66.

Martin-Creuzburg, D., Beck, B., and Freese, H.M. (2011). Food quality of heterotrophic bacteria for Daphnia magna: evidence for a limitation by sterols. FEMS Microbiology Ecology 76: 592-601.

Meffe, G. K., and E. E. Snelson. (1989). An ecological overview of Poeciliid fishes. In: Ecology and Evolution of Livebearing Fishes. Prentice Hall, NJ, pp. 13-32.

Pare, P. W. and J. H. Tuminson (1999). Plat volatiles as a defense against insect herbivores. Plant Physiology 121:325-331.

Pauls, S.U., Graf, W., Haase, P., Lumbsch, H.T., and Waringer, J. (2008). Grazers, shredders and filtering carnivores- The evolution of feeding ecology in Drusinae (Trichoptera: Limnephilidae): Insights from a molecular phylogeny. Molecular Phylogenetics and Evolution 46 (2): 776-791.

Pennings, S.C., Nadeau, M.T., and Paul, V.J. (1993). Selectivity and growth of the generalist herbivore Dolabella auricularia feeding upon complementary resources. Ecology 74(3): 879-890.

Power, M. E. (1992). Top-down and bootom-up forces in food webs: Do plants have primacy? Ecology 73(3):733-746. 
Simpson, S.J. and Simpson, C.L. (1990). The mechanisms of nutritional compensation by phytophagous insects. Insect-plant interactions, Volume 2. (ed E. A. Bernays), pp 111-160. CRC Press, Boca Raton.

Sinclair, A.R.E., C. J. Krebs, and J.N.M. Smith. (1982). Diet quality and food limitation in herbivores: The case of the snowshoe hare. Canadian Journal of Zoology 60(5): 889-897.

Smoot, J.C. and Findlay, R.H. (2010). Caloric needs of a detritivorous gizzard shad Dorosoma cepedianum are met with sediment bacterial and algal biomass. Aquatic Biology 8: 105-114.

Stachowicz, J.J. and Hay, M.E. (1996). Facultative mutualism between and herbivorous crab and a coralline alga: advantages of eating noxious seaweeds. Oecologia 105: 377-387.

Strong, D. R. (1992). Are trophic cascades all well? Differentiation and donor-control in speciose ecosystems. Ecology 73(3):747-754.

Targett, T. E. and Targett, N.M. (1990). Energetics of food selection by the herbivorous parrotfish Sparisoma radians: roles of assimilation efficiency, gut evacuation rate, and algal secondary metabolites. Marine Ecology Progress Series 66: 13-21.

Van Damme, R. (1999). Evolution of herbivory in lacertid lizards: Effects of insularity and body size. Journal of Herpetology 33(4): 663-674.

Van der Wal, R., N. Madan, S. van Lieshout, C. Dormann, R. Langvatn and S.D. Albon. (2000). Trading forage quality for quantity? Plant phenology and patch choice by Svalbard reindeer. Oecologia 123:108-115.

White, T. C. R. (1985). When is a herbivore not a herbivore? Oecologia (Berlin) 67: 596597. 
VITA

JESSICA SANCHEZ MONTELONGO

Born, Ancon, Panama

2005-2009

B.S., Biological Sciences

Sam Houston State University

Huntsville, TX

2009-2010

Teaching Assistant

Ecology and General Biology

Sam Houston State University

Huntsville, TX

2010-2012

M.S., Biological Sciences

Sam Houston State University

Huntsville, TX

2010-2012

Teaching Assistant

General Biology, Vertebrate Embryology and Zoology

Sam Houston State University

Huntsville, TX

2010-2012

Graduate Scholarship Fellow

Sam Houston State University

Huntsville, TX

2012-2013

Teaching Assistant

Human Biology

Florida International University

Miami, FL

2013-2016

Editorial Assistant, Oecologia

Florida International University

Miami, FL

2016-2018

Head Editorial Assistant, Oecologia

Florida International University

Miami, FL 


\section{PUBLICATIONS AND PRESENTATIONS}

Sanchez, J. L., and J. C. Trexler. 2018. When is an herbivore not an herbivore? Detritivory facilitates herbivory in a freshwater system. Ecology and Evolution. doi $10.1002 /$ ece 3.4133

Sanchez, J. L., and J. C. Trexler. 2016. The adaptive evolution of herbivory. Paper presented at the Association of Ichthyologists and Herpetologists, New Orleans, LA.

Sanchez, J. L., and J. C. Trexler. 2016. The adaptive evolution of herbivory in freshwater systems. Ecosphere 7(7):e01414. 10.1002/ecs2.1414.

Sanchez, J. L., and J. C. Trexler. 2015. Studying the adaptive evolution of herbivory in freshwater systems. Paper presented at the Ecological Society of America, Baltimore, MD.

Trexler, J. C., E. E. Gaiser, J. Kominoski, and J. L. Sanchez. 2015. The Role of Periphyton Mats in Consumer Community Structure and Function in Calcareous Wetlands: Lessons from the Everglades. Pages 155-179 In Entry, J., K. Jayachandran, A.D. Gottlieb, A. Ogram (eds.) Microbiology of the Everglades Ecosystem. CRC Press, Boca Raton, Florida.

Sanchez, J. L., and J. C. Trexler. 2014. Studying the adaptive evolution of herbivory using the Sailfin Molly, Poecilia latipinna. Paper presented at the Association of Ichthyologists and Herpetologists, Chattanooga, TN.

Sanchez, J. L., B. Boutwell, S. T. Hamontree, G. P. Garrett, R. H. Lewis, A. N. Ragan, M. Tobler and R. Deaton Haynes. 2014. Reproductive characteristics of two Gambusia congeners in West Texas. The Southwestern Naturalist 59 (3): 438-441. doi:10.1894/LW05.1

Sanchez, J. L., and J. C. Trexler. 2013. Studying the adaptive evolution of herbivory using the Sailfin Molly, Poecilia latipinna. Paper presented at the Association of Ichthyologists and Herpetologists, Albuquerque, NM.

Sanchez, J. L. N. Allan, G. P. Garrett, C. W. Kroll. R. H. Lewis, E. Marsh-Matthews, S. B. Stoops, J. West, and R. Deaton. 2013. Current distribution of the introduced largespring gambusia, Gambusia geiseri, in Texas. The Southwestern Naturalist 58 (4): 497-502. doi: 10.1894/0038-4909-58.4.497 